\title{
Acoustical Imaging and Mechanical Properties of Soft Rock and Marine Sediments (Final Technical Report \#15302)
}

Reporting Period: 01/02/01 - 12/31/03

Thurman E. Scott, Jr., Ph.D. Younane Abousleiman, Ph.D.

Report Issued: April 2004

DOE Award Number: DE-FC26-01BC15302

PoroMechanics Institute The University of Oklahoma Sarkeys Energy Center, Room P-119

100 East Boyd Street

Norman, Oklahoma 73019-1014 


\section{DISCLAIMER}

"This report was prepared as an account of work sponsored by an agency of the United States Government. Neither the United States Government nor any agency thereof, nor any of their employees, makes any warranty, express or implied, or assumes any legal liability or responsibility for the accuracy, completeness, or usefulness of any information, apparatus, product, or process disclosed, or represents that its use would not infringe privately owned rights. Reference herein to any specific commercial product, process, or service by trade name, trademark, manufacturer, or otherwise does not necessarily constitute or imply its endorsement, recommendation, or favoring by the United States Government or any agency thereof. The views and opinions of authors expressed herein do not necessarily state or reflect those of the United States Government or any agency thereof." 


\begin{abstract}
The research during this project has concentrated on developing a correlation between rock deformation mechanisms and their acoustic velocity signature. This has included investigating: (1) the acoustic signature of drained and undrained unconsolidated sands, (2) the acoustic emission signature of deforming high porosity rocks (in comparison to their low porosity high strength counterparts), (3) the effects of deformation on anisotropic elastic and poroelastic moduli, and (4) the acoustic tomographic imaging of damage development in rocks. Each of these four areas involve triaxial experimental testing of weak porous rocks or unconsolidated sand and involves measuring acoustic properties. The research is directed at determining the seismic velocity signature of damaged rocks so that 3-D or 4-D seismic imaging can be utilized to image rock damage. The four areas of study are described below:
\end{abstract}

1. Triaxial compression experiments have been conducted on unconsolidated Oil Creek sand at high confining pressures. The experiments were designed to simulate environmental conditions of sands that undergo liquefaction - a process that may be responsible for problems such as massive sand production or the shallow water flow phenomena. These are two critical problems which cost the oil and gas industry hundreds of millions of dollars per year. The experiments were conducted while measuring the compressional and shear wave velocities. The experiments indicate that shear wave velocities sharply decrease, and $V_{p} / V_{s}$ ratios markedly increase: (1) during liquefaction of sand at high pressure in undrained triaxial experiments, and (2) during plasticity of sand in drained triaxial experiments. The associated mechanical parameters are also indicative of the enhanced weakening of these sands under the above described conditions.

2. Initial experiments on measuring the acoustic emission activity from deforming high porosity Danian chalk were accomplished and these indicate that the AE activity was of a very low amplitude. Even though the sample underwent yielding and significant plastic deformation the sample did not generate signficant $A E$ activity. This was somewhat surprising. These initial results call into question the validity of attempting to locate $A E$ activity in this rock type. As a result, the testing program was slightly altered to include measuring the acoustic emission activity from many of the rock types listed in the research program. The experimental results indicate that $A E$ activity in the sandstones is much higher than in the carbonate rocks (i.e., the chalks and limestones). This observation may be particularly important for planning microseismic imaging of reservoir rocks in the field environment. The preliminary results suggest that microseismic imaging of reservoir rock from acoustic emission activity generated from rock matrix deformation (during compaction and subsidence) of soft rock would be extremely difficult to accomplish. Acoustic emission in the observed field (i.e., microseismic activity) in soft rock may in fact be due to reactivation of faults and fractures and not from deforming intact rock (i.e. matrix deformation).

3. A series of triaxial compression experiments were conducted to investigate the effects of induced stress on the anisotropy developed in dynamic elastic and poroelastic parameters in rocks. A new technology was developed for measuring anisotropic elastic and poroelastic parameters. The measurements were accomplished by utilizing an array of piezoelectric compressional and shear wave sensors mounted around a cylindrical sample of porous Berea sandstone. Three different types of applied states of stress were investigated using hydrostatic, triaxial, and uniaxial strain experiments. During the 
hydrostatic experiment, where an isotropic stress state was applied to an initially isotropic porous rock, the vertical and horizontal acoustic velocities and dynamic elastic moduli increased as pressure was applied and no evidence of stress induced anisotropy was observed. The poroelastic moduli (Biot's effective stress parameter) decreased during the test but also with no evidence of anisotropy. The triaxial compression test involved an axisymmetric application of stress with an axial stress greater than the two constant equal lateral stresses. During this test a marked anisotropy developed in the acoustic velocities and in the dynamic elastic and poroelastic moduli. As axial stress increased the magnitude of the anisotropy increased as well. The uniaxial strain test involved axisymmetric application of stresses with increasing axial and lateral stresses but while maintaining a zero lateral strain condition. The uniaxial strain test exhibited a quite different behavior from either the triaxial or hydrostatic tests. As both the axial and lateral stresses were increased, an anisotropy developed early in the loading phase but then was effectively 'locked in' with little or no change in the magnitude of the values of the acoustic velocities, or the dynamic elastic and poroelastic parameters as stresses were increased. These experimental results show that the application of triaxial states of stress induced significant anisotropy in the elastic and poroelastic parameters in porous rock.

4. Tomographic acoustic imaging was utilized to image the internal damage in a deforming porous limestone sample. During this experiment compressional wave velocities from an array of sensors mounted on the core sample were used to image deformation. The results indicate that as an axial stress is applied to the sample the velocity in the sample increases. Near the peak strength a marked diffuse low velocity zone develops in the center of the core which eventually localizes into an inclined zone. After the experiment was completed an inclined shear zone was observed in the core sample.

Results indicate that the deformation damage in rocks induced during laboratory experimentation can be imaged tomographically in the laboratory. By extension the results also indicate that 4-D seismic imaging of a reservoir may become a powerful tool for imaging reservoir deformation (including imaging compaction and subsidence) and for imaging zones where drilling operation may encounter hazardous shallow water flows. 


\section{TABLE OF CONTENTS}

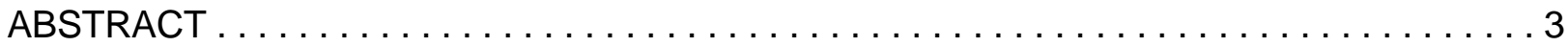

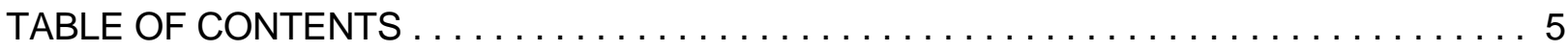

LIST OF GRAPHICAL MATERIALS $\ldots \ldots \ldots \ldots \ldots \ldots \ldots \ldots \ldots \ldots \ldots \ldots \ldots \ldots \ldots \ldots \ldots$

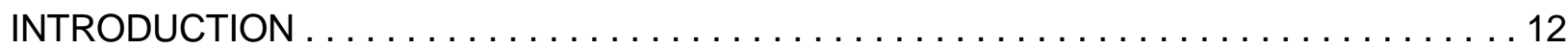

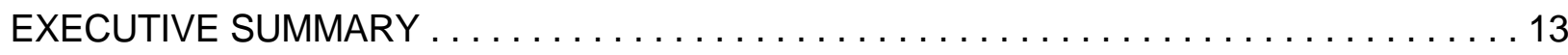

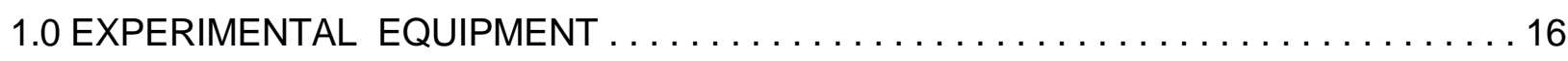

2.0 ACOUSTIC VELOCITY OF SATURATED SANDS: APPLICATION TO

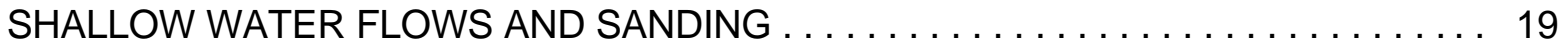

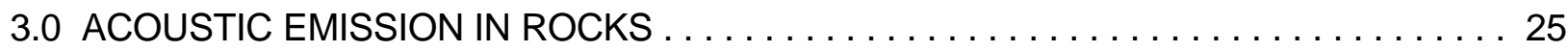

4.0 THE EFFECTS OF STRESS INDUCED ANISOTROPY ON DYNAMIC ELASTIC

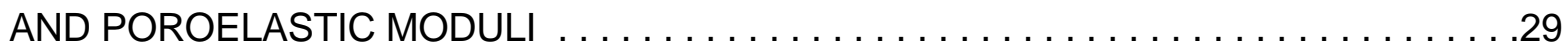

5.0 TOMOGRAPHIC IMAGING OF ROCK DAMAGE $\ldots \ldots \ldots \ldots \ldots \ldots \ldots \ldots \ldots \ldots \ldots$

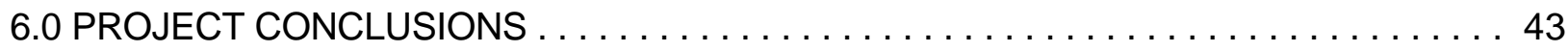

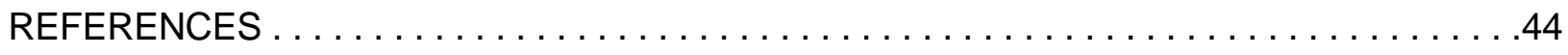

LIST OF ACRONYMS AND ABBREVIATIONS $\ldots \ldots \ldots \ldots \ldots \ldots \ldots \ldots \ldots \ldots \ldots \ldots \ldots$ 


\section{LIST OF GRAPHICAL MATERIALS FOR THE PROJECT}

FIGURE 1 - The 3,000,000 lb. TerraTek load frame with its 20,000 psi triaxial pressure vessel. The command and control, acoustic emission, and ultrasonic velocity systems are located to the left of the load frame. These components comprise a major part of the new Geomechanical Acoustic Imaging System. ..............50

FIGURE 2 - A schematic of the load frame, triaxial cell, and data acquisition modules of the Geomechanical Acoustic Imaging System..................... 51

FIGURE 3 - A schematic of the acoustic velocity system for compressional and shear wave anisotropy measurements and for acquisition of the full dynamic tensor data set. . . . . . . . . . . . . . . . . . . . 52

FIGURE 4 - Axial acoustic velocity platens constructed for the project. . . . . . . . . . . .53

FIGURE 5 - Diagram illustrating the lateral acoustic velocity sensors constructed for the project. The top photograph shows a rock core sample with both a 3-component sensor and a single-component acoustic sensor mounted on the surface. . . . . . . . . . . . . . . . . . . . . . . . . . . 54

FIGURE 6 - A photograph of the new sample assembly for acoustic measurements on a transversely isotropic rock . . . . . . . . . . . . . . . . . . . 55

FIGURE 7 - The stress-strain curve for an undrained triaxial compression experiment at 2000 psi confining pressure and 1000 psi starting

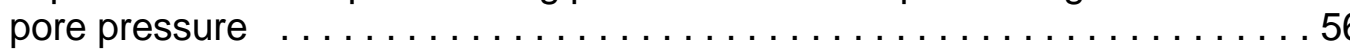

FIGURE 8 - The shear stress (q) versus effective mean pressure (p') plot for an undrained triaxial compression experiment at 2000 psi confining pressure and 1000 psi pore fluid pressure . . . . . . . . . . . . . . . . 57

FIGURE 9 - The shear stress (q) versus pore pressure plot for an undrained triaxial compression experiment at $2000 \mathrm{psi}$ confining pressure and $1000 \mathrm{psi}$

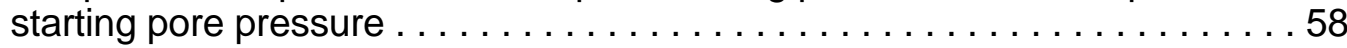

FIGURE 10 - The stress-strain curve for an undrained triaxial compression experiment at $5500 \mathrm{psi}$ confining pressure and $600 \mathrm{psi}$ starting pore pressure ......... 59

FIGURE 11 - The shear stress (q) versus effective mean pressure (p') plot for an undrained triaxial compression experiment at 5500 psi confining pressure and $600 \mathrm{psi}$ starting pore fluid pressure $\ldots \ldots \ldots \ldots \ldots \ldots \ldots \ldots \ldots$

FIGURE 12 - The shear stress (q) versus pore pressure plot for an undrained triaxial compression experiment at 5500 psi confining pressure and $600 \mathrm{psi}$ starting pore fluid pressure 
FIGURE 13 - Stress-strain plots on a series of undrained triaxial compression experiments on unconsolidated Oil Creek sand. The first numbers of the legend represent the confining pressure and the second number

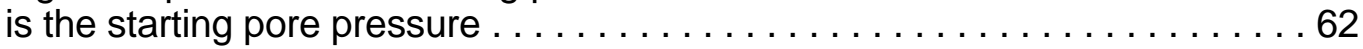

FIGURE 14 - A comparison of the strength effects of various types of jacket types on

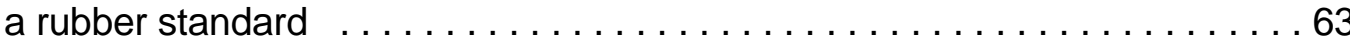

FIGURE 15 - A comparison of jacket strength effect on the deformation of

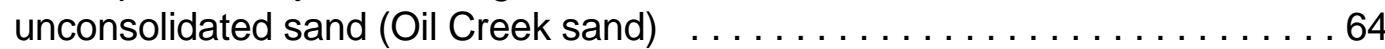

FIGURE 16 - The differential stress-axial strain curve for the undrained Oil Creek sand at 4500 psi confining pressure and the drain experiment at 2000 psi confining pressure. . . . . . . . . . . . . . . . . . . 65

FIGURE 17 - The changes in pore pressure during the undrained triaxial compression experiments on Oil Creek sand. . . . . . . . . . . . . . . . . . 66

FIGURE 18 - The deformational stress paths of the Oil Creek sand mapped in differential stress-effective mean pressure stress space.

FIGURE 19 - Shear wave velocities of the Oil Creek sand during the undrained triaxial experiment.

FIGURE 20 - The change in the compressional wave velocity $(\mathrm{Vp})$ differential stress during the undrained triaxial compression experiment. . . . . . . . . . . . 69

FIGURE 21 - The change in the $\mathrm{Vp} / \mathrm{Vs}$ ratio with differential stress during the undrained triaxial compression experiment. . . . . . . . . . . . . . . 70

FIGURE 22 - The shear moduli during the undrained triaxial compression test. ........ 71

FIGURE 23 - The Young's modului during the undrained triaxial compression test. . . . . 72

FIGURE 24 - The change in Poisson's ratio during the undrained triaxial compression experiment. . . . . . . . . . . . . . . . . . . . . 73

FIGURE 25 - The shear wave velocity during the drained triaxial compression experiment at 2000 psi confining pressure and 1000 psi pore fluid pressure. . . . . . . . . 74

FIGURE 26 - The compressional wave velocity during the triaxial experiment. . . . . . . 75

FIGURE 27 - The $V p / V s$ ratio during the drained triaxial experiment. . . . . . . . . . . . 76

FIGURE 28 - The change in shear moduli during the drained triaxial experiment. . . . . . . . . . . . . . . . . . 77

FIGURE 29 - The change in Young's moduli during the triaxial experiment. ...........78 
FIGURE 30 - The change in Poisson's ratio during the the drained triaxial experiment. . . . . . . . . . . . . . . . 79

FIGURE 31 - Undrained triaxial pathways for three sands with different amounts of

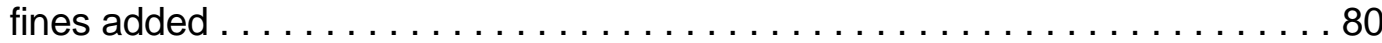

FIGURE 32 - Pore pressure-time curves for three different mixtures of Oil Creek sand as finer material is added to the sand. . . . . . . . . . . . . . . . . . 81

FIGURE 33 - Stress-strain diagram for Danian chalk (sample 1) . . . . . . . . . . 82

FIGURE 34 - AE rate diagram for Danian chalk (sample 1) $\ldots \ldots \ldots \ldots \ldots$

FIGURE 35 - Cumulative AE for Danian chalk $\ldots \ldots \ldots \ldots \ldots \ldots \ldots \ldots \ldots \ldots$

FIGURE 36 - Stress-strain diagram for Berea sandstone AE reference $\ldots \ldots \ldots \ldots . . .65$

FIGURE 37 - AE rate diagram for Berea sandstone $A E$ reference $\ldots \ldots \ldots \ldots \ldots \ldots 86$

FIGURE 38 - Cumulative AE for Berea sandstone AE reference . . . . . . . . . . . . . 87

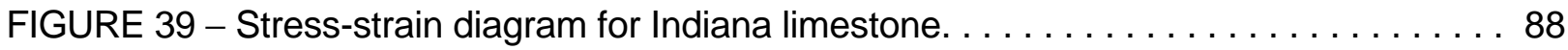

FIGURE 40 - AE rate diagram for Indiana limestone. . . . . . . . . . . . . . 89

FIGURE 41 - Cumulative AE for Indiana limestone $\ldots \ldots \ldots \ldots \ldots \ldots \ldots \ldots$

FIGURE 42 - Stress-strain diagram for Cordoba Cream limestone . . . . . . . . . . . 91

FIGURE 43 - AE rate diagram for Cordoba Cream limestone $\ldots \ldots \ldots \ldots \ldots \ldots 2$

FIGURE 44 - Cumulative AE for Cordoba Cream limestone $\ldots \ldots \ldots \ldots \ldots . \ldots 3$

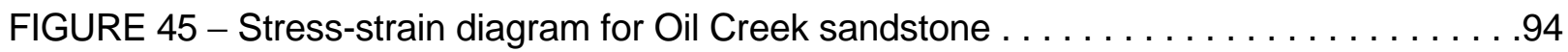

FIGURE 46 - AE rate diagram for Oil Creek sandstone . . . . . . . . . . . . . . 95

FIGURE 47 - Cumulative AE for Oil Creek sandstone. ..................... 96

FIGURE 48 - The three dimensional orientation of the acoustic raypaths on the cylindrical core samples. This is the new single core method . . . . . . . . . 99

FIGURE 49 - A schematic illustrating the various acoustic raypaths in the cylindrical samples. . . . . . . . . . . . . . . . . . . . 98

FIGURE 50 - A schematic illustrating the types of deformation experiments conducted in the study. . . . . . . . . . . . . . . . . . . . . . . . 99 
FIGURE 51 - A plot of the confining stress vs. axial and circumferential strains during a hydrostatic compression experiment. . . . . . . . . . . . . . 100

FIGURE 52 - A plot of the compressional wave velocities during the hydrostatic compression experiment. . . . . . . . . . . . . . . . . . . . 101

FIGURE 53 - A plot of the shear wave velocities obtained during the hydrostatic compression experiment. . . . . . . . . . . . . . . . . . . . 102

FIGURE 54 - A plot of the anisotropic Young's moduli obtained during the hydrostatic compression experiment............................. 103

FIGURE 55 - A plot of the anisotropic shear moduli obtained during the hydrostatic compression experiment. . . . . . . . . . . . . . . . . . . . . . . . 104

FIGURE 56 - A plot of the anisotropic Biot's effective stress parameters during the hydrostatic compression experiment. . . . . . . . . . . . . . . . . 105

FIGURE 57 - A plot of differential stress vs. axial and circumferential strains during a triaxial compression experiment. . . . . . . . . . . . . . . . . 106

FIGURE 58 - A plot of the compressional wave velocities during the triaxial compression

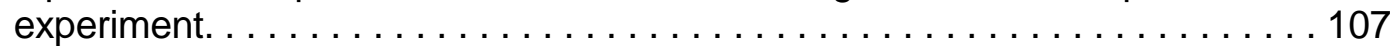

FIGURE 59 - A plot of the shear wave velocities obtained during the triaxial compression experiment. . . . . . . . . . . . . . . . . . . 108

FIGURE 60 - A plot of the anisotropic Young's moduli obtained during the triaxial compression experiment. ........................... 109

FIGURE 61 - A plot of the anisotropic shear moduli obtained during the triaxial compression experiment. . . . . . . . . . . . . . . . . . . 110

FIGURE 62 - A plot of the anisotropic Biot's effective stress parameters during the triaxial compression experiment.

FIGURE 63 - A plot of the differential stress vs. confining stress during the uniaxial strain experiment. . . . . . . . . . . . . . . . . . . . 112

FIGURE 64 - A plot of the compressional wave velocities obtained during the uniaxial strain experiment.

FIGURE 65 - A plot of the shear wave velocities obtained during the uniaxial strain experiment. ..................................... 114

FIGURE 66 - A plot of the anisotropic Young's moduli obtained during the uniaxial strain experiment. ......................................... 
FIGURE 67 - A plot of the anisotropic shear moduli obtained during the uniaxial strain experiment. . . . . . . . . . . . . . . . . . 116

FIGURE 68 - A plot of the anisotropic Biot's effective stress parameters during the uniaxial strain experiment. . . . . . . . . . . . . . . . . . . 117

FIGURE 69 - A schematic of the equipment for the ultrasonic tomography experiment. . . . . . . . . . . . . . . . .

FIGURE 70 - A schematic showing the dimensions of the sample and the locations of the acoustic sensors for the vertical tomography. . . . . . . . . . . 119

FIGURE 71 - A cross-sectional view of the acoustic pulse transmission sensors on the rock core sample set up for vertical tomography. . . . . . . . . . . 120

FIGURE 72 - A 3-dimensional view of the configuration of acoustic raypaths in a sample setup for vertical tomography . . . . . . . . . . . . . . . . 121

FIGURE 73 - A photograph of the jacket/sample assembly for vertical tomography. . . . . 122

FIGURE 74 - A photograph of the sample in the Keck load frame before insertion into the pressure cell . . . . . . . . . . . . . . . . . 123

FIGURE 75 - A photograph illustrating the scale of the large size of the tomographic imaging samples (6 inch diameter) compared to smaller NX, 1.5 inch, and 1 inch diameter samples.

FIGURE 76 - A photograph of Keck Acoustic Imaging System during testing. . . . . . . . 125

FIGURE 77 - The stress-strain curve for Indiana Limestone at 500 psi

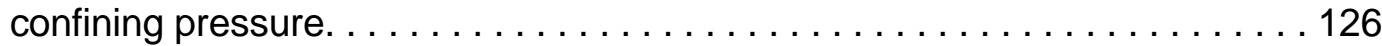

FIGURE 78 - The tomogram for Indiana limestone at 500 psi confining pressure with no differential stress applied. . . . . . . . . . . . . . 127

FIGURE 79 - The tomogram for Indiana limestone at 500 psi confining pressure

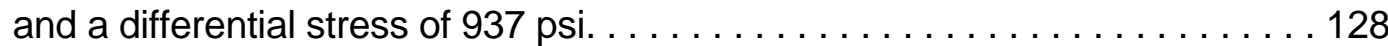

FIGURE 80 - The tomogram for Indiana limestone at 500 psi confining pressure

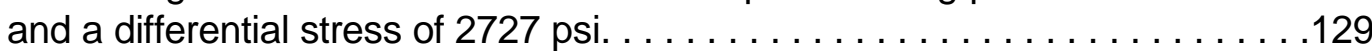

FIGURE 81 - The tomogram for Indiana limestone at 500 psi confining pressure and a differential stress of 6756 psi. . . . . . . . . . . . . . . . . 130

FIGURE 82 - The tomogram for Indiana limestone at 500 psi confining pressure

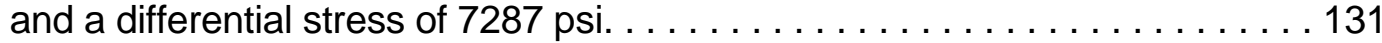

FIGURE 83 - The tomogram for Indiana limestone at 500 psi confining pressure and a differential stress of 7463 psi. . . . . . . . . . . . . . . . . 132 
FIGURE 84 - The tomogram for Indiana limestone at 500 psi confining pressure

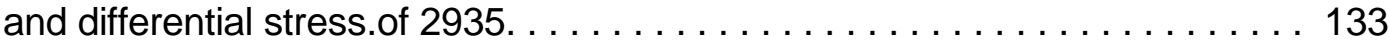

FIGURE 85 - The tomogram for Indiana limestone at 500 psi confining pressure and after completely unloading the differential stress.............. 134

FIGURE 86 - A photograph of the fractured sample tested at

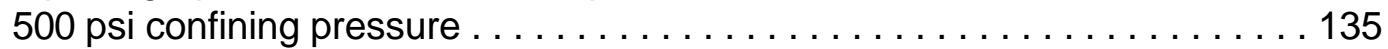


Introduction

Damage to weakly cemented or unconsolidated sands during the production and drilling of reservoirs is a costly problem for the oil and gas industry. For example, the unexpected compaction of the Ekofisk chalk resulted in over 1 billion dollars in remedial work being applied to production facilities overlying the reservoir. In this case the production facilities had to be reconstructed to a higher position above sea level to accommodate over 16 feet in subsidence. Reservoir compaction can also result in casing failures, loss of reservoir permeability, and damage to surface production facilities. Such problems are increasingly becoming common because the mechanically stable 'easy to drill and produce' reservoirs have been depleted leaving more expensive, problematic reservoirs for present and future oil and gas production.

Another example of the problem generated by drilling unconsolidated sands is the problem of shallow water flows. Such flows occur at shallow depths below the seafloor (less than 2000 feet) but in deep water (2000 to 4000 feet). These flows occur when the unconsolidated sands suddenly flow up the annulus of the borehole and flow onto the seabed. The flow can cause washouts and loss of the supporting surface casing (Furlow 1999a). The damage to the Ursa development project in Mississippi Canyon Block 810 resulted in the loss of $\$ 150$ million dollars for the partners in the project (Furlow, 1988a).

While both of the above scenarios are distinctly different (i.e., compaction and shallow water flows) both involve damage of poorly consolidated or weakly cemented rocks.

In the case of shallow water flows the current industry thinking is to utilize predrill seismic imaging of these sands to sidestep potential hazards (Furlow, 1999b). However, there is little or no data on the acoustic properties of such sands. In addition the areal extent andrthe amount of damage induced during compaction possibly could also be seismically image if we knew the properties of the damaged rock.

This research project was designed to determine the acoustic signature of deforming rocks and sands so that 3-D or 4-D seismic imaging could be used to image zones of damage (e.g., for compaction) or image zones where damage may occur (e.g., the case of shallow water flows). As such the research in this study is intended to extend the use of seismic imaging from that of its present day applications. These include imaging lithology, firefloods, waterfloods, monitoring oil/water contacts. We suggest that seismic imaging could be used to monitor rock damage and rock deformation that occurs while oil and gas production is on going.

During this study we examine the acoustic signatures of weak rocks and unconsolidated sands during laboratory high pressure experiments. In the first part of this report we have a brief description of the unique laboratory facilites used in the study. The second part of the report addresses the compressional and shear wave acoustic signature of deforming unconsolidated sands. The third section addresses acoustic emission activity in high porosity rocks. The fourth section shows the newly developed methods for measuring anisotropic elastic and poroelastic properties (both inherent and stress induced) in rocks. Finally, the fifth section shows the newly development acoustic tomographic time lapse imaging of a developing damage zone (a shear fracture) in a porous limestone. 


\section{Executive Summary}

The petroleum industry is increasingly directing exploration and development efforts to produce oil and gas from mechanically problematic reservoir rocks. An example of this is the problem of shallow water flows (SWF) encountered during deepwater drilling operations. This occurs when unconsolidated sands begin to violently flow up the annulus of a wellbore and occurs in deep water environments but occurs in sands located at shallow depths below the mudline. This violent process can result in loss of the wellbore and in some cases the loss of multiple wells drilled from a single template on the seafloor. SWF generated a loss of 150 million dollars for the companies involved in the Ursa deep water drilling project (Furlow 1998a,b;1999a,b). Another example is the problem of reservoir compaction. Production from soft or weak rocks such as high porosity limestones and chalks can create damaging reservoir subsidence and compaction - processes that can lead to severe casing damage, loss of wellbores, loss of permeability, and damage to surface production facilities. The Ekofisk chalk in the North Sea is a classic example of severe production induced compaction in a reservoir where over 16 feet of subsidence occurred at the surface. Remedial work to repair damage to surface production facilities at the Ekofisk site resulted in the loss of 1 billion dollars to oil and gas companies involved in the project (Sulak 1991). Both of these scenarios involve severe deformation of weakly cemented, high porosity rocks and unconsolidated sediments. New technologies, such as 3-D and 4-D seismic surveys, may play an important future role in predrill detection of potential hazards (such as shallow water flows) or the tracking of damage induced during production (in the case of the Ekofisk reservoir). The goal of this research study was to examine the acoustic behavior (i.e., the compressional and shear wave velocities) of deforming high porosity rock and unconsolidated sands and correlate those velocities to different deformational mechanisms. This report is divided into four research areas: (1) acoustic velocity signature during the drained and undrained deformation of unconsolidated sands, (2) acoustic emission signature of deforming high porosity rocks, (3) changes in elastic and poroelastic moduli during deformation, and (4) acoustic tomographic imaging of a high porosity rock during a deformation experiment. A short description follows:

(1) The problem of shallow water flows required an examination of the deformation of unconsolidated sands during triaxial tests. In these experiments Oil Creek sand was tested in both drained and undrained conditions. In many cases SWF are thought to occur in sands at high pore pressure which are sealed from the surrounding rock units. If deformed, such sands would be 'undrained' meaning pore pressure would increase if they were subjected to high stresses. These deformation experiments were carried out while measuring both the compressional and shear wave velocities. During drained triaxial tests the shear wave velocities increased during the initial stages of loading but decreased as the sand sample went into plasticity. The sharp reduction in shear wave velocity resulted in increases in the $V_{p} / V_{s}$ ratios during plasticity. Undrained triaxial compression experiments at high pressures showed a similar pattern. In this case the sands underwent a 'liquefaction' type of instability that may be associated with the runaway instability of sands during SWF. The shear wave velocities decreased during this period of instability and the $V_{p} / V_{s}$ ratios increased. In both cases where the sands failed the shear wave velocity decreased and the $V_{p} / V_{s}$ ratios increased. These laboratory results confirm what engineering field studies of shallow water flows have already suspected - that coupling between sand grains (as evidenced by the low shear velocities) is very low, making them easily mobilized during deformation. The experiments suggest that areas prone to SWF will have low shear wave velocities and high $V_{p} / V_{s}$ ratios and that these are the regions to side step during drilling operations. 
(2) A series of triaxial compression tests were conducted on various rock types in the study to measure acoustic emission activity. The results conducted on high porosity chalks were both surprising and disappointing. They were surprising in that acoustic emission activity during both shear failure and extensive plastic deformation was extremely low and the events that were recorded were of low amplitude. This result was disappointing in that it meant that 3-D location (imaging) of the damage within the chalk samples could not be accomplished. The few field studies available indicate that microseismic activity during deformation of chalk reservoirs occurs along preexisting fractures and faults and that little or no microseismic activity occurs within the rock unit between these features even though the rock is undergoing severe compaction. The experiments in this study seem to verify the observation that matrix deformation does not generate detectable levels of $A E$ activity in the frequency range tested. The acoustic emission activity of the chalks was compared to activities obtained during deformation experiments carried out on sandstones. The sandstones generated much higher levels of acoustic emission events especially during the failure process. The results suggest that it would be highly improbable to image matrix damage in high porosity chalks (e.g., bulk rock) with either acoustic emission (in laboratory tests) or microseismic (in the field) studies.

(3) Most stress states in the subsurface are anisotropic (i.e., the stresses are not equal in all directions or hydrostatic). However few studies have examined the effects of non-isotropic states of stresses in rocks on rock elastic and poroelastic properties. Identifying the effects of induced stress on rock and poroelastic properties was a primary task of this investigation. Previous research has demonstrated inherent anisotropy (i.e., anisotropy associated with sedimentary bedding, layers, and planar features such as fractures) can affect seismic velocities and elastic moduli. If uncorrected the rock anisotropy may lead to large errors in interpreting seismic surveys. The goal of this research was to answer two questions: (1) Is the effect of induced stress on anisotropy significant? and (2) Is the array of acoustic information sufficient to determine the anisotropic elastic and poroelastic moduli? The answer to the second of these two questions is a resounding 'yes'. During this study a new method was developed to measure an array of compressional and shear wave velocities on a cylindrical core sample while subjected to triaxial state of stress. The rock selected for study was very homogeneous and during hydrostatic deformation, where equal pressures were applied around the sample, the rock remained isotropic as the axial and lateral compressional and shear wave velocities increased. The velocity data was used to calculate the elastic moduli, such as Young's modulus, shear modulus, Poisson's ratio, and bulk modulus. In addition, the poroelastic Biots effective stress parameter was also calculated for the first time from compression and shear wave velocity data. During the hydrostatic experiment the dynamic Biot's effective stress parameter decreased as pressure was increased; an observation previously observed during earlier static experiments. Experiments were conducted on two additional types of deformational stress paths - a triaxial deformation path and a uniaxial strain path. The triaxial test involved applying an increasing axial stress while the horizontal stresses remain constant. During this experiment the anisotropy increased monotonically as deformation increased. The elastic moduli $(E, G, K)$ in the vertical direction (aligned with the maximum stress) increased while the lateral elastic moduli decreased. The poroelastic moduli exhibited the opposite pattern with the Biot's effective stress parameter in the axial direction decreasing with increasing stress. The results of this experiment answer the first question posed in this section -- Is the effect of stress induced isotropy significant? The answer is 'yes.' The anisotropy generated in the triaxial test on porous sandstone was as large as that observed in inherent anisotropy in layered rocks. This means in some seismic surveys it 
may be important to account for errors created by induced stresses. A uniaxial strain test was also conducted. This experiment is designed to simulate the type of deformation that would occur during continual burial of the rock or during drawdown of a petroleum reservoir. In this type of experiment the sample is loaded in the axial direction and the lateral stresses are changed to maintain a zero lateral deformation. During this type of experiment the velocities changed very quickly and then 'locked' into an unchanging condition even though both the axial and lateral stresses were increasing. The reason for this type of behavior was unclear. In summary, these experiments allow the research team, for the first time, to track and evaluate the changes in elastic and poroelastic moduli as triaxial stresses are applied. The results indicate the subsurface elastic stress states do affect acoustic velocities and suggest that this factor may need to be accounted for in future improvements in seismic surveys.

(4) The final section of the research involved acoustic tomographic imaging of a rock sample (with dimensions of 6 inches in diameter and 10.5 inches length) during triaxial deformation. For the first time, a vertical cross section of a shear failure in a volume of rock was acoustically imaged. The method involved placing an extensive array of compressional wave sensors on either side of a large core sample of porous limestone. The sample was placed in the triaxial cell and deformed with a series of 'step-hold' tests where confining pressure was first applied to the sample and then a small increase in axial stress was applied, and then several hundred compressional wave raypaths were shot. These were utilized to generate images at various states of stress until the sample failed. The results indicated that early in the loading phase the acoustic velocities slightly increased. As the deformation neared the peak stress (i.e., ultimate strength) on the stress-strain curve, a centralized diffused low velocity zone developed. As the rock failed the low velocity zone increased in intensity and in the post peak failed region the sample exhibited an inclined low zone. After the experiment was completed an inclined shear fracture was observed that aligned with the inclined low velocity zone. These results suggest that for the first time we were able to image the damage associated with process of dilatancy prior to shear failure and image the damage halo associated with the shear fracture itself.

In summary this research provided results on a broad range of experiments on a variety of weak rocks and unconsolidated sands. The conclusions indicate that the acoustic velocity changes during rock deformational failure processes is significant in both sands and weak rocks. In addition, we developed a new method for imaging these processes in the laboratory and suggest that these results can be extended to 3-D and 4-D field seismic surveys. 


\subsection{Experimental Setup and Equipment}

\subsection{Laboratory testing equipment}

Laboratory techniques and testing technologies include: (1) compressional and shear acoustic velocities (determined by the time of flight method), (2) acoustic emission (single channel methods), (3) shear wave bender element measurements, (4) ultrasonic tomography, and (5) dynamic elastic tensor measurements. The testing program utilized a variety of systems in the Geomechanical Acoustic Imaging System (GAIS). Figure 1 is a photograph of the completed GAIS as it now stands in the O.U. Geomechanical Acoustic Laboratory. Figures 2 and 3 are schematics of the equipment modules for some parts of the GAIS that will be used in the study. Figure 2 shows the data acquisition system and the command and control system for the load frame and triaxial pressure cell of the GAIS. Figure 3 is a schematic of the ultrasonic velocity system.

The equipment includes:

1. A TerraTek $3,000,000 \mathrm{lb}$. load frame and $138 \mathrm{MPa}$ triaxial cell used for the dynamic tensor, ultrasonic velocity, acoustic tomography tests.

2. An MTS $600,000 \mathrm{lb}$. load frame and $138 \mathrm{MPa}$ triaxial cell to be used unconsolidated sand tests and the acoustic emission tests.

3. The 15 channel Vallen Systeme for acoustic emission full waveform acquisition.

4. The 24 channel Physical Acoustics Corporation (PAC) Mistras System for both AE event parametrics and full waveform acquisition.

5. The 8 channel Spartan Acoustic Emission system from PAC.

6. Two Tektronix TDS420 digital storage oscilloscopes (for acoustic velocity measurements).

7. A switchbox for high voltage pulses and acquired acoustic velocity waveforms.

8. An HP3852 data acquisition system (used for both command and control, and data acquisition of the Geomechanical Acoustic Imaging System).

9. An MTS TestStar II controller for control of the load frames and triaxial pressure cells.

10. An MTS extensometer (Model 632.92B-05) for axial strain measurements.

11. An MTS extensometer (Model 632.90B-04) for circumferential strain measurements.

12. 1.5-, 2.125-, 3-, and 4-inch diameter acoustic compressional and shear wave velocity platens.

13. 3-inch acoustic velocity platens with shear wave piezoelectic bender elements installed.

14. Internal load cells rated to $20,000,200,000$, and $300,000 \mathrm{lbs}$. for both the MTS 319 and the TerraTek load frame.

These are also used in the deformational pathways including: triaxial deformation, uniaxial strain, hydrostatic compression, and K-ratio tests.

\subsection{New acoustic platens}

Four different sets of axial acoustic platens were machined and assembled for the research project. These correlate to the different sample sizes to be tested during the experimental program. Sample diameters are 1.5, 2.125, 3, and 4 inches. The sample length-to-diameter ratios will be 2 to 1 as outlined in the ASTM rock testing procedures. The platens contain pore pressure ports and three piezoelectric elements (one compressional and two orthogonally oriented shears) with a nominal center frequency of $600 \mathrm{KHz}$. The 2.125-inch diameter platens 
had been previously developed and described by Scott et al. (1993) and the other platens were made specifically for this research project. The above mentioned acoustic platens are well suited for testing weakly cemented rock samples or competent, lithified rock samples (see Scott et al. 1993, 1998a,b for examples). However, one goal of the research program is to examine the acoustic properties of unconsolidated sands, since these are the problematic formations that lead to catastrophic shallow water flows. These SWF are not only problematic for drilling and production engineers but represent challenges for laboratory researchers as well. A new type of platen is being designed for this study, and is based on a modification of the type used to study the acoustic properties of soils undergoing mechanical deformation testing. These platens (Figure 4) contain the same $600 \mathrm{KHz}$ compressional and shear wave piezoelectric elements in the standard loading platen (outlined in the above paragraph) but also have a piezoeletric bender element embedded in them. Bender elements extend up into the unconsolidated sand and provide a high energy, low frequency, shear wave pulse through the poorly consolidated sample (Gohl and Finn 1991; de Alba and Baldwin 1991; Arulnathan et al. 1998). Standard 600 $\mathrm{KHz}$ plate type piezoelectric elements do not yield very discernable shear waves at low effective confining pressures due to the loss of coupling between the grains. (Shear waves propagate only through the solid grain-to-grain framework.) The high amplitude pulse generated by bender elements can even propagate a shear wave through loose, unpressured sand packs.

The platens developed in this study are designed for use in triaxial pressure cells with much higher confining pressures (up to 20,000 psi) than what is traditionally used in soil mechanics experiments (generally less than 600 psi). These new platens have been successfully used in obtaining shear wave velocities in unconsolidated, unstressed sand samples during benchtop tests as low as $40 \mathrm{~m} / \mathrm{sec}$.

\subsection{Lateral acoustic emission and acoustic velocity sensors}

A series of lateral acoustic sensors were made for the project. The design has been successfully used by Scott et al. (1993) in previous research. Two different types of lateral sensors have been made for this research project. They include: (1) single element acoustic emission sensors, and (2) three component sensors with one compressional and two orthogonally mounted shear wave elements (see Figure 5). The single element sensors are designed for acoustic emission experiments. All acoustic piezoelectric elements are .25 inch in diameter and have a nominal center frequency of $600 \mathrm{KHz}$. In the single component model these are mounted (cast) in an epoxy shell with a diameter of .35 inch. In the three component model the elements are mounted in an in-line housing 1 inch in length and .35 inch in width (Figure 5). The mounting of these sensors on a rock core sample is shown in figure 6.

\subsection{Rock Samples}

Researchers in the PoroMechanics Institute selected and acquired (1) Danian outcrop chalk, (2) Cordoba Cream (Austin) Chalk, (3) Indiana Limestone, and (4) unconsolidated Oil Creek sand for experiments.

These include:

Danian Chalk. This is a clean, white outcrop chalk obtained from Denmark. It has a porosity of $35 \%$ and is equilivalent in strength and character to the Ekofisk Chalk of the North Sea and will therefore represent a superb analog for the Ekofisk Reservoir. The Ekofisk Reservoir 
represents a reservoir which has undergone severe subsidence and compaction (over 30 feet) in the last 30 years.

Cordoba Cream Limestone. This is the generic name given to the soft, buff colored Austin chalk quarried in Texas. It has a lower porosity (25\%) than either the Danian or Ekofisk Chalk rocks. This limestone is primarily calcite (85\%) but has a large percentage of clays $(10-13 \%)$ which significantly weakens the strength of rock. It is medium-to-coarse grained, has calcite cement, and contains small fossils.

Indiana Limestone. A block of high porosity Indiana Limestone was also obtained for the research program. This block of rock was more uniform than others in the study. It is stronger than the other rocks to be tested in the experimental program and therefore represents the high strength end of samples that will be analyzed in the study. As a reservoir analog this rock type would be expected to generate damaging compaction and subsidence only in the most severe cases (i.e., at high effective confining pressures near depletion of the reservoir).

Oil Creek Sandstone. This sandstone is a very clean quartz arenite ( $99.9 \%$ quartz) from Mill Creek, Oklahoma in the Oil Creek Formation (Middle Ordovician Simpson Group). Porosities average around $33-35 \%$. This sandstone is very friable and is composed of well rounded grains. The blocks of Oil Creek were hand cut from a glass sand quarry operated by U.S. Silica. Th Oil Creek weakly cemented sandstone is friable enough so that the cores can be cut with a special hand coring device developed in the PoroMechanics Institute for preparing soft rock samples. Disaggregated Oil Creek Sandstone is sold for use as a proppant in hydraulic fracture treatments and is locally known as Oklahoma \#2. It has been washed, cleaned, and sieved. As such, this sand makes excellent material for the unconsolidated sand packs for the research program. 
2.0 Acoustic Velocity of Saturated Sands: Application to

Shallow Water Flows and Sanding

An understanding of the deformation of unconsolidated sands at high confining pressures has important implications for the petroleum industry. Two particularly troublesome problems are 1) sand production, which occurs during the production of oil and gas from weakly cemented or uncemented sand formations, and 2) the problem of shallow water flows, during which uncontrolled sand flow occurs during drilling of wells in deep water sediments. Sand production, which involves massive sand flow into well bores during extraction of oil and gas, has been a problem since the early 1930's. The phenomena continues to plague the industry and has been well documented (Suman et al, 1983). Shallow water flows generally occur from sand formations at shallow depths below the seafloor (less than 2000 feet) but in deep water (20004000 feet). They were first identified in 1985 in the Gulf of Mexico. The flow of these sands can be so severe that it often leads to loss of the surface casing, loss of drilling templates and abandonment of the well (Furlow 1998a,b). Shallow water flows are a major financial problem for the petroleum industry. An analysis of the severity of the problem indicated that the industry had lost 175 million dollars on 106 drilled wells (Alberty 2000). Recently, Huffman and Castagna (2001) suggested that shallow water flows were possibly due to liquefaction of these geopressured sands. Liquefaction has been long studied in civil engineering and occurs when saturated soils exhibit excessive deformational strain response (Vaid and Sivathayalan 1999). During static triaxial compression undrained experiments on saturated sands, liquefaction is evidenced by strain-softening on the stress-strain curve (Vaid and Eliadorani, 1998). The goal of this research is to determine if there are specific quasistatic conditions and acoustic signatures for liquefaction of saturated sand at great depth that could be used as criteria to identify the onset of sanding or shallow water flows.

With these observations in mind we developed an experimental program to determine: (1) the best experimental procedures for conducting triaxial tests on weak sands but at high pressures (outside the traditional domain of soil mechanics); (2) the deformational behavior of unconsolidated sands at pressure/stress conditions, that best approximates the conditions observed in the deep water marine environment, where liquefaction in unconsolidated sands would occur; and (3) the compressional and shear wave acoustic velocity signatures of the drained/undrained deformation of these sands.

\subsection{Experiments on Unconsolidated Sands}

A series of undrained triaxial have been conducted to outline, for the Oil Creek sand, the conditions where these instabilities occur. This sand is very clean $(99.9 \%$ quartz) and the grains are well rounded with grain sizes which averages around $.2 \mathrm{~mm}$. These tests were on NX size samples during which the axial and lateral strains and pore pressure changes were monitored as deformation proceeded. Figures 7,8,9,10,11 and 12 show the results of a comparison of two triaxial undrained tests on the Oil Creek sand. Three plots are used to define each experiment. The first diagram plots the axial stress-strain curve. The second plots the effective mean pressure versus shear stress. The third diagram plots the pore pressure evolution versus shear stress. These experiments were conducted at a constant axial deformation rate of $.005 \mathrm{in} / \mathrm{min}$. After the initial hydrostatic loading was completed the "B" value was checked (i.e., Skempton's parameter) to insure that the sample was $100 \%$ water saturated. The $B$ value is ratio of the pore pressure to confining pressure as change confining pressure is increased. A value of 1 in an unconsolidated sample generally indicates the sample is fully saturated. 
These two sets of data represent just two runs out of several dozen that were conducted to locate the conditions where the Oil Creek sand undergoes liquefaction. The undrained experiment at 2000 psi confining pressure and 1000 psi pore fluid pressure is shown in figures 7, 8, and 9. The stress-strain curve for this sand exhibits an initial linear elastic section until a differential stress of 750 psi is attained (Figure 7). After that point the sample exhibits a work hardening stress-strain curve until about $16 \%$ percent axial strain after which it exhibits a steady-state nature. Figure 9 shows the evolution of the pore fluid pressure during the experiment. Initially, the pore pressure increases (during the elastic loading phase) and then begins to decrease.

The stress-strain curve work hardens as deformation continues until the critical state is achieved. The critical state in soil mechanics is defined as the point were the sample continues to deform with no change in volume (Schofield and Wroth, 1968). It is important to note that no instability, or strain softening, was observed in this sand sample. Evidence that the critical state has been achieved is that the effective stress condition (point $a$ in Figure 8) and the pore pressure (point b in Figure 9) are 'locked in' while the sample continue to deform (strain path from $c$ to $d$ in Figure 7 ).

The undrained experiment at 5500 psi confining pressure and 600 psi pore pressure exhibits a very different behavior. The stress-strain curve shows an initial elastic portion (up to $1 \%$ axial strain) and then evidences a slight strain softening (Figure 10). At about 6\% axial strain the sample begins to work hardening. Both of the the two triaxial experiments described in this section were conducted under stroke control. If the sample had been conducted under load control the strain softening portion of the stress-strain curve would be a 'runaway' instability which would be equivalent to liquefaction. The weakening of the sample can easily be observed in figure 11. The pore pressure increases during this experiment all the way to the critical state point (Figure 12). The critical state condition was achieved at point $d$ in figure 10, at point $e$ in figure 11, and at point $f$ in figure 12.

Figure 13 shows a series of stress-strain curves for the deformation of sand at various confining pressures. A total of eleven experiments were conducted. All the samples with effective confining pressures above 3400 psi show liquefaction behavior (as evidenced by the softening in the stress-strain curves).

The appearance and behavior of the stress-strain and the pore pressure curves are similar in morphology to those exhibited by high porosity sands tested in soil mechanics research. The only difference is that the deformational behaviors are occuring at much higher stress conditions than those observed in soil mechanics.

\subsection{Selecting the Jacketing Material for Triaxial Experiments}

Studying the deformational behaviors of weak, unconsolidated sands at high pressures presents the experimentalist with a series of interesting challenges. First, and foremost among these is the problem of selecting suitable jacketing materials to encase the samples during triaxial tests. Several important considerations for selecting the jacket type include:

1) The material should be strong enough to keep out the confining fluid and be able to withstand extremely high distortional strains without rupturing.

2) The jacket should not significantly affect the strength of a weak unconsolidated sand sample. If care is not taken to insure that the jacket strength does not affect the overall deformational strength of the sample then the experimental results may not be valid. The jacket strength may not only alter the sample strength, but it could also significantly change 
the elastic properties and the type of deformational behavior (e.g., brittle versus ductile) of the sample.

3) The jacket should have a surface to which sensors can be attached (e.g., acoustic sensors and shear wave bender elements) and is smooth enough for the free movement of features such as extensometer chains (which are part of the devices to measure circumferential strain).

4) The jacket material should be chemically non-reactive to both the pore fluid and the confining fluid.

In rock mechanics triaxial experiments jacketing materials, such as viton rubber, buna-N rubber, or heat shrinkable plastic materials such as polyolefin or teflon are used under confining pressure conditions of from 200 to 20,000 psi. The jackets are strong enough to maintain seal integrity to prevent the confining fluid (generally oil) from leaking and contaminating the pore fluid (if saturated) and/or the rock. Soil mechanics triaxial tests are conducted at confining pressures of only 0 to 100 psi with water as a confining medium and thin latex membranes used as jackets. So the first step in determining the strength of the sands at high confining confining pressures was to determine which jacketing material to utilize. A series of unconfined tests were conducted on latex rubber, buna- $\mathrm{N}$ rubber, polyolefin, and teflon jackets. Figure 14 such the results of such experiments on a cast NX size sample (2.125 inch diameter by 4.25 inch length) of 3010 rubber. This rubber sample was loaded in unconfined compression both with and without the each of the jackets to see if the jacket resisted lateral expansion of the sample. Evidence that this was occurring would be from a higher loading stress at given strain level. The results clearly indicate that the best jacketing material would be the thin latex membrane (used in soil mechanics) with the buna- $\mathrm{N}$ exhibiting a slightly higher effect than the latex and with the polyolefin, and teflon each successively exhibiting a much higher strength effect. The polyolefin and teflon were both deemed unacceptable for testing unconsolidated sand samples as they altered both the strength and the Young's modulus and Poisson's ratio of the rubber standard. The buna- $\mathrm{N}$ rubber and latex shifted the initial strength of the sample by only about 10 psi and did not affect

the Young's moduli and only slightly affected the Poisson's ratio of the rubber standard.

The latex rubber and buna-N rubber jackets would seem to be the most promising jackets for use on the unconsolidated sands. The latex was initially thought to be too unstable to use at high confining pressures. A ruptured membrane would result in sand being distributed throughout the pressure cell - a factor which can permanently damage the steel threads rendering the cell useless. (Note: pressure lines and pressure intensifiers can be protected by filters- it is protection of the triaxial cell which in paramount in this case). Therefore the initial triaxial tests on dry sand (Figure 14) were conducted with buna-N rubber sleeves which had a wall thickness of $3 \mathrm{~mm}$.

However, a comparison of dry sands using latex and buna- $\mathrm{N}$ indicated that the buna-N significantly affected the strength of the dry sand (Figure 15). Given this observation the experimental staff decided to spend time in testing, with extreme care, the suitability of the use of latex membranes at high confining pressures. These membranes have a wall thickness of only $0.4 \mathrm{~mm}$ thick and extremely flexible but have the disadvantage of decomposing due to reactions with the confining fluid (mineral oil). During testing it was determined the latex membranes could maintain their integrity to confining pressures of 10000 psi for at least 3 hours if the grain size was around $.2 \mathrm{~mm}$ (which deemed sufficient for our planned testing program).

Some of the sand samples were deformed to very high axial strains ( 20\%). The extreme barreling of the sample and the high axial shortening causes the flexible jackets to 'wrinkle' and 
fold to accommodate the strains. Again the flexible latex seemed to minimize the effects of this process than either of the thicker jackets.

\subsection{Acoustic properties of unconsolidated sands}

A series of triaxial compression experiments have been conducted on unconsolidated Oil Creek sand at high confining pressures. The experiments were designed to simulate environmental conditions of sands that undergo liquefaction - a process that may be responsible for problems such as massive sand production or the shallow water flow phenomena. These are two critical problems which cost the oil and gas industry hundreds of millions of dollars per year. The experiments were conducted while measuring the compressional and shear wave velocities. The experiments indicate that shear wave velocities sharply decrease, and $\mathrm{Vp} / \mathrm{Vs}$ ratios markedly increase: 1) during liquefaction of sand at high pressure in undrained triaxial experiments, and 2) during plasticity of sand in drained triaxial experiments. The associated mechanical parameter are also indicative of the enhanced weakening of these sands under the above described conditions.

The Oil Creek sand used in the study (Mill Creek, OK) has an average grain size of .2 mm. The sand is very well rounded and clean (99.9\% quartz). The prepared samples were NX sized, 5.4 $\mathrm{cm}$. (2.125 in.) in diameter and $10.2 \mathrm{~cm}$. (4 in.) in length. The initial starting porosity in these tests was 37 percent. During the experiment an MTS 632.92B extensometer was utilized to measure circumferential strain. The axial deformation was measured from stroke displacement of the axial piston and corrected for (a small) elastic piston distortion. The axial compressional and shear wave piezoelectric elements were housed in the steel loading platens and had a nominal frequency of $600 \mathrm{KHz}$. Thin lead foil sheets, $.15 \mathrm{~mm}$ thick, were used to facilitate coupling between the sand pack and the steel end platens. The platens contain a $6.4 \mathrm{~mm}$. (.25 in.) porous frit centrally located to allow introduction of pore fluid to the sand sample during testing. A Tektronix TDS420 oscilloscope was used to acquire the waveforms for storage and analysis (Scott et al., 1998). The experiments were conducted in an MTS Model 315 load frame with a 2,669 kN $(600,000 \mathrm{lb}$.) actuator. The system has an integral triaxial pressure vessel (model 138) with a capability of $137.9 \mathrm{MPa}$. (20 Ksi) pore and confining pressures. An Isco model 500D servo-electro-mechanical fluid syringe pump was used for sample in-vessel saturation and the application pore fluid pressure during testing. An in-house designed internal load cell was utilized for the accurate measurement of axial loads on the weak sand samples.

\subsubsection{Experimental results}

The results of an undrained triaxial compression experiment at $31 \mathrm{MPa}$. (4,500 psi) confining pressure and 6.9 MPa. (1,000 psi) starting pore pressure are shown in Figures 16 through 21 . The undrained triaxial differential stress $\left(\sigma_{1}-\sigma_{3}\right)$ versus axial strain is shown in Figure 16. The data curve for the undrained experiment in Figure 16 is delineated by five letters, a,b,c,d, and e (note these letters will be utilized to demark the same conditions on each of the successive plots). Point ' $a$ ' represents the start of the triaxial compression experiment. Point ' $b$ ' represents the onset of yielding. Point ' $c$ ' is the start of instability and strain softening. With continued deformation the sample begins to work harden again (at point ' $d$ ') and this continues until the experiment was arbitrarily terminated (at point 'e'). During the undrained experiment the pore pressure rapidily increased during the initial stages of loading and then achieved a nearly steady state nature (Figure 17). During the experiment the pore pressure increased from 6.9 MPa. (1,000 psi) to nearly 17.2 MPa. (2,500 psi.) A plot of the undrained data in the effective mean stress, $\left(\sigma_{1}+2 \sigma_{3}\right) / 3-p$, versus the differential stress (undrained part of Figure 18) indicates the development of the instability at point ' $c$ ' and strain softening until point ' $d$ '. This 
instability is typically associated with the development of liquefaction (Vaid and Eliadorani, 1998). Figures 19 through 20 show the acoustic velocity data. During the undrained experiment the shear wave velocity starts at $1,025 \mathrm{~m} / \mathrm{s}$ and shows a slight increase as the differential stress is applied (Figure 19). At about $26 \mathrm{MPa}$ differential stress yielding begins to occur (at point 'b') and the velocity begins to decrease. At the point of instability (point 'c'), this rate of decrease develops more sharply and this continued until the experiment was terminated. The compressional wave velocity data are illustrated in Figure 20 and these show a continuous velocity increase from about $2,210 \mathrm{~m} / \mathrm{s}$ up to $2,360 \mathrm{~m} / \mathrm{s}$. Figure 21 shows a plot of the $\mathrm{Vp} / \mathrm{Vs}$ ratio from that undrained experiment. The data evidences that the $\mathrm{Vp} / \mathrm{Vs}$ ratio increases during the experiment. The sharpest increase occurs just after the onset of the instability at point ' $c$ '. The shear wave data affects more sharply the $\mathrm{Vp} / \mathrm{Vs}$ data than does the compressional wave data. The dynamic shear modulus, the dynamic Young's modulus, and the dynamic Poisson's ratio are shown, respectively, in Figures 22, 23, and 24 . The shear moduli directly reflect the morphology of the shear wave velocity data shown in Figure 22. The dynamic Young's modulus, shown in Figure 23, also shows the strong influence of the shear wave velocity data. Both the Young's moduli and the shear moduli decrease after yielding (at point 'b') in Figures 22 and 23. After the instability, at point ' $c$ ', the loss of strength in these mechanical parameters rapidily increases and this continues until the end of the test. The data from the Poisson's ratio obtained from the undrained experiment are quite different (Figure 24). There is very little change evident in the initial stages but during the instability, the Poisson's ratio increases sharply.

The results from a drained triaxial compression experiment conducted at 13.8 MPa. (2,000 psi) confining pressure and 6.9 MPa. (1,000 psi) pore fluid pressure are shown for comparison to the undrained experiment. The drained stress/pressure/strain data are super-imposed on the plots in Figures 16 through 18. The acoustic velocity data are shown in Figures 25-27 and the dynamic elastic moduli derived from that acoustic data are shown in Figures 28-30. The drained experimental stress-strain data does not show evidence of an instability or strain softening (Figure 16). The stress-strain curve show yielding to start at around $12 \mathrm{MPa}$ followed by increased plastic deformation. In the initial stages (the first $2 \mathrm{MPa}$ of loading), the shear wave velocity increases after which a nearly steady state nature is observed. At about $15 \mathrm{MPa}$ of differential stress (Figure 25), the shear wave velocity begins to decrease. The compressional wave velocity data increases throughout the experiment (Figure 25). The $\mathrm{Vp} / \mathrm{Vs}$ ratio versus the differential stress plot is shown in Figure 27. During the initial stages of deformation, the $\mathrm{Vp} / \mathrm{Vs}$ ratio decreases (in the first $2 \mathrm{MPa}$ ), then achieves a steady state nature. Above $15 \mathrm{MPa}$ the ratio shows an increase. The dynamic shear moduli and Young's moduli (Figures 28 and 29) reflect the strong influence of, and the same nature as the, shear wave velocity data in Figure 26. The dynamic Poisson's ratio versus the differential stress for the experiment is shown in Figure 30. The initial Poisson's ratio values start at .41 , slightly decrease, achieve a steady state nature, and finally increase at the end of the experiment.

\subsubsection{Discussion}

Undrained experiments conducted at high confining pressures can exhibit the strain softening instability associated with liquefaction. This is commonly observed in low pressure soil mechanics research studies (Vaid and Eliadorani, 1998). The data suggest that liquefaction of sand may indeed be a mechanism for shallow water flows in the marine environment and may be a mechanism for massive sand production. The drained experiments do not show evidence of a strain softening instability. Instead they show a slight work hardening during plastic deformation. The drained data do not seem indicate a favorable condition where shallow water flows or sand production would likely develop. 
Since shear waves only propagate through the mineral grains and through grain-to-grain contacts and not the fluid component, their response reflects the deformational behavior of the sands more strongly than do the compressional wave data. The loss of cohesion between the grains during liquefaction, (in the undrained experiment) and plasticity during the drained experiment are both reflected in the decreases in shear wave velocity and subsequent increase in the $\mathrm{Vp} / \mathrm{Vs}$ ratio. The same loss of cohesion (and strength) during these failures are reflected in the lower values of the dynamic shear moduli and Young's moduli. The dynamic Poisson's ratio during the liquefaction phase of the undrained experiment and during the plastic deformation of the drain test increases as deformation proceeds. Generally, unconsolidated sands show higher Poisson's ratios than consolidated sands. A higher Poisson's ratio would be expected if the grains were becoming 'decoupled' as evidenced by the shear wave data.

It should be noted that precursory decreases in shear wave velocity (and increases in $\mathrm{Vp} / \mathrm{Vs}$ ratios) occur before plastic yielding (in the drained case) and before the liquefaction instability (in the undrained case). The data suggest that the seismic imaging of sands with high $\mathrm{Vp} / \mathrm{Vs}$ ratios and lower shear wave velocities than surrounding sands may be cause for concern.

\subsection{The Effects of Added Fines and Porosity on Strength of Unconsolidated Sands}

In addition to examining the velocity behavior of drained and undrained behavior of Oil Creek sand a brief series of experiments was conducted to investigate the effects of added fines on the deformation strength of this type of sand. The Oil Creek is a clean quartz arenite and therefore may not be representative of the types of marine sands where shallow water flows are occuring. Figure 31 shows the effects of added fines. The addition of $10 \%$ silt and $10 \%$ silica flour greatly reduce the strength of the sand but also lead to greater increases in pore pressure (Figure 32). 


\subsection{ACOUSTIC EMISSION IN ROCKS}

\subsection{INTRODUCTION}

AE activity has been extensively studied in granites and gneisses (Carlson and Young 1993; Lockner et al. 1977; Lockner and Byerlee 1978; Sondergeld and Estey 1981; Dowding et al. 1985; Yanigadani et al. 1985; Spetzler and Mizutani 1986; Nishizawa et al. 1990; Lockner et al. 1991), in coal (Chugh and Heidinger 1980; Khair and Hardy 1984), andesite (Nishizawa et al. 1985), pyrophyllite (Spetzler et al. 1981), sandstone (Lockner and Byerlee 1977; Zang et al. 1996), and quartizite (Hallbauer et al. 1973). Very few studies have been conducted on porous, weak rock types. During this study the research team also obtained the acoustic emission signatures of high porosity sandstones, limestones, and chalks undergoing deformation at high pressures. Acoustic emission activity is generated as elastic waves from the microscopic deformation of grains, grain cements, creation of microcracks, and collapse of pore spaces. These elastic waves can be detected by commercial acoustic emission recorders. The goal of the $A E$ research in this project is to identify the signature and intensity of acoustic emissions generated during deformation of a rock and correlate it to a specific deformational mechanism (e.g., compaction or shear fracturing). Acoustic emission activity studies of rock have been conducted since Scholz (1968). The importance of detecting this activity in the natural setting has been recognized by the oil and gas industry as they are beginning to monitor the microseismic activity of reservoirs during the production of hydrocarbons and during water flooding operations. Some of the companies operating in the North Sea, such as Phillips Petroleum, have done some limited acoustic/microseismic monitoring of reservoirs to determine if the subsidence has an acoustic emission signature and where it is located within the reservoir (Rutledge et al. 1994). Those initial results indicate that microseismic activity is being generated during localized shearing and reactivation of faults as opposed to being evenly distributed within the reservoir due to uniform compaction and subsidence. In such cases 3-component geophones were cemented in the casing of the wellbores for a limited amount of time (Rutledge et al. 1994). In the future it may be possible to have permanent seismic networks for both active imaging (i.e., tomography, or reflection or refraction surveys) and for passively imaging acoustic emission (microseismic) information to detect and map out reservoir rock damage within the reservoir.

\subsubsection{Experimental Equipment}

Acoustic emission (AE) systems generally work in two distinctly different modes. In one mode, the $\mathrm{AE}$ events are captured and characterized according to $\mathrm{AE}$ parameters such as their amplitude, duration, number of counts, energy in the event, and rise time. This is generally accomplished by a high speed DSP processor in the system. The data throughput is very fast as the resulting data, e.g., duration or amplitude, are directly stored on the PC and the acoustic waveform data is discarded. In the second type of AE mode the complete event waveforms are captured and stored on the PC for later retrieval. This mode of operation is very slow because of the large data files. This slows data throughput so that only a fraction of the waveforms generated by deforming rock can be stored. In the Keck Geomechanical Acoustic Imaging System both systems are utilized. During these tests AE data was obtained by monitoring the rock sample primarily with the 24-channel Mistras System and an 8-channel Spartan AT AE System (from Physical Acoustics Corporation). After meeting an amplitude threshold criterion (in these tests it is set at $40 \mathrm{db}$ ) the signals are characterized according to AE parameters such as amplitude, duration, number of counts, energy, etc. Each $A E$ event is also time stamped to 
within 50 nsec of its occurrence. The plug in filters are designed to bandpass the wavelengths of interest in the testing program and screen out sources of acoustic noise. This waveform data is particularly important in determining the settings of the Physical Acoustics Corporation AE systems. So a series of reconnaissance tests were conducted to record some waveforms to determine what the amplitude, duration, and hit lockout time settings should be on the Mistras and Spartan AE Systems before conducting the more controlled tests. A preamplifier gain of 40 $\mathrm{db}$ was utilized for all AE systems. The acoustic sensors used in these tests were designed inhouse at OU.

\subsubsection{Experimental Results}

A series of triaxial compression experiments were conducted on each rock type to evaluate the AE activity of porous rocks at 1000 psi confining pressure. Each rock type was deformed until it achieved failure or its ultimate strength. The first rock type tested was the Danian chalk, which is an analog to the Ekofisk chalk and many carbonate reservoirs. The rock had low strength during ductile compaction. Surprisingly, the acoustic emission activity was very low in both amplitude and in the number of events generated during this plastic deformation. The low level of activity would make acoustic emission imaging an extremely difficult, if not impossible, task. Several repeat tests were conducted on this chalk to verify that the results were inherent to the rock type and not due to unforeseen equipment problems. After obtaining these initial results it was decided to amend the testing program to include other rock types including Oil Creek sandstone, Indiana limestone, and Cordoba Cream limestone. Berea sandstone samples were cored, cut, and tested during this phase because its acoustic emission behavior is well documented. A comparison of the AE data from the Berea sandstone versus the Danian chalk is most informative. Using the exact same experimental setup the Berea sandstone exhibited over 130,000 events whereas the Danian chalk generated only 2300 events under the same deformational conditions. Subsequent experiments on other sandstones and limestones indicated that all the high porosity carbonate rocks (e.g., the chalks and limestones) exhibited much lower acoustic emission activities during deformation than did the sandstones. Respectively, the Danian chalk, Cordoba Cream limestone, and Indiana limestone exhibited 2300,80 , and 1700 events. The sandstones were much higher with 130,000 and 280,000 events detected for the Berea and the Oil Creek sandstones, respectively. Besides the observation that the carbonates exhibited much lower AE activities than did the sandstones, some other preliminary observations could be made from this initial limited data set. A higher ultimate strength of the rock type would not seem to be a unique indicator of higher AE activity. Both the Indiana limestone and the Berea sandstone had similar ultimate strengths at yielding but the acoustic emission activity was much lower in the Indiana limestone. Also, the grain sizes of the Indiana and Cordoba Cream limestones were similar to the Berea and Oil Creek sandstones. However, these generated vastly different AE activities.

These preliminary results are important as they suggest the acoustic emission monitoring of matrix deformation of soft carbonate rocks during reservoir deformation may be very difficult. In the case of Rutledge et al. (1994) they concluded that the microseismic activity they were monitoring was from shear fault activation during production of the Ekofisk and not from the matrix compaction. The experimental results from this study suggest that the low level of acoustic emission activity may be common to high porosity carbonate rocks. The acoustic velocity (seismic survey) imaging appears to be a much more promising approach.

A series of acoustic emission experiments were conducted on the other high porosity sandstones, limestones, and chalks. The rock core samples were subjected to triaxial stress 
deformations and the acoustic emission activity was recorded as the samples were deformed to the point where either brittle shear failure occurred or a significant plastic deformation was evidenced. The first rock type tested was the Danian chalk. This rock type is thought to be best representative of the deformation of chalk formations like the Ekofisk chalk in the North Sea. The core sample was tested under triaxial stress conditions at a confining pressure of 1000 psi. The results were somewhat surprising. The acoustic emission activity was very quiet as compared to that generally observed in sandstones and granites (see references previously listed). Both the acoustic amplitudes and the rate of acoustic emission rate were low (Figures 33, 34, and 35). The low level nature of the AE activity in the chalk, which was clearly undergoing ductile deformation with significant plastic strain (Figures 33, 34, and 35), had no locatable $A E$ events under the current testing configuration. As previously noted one of the goals of the research program was to conduct hypocentral location of AE activity during deformation of the chalk. The recorded low level activity, both in the AE rate and amplitudes, calls into question whether this task can be accomplished on such a ductile rock. To clarify these questions the investigators in the research program decided to conduct some limited tests on Berea sandstone and utilize this as an $\mathrm{AE}$ reference standard in the research program. Under 1000 psi confining pressure the Berea sandstone initially exhibited: (1) quiet AE activity during initial loading of the sample, (2) increased AE activity at a point on the stress-strain curve halfway to the ultimate strength of the sample, and (3) a higher level of $A E$ activity near failure. Figures 36, 37, and 38 show data from one of the Berea triaxial reference tests for this study (Note: several of these were conducted to ensure reproducibility of the data.) These samples exhibited normal AE activity for a Berea sandstone sample deformed under these conditions. A comparison of the cumulative AE data for Berea and Danian chalk illustrates the vast difference between the behavior of the two rock types. During the Danian chalk test (Figure 35) the deformed sample exhibited only $8000 \mathrm{AE}$ events, even after significant ductile deformation. The Berea sandstone sample showed 130,000 events prior to brittle shear failure (Figure 38). It was decided that, at this stage of the study, it would be more exciting to compare the differences in AE activity for the other rock types obtained for the study including the Indiana limestone, the Oil Creek sandstone, and the Cordoba Cream limestone. A series of experiments comparing the $\mathrm{AE}$ activity for each rock type under controlled conditions where all other experimental variables were held constant (e.g., confining pressure) was deemed important to our research program. With this in mind the research team assembled samples of Indiana limestone, Oil Creek sandstone, Cordoba Cream limestone, and additional samples of chalk (the primary rock type of interest) and the Berea sandstone reference sample. The stress-strain curves and the AE rate diagrams for the Indiana limestone are shown in Figures 39 and 40. Interestingly, this rock exhibited a brittle failure at about 10,000 psi differential stress but also had a low level of acoustic emission activity. The cumulative value at termination of the experiment was only 1700 events (Figure 41). This was significantly lower than the Berea sample but in line with the observations of low activity in the Danian chalk sample. The results for the Cordoba Cream limestone are shown in Figures 42, 43, and 44. This rock type deformed ductilely and exhibited only 80 events under conditions comparable to the Berea, Indiana, and Danian chalk samples. The Oil Creek sandstone (Figures 45, 46, and 47) generated the most AE activity of any rock type observed in the test program. At termination of the experiment this high porosity sandstone exhibited 280,000 AE events (nearly double that of the Berea sandstone).

The two sandstones exhibit the highest acoustic emission activities in the study as compared to the limestones and chalks. It is important to note that though the Indiana limestone is stiffer than the Oil Creek sandstone the AE activity of the limestone is significantly lower. This means, significantly, that stiffness and strength are not necessarily indicators as to the activity, intensity, or amplitude of acoustic emission events that will be observed during a deformation experiment. These results suggest that the deformation of calcite and carbonate grains and cements (which 
dominate the composition of the limestones and chalks) generates a very low level of AE activity as compared to the deformation of the quartz-rich sandstones. It is also important to note that the level of $A E$ activity does not appear to be dependent upon grain size. The Indiana limestone and the Cordoba Cream limestone both exhibit low AE activities as compared to the two sandstones which have equivalent grain sizes.

These preliminary results indicate the acoustic emission activity from the matrix of deforming high porosity limestones and chalks is very difficult to detect. The AE events are infrequent and have a low amplitude as compared to sandstones tested in the experimental program. Analyzing these results within the context of the main premise of the study to image the deformational signatures in reservoir rocks suggests that $A E /$ microseismic imaging of matrix pore collapse and compaction will be difficult to accomplish in the field setting even if ultrasonic detectors are set in place in the reservoir. This may not be true of the sandstones which exhibit more energetic $\mathrm{AE}$ activities during the deformation experiments. 
The principal stresses in rock formations located in the subsurface are rarely equal. Nelson (1981) noted that in the U.S. the horizontal stresses can be as low as $20 \%$ of the vertical stress. Such an anisotropic state of stress plays an important role in many petroleum engineering and geological engineering problems, including analyzing borehole stability, fault stability, oil and gas reservoir deformation, slope stability, etc. The superposition of an anisotropic state of stress on porous rocks results in changes in the rock elastic and poroelastic moduli. This is designated as 'stress-induced' anisotropy and is differentiated from 'inherent anisotropy' which results from layering, bedding, fractures, and other geological features as a natural part of the rock. Inherent anisotropy has been extensively studied by geologists, geophysicists, and engineers. However, the effects of stress induced anisotropy have not been researched. This experimental study is designed to provide information on the nature and magnitudes of stress induced anisotropy on the elastic and poroelastic parameters in porous rock.

Theoretical aspects of wave propagation in a transversely isotropic rock have been investigated by Levin (1979), Byun (1984), Crampin (1984a), (Crampin 1984b), Crampin (et al. 1984), Helbig (1984), Byun and Cheng. (1986), Thomsen (1986), Nikitin and Chesnokov (1981), Chesnokov and Zatsepin (1991), Vshivtsev et al. (1995), and Zeng (1999). Also, the fact that nonisotropically stress-induced variations in the elastic and poroelastic moduli exists could be indirectly-derived from deformation experiments that show that an extensive stress-induced variations in acoustic (seismic) velocity anisotropy occurs during triaxial deformation experiments (in axi-symmetric cylinders) (Nur 1971), Wu et al., 1990; Zamora and Poirier, 1990; Sayers, 1998a and b; Scott et al., 1993; King et al., 1995.

Inherent anisotropy, that anisotropy due to geological features such as bedding, sedimentary layering, and fractures, has been studied extensively. For example, the dynamic elastic moduli (e.g., Young's moduli and shear moduli) for transversely isotropic (e.g., hexagonal symmetry) rocks have been obtained by Podio (1968), King (1969), Jones and Wang (1981), Lo et al. (1986), White et al. (1993) and King et al. (1994). These studies utilized compressional and shear wave velocity data to calculate the components of the stiffness matrix. Their results indicate that inherent transverse isotropy can be quite large, i.e., up to $20 \%$.

The calculation of elastic parameters from dynamic data has been well documented within the physics, geophysics, and engineering literature. The method involves acquisition of acoustic compressional and shear wave velocities within a transversely isotropic rock. This data is then used to calculate the components of the stiffness matrix):

$$
\left[\begin{array}{l}
\boldsymbol{\sigma}_{11} \\
\boldsymbol{\sigma}_{22} \\
\boldsymbol{\sigma}_{33} \\
\boldsymbol{\sigma}_{12} \\
\boldsymbol{\sigma}_{13} \\
\boldsymbol{\sigma}_{23}
\end{array}\right]=\left[\begin{array}{cccccc}
\mathrm{c}_{11} & \mathrm{c}_{12} & \mathrm{c}_{13} & 0 & 0 & 0 \\
\mathrm{c}_{12} & \mathrm{c}_{11} & \mathrm{c}_{13} & 0 & 0 & 0 \\
\mathrm{c}_{13} & \mathrm{c}_{13} & \mathrm{c}_{33} & 0 & 0 & 0 \\
0 & 0 & 0 & \mathrm{c}_{44} & 0 & 0 \\
0 & 0 & 0 & 0 & \mathrm{c}_{55} & 0 \\
0 & 0 & 0 & 0 & 0 & \mathrm{c}_{55}
\end{array}\right]\left[\begin{array}{l}
\boldsymbol{\varepsilon}_{11} \\
\boldsymbol{\varepsilon}_{22} \\
\boldsymbol{\varepsilon}_{33} \\
\boldsymbol{\varepsilon}_{12} \\
\boldsymbol{\varepsilon}_{13} \\
\boldsymbol{\varepsilon}_{23}
\end{array}\right]
$$

These stiffness components are then used to calculate the anisotropic Young's moduli and shear moduli (see Podio et al., 1968; King 1969; and Lo et al., 1986 for details of the calculations). The method requires a minimum of five acoustic raypaths to calculate the full set 
of dynamic elastic moduli. The acoustic raypaths include a set of compressional waves propagating parallel and normal to the axis of symmetry, a set of shear waves with planes of polarization oriented normal and parallel to the plane of symmetry, and an 'off-axis' compressional wave velocity typically oriented at $45^{\circ}$ to the axis of symmetry.

Experimentally there are two methods to determine the components of the compliance matrix so that the anisotropic elastic and poroelastic parameters can be determined. One method involves static testing where a cylindrical rock sample is subjected to changing boundary stresses and the moduli are calculated from the stresses and strains. The second method involves using mult-raypath multi-azimuthal acoustic wave propagation (both compressional and polarized shear waves) to calculate the elastic parameters. We assert the completion of the full elastic and poroelastic tensor for a stress-induced transverse isotropy can only be accomplished on a single core sample utilizing dynamic (e.g., ultrasonic) methods. Attempts have been made to complete the tensor using static methods but these do not yield enough parameters for completion of the compliance matrix. If a right circular cylinder is placed under axisymmetic conditions with axial and lateral strain gages then only $E_{v}, v_{v h}, G_{v}$ can be measured. Neither $E_{h}$, $v_{\mathrm{hh}}, v_{\mathrm{hv}}$ or $\mathrm{G}_{\mathrm{h}}$ can be obtained. This was pointed out in earlier work by Kohata et al. (1997). For a triaxial test on a cylindrical sample with an axisymmetic state of stress $\left(\sigma_{3}>\sigma_{2}=\sigma_{1}\right)$ where the axial stress $\left(\sigma_{3}\right)$ is cycled and the horizontal stresses $\left(\sigma_{2}\right.$ and $\left.\sigma_{1}\right)$ are maintained constant (from Lings et al. 2000):

$$
\begin{gathered}
v_{v h}=-\left(\frac{\delta \varepsilon_{h}}{\delta \varepsilon_{v}}\right)_{\delta \sigma_{h}^{\prime}=0} \\
E_{v}=\left(\frac{\delta \sigma_{v}^{\prime}}{\delta \varepsilon_{v}}\right)_{\delta \sigma_{h}^{\prime}=0}
\end{gathered}
$$

In this case the vertical Young's modulus $\left(E_{v}\right)$ and one of the three Poisson's ratios $\left(v_{v h}\right)$ can be determined. If on the same sample the lateral stresses are cycled and the vertical stress is maintained constant then:

$$
\begin{aligned}
& \frac{E_{v}}{\left(1-v_{h h}\right)}=\left(\frac{\delta \sigma_{h}^{\prime}}{\delta \varepsilon_{h}}\right)_{\delta \sigma_{v}^{\prime}=0} \\
& \frac{2 v_{h v}}{\left(1-v_{h h}\right)}=-\left(\frac{\delta \varepsilon_{v}}{\delta \varepsilon_{h}}\right)_{\delta \sigma_{v}^{\prime}=0}
\end{aligned}
$$

(from Lings et al. 2000). In this case the values for the horizontal Young's modulus and the two remaining Poissons ratios cannot be isolated. Without these parameters the compliance matrix cannot be completed. There have been two attempts to get around this problem. Kohata et al. (1997) attempted to estimate horizontal Young's modulus (in soil samples) by forcing the large assumption that one of the two Poisson's ratios in the vertical plane (the measured $v_{v h}$ ) was equal to the undetermined Poisson's ratio in the horizontal plane $\left(v_{\mathrm{hh}}\right)$. This allowed them to estimate the Young's modulus in the horizontal plane. They suggest that the error induced by this assumption is 'insignificant' in the case of the soil samples they studied. We do not concur and especially so in the case of rocks. Their own numbers suggest that a hypothetical difference of 0.15 versus 0.25 in the value of Poisson's ratio would result in a variation of 'only' 
0.88 in the horizontal Young's modulus. A 12 percent error in the estimation of the anisotropic Young's modulus is significant since the maximum stress induced anisotropy in Young's moduli observed in rocks to date is around 20 percent (Scott and Abousleiman, 2002).

Lings et al. (2000) also could not complete the elastic tensor in an experimental examination of clay samples deformed as right circular cylinders under axisymmetric deformation. They note, as Kohata et al. (1997), that in this test configuration $E_{h}, v_{h h}, v_{h v}$, and $G_{h}$ cannot be obtained. They leave their examination to observing the effects of deformation on the parameters $E_{v}$ and $v_{\mathrm{vh}}$, and the combined parameters $E_{h} / 1-v_{\mathrm{hh}}$ and $v_{\mathrm{hv}} /\left(1-v_{\mathrm{hh}}\right)$ since the individual elastic moduli could not be separated.

Lockner and Beeler (2003) attempted to complete the compliance matrix using static methods. They acknowledge that $G_{h}$ cannot be obtained. However they state that $E_{h}, E_{v}, v_{v h}$, and $v_{\mathrm{hh}}$ can be determined from a strain gage response to independent application of axial load and confining pressure.' They conducted their experiments on cylindrical samples under axisymmetric samples as did Kohata et al. (1997) and Lings et al. (2000). They plot up two distinct Poisson's ratios in research and do not define how they arrived at these data. Given the limitations of this experimental configuration clearly pointed out by Kohata et al. (1997) and Lings et al. (2003) it is unclear how they arrived at their data. They are clearly not utilizing the assumption of Kohata et al. (1997) that $v_{\mathrm{vh}}=v_{\mathrm{hh}}$ since they are plotting two unequal Poisson's ratios. We concur with Kohata et al. (1997) and Lings et al. (2000) that the specimen geometry utilized by Lockner and Stanchits, 1997) and Lockner and Beeler (2003) under axisymmetric stress conditions, where two horizontal stresses are, do not allow $E_{h}$ or $v_{h h}$ (or $v_{h v}$ ) to be determined.

Given the above reasoning it is not possible to complete the components of the compliance matrix derived from static data on a single core sample. If this is the case then elastic and poroelastic moduli cannot be calculated as was done by Lockner and Beeler (2003). Dynamic experiments, which use ultrasonic wave propagation (Scott and Abousleiman 2002a; and Scott and Abousleiman, 2002b) present the only method for obtaining the complete set of elastic and poroelastic moduli in stress induced rock.

Another parameter which is important to engineers is the poroelastic Biot's effect stress parameter. This parameter governs the amount of pore fluid stress transmitted to rock porous framework and is defined as:

$$
\sigma_{i j}^{\prime}=\sigma_{i j}+\alpha_{i j} p
$$

as $\sigma_{i j}^{\prime}$ is the effective stress, $\sigma_{i j}$ is the stress, $p$ is pore pressure, and $\alpha$ is the Biot's effective stress parameter (Biot and Willis, 1957). Biot's parameter for an isotropic rock is experimentally determined by either of two methods. The first method is the direct method where a jacketed rock sample is placed under a hydrostatic state of stress (e.g., all principal stresses are equal) and the Biot's effective stress parameter is determined from a ratio of the change in pore fluid volume to the total volume change of the rock. The second method, the indirect method involves measuring the bulk modulus of the solid grain $\left(\mathrm{K}_{\mathrm{s}}\right)$ in an unjacketed drained hydrostatic experiment and measuring the bulk modulus of the rock $(K)$ in a separate hydrostatic experiment. The Biot's effective stress parameter is calculated as $\alpha=1-\left(\mathrm{K} / \mathrm{K}_{s}\right)$. Typical values of the Biot's effective stress parameter experimentally range from .3 to 1 (Fatt 1969; Yew and Yogi, 1979; Laurent et al., 1993; Abousleiman et al., 1994; Fabre and Gustkiewiez, 1998; and Franquet and Abass 1999). However, both of these methods are used to provide data on the 
isotropic Biot's parameter and cannot be used in the case of a transverse isotropy. This is due to the fact that both the indirect and direct methods involve measurement of volumetric properties of the rock and no directional components can be separated out.

The theoretical basis for an anisotropic Biot's parameter was established by Biot and Willis (1957), Carroll (1971), Thompson and Willis (1991), Abousleiman and Ghassemi (1992), Abousleiman and Cheng (1996), and Cheng (1997). Abousleiman and Cheng (1993), Cheng (1997), and Abousleiman and Cui (2001) determined that the directional effective stress components $\left(\alpha_{\mathrm{ij}}\right)$ could be determined from the components of the stiffness matrix:

$$
\alpha_{i j}=\delta_{i j}-\frac{C_{i j k k}}{3 K_{s}}
$$

For a transversely isotropic rock the axial Biot's effective stress parameter $\left(\alpha_{33}\right.$ - paralleing the axis of symmetry) could be determined by:

$$
\alpha_{33}=1-\frac{2 C_{13}+C_{33}}{3 K_{s}}
$$

and the lateral Biot's effective stress parameter $\left(\alpha_{11}\right)$ by:

$$
\alpha_{11}=1-\frac{C_{11}+C_{12}+C_{13}}{3 K_{s}}
$$

The role of induced, anisotropic state of stress on the elastic and poroelastic parameters has not been investigated to date. There is, however, ample indirect evidence that anisotropic stresses do induce anisotropy within rocks. The changes in anisotropy in rocks have been extensively examined utilizing measurement of compressional and shear wave velocities during triaxial compression experiments on rocks. During such an experiment a jacketed rock core sample is placed in a pressure cell and a lateral confining pressure is applied. Then an axial loading piston is used to apply an increasing vertical stress. The resulting stress state $\left(\sigma_{1}>\sigma_{2}=\sigma_{3}\right)$ creates marked changes in acoustic compressional and shear wave velocities propagated in the axial and lateral directions of the core. Typically the axial velocity increases and the lateral velocity slightly decreases (see examples in Nur and Simmons, 1969; Fjaer et al., 1989; Sayers and van Munster, 1991; and Scott et al., 1993). The amount of velocity change can be quite large, i.e., up to $30 \%$. The velocity data from these studies, while indicating that stress induced anisotropy exists, cannot be used to calculate the dynamic elastic moduli. An additional measurement, an 'off-axis' compressional wave measurement at $45^{\circ}$ to the axis of symmetry, is required to calculate the $\mathrm{C}_{55}$ component of the stiffness matrix. Attempts have been made to estimate this component (Bachman 1983) but, to date, it has not been measured in sufficient detail to allow a complete set of stiffness components to be made for a soil, sediment, or rock. Similar work has been accomplished on anisotropy in soils (Graham and Houlsby, 1983; Pennington et al., 1997; Lings et al., 2000) where acoustic data has been used to estimate the anisotropic shear moduli but the Young's moduli in these studies is still calculated via an indirect method. So, to date, no studies in either rocks or soils, is sufficiently 
complete where a total set of elastic and poroelastic parameters have been measured. The primary difficulty is due to the experimental difficulty in obtaining the full array of acoustic raypath data from a single rock sample.

The experimental method utilized to determine the dynamic elasticity parameters in an inherently (i.e., sedimentary) transversely isotropic rock cannot be used in the case of stress induced isotropy. For inherent anisotropy (see Podio et al., 1968; King 1969; and Lo et al., 1986) the 'three oriented core' method was used where cores are cut at $0^{\circ}, 90^{\circ}$, and $45^{\circ}$ to the axis of inherent symmetry and the acoustic compressional and shear wave velocities were measured down the axis of each of the three cores. However, in the case of applying a triaxial state of stress to an initially isotropic rock, the axis of symmetry of the stress-induced anisotropy will always be aligned with the loading piston and directionally cut rock cores are useless. The research team at the OU PoroMechanics Institute developed a method to measure an entire array of compressional and shear wave velocities during a stress induced anisotropy on one core sample by mounting a special set of directionally oriented acoustic sensors

\subsection{Experimental Equipment}

The experiments were conducted on right circular cylinders of Berea sandstone $7.62 \mathrm{~cm}$ in diameter and $15 \mathrm{~cm}$ in length. The Berea sandstone block selected for this study was exceptionally uniform and contained little or no visible bedding planes or fractures. Compressional wave velocity measurements were used to confirm that this sample had very little anisotropy or heterogeneity. The cylindrical samples were surface ground to within .00001 $\mathrm{cm}$ plane parallel. The samples were oven dried at $60^{\circ} \mathrm{C}$ for at least 24 hours prior to testing.

The experiments were conducted in an MTS servo controlled load frame (model 315) with a maximum capacity of $2669 \mathrm{kN}(600,000 \mathrm{lbs})$. The triaxial pressure cell has 60 electrical feedthroughs for acoustic leads and wires for extensometry. The cell has a maximum pressure confining pressure capacity of $140 \mathrm{MPa}$ and $140 \mathrm{MPa}$ pore fluid pressure. Axial strains were measured from stroke of the axial piston and corrected for elastic distortion of the loading frame. An MTS model 632.92B-05 extensometer was used to measure the circumferential strains around the sample. This extensometer was mounted on the outside of the jacketed rock sample.

The acoustic system is composed of six components: (1) a Tektronix TDS420a oscilloscope, (2) a Hewlett-Packard 3488a VHF switchbox, (3) a 300 volt pulse generator to excite the piezoelectric acoustic sensors, (4) an IBM PC for command and control of the oscilloscope and the switchbox and for acquisition and storage of the acoustic waveform data, (5) a set of axial loading platens containing acoustic sensors, and (6) a set of lateral acoustic sensors. The acoustic sensors, both axial and lateral, and the pulse generator were constructed in house at the University of Oklahoma. All acoustic sensors were constructed from $600 \mathrm{KHz} \mathrm{PZT-5a}$ piezoeletric crystals. All the lateral sensors, except the ones mounted for acquisition of the $45^{\circ}$ compressional wave, were mounted in three component housings containing a compressional wave and two orthogonally mounted shear wave elements. These housings were approximately $2.5 \mathrm{~cm}$ in length and $.8 \mathrm{~cm}$ in width. The lateral compressional wave sensors for the off-axis $45^{\circ}$ measurement contained one element and were approximately $.8 \mathrm{~cm}$ in diameter. The steel axial platens were $7.62 \mathrm{~cm}$ in diameter and internally contained one compressional wave and two orthogonally mounted shear wave sensors.

The following notation system was used for samples. The 3-direction is the vertical stress and is coincident with the axis of the cylindrical sample, and the 1- and 2-directions are the horizontal directions (see Figure 48 for orientations). A total of 11 acoustic raypaths were 
acquired on the cylindrical samples including $V_{P 33}, V_{P 22}, V_{P 11}, V_{S 31}, V_{S 32}, V_{S 12}, V_{S 13}, V_{S 32}, V_{S 23}$, $V_{P 45(1-3 a)}$, and $V_{P 45(1-3 b)}$. Only five of these raypaths are required to calculate the elastic and poroelastic parameters in a transversely isotropic material. These include $V_{P 33}$ (the vertical compressional wave), $V_{P 11}$, (the horizontal compressional wave), $V_{P 45(1-3 a)}$ (one of the compressional waves in the 1-3 plane oriented at $45^{\circ}$ to the core axis), $\mathrm{Vs}_{31}$ (the vertically propagating shear wave polarized in the 1-3 plane), and the horizontally propagating shear wave $\left(V_{S 12}\right)$ polarized in the horizontal (1-2) plane (see Figure 49). The other seven raypaths are required to document that the rock is transversely isotropic and to identify the point in the experiment at which the transversely isotropic condition degenerates. The elastic and poroelastic moduli are designated with subscripts $\mathrm{v}$ and $\mathrm{h}$ to designate the vertical and horizontal directions, respectively.

\subsection{Experimental Method}

In order to study the effects of superposition of an anisotropic state of stress on a porous rock three different types of deformation experiments were conducted. These include: (1) a hydrostatic compression experiment, (2) a triaxial compression experiment, and (3) a uniaxial strain experiment (see Figure 50). During the hydrostatic compression experiment both the axial stress and the lateral confining pressure are raised together while monitoring both the acoustic velocities and the axial and lateral strains. During a triaxial compression experiment the axial stress is increased but the lateral confining pressure is maintained at a constant value. Both of these experiments are commonly used in engineering testing programs to determine elastic moduli and failure strengths but neither is thought to best represent the deformation of rocks in the subsurface. Of the three experiments listed above petroleum engineers and geologists tend to view the uniaxial strain experiment as the one that best approximates the stresses which evolve in a rock sample in the subsurface. For example during burial of a rock or sediment, one- dimensional compaction is viewed as the dominant deformational pattern. The lateral strains are restricted while most deformation occurs in the vertical direction. During extraction of oil and gas from a petroleum reservoir most of the deformation occurs in the vertical direction since large variations in the lateral strains cannot be accommodated (except in the case where large tectonic forces are present). The uniaxial strain test is conducted by increasing both the axial and confining stresses while maintaining a zero lateral strain condition. In practice such an experiment is conducted by tying the feedback loop of the circumferential extensometer to the confining pressure and setting it to maintain a zero lateral strain condition as the axial load is increased. 


\subsection{RESULTS}

\subsubsection{Hydrostatic Compaction}

The hydrostatic compression experiment was conducted by raising the confining pressure $\left(\sigma_{1}\right)$ and the axial stress $\left(\sigma_{3}\right)$ equally up to a final value of $65 \mathrm{MPa}$. Figure 51 plots the axial and lateral strains measured during this experiment. There is an initial rapid increase in strains as pressure is applied. After $20 \mathrm{MPa}$ confining pressure the rate of change decreases. The axial and lateral strain data track each other fairly closely evidencing that, for the most part, the rock deformed fairly homogeneously. Figure 52 shows the compressional wave velocities $V_{P 33}, V_{P 11}$, and $\mathrm{V}_{\mathrm{P} 45(1-2)}$. The three initial compressional wave velocities all start around $2700 \mathrm{~m} / \mathrm{s}$ and increase rapidly up to $3600 \mathrm{~m} / \mathrm{s}$ at $20 \mathrm{MPa}$. At higher pressures the rate of increase is lower with a final velocity of around $3800 \mathrm{~m} / \mathrm{s}$ at $65 \mathrm{MPa}$. Figure 53 shows the shear wave velocities and these show increases from $1850 \mathrm{~m} / \mathrm{s}$ up to $2300 \mathrm{~m} / \mathrm{s}$ at the completion of the test. The calculated dynamic Young's moduli are shown in figure 54 and the dynamic shear moduli are shown in figure 55. The Young's moduli start at $16 \mathrm{GPa}$ and increase up to $27 \mathrm{GPa}$ at $65 \mathrm{MPa}$ hydrostatic pressure. The shear moduli start at $8 \mathrm{GPa}$ and increase up to $13 \mathrm{GPa}$. The dynamic poroelastic anisotropic Biot's parameters are plotted in figure 56 and the data starts at .8 and decreases down to .55. The initial rapid increases in deformational strains and acoustic velocities, and concurrent increases in the derived Young's moduli and shear moduli, are consistent with observations from most rocks subjected to hydrostatic deformation. The initial increases are attributable to the initial rapid closure of some of the open pore spaces, microcracks, and grain-to-grain contacts as pressure is applied. As stresses are further increased the population of pore space and microcracks available for closure decreases and the rate at which the rock framework subsequently stiffens also decreases. The observed decreases in the Biot's effective stress parameters as pressure is applied are also consistent with results from static measurements of isotropic Biot's parameter (Abousleiman et al., 1994). As the rock framework stiffens the Biot's effective stress parameter decreases.

\subsubsection{Triaxial Compression}

A triaxial compression experiment was conducted at an initial hydrostatic pressure of $20 \mathrm{MPa}$. During this test the axial stress was increased while the lateral (horizontal) confining pressures were maintained at a constant value. Figure 57 shows the stress-strain data for this experiment. Plotted are the axial strain, the circumferential strain, and the calculated volumetric strain. The test was terminated at an axial stress of $100 \mathrm{MPa}$. Previous research by Scott et al. (1993) indicated that above this axial stress Berea sandstone begins to develop significant permanent damage. The current experiments are intended to attempt to keep stress conditions within the elastic range and to avoid very high stress conditions where damage occurs and shear fractures within the rock begin to localize (creating severe heterogeneity). Figure 58 is a plot of the compressional wave velocities and figure 59 is a plot of the shear wave velocities.

$$
\left.\underline{M}\right|_{\triangle \sigma=0 M P a}=\left[\begin{array}{cccccc}
25.37 & 3.28 & 4.53 & 0 & 0 & 0 \\
3.28 & 25.37 & 4.53 & 0 & 0 & 0 \\
4.53 & 4.53 & 24.44 & 0 & 0 & 0 \\
0 & 0 & 0 & 11.04 & 0 & 0 \\
0 & 0 & 0 & 0 & 10.89 & 0 \\
0 & 0 & 0 & 0 & 0 & 10.89
\end{array}\right]
$$


During triaxial deformation the vertical (axial) compressional wave velocity increases and the horizontal (lateral) velocity decreases. The compressional wave velocity propagating at $45^{\circ}$ to the axis of the sample remains nearly unchanged as deformation proceeds. The shear wave polarized in the vertical plane illustrates only a slight increase in velocity but the horizontal shear wave shows a much higher decrease. The axial and lateral velocity data are consistant with those obtained by previous researchers on velocity anisotropy during triaxial deformation (Scott et al., 1993). The interpretation generally applied to these observations is that microcracks (and some pore spaces) are elastically opened in the horizontal direction and closed in the vertical direction (Hadley 1975a,b). The addition of the 'off-axis' compressional wave from this study, combined with the axial and lateral data, allow a calculation for the first time of the dynamic Young's moduli (Figure 60) and shear moduli (Figure 61). As axial stress is applied, the vertical Young's moduli increases and the horizontal Young's moduli decreases. The magnitude of the changes are nearly the same (i.e., the vertical Young's moduli show approximately the same amount of increase at a given axial stress level as the horizontal Young's moduli show in a decrease). The shear wave data exhibits a slightly different pattern. The horizontal shear wave illustrates a significant decrease whereas the vertically oriented shear wave shows only a very slight increase. The stiffness matrices for 0 and 98.6 MPa differential stress during the triaxial compression test at $20 \mathrm{MPa}$ confining pressure are:

$$
\left.\underline{M}\right|_{\Delta \sigma=91.6 \mathrm{MPa}}=\left[\begin{array}{cccccc}
21.15 & 3.15 & 1.64 & 0 & 0 & 0 \\
3.15 & 21.15 & 1.64 & 0 & 0 & 0 \\
1.64 & 1.64 & 29.53 & 0 & 0 & 0 \\
0 & 0 & 0 & 9.00 & 0 & 0 \\
0 & 0 & 0 & 0 & 11.47 & 0 \\
0 & 0 & 0 & 0 & 0 & 11.47
\end{array}\right]
$$

Figure 62 shows the changes in the anisotropic Biot's effective stress parameters during triaxial loading. In this case the axial (vertical) Biot's parameter decreases and the horizontal Biot's parameter increases. Two additional observations are evident in the elastic and poroelastic data. First, the results indicate that as axial stress is applied there is a linear decrease (or increase) in the respective moduli (i.e., the rate of change as stress is increased is not significantly different at low stress versus high stress levels). Second, as stress is continually applied the velocities and moduli in the horizontal and vertical directions continue to diverge.

\subsubsection{Uniaxial Strain}

The uniaxial strain experiment illustrates a pattern significantly different than either the hydrostatic or the triaxial test. Figure 63 plots the differential stress and confining pressure data for the uniaxial strain test. In this experiment both the vertical stress $\left(\sigma_{3}\right)$ and horizontal stress $\left(\sigma_{1}\right)$ are increasing but in a controlled manner that allows the circumferential (e.g., horizontal strains) to be maintained at zero. As such, the sample is undergoing increasing compression in all three directions but with strain only occurring in the vertical direction. Figure 64 and figure 65 show the compressional and shear wave data from this experiment. Both data sets show the same pattern; after an initial rapid change in velocities and higher increases in the vertical direction, the anisotropy becomes effectively 'locked in' and does not change even though the vertical stress and horizontal stresses are both increasing. The same pattern is evident in both the anisotropic Young's moduli (66) and the anisotropic shear moduli (Figure 67). The Biot's effective stress parameters are shown in figure 68. As the sample is loaded the Biot's parameter decreases and a marked anisotropy develops and at about $20 \mathrm{MPa}$ confining 
pressure the anisotropy becomes 'locked in' and from 20 to $60 \mathrm{MPa}$ the anisotropy remains constant.

The magnitudes of the vertical and horizontal anisotropy also do not change staying at values of .65 and .55. The stiffness matrices for confining pressures of 6.9 and $58.6 \mathrm{MPa}$ during the uniaxial strain experiment were:

$$
\begin{aligned}
\left.\underline{M}\right|_{\sigma_{3}=6.9 M P a} & =\left[\begin{array}{cccccc}
22.00 & 3.34 & 1.93 & 0 & 0 & 0 \\
3.34 & 22.00 & 1.93 & 0 & 0 & 0 \\
1.93 & 1.93 & 21.00 & 0 & 0 & 0 \\
0 & 0 & 0 & 9.33 & 0 & 0 \\
0 & 0 & 0 & 0 & 9.56 & 0 \\
0 & 0 & 0 & 0 & 0 & 9.56
\end{array}\right] \\
\underline{\left.M\right|_{\sigma_{3}=58.6 M P a}} & =\left[\begin{array}{cccccc}
25.47 & 3.70 & 8.7 & 0 & 0 & 0 \\
3.70 & 25.47 & 8.7 & 0 & 0 & 0 \\
8.7 & 8.7 & 32.25 & 0 & 0 & 0 \\
0 & 0 & 0 & 10.88 & 0 & 0 \\
0 & 0 & 0 & 0 & 12.42 & 0 \\
0 & 0 & 0 & 0 & 0 & 12.42
\end{array}\right]
\end{aligned}
$$

\subsection{Discussion}

The test results show that the magnitudes and degree of anisotropy of elastic and poroelastic moduli are strongly affected by evolution of deformational stresses (e.g., deformational path). The hydrostatic experiment serves as a baseline for the later triaxial and uniaxial strain tests since it was the closest to the ideal case where an attempt was made to examine the superposition of an isotropic stress field onto a nearly isotropic porous rock. During that hydrostatic experiment the rock showed little or no development of anisotropy as stresses were increased. As such, the data supports an initial important observation: that the application of an increasing isotropic state of stress on an inherently isotropic rock results in isotropic deformation (e.g., the hydrostatic experiment). However the application of an anisotropic state of stress on an isotropic porous rock will result in the development of anisotropic elastic and poroelastic parameters. Furthermore the degree of anisotropy is quite large. In the case of the triaxial experiment the vertical (axial) Young's moduli increases to $30 \mathrm{MPa}$ and the horizontal (lateral) decreases to $20 \mathrm{MPa}$. In the uniaxial strain experiment the vertical Young's moduli increased to $26 \mathrm{MPa}$ and the horizontal to $21 \mathrm{MPa}$. Another important observation is that the evolution of anisotropic stress application (i.e., the deformational path) strongly affects both the magnitude and degree of the anisotropy. In the case of the triaxial test, where vertical stress was continually increased but the horizontal stresses were held constant, the anisotropy continually increased until the test was terminated at $100 \mathrm{MPa}$. In the uniaxial strain experiment the anisotropy developed early in the loading phase and then was 'locked in' and did not change as both the axial and lateral stresses were increased. The nature of the evolving anisotropy is also different in each test. In the triaxial experiment the vertical (axial) values of the Young's moduli and shear moduli both increase whereas the horizontal (lateral) moduli decrease. In the uniaxial strain experiment both increase. The magnitude of the values and the degree of 
anisotropy in the Biot's effective stress parameters is also significant. Changes of 10 to 20 percent were observed during the triaxial and uniaxial strain experiments, respectively.

Most engineers, geologists, and geophysicists acknowledge that rocks in the subsurface are anisotropic. Anisotropy due to inherent geological features such as bedding, layering, or oriented fractures has been well studied and documented. The results from this study show that a significant portion of that in-situ anisotropy may be stress induced as well. 


\subsection{TOMOGRAPHIC IMAGING OF ROCK DAMAGE}

The research team developed a method and the experimental procedures for acquiring the data needed for ultrasonic tomography of rock core samples under triaxial stress conditions. Traditional triaxial compression experiments, where axial (sometimes lateral) compressional and shear wave velocities are measured, provide little or no information about the internal spatial distribution of mechanical damage within the sample. Seismic tomography, utilized for example, in crosswell tomography, allows an imaging of the velocities within a discrete zone within the rock. Ultrasonic or acoustic tomography is essentially the extension of that field technology applied to rock samples deforming in the laboratory at high pressures.

Porous limestones are responsible for the severe subsidence and compaction in the North Sea. As such we selected high porosity limestone for the first efforts at tomographic imaging of soft rocks. Field evidence from the North Sea suggests that compaction, which has resulted in over 30 feet of subsidence to date, is heterogeneously distributed within the reservoir. The initial tomographic studies (Scott et al., 1994a,b; 1998) were accomplished on well cemented, competent rocks such as Berea sandstone. The extension of the technology to weaker samples is more difficult but potentially much more rewarding. Three different types of sensors were considered (and tested) for the tomographic imaging project: $600 \mathrm{KHz}$ PZT, $1 \mathrm{MHz}$ PZT, and PVDF film sensors. $600 \mathrm{KHz}$ crystals were selected because they generated a sufficiently high amplitude pulse to propagate across the damaged limestone. A number of different configurations were considered for placement of the acoustic arrays. During the experiment shown in this report we concentrated on vertical tomographic imaging of the rocks.

\subsection{INTRODUCTION}

Acoustic tomography on laboratory scale rock samples represents a technique for determining the variations in velocity heterogeneities in samples undergoing deformation. The method is based on measuring the acoustic (or seismic) velocities along a large number of raypaths and then these velocities are used to reconstruct a 2-dimensional internal image of a rock section. Stacking a series of 2-D images can provide a three-dimensional internal image of a volume of rock. The technique was first used in the mid 1970's principally in cross-well tomography and has been used to map rock lithologies, track $\mathrm{CO}_{2}$ floods, fire floods, and waterfloods during petroleum enhanced recovery operations (Bregman et al. 1989; Justice et al., 1989; Johnston 1997).

Acoustic (ultrasonic) tomography has also been used in the laboratory to image:

1) dilatancy created during triaxial compressive failure (Yanigadani et al. (1987). The damage in circular cross section of core was imaged.

2) hydraulic fracturing in granite samples (Falls et al., 1992). In this study a mode I fracture was detected from the lower wave velocities in the vicinity of the crack.

3) elastic stress distributions (Scott et al., 1994a,b), during compressive indentation testing. In these tests the elastic closure of microcracks in highly stressed regions of a rock exhibited higher velocities.

4) compactive failure during indentation experiments (Scott et al., 1998). In that study the compressional wave velocities decreased due to the breakage of cements between the grains during compaction. 
The advances in ultrasonic tomographic imaging will be in its use under triaxial (e.g., high confining pressure) conditions as this is the stress condition which best approximates those which occur in the subsurface. Only the study of Scott et al., (1998) was conducted under such conditions. To date no other experiments utilizing tomographic imaging have been conducted under triaxial stress conditions. It should be noted that there is a major difference between the field uses of seismic tomography and the laboratory uses of ultrasonic tomography. Seismic tomography in the field is primarily utilized to image 1) rock lithologies, or 2) changes in pore fluid properties (e.g., oil/water displacement during $\mathrm{CO}_{2}$ flooding). While acoustic (ultrasonic) tomography in the laboratory is generally undertaken to image changes in rock properties (e.g., elastic deformation) or rock damage (e.g., fracturing). In the current research program, the research team will image compactive soft rocks to determine the heterogeneity of damage.

\subsection{EXPERIMENTAL METHOD (Tomography)}

Several methods were considered for the geometrical arrangement of acoustic sensors and tomographic imaging planes within the triaxial core samples. Initially, the research team proposed to tomographically image the rock along three horizontal planes and one vertical plane to locate and discern the degree of uniformity of the deformational mechanisms within the rock (particularly in regard to damage developing in the rock). However, this proved difficult due to the problems associated with sealing the large number of electrical leads from the high pressure confining oil. Since imaging on horizontal planes had been accomplished in previous research (Scott et, 1994a,b) it was decided to concentrate on the more technically challenging vertical plane tomographic imaging. The preliminary experimental results indicated that large velocity changes were occuring in the Indiana limestone at 500 psi confining pressures. Under these conditions the sample exhibited shear failure and dilatancy. It was decided to attempt to tomographically image the damage occuring in this rock type under the same confining pressure conditions.

The equipment utilized in making acoustic tomography measurements is shown in Figure 69. It consists of a 1) Tektronix TDS 420 digital storage oscilloscope, 2) a switchbox, and 3) an array of acoustic sensors mounted on the rock sample (see Figure 70). Any acoustic sensor can be used as a source or receiver in the current configuration. The acoustic sensors are made inhouse. Two methods were considered for acquisition of the tomographic images. This method involves firing one pulse and receiving one wave. Scott et al. (1994a,b; 1998). The method has the technical disadvantages in that 1 ) it is inefficient since it requires numerous pulses (one from each sensor-receiver pair), and 2) it requires several minutes to complete the waveform acquisition process. It should be noted that the technical acquisition of tomogram is every bit analogous to obtaining a photograph from a camera where the shutter lens is held open for a long period of time. The longer the lens remains opens (or in the case of tomography the longer it takes to obtain all the raypaths) the more potential that the subject to be imaged may undergo changes. In the case of a rock sample undergoing damage at high pressures, the process is continually evolving so it would be advantageous to complete the acquisition in the shortest time possible. Ideally, the best way to shoot the tomogram would be to use a minimum of 10 pulses and record the waves on all the receivers in a given array. This is how field seismic measurements are accomplished. The big problem with using this same method on a core sample is that a geometrical array of piezoelectric receiver crystals have characteristics that are strongly influenced by their size and their geometrical position relative to the acoustic source. Given this problem it is advantageous to use a DSO to acquire the acoustic waves since scaling of the received wave can be easily changed to accommodate changes in the amplitude of the 
waveforms. Stated succinctly, we are sacrificing speed of acquisition of the waveforms for the increase in a clarity and accuracy.

Figure 70 shows a schematic of the sample utilized in the tomography testing. The core sample was $15.2 \mathrm{~cm}$ in diameter and $26.7 \mathrm{~cm}$ in length. Figure 71 provides a 2-dimensional view of the location of the acoustic sensors. There are twenty sensors (ten on each side of the sample). In this array each of the ten sensors on one side represents the pulsers and the ten on the opposite side represent the receivers. Two aspects of the raypath patterns in this vertical plane should be noted. First, the raypath fan beams are not symmetrical but vary from pulser to pulser. Second, the coverage at the ends of the rectangular cross section is extremely limited (Figure 71). This is due to the fact that the steel end platens preclude the placement of acoustic sensors in this region of the sample. The poor coverage is typical of and directly analogous to the problems encountered in crosswell tomography when sensor coverage is poor. Figure 72 is a 3-dimensional view of the vertical array of the acoustic raypaths in the rock sample. In the vertical configuration there are one hundred raypaths that can be potentially used in the tomogram.

Preliminary tests indicated that it would be best to pulse each raypath two times to insure adequate acquisition of the waves. The arrival time of each wave was identified manually to insure accuracy. The tomograms could be can generated in two forms. Absolute velocity images record the exact velocities and difference imaging which involves subtracting successive velocity images from the initial image to track changes as deformation occurs. These have been successfully used by Scott 1994a and Scott 1994b. In this study the research team decided to present the data as absolute velocity images so that the evolutionary damage during successive loading phases of the experiments could be observed.

Figure 73 shows the jacketed sample limestone sample ready for ultrasonic tomography. It is capped by steel loading pistons which are used to apply the axial stress to the sample. The acoustic sensors glued to the rock can also be seen in this figure. Figure 74 shows a the sample mounted on the Keck Triaxial stage prior to lifting it into the cell for the experiment. Figure 75 dramatically indicates the scale effect of this type of experiment. Most rock deformation experiments test 2 inch, 1.5, and 1.0 diameter samples (which are pictured next Keck sample). The Keck Geomechanical Acoustic Imaging system can handle large instrumented samples when compared to most existing rock presses. A photograph of the Keck Geomechanical Acoustic Imaging System is shown in figure 76. The load frame is to the right side of the photograph and the data reduction system is shown to the left side.

The experiment on the core sample was conducted as a 'step and hold' type. First, 500 psi confining pressure was applied to the sample and an initial tomogram was taken. Then a small axial stress applied to the sample and 'held' while another tomogram was shot. This successive process of raising the stress and holding at a given level while a tomogram was acquired was continued until the sample failed. The stress-strain curve for the experiment is shown in figure 77. The sample had an ultimate strength of 7463 psi and then exhibited strain softening after failure. Tomgrams were acquired at stress levels of $0,937,2727,6756,7287,7463$ psi in the loading phase. In addition one tomogram was shot after the sample failed and unloaded to 2963 psi. After this the axial stress was removed allowing only the confining pressure to remain around the sample and a final tomogram was shot.

The initial tomogram shot at $500 \mathrm{psi}$ is shown in figure (78). Note the velocity scales in all the tomographic images is the same (from $3900 \mathrm{~m} / \mathrm{s}$ to $4065 \mathrm{~m} / \mathrm{s}$ ). Low velocities are represented by green/blue colors and high velocities are shown by orange/red colors. The initial 
velocity tomogram indicated little or no heterogeneity at this velocity scale. The average velocity is around $4008 \mathrm{~m} / \mathrm{s}$. Next an axial stress was applied (937 psi - figure 79) and this tomogram shows a slight increase in velocity in the center of the diagram. This central velocity high continues to increase at 2727 psi (Figure 80). At 6756 (Figure 81) the increase in velocity seems to indicate little change from the previous diagram. At 7287 (Figure 82) a generalized diffuse low velocity zone begins to develop in the center of the core sample. At a stress level of 7463 psi (Figure 83) a sharp central zone of low velocity is developing. The low velocities at such high stress levels is generally indicative of the dilatancy damage within the core. The tomograms interestingly indicate the this microcrack damage is confined to a central region of the core and no damage is present at the ends of the core. This tomogram represent the peak stress attained by the sample and after this the sample fractured. Figure 84 shows the postpeak tomogram after the sample had failed to a residual strength of 2935 psi. The low velocity zone shows a distinct asymmetry. The final tomogram was shot in the unloaded condition (Figure 85) and this illustrates a distinctive inclined damage zone which may be associated with the shear fracture observed in the sample (Figure 86) after completion of the experiment.

\subsection{CONCLUSIONS}

Ultrasonic tomography has been utilized to image the damage observed within cross sectional vertical slice of the porous limestone sample. The results indicated that during the failure process a centralized diffuse zone of damage developed within the core. The end of test this diffuse low velocity zone had taken on a distinct inclined nature very similar to the post test shear fracture visibly observed in the core. The results suggest that damage, both in the laboratory and field environments, could concievably be imaged with techniques such as ultrasonic velocity. The magnitude of the velocity variations is sufficiently high enough that field seismic tomography or 3-D seismic acquisition could detect the changes in the damaged rock. 


\subsection{Project Conclusions}

The five most important observations made during the course of the research include:

(1) The acoustic measurements on sands undergoing liquefaction indicates that shear wave velocities markedly decrease and the concurrent $V_{p} / V_{s}$ ratio increases as deformation occurs. The same observations were made for sand undergoing shear failure. Sands that were not in failure (i.e., under elastic states of stress or were deforming in response to an application of hydrostatic stresses) did not exhibit these traits. The results suggest that the observation of a zone of low shear wave velocities, in either laboratory experiment or on a seismic survey, indicates an area where failure of the unconsolidated sand may be occurring (or is about to occur). In the case of drilling a well in deepwater it may been an area with a high potential for creating a shallow water flow.

(2) Both the dynamic elastic and poroelastic moduli respond to anisotropic states of stress. It has been well documented that inherent anisotropy (due to bedding, sedimentary layering, and fractures) affects the processing of seismic data. The research in this study, documents for the first time, that anisotropic states of stress (i.e., non-equal stresses) can result in a major changes in the anisotropy elastic and poroelastic moduli and that the observed changes are of a magnitude similar to that observed due to inherent anisotropy. Future improvements in seismic processing may require that stress induced anisotropy be considered. A major outcome of the study is that a new single core laboratory method for completing components of the anisotropic elastic and poroelastic tensors was developed. This configuration could be used to study both inherent and stress-induced anisotropies.

(3) A new method for measuring anisotropic Biot's effective stress parameter was developed during the course of this study. Biot's effective stress parameter is important in defining the insitu state of stress in the subsurface and is important to earthquake research, the development of oil and gas reservoirs, and geothermal research. Previous work on the Biot's effective stress parameter has been documented for the isotropic case. Theory had been developed for this parameter in anisotropic situations but, until this research, no known method was available for actually measuring them either in the field or in the laboratory. In this study we show, for the first time, how to derive the anisotropoic poroelastic parameters from acoustic wave propagation and we conducted several experiments to observe their change during deformation.

(4) Acoustic emission testing on weak rock samples yielded some surprising results. AE activity was observed to be very dependent on mineral grain types. Rocks with quartz and sand grains exhibited much higher acoustic emission activities than rocks with calcite or carbonate grains (even at comparable porosities). The low level of acoustic emission activity in chalk samples precluded any attempt to use $A E$ hypocentral imaging to locate compaction zones in these weak rocks.

(5) Acoustic tomography was successfully utilized to time lapse image the development of a damage zone in porous limestone. A series of images, progressing from elastic deformation through the development of a shear fracture, were made to image the velocity changes in a vertical cross section of a rock core sample. This aspect of the research suggests the tantalizing option of expanding the seismic tomography to include imaging rock damage in the subsurface. For example, time lapse imaging could be used to image rock deformation in: (1) dam sites, (2) slope stability problems, (3) petroleum reservoirs undergoing compaction and subsidence, (4) petroleum reservoirs were fault reactivation due to induced seismicity is created, and (5) earthquake zones. 


\section{REFERENCES}

Abousleiman, Y. \& Ghassemi, A. 1992. Laboratory determination of poroelastic parameters, Part I, Biot's effective stress, University of Oklahoma RMI Consortium Report RMC 92-12.

Abousleiman, Y. \& Cheng, A. 1993. Anisotropic poroelasticity with applications, University of Oklahoma RMI Consortium Report RMC 93-19. 36p.

Abousleiman, Y. \& Cheng, A. 1996. Mandel's problem revisited, in Geotechnique 46, No. 2, pp. 197-195.

Abousleiman, Y., Chhaljani, R., \& Roegiers, J-C. 1994. Effect of stress variation on Biot's parameter, in First North American Rock Mechanics Symposium, Poster Session Abstracts, pp. 1-4.

Abousleiman, Y. and Cui, L., (1998) Poroelastic solutions in transversely isotropic media for wellbore and cylinder, Int. J. Solids, Structures, 35, pp. 4905-4929.

Abousleiman, Y. and Cui, L., (2001) The theory of anisotropic poroelasticity with applications, In Modeling in Geomechanics, Zaman, M., Gioda, G., and Booker, J., pp. 561-593.

Alberty, M.W., 2000. Shallow water flows: A problem solved or a problem emerging, Offshore Technology Conference 2000, OTC Paper 11971, pp. 67-73.

Amadei, B. 1983. Rock Anisotropy and the Theory of Stress Measurements, Springer-Verlag, $478 p$.

Aoki, T., Tan, C.P., \& Bamford, W.E. 1993. Effects of deformation and strength anisotropy on borehole failures in saturated shales, Int. J. Rock Mech. Min. Sci. \& Geomech. Abstr., Vol. 30, No. 7, pp. 1031-1034.

Arulnathan, R., Boulanger, R. W., and Riemer, M. F. (1998). Analysis of bender element tests, Geotechnical Testing Journal (GTJODJ), Vol. 21, No. 2, June 1998, pp. 120-131.

Azeemuddin, M., Scott, T. E., Roegiers, J.-C., and Zaman, M. (1994). Acoustic velocity anisotropies in Cordoba Cream limestone during different deformational stress paths, Proceedings, $1^{\text {st }}$ North American Rock Mechanics Symposium, Austin, Texas, pp. 775782.

Bachman, R.T., 1983. Elastic anisotropy in marine sedimentary rocks. J. Geophy. Res., Vol. 88, No. B1, pp. 539-545.

Biot, M.A., \& Willis, D.G. 1957. The elastic coefficients of the theory of consolidation, Jour. of App. Mech., Paper 57, pp. 594-601.

Boldt, L. (1992). The effects of confining pressure on the mechanical behavior and deformation mechanisms for the Oil Creek Sandstone in laboratory tests, M.Sc. Thesis, The University of Oklahoma, Norman, $121 \mathrm{p}$.

Bregman, N.D., Hurley, P.A., and West, G.F.: ' Seismic Tomography at a Fire Flood Site," Geophysics (1989), 54, 1082-1090.

Byun, B.S. 1984. Seismic parameters for transversely isotropic rock. Geophysics, Vol. 49, No. 11, pp. 1908-1914.

Carlson, S.R. and Young, R.P., 1993. Acoustic emission and ultrasonic velocity study of excavation-induced microcrack damage at the underground research labatory, Int. J. Rock Mech. Min. Sci. \& Geomech. Abstr., Vol. 30, No. 7, pp. 901-907.

Carroll, M.M. 1979. An effective stress law for anisotropic elastic deformation, in J. Geophy. Res., Vol. 84, No. B13, pp. 7510-7512.

Cheng, A.H.-D. 1997. Material coefficient of anisotropic poroelasticity, Int. J. Rock Mech. \& Min. Sci. , 34, pp 199-205.

Chesnokov, E.M. \& Zatsepin, S.V. 1991. Effects of applied stress on effective elastic anisotropy in cracked solids. Geophys. J. Intern., Vol. 102, pp. 563-569. 
Chugh, Y.P. and Heidinger, G.H., 1980. Effect of coal lithology on observed microseismic activity during laboratory tests. Second Conference on Acoustic Emission/Microseismic Activity in Geologic Structures.

Crampin, S. 1984a. Effective anisotropic elastic constants for wave propagation through cracked solids. Geophys. J. R. astr. Soc., 76, pp.135-145.

Crampin, S. 1984b. An introduction to wave propagation in anisotropic media. Geophys. J. R. astr. Soc., 76, pp. 17-28.

Crampin, S., Chesnokov, E.M., and Hipkin, R.G. 1984. Seismic anisotropy - the state of the art: II. Geophysics, Vol. 76, pp. 1-16.

Cui, L., Cheng, H.D., Kaliakin, V.N., Abousleiman, Y. \& Roegiers, J.-C. 1996. Finite element analysis of anisotropic poroelasticity: A generalized Mandel's problem and an inclined borehole problem, Int. Jour. for Numer. and Analy. Meth. in Geomech., Vol. 20, pp. 381401.

de Alba, P. and Baldwin, K. C. (1991). Use of bender elements in soil dynamics experiments, Recent Advances in Instrumentation, Data Acquisition, and Testing in Soil Dynamics, S. K. Bhatia and G. W. Blaney, eds., ASCE Special Publication No. 29, pp. 86-101.

Dowding, C.H., Samama, L., Shah, S.P., and Labuz, J.F., 1985. Location of acoustic emissions during fracture in slightly anisotropic granite, $26^{\text {th }}$ U.S. Symposium on Rock Mechanics, Rapid City, SD, June 1985.

Fabre, D. \& Gustkiewicz, J. 1998. Influence of rock porosity on Biot's coefficient, in Poromechanics, Thimus, (ed.), pp. 561-566

Falls, S.D., Young, R.P., Carlson, S.R., and Chow, T., 1992, Ultrasonic tomography and acoustic emission in hydraulically fractured Lac du Bonnet grey granite, J. Geophys. Res. 97, B5, pp. 6867-6884.

Fatt, I. 1959. The Biot-Willis elastic coefficients for a sandstone, Trans. AIME, June, 1959, pp. 296-297.

Faul, R., Reddy, B.R., Griffith, J., Fitzgerald, R., and Waugh, B., 2000, Next-generation cementing systems to control shallow water flow, Offshore Technology Conference 2000, OTC Paper 11977, pp. 117-122.

Fjaer, E., Holt, R.M., \& Raaen, A.M. 1989. Rock mechanics and rock acoustics, in Rock at Great Depth, V. Maury and Fourmaintraux (eds.), pp. 355-362.

Franquet, J.A., \& Abass, H.H. 1999. Experimental evaluation of Biot's poroelastic parameter Three different methods, in Rock Mechanics for Industry, Amadei, Kranz, Scott, and Smeallie (eds.), pp. 349-355.

Furlow, W. (1998a). Shallow water flows: how they develop; what to do about them, Offshore, September, p. 70.

Furlow, W. (1998b). Ursa wells extreme example of shallow flow difficulties, Offshore, February, p. 32.

Furlow, W. (1999a). How one of the biggest fields in the U.S. Gulf Coast almost got away, Offshore, May, p. 74.

Furlow, W. (1999b). Part 1: Panel urges more SWF detection, pre-drill planning, Offshore, December, p. 60.

Gohl, W. B. and Finn, W. D. L. (1991). Use of piezoelectric bender elements in soil dynamics testing, Recent Advances in Instrumentation, Data Acquisition, and Testing in Soil Dynamics, S. K. Bhatia and G. W. Blaney, eds., ASCE Special Publication No. 29, pp.118133.

Graham, J. \& Houlsby, G.T., 1983. Anisotropic elasticity of a natural clay. Geotechnique 33, No. 2, pp. 165-180.

Hadley, K. 1975a. Anomalies in dilatant rock samples. Pure and Applied Geophysics, Vol. 113, pp. 1-23. 
Hadley. K. 1975b. Azimuthal variation of dilatancy. J. Geophy. Res. 80, pp. 4845-4850.

Hallbauer, D.K., Wagner, H., and Cook. N.G.W., 1973. Some observations concerning the microscopic and mechanical behavior of quartzite specimens in stiff, triaxial compression. Int. J. Rock Mech. Min. Sci. \& Geomech. Abstr., Vol. 10, pp. 713-726.

Helbig, K. 1984. Anisotropy and dispersion in periodically layered media. Geophysics, Vol. 49, No. 4, pp. 364-373.

Huffman, A., and Castagna, J.P., Shallow water flow prediction from seismic analysis of multicomponent seismic data, Offshore Technology Conference 2000, OTC Paper 11974, pp. 99-107.

Jones, L.E.A., \& Wang, H.F., 1981. Ultrasonic velocities in Cretaceous shales from the Williston basin, Geophysics, v. 46, 3, p. 288-297.

Johnston, D.H.: “A Tutorial on Time-Lapse Seismic Reservoir Monitoring," OTC 8289 (1997).

Justice, J.H., Vassiliou, A.A., Logel, J.D., Hansen, P.A., Hall, B.R., Hutt, P.R., and Solanki, J.J.: "Acoustic Tomography for Monitoring Enhanced Oil Recovery," Geophysics, The Leading Edge of Exploration (1989) 8, no. 2, 12-19.

Khair, A.W. and Hardy, H.R. Jr., 1984. AE monitoring of simulated coal outbursts. Third Conference on Acoustic Emission/Microseismic Activity in Geologic Structures and Materials.

King, M.S. 1969. Static \& dynamic elastic moduli of rocks under pressure, in Somerton, W.H. (ed.) Rock Mechanics-Theory and Practice: Proceedings $11^{\text {th }}$ U.S. Symposium on Rock Mechanics, p. 329-351.

King, M.S., Andrea, M., \& Shams Khanshir, M., 1994. Velocity anisotropy of carboniferous mudstones, International Journal of Rock Mechanics Mining Sciences and Geomechanics Abstracts, v. 31, 3, p. 261-263.

King, M.S., Chaudhry, N.A., and Shakeel, A. 1995. Experimental ultrasonic velocities and permeability for sandstones with aligned cracks. Int. Jour. Rock Mech. Min. Sci. \& Geomech. Abstr., Vol. 32, No. 2, pp. 155-163.

Kohata, Y., Tatsuoka, F., Wang, L., Jiang, G.L., Hoques, E., and Kodaka, T. 1997. Modelling the non-linear deformation properties of stiff geomaterials. Geotechnique, 47, No. 3, pp. 563-580.

Laurent, J., Bouteca, M.J., Sarda, J.-P., \& Bary, D. 1993. Pore-pressure influence in the poroelastic behavioir of rocks: Experimental studies and results, in SPE Formation Evaluation, June 1993, pp. 117-122.

Levin, F.K. 1979. Seismic Velocities in transversely isotropic media. Geophysics, Vol. 44, No. 5, pp. 918-936.

Lings, M.L., Pennington, D.S., and Nash, D.F.T. 2000. Anisotropic stiffness parameters and their measurement in a stiff natural clay. Geotechnique 50, No. 2, pp. 109-125.

Lo, Tien-when, Conyer, K., and Toksoz, N.M., 1986, Experimental determination of elastic anisotropy of Berea sandstone, Chicopee shale, and Chelmsford granite, Geophysics, Vol. 51, No. 1, pp. 164-171.

Lockner, D. and Byerlee, J.D., 1977. Hydrofracture in weber sandstone at high confining pressure and differential stress. Journal of Geophysical Research, Vol. 82, No. 14, pp. 2018-2026.

Lockner, D. and Byerlee, J., 1978. Development of fracture planes during creep in granite, Second Conference on Acoustic Emission/Microseismic Activity in Geological Structures and Materials. 
Lockner, D.A. Byerlee, J.D., Kuksenko, V., Ponomarev, A., and Sidorin, A., 1991. Quasi-static fault growth and shear fracture energy in granite, Nature, Vol. 350, pp. 39-42.

Lockner, D.A. Walsh, J.B., and Byerlee, J.D., 1977. Changes in seismic velocity and attenuation during deformation of granite. Journal of Geophysical Research, Vol. 82, No. 33, pp. 5374-5378.

Lockner, D.A. and Beeler, N.M. 2002. Stress-induced anisotropic poroelasticity response in sandstone. ASCE.

Lockner, D.A.. and Stanchits, S.A. 2002. Undrained poroelastic reponse of sandstones to deviatoric stress change. Jour. Geophys. Res., Vol. 107, No. B12, pp. ETG13-1-ETG13-14.

McConnell, D.R., and Campbell, K.J., 1999. Interpretation and identification of potential shallow water flow from seismic data. Conference proceedings, 1999 International Forum on Shallow Water Flows, October 6-8, 1999.

McConnell, D.R., 2000. Optimizing deepwater well locations to reduce the risk of shallow-water flow using high-resolution 2D and 3D seismic data, Offshore Technology Conference 2000, OTC Paper 11973, pp. 87-97.

Nelson, R.A. (1981). A discussion of the approximation of subsurface (burial) stress conditions in laboratory experiments, in 'Mechanical Behavior of Crustal Rocks' , N.L. Carter, M. Friedman, J.M. Logan, and D.W. Stearns, eds., pp. 311-321.

Nishizawa, O., Kusunose, K., Satoh, T., and Takahashi, M., 1990. Positive feedback fracture process induced by nonuniform high-pressure water flow in dilatant granite. Journal of Geophysical Research, Vol. 95, No. B13, pp. 21583-21592.

Nishizawa, O., Onai, K., and Kusunose, K., 1985. Hypocenter distribution and focal mechanism of AE events during two stress stage creep Yugawara andesite. Pageoph., Vol. 122, pp. 36-52.

Nitkin, L.V., and Chesnokov, E.M. 1981. Influence of a stressed condition on the anisotropy of elastic properties in a medium. Izvestiya, Earth Physics, Vol. 17, No. 3, pp. 174-183.

Nitkin, L.V., and Chesnokov, E.M. 1984. Wave propagation in elastic media with stress-induced anisotropy. Geophys. J. R. astr. Soc. 76, pp. 129-133.

Nur, A., \& Simmons, G., 1969. Stress-induced velocity anisotropy in rock: an experimental study, Journal Geophysical Research, v. 74, 27, p. 6667-6674.

Nur, A. 1971. Effects of stress on velocity anisotropy in rocks with cracks. Jour. Geophys. Res., Vol. 76, No. 8, pp. 2022-2034.

Pennington, D.S., Nash, D.F.T., and Lings, M.L. 1997. Anisotropy of Go shear stiffness in Gault Clay. Geotechnique, 47, No. 3, pp. 391-398.

Podio, A.L., Gregory, A.R., \& Gray, K.E., 1968. Dynamic properties of dry and water saturated Green River Shale under stress, Transactions Society of Petroleum Engineers of AMIE, v. 243, sect. II, p. 389-404.

Rutledge, J.T., Fairbanks, T.D., Albright, J.N., Boade, R.R., Dangerfield, J., and Landa, G.H., 1994. Reservoir induced seismicity at the Ekofisk oil field. Eurock '94, pp. 589-595.

Sayers, C.M., \& van Munster, J.G. 1991. Microcrack-induced seismic anisotropy of sedimentary rocks, Journal of geophysical research, Vol. 96, No. B10, pp 16,529-16,533.

Schofield, A.N., and Wroth, C.P. (1968) Critical state soil mechanics, McGraw-Hill, London, England.

Scholz, C.H., 1968. Microfracturing and the inelastic deformation of rock in compression. J. Geophy. Res., Vol. 73, pp. 1417-1432.

Scott, T. E., Ma, Q., and Roegiers, J.-C. (1993). Acoustic velocity changes during shearinduced compaction of sandstone, International Journal of Rock Mechanics and Mining Sciences, Vol. 30, No. 6, pp.763-769. 
Scott, T. E., Zaman, M. M., and Roegiers, J.-C. (1998a). Acoustic velocity signatures associated with rock-deformation processes, Journal of Petroleum Technology (SPE 39403), Vol. 50, No. 6, pp. 70-74.

Scott, T. E., Azeemuddin, M., Zaman, M., and Roegiers, J.-C. (1998b). Stress-induced variations in acoustic velocities in chalk, Proceedings, $3^{\text {rd }}$ North American Rock Mechanics Symposium, Cancún, Mexico.

Scott, T.E., Ma, Q., Reches, Z., and Roegiers, J.- C., 1994a, Dynamic stress mapping utilizing ultrasonic tomography, The Proceedings of the 1st North American Rock Mechanics Symposium, Nelson and Laubach (eds), Balkema, Rotterdam.

Scott, T.E., Ma, Q., Roegiers, J.-C., and Reches, Z., 1994b, Acoustic tomographic difference imaging of dynamic stress fields, presented in EUROCK 94, Aug. 29-31, Delft, The Netherlands, Rock Mechanics in Petroleum Engineering, Balkema, Rotterdam.

Sayers, C.M. 1988a. Inversion of ultrasonic wave velocity measurements to obtain the microcrack orientation distribution function in rocks. Ultrasonics, Vol. 26, pp. 73-77.

Sayers, C.M. 1988b. Stress-induced ultrasonic wave velocity anisotropy in fractured rock. Ultrasonics, Vol. 26, pp. 311-317.

Sondergeld, C.H. and Estey, L.H., 1981. Acoustic emission study of microfracturing during the cyclic loading of westerly granite. Journal of Geophysical Research, Vol. 86, No. B4, pp. 2915-2924.

Spetzler, H. and Mizutani, H., 1986. Comment on "Localization of dilatancy in Ohshimi granite under constant uniaxial stress." Journal of Geophysical Research, Vol. 91, No. B6, pp. 6565-6566.

Spetzler, H.A., Sobolev, G.A., Sondergeld, C.H., Salov, B.G., Getting, I.C., and Koltsov, A., 1981. Surface deformation, crack formation, and acoustic velocity changes in pyrophyllite under polyaxial loading. Journal of Geophysical Research, Vol. 86, No. B2, pp. 1070-1080.

Sulak, R. M. (1991). Ekofisk Field: The first 20 years, Journal of Petroleum Technology, October, pp. 1265-1271.

Suman, G.O., Ellis, R.C. and Snyder, R.E., (1983) Sand control handbook, Second Edition. Gulf Publishing Company, Houston.

Teufel, L. W., Rhett, D. W., and Farrel, H. E. (1991). Effect of reservoir depletion and pore pressure drawdown on in-situ stress and deformation in the Ekofisk Field, Proceedings, $32^{\text {nd }}$ U.S. Symposium on Rock Mechanics, Norman, Oklahoma, pp. 63-72.

Thompson, M., \& Willis, J.R., 1991. A reformation of the equations of anisotropic poroelasticity, Trans. ASME, Vol. 58, pp. 612-616.

Thomsen, L. 1986. Weak elastic anisotropy. Geophysics, Vol. 51, No. 10, pp. 1954-1966.

Vaid, Y.P., and Eliadorani, A. (1998) Instability and liquefaction of granular soils under undrained and partially drained states, Can. Geotech. J., 35, pp. 1053-1062.

Vaid, Y.P., and Sivathayalan, S., (1999). "Fundamental factors affecting liquefaction susceptibility of sands, in Physics and Mechanics of Soil Liquefaction", Lade \& Yamamuro eds., Balkema, pp. 105-119.

Vshivtsev, A.S., Zhukovskiy, K.V., and Chesnokov, E.M. 1995. An effect of initial nonuniform stresses on the elastic properties of an isotropic body. Physics of the Solid Earth, Vol. 31, No.5. pp. 429-436.

Wang, Z.Z. 2001. Seismic anisotropy in sedimentary rocks. In 2001 SEG extended abstracts.

White, J.E., Martineau-Nicoletis, L., and Monash, C. 1983. Measured anisotropy in Pierre shale. Geophysical Prospecting, 31, pp. 709-725.

Wu, B, King, M.S., \& Hudson, J.A., 1990. Stress-induced ultrasonic wave velocity anisotropy in a sandstone, p. 101-107.

Yanigadani, T., Ehara, S., Nishizawa, O., Kusunose, K., and Terada, M., 1985. Localization of dilatancy in Ohshima granite under constant uniaxial stress. Journal of Geophysical Research, Vol. 90, No. B8, pp. 6840-6858. 
Yew, C.H., and Jogi, P.N. 1978. The determination of Biot's parameters for sandstones, Part 1: Static tests. Exp. Mech., May 1978, pp. 167-178.

Zamora, M., and Poirier, J.P. 1990. Experimental study of acoustic anisotropy and birefringence in dry and saturated Fontainbleau sandstone. Geophysics, Vol. 55, No.11, pp. 1455-1465.

Zang, A., Wagner, C.F., and Dresen, G., 1996. Acoustic emission, microstructure, and damage model of dry and wet sandstone stressed to failure. Journal of Geophysical Research, Vol. 101, No. B8, pp. 17507-17521.

Zheng, Zhiqiong 2000. Seismic anisotropy due to stress-induced cracks. Int. Jour. Rock Mech. \& Min. Sci., 37, pp. 39-49. 


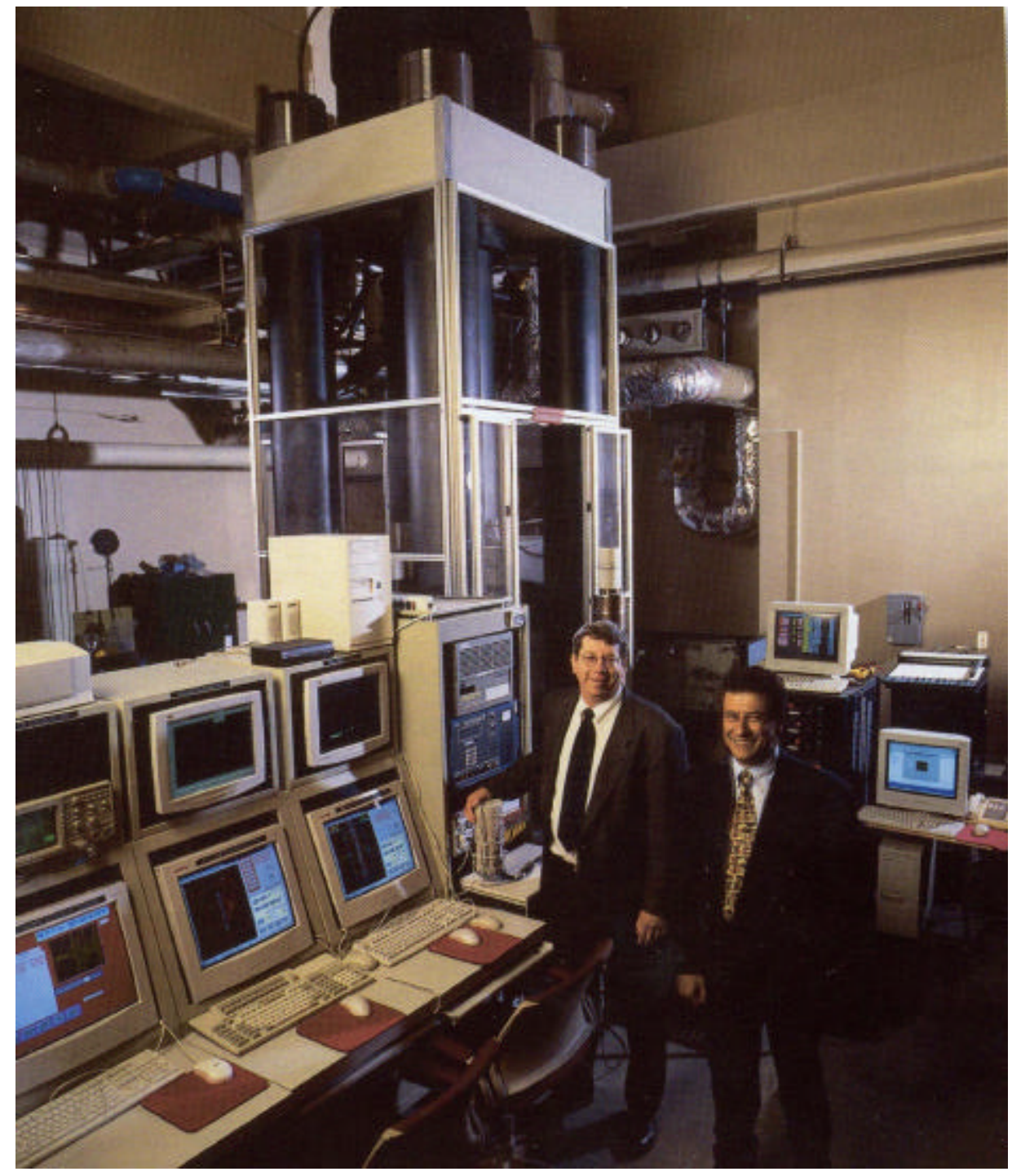

Fig.1. The 3,000,000 lb. TerraTek frame with its 20,000 psi triaxial pressure vessel. The command and control, acoustic emission, and ultrasonic velocity systems are located to the left of the load frame. These components comprise a major part of the new Geomechanical Acoustic Imaging System. 


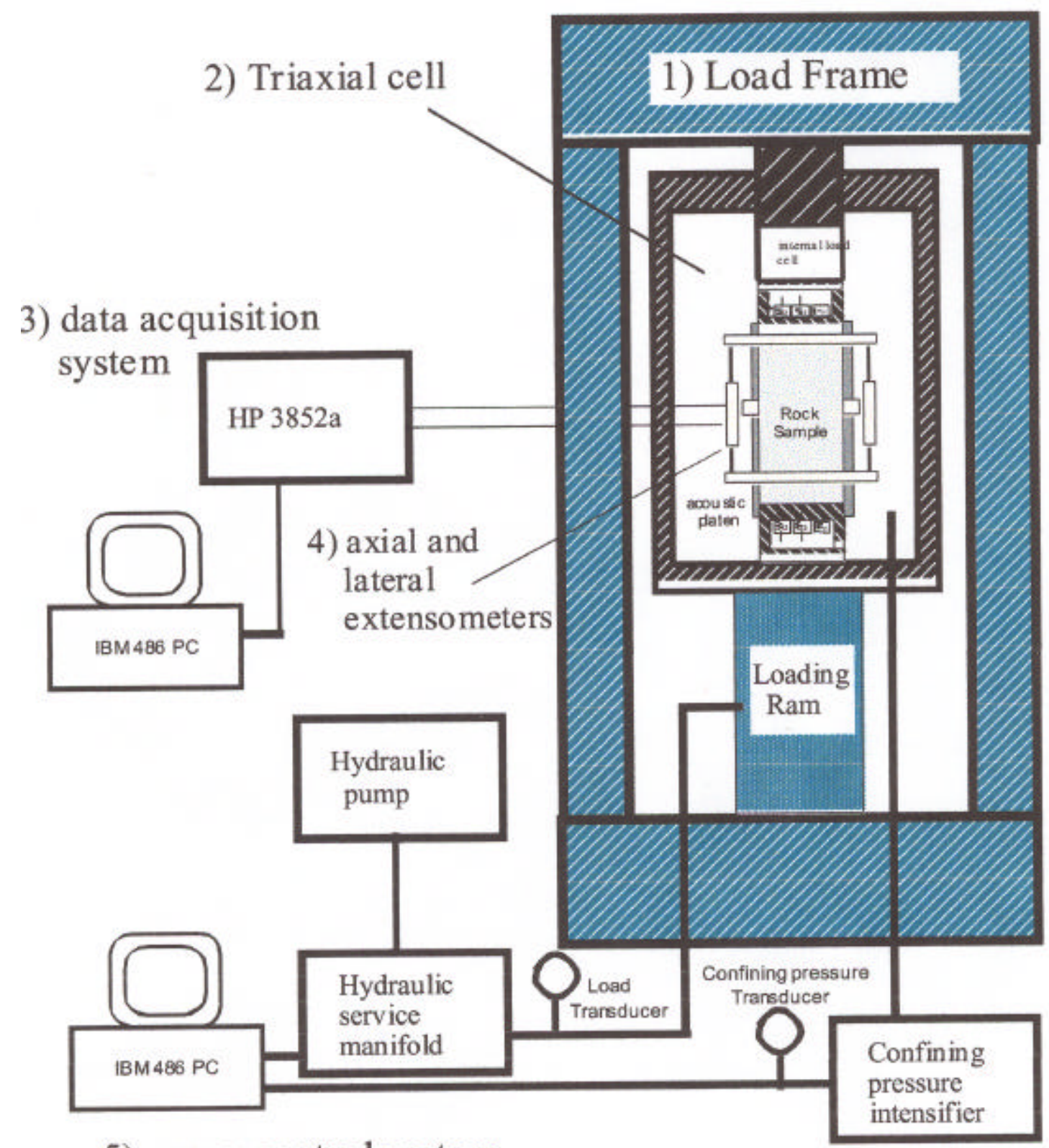

5) servo-control system

Fig. 2. A schematic of the load frame, triaxial cell, and data acquisition modules of the Geomechanical Acoustic Imaging System. 


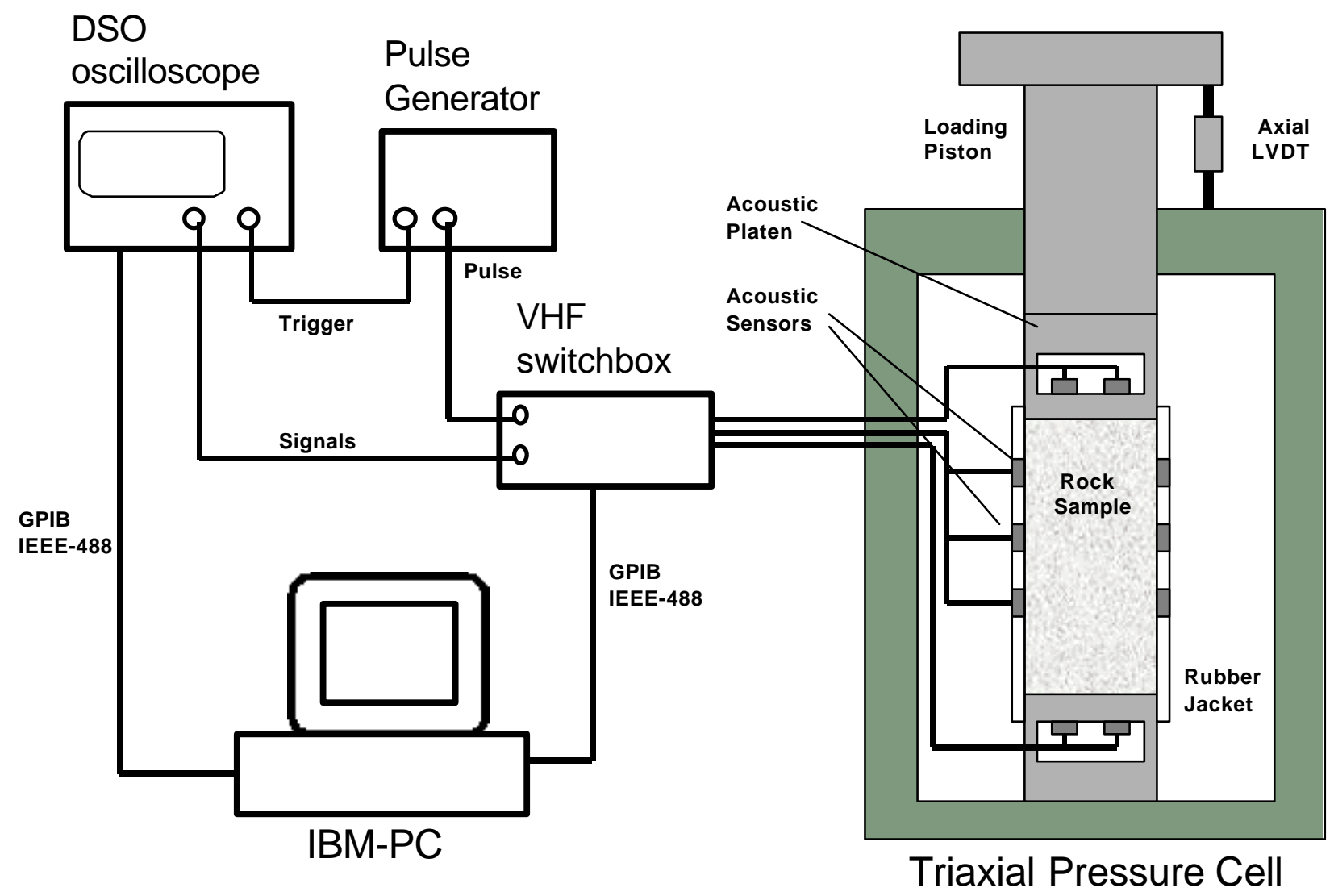

Fig. 3. A schematic of the acoustic velocity system for compressional and shear wave anisotropy measurements and for acquisition of the full dynamic tensor data set. 


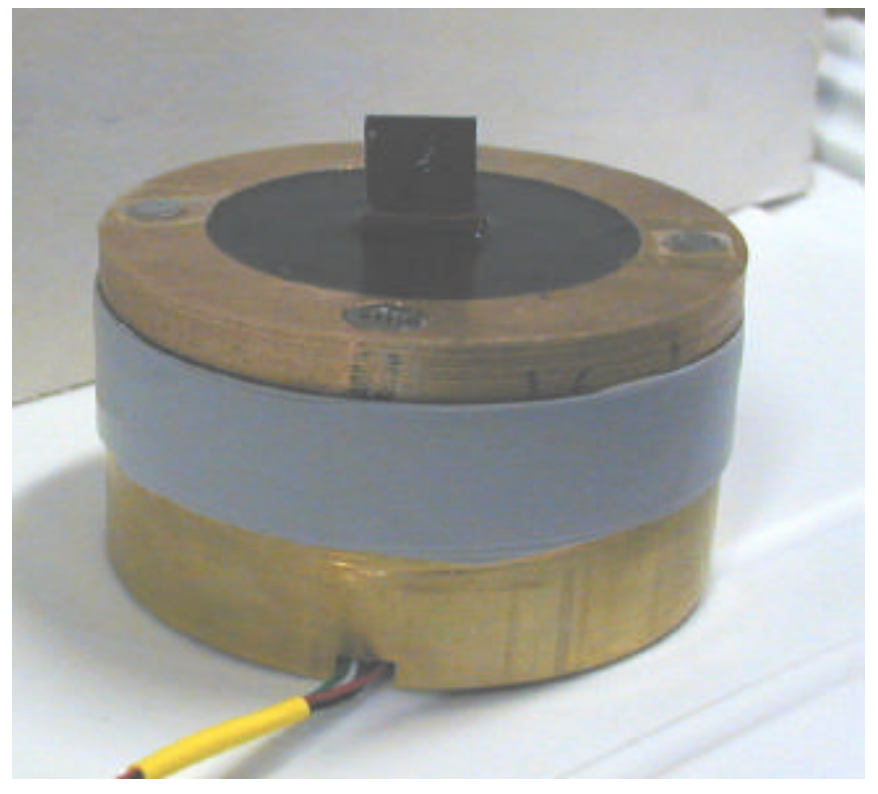

Axial acoustic platen for soft rocks. The piezoelectric elements are mounted in the center recess. The platen mounts on top of the rock in this orientation. The pore fluid port is hidden from view in this picture. This is a view of the axial acoustic platen for unconsolidated sand samples. This a base platen and the jacketed sand sample would sit on top of the platen. The bender element for shear wave generation extends above the platen.

Fig. 4. Axial acoustic velocity platens constructed for the project. 

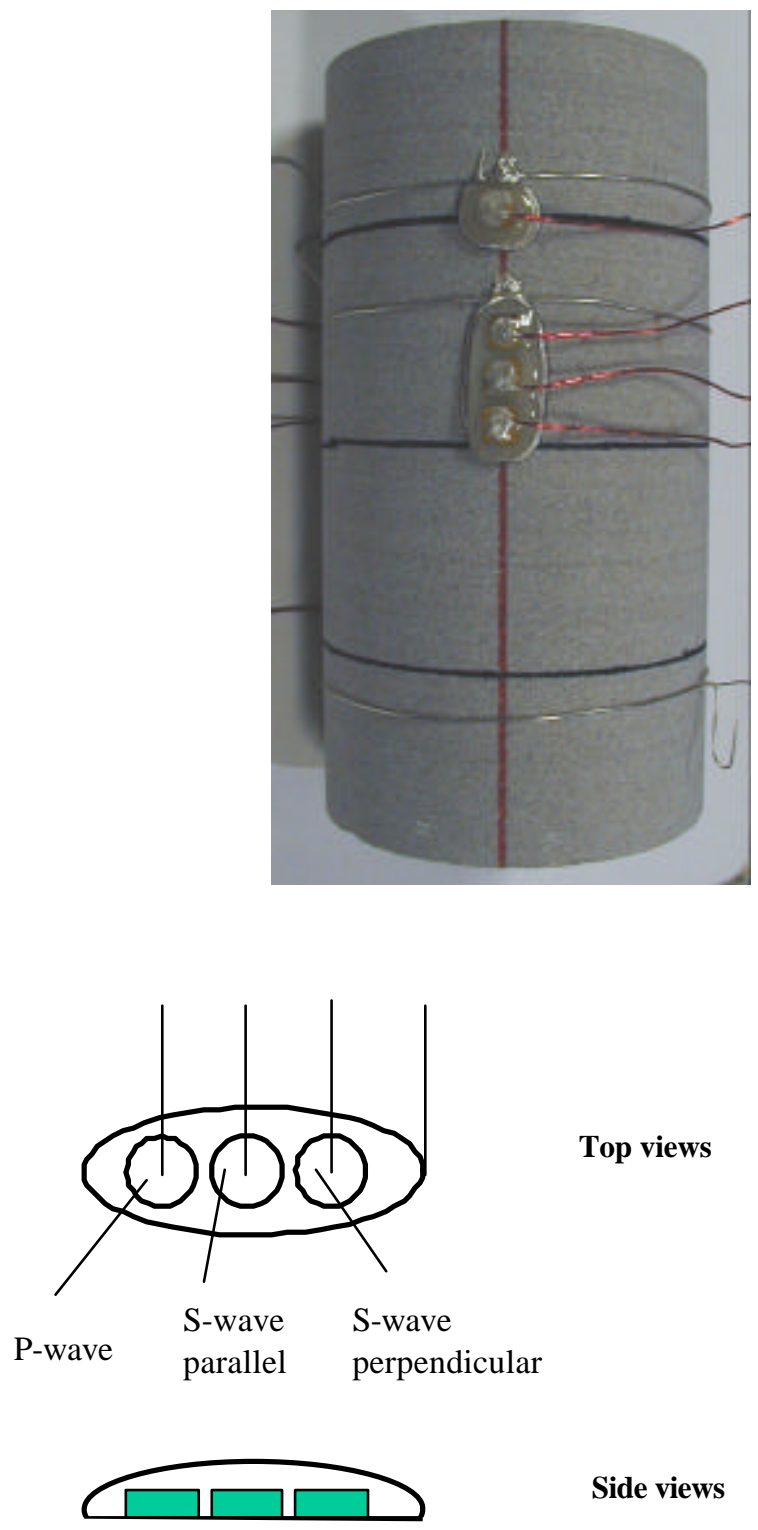

Top views

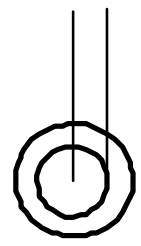

P-wave

3-component lateral housing for compressional

Acoustic emission and shear wave velocities lateral sensor $(600 \mathrm{KHz})$

Fig. 5. Diagram illustrating the lateral acoustic velocity sensors constructed for the project. The top photograph shows a rock core sample with both a 3-component sensor and a single component acoustic sensor mounted on the surface. 


\section{Sample assembly for acoustic measurements on a transversely isotropic rock}

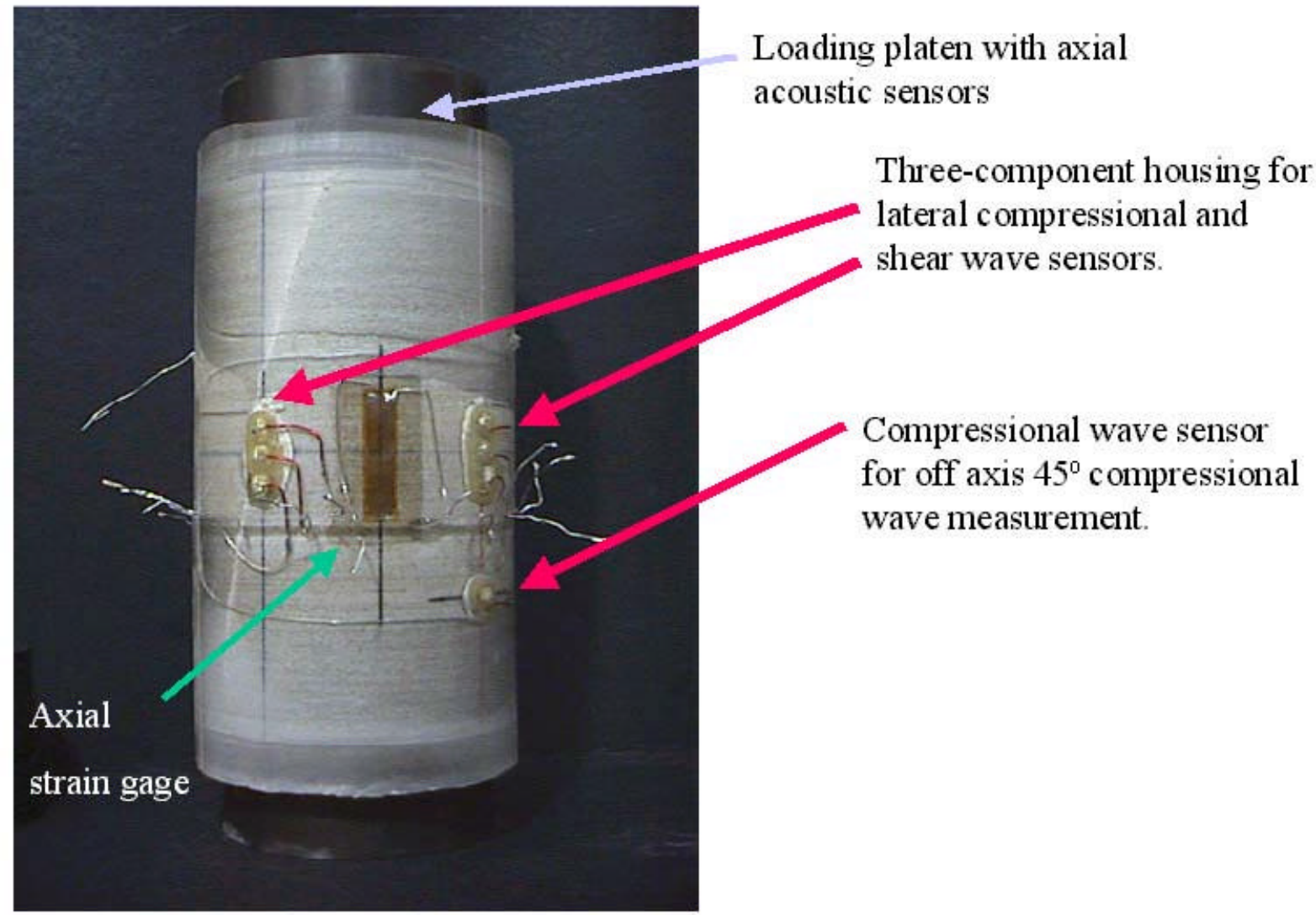

Fig. 6. A photograph of the new sample assembly for acoustic measurements on a transversely isotropic rock. 


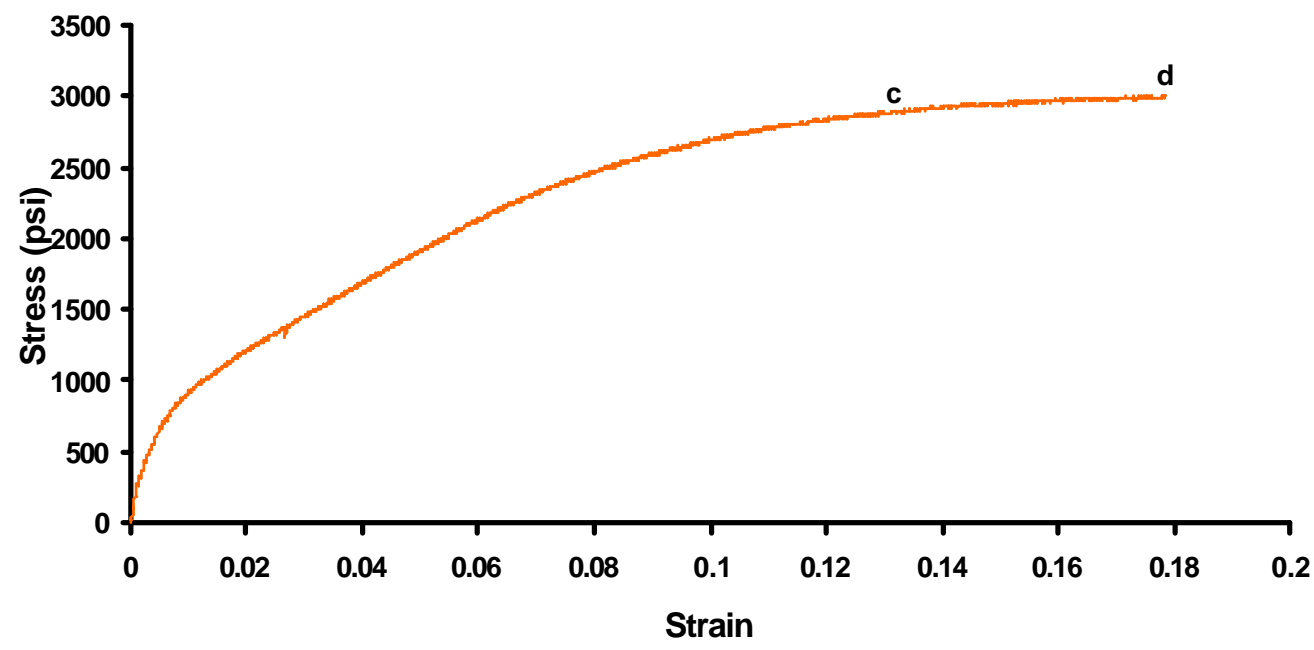

Fig. 7. The stress-strain curve for an undrained triaxial compression experiment at 2000 psi confining pressure and 1000 psi starting pore pressure. 


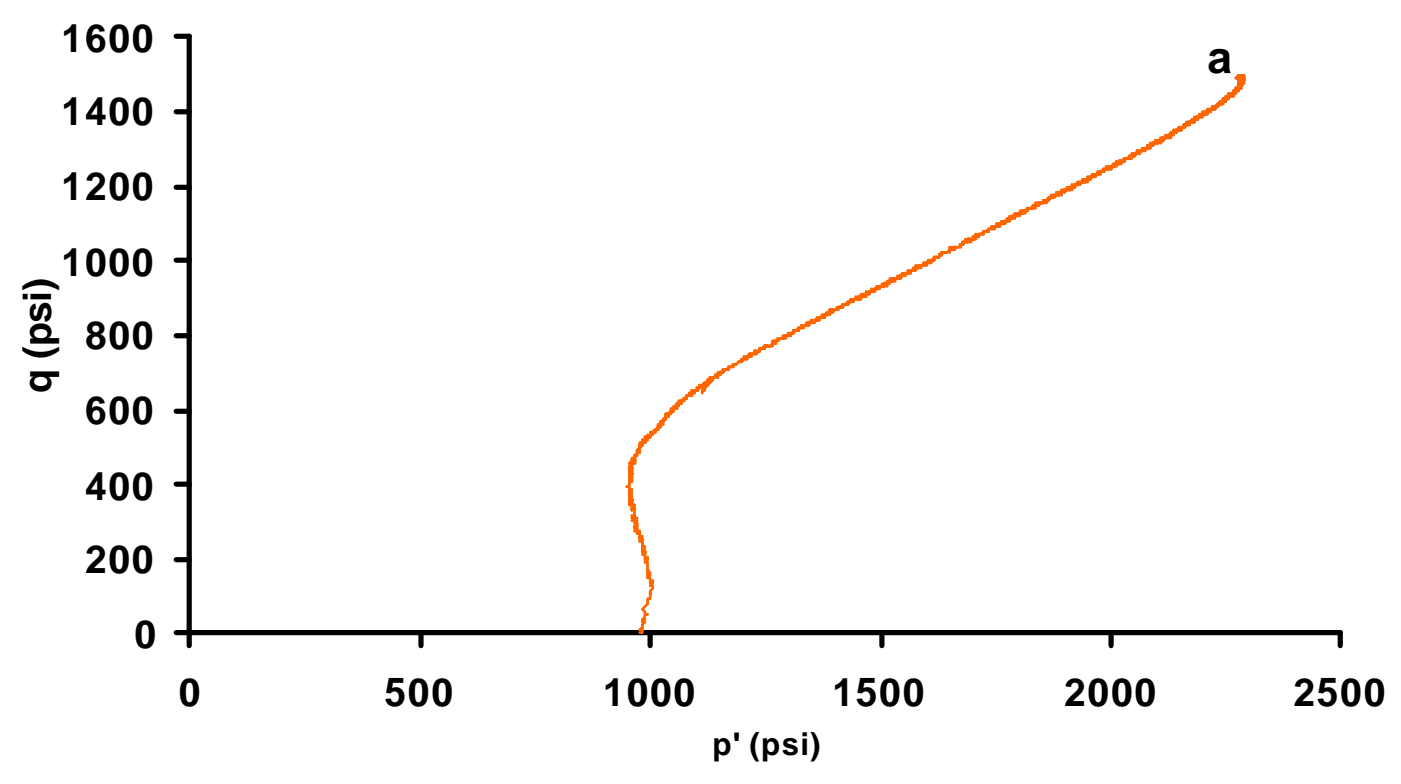

Fig. 8. The shear stress $(q)$ versus effective mean pressure $\left(p^{\prime}\right)$ plot for an undrained triaxial compression experiment at 2000 psi confining pressure and 1000 psi starting pore pressure. 


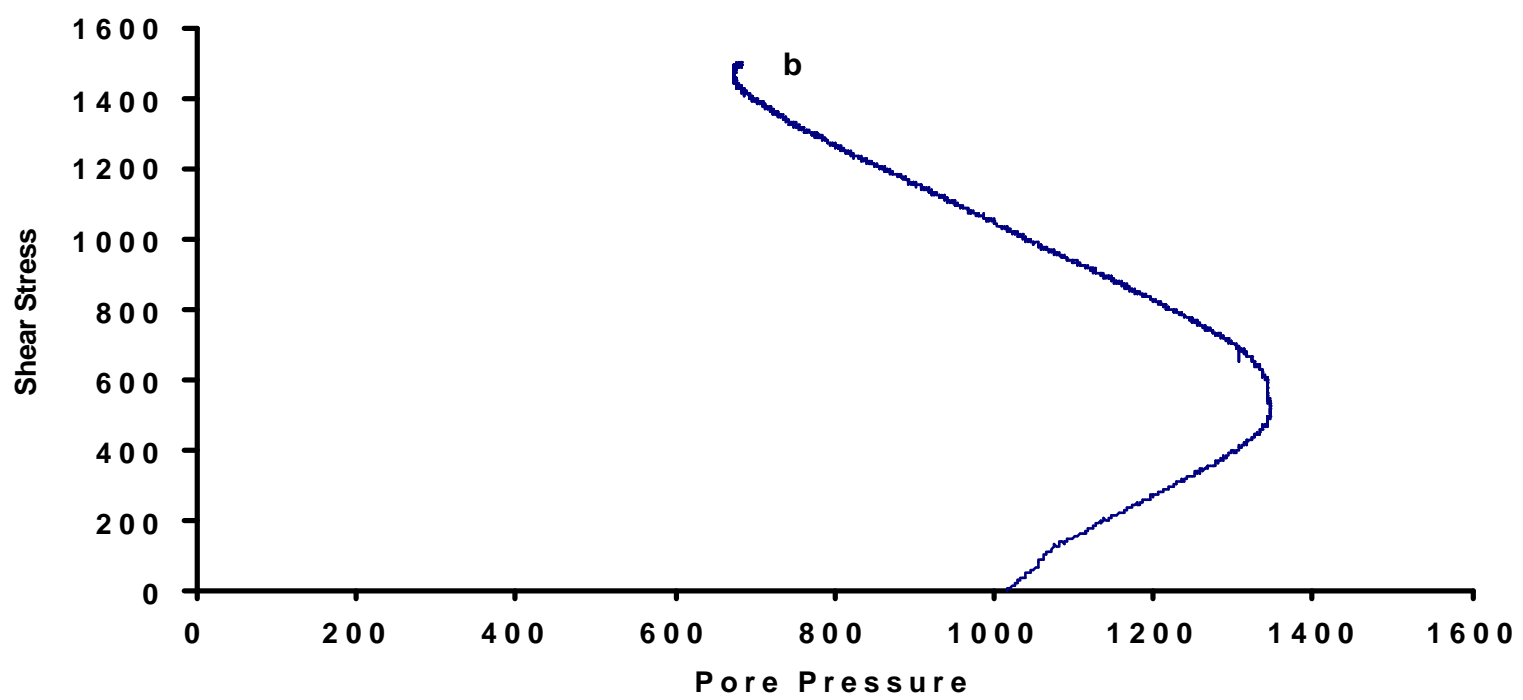

Fig. 9. The shear stress (q) versus pore pressure plot for an undrained triaxial compression experiment at 2000 psi confining pressure and 1000 psi starting pore pressure. 


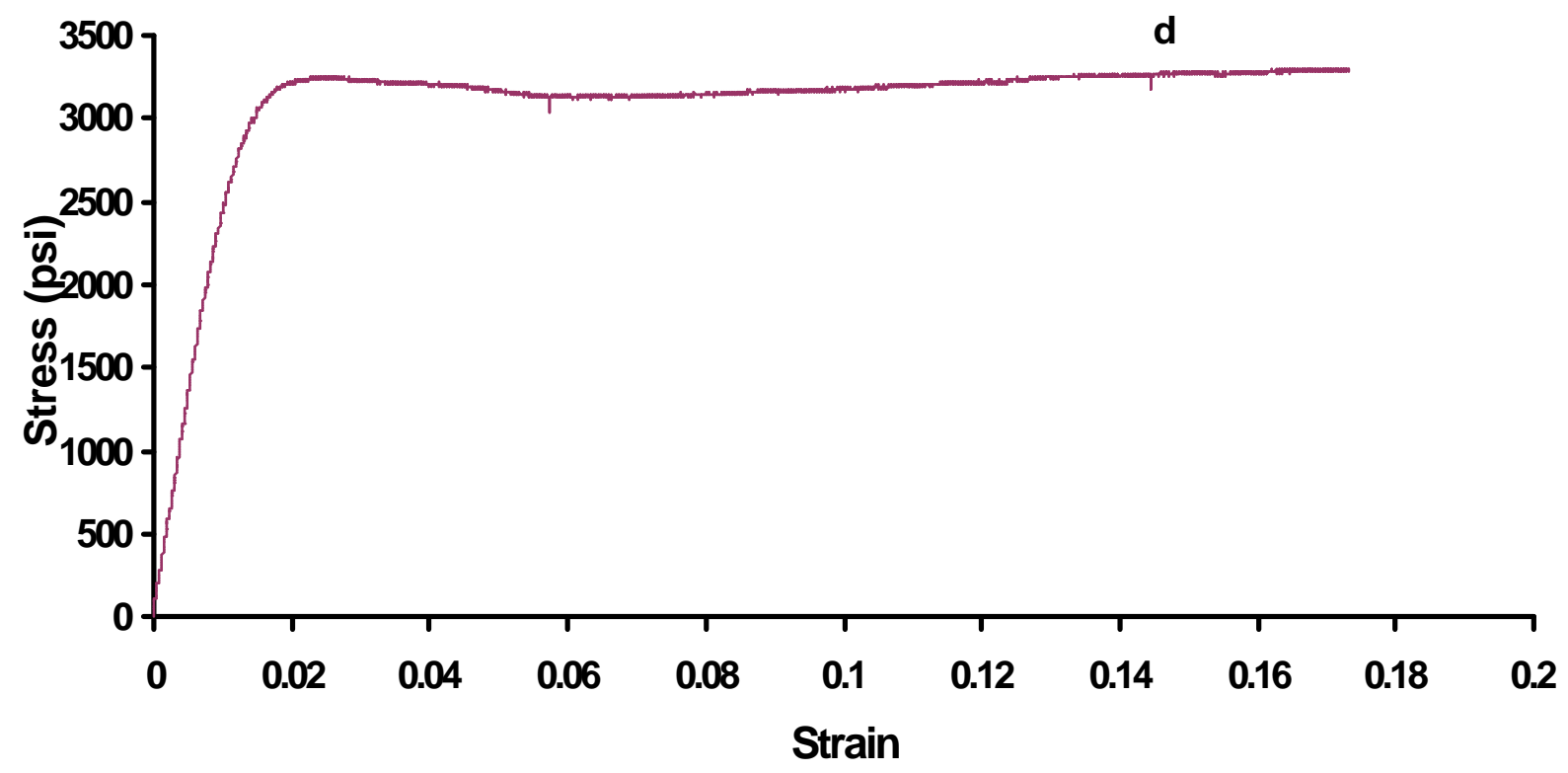

Fig. 10. The stress-strain curve for an undrained triaxial compression experiment at 5500 psi confining pressure and 600 psi starting pore pressure. 


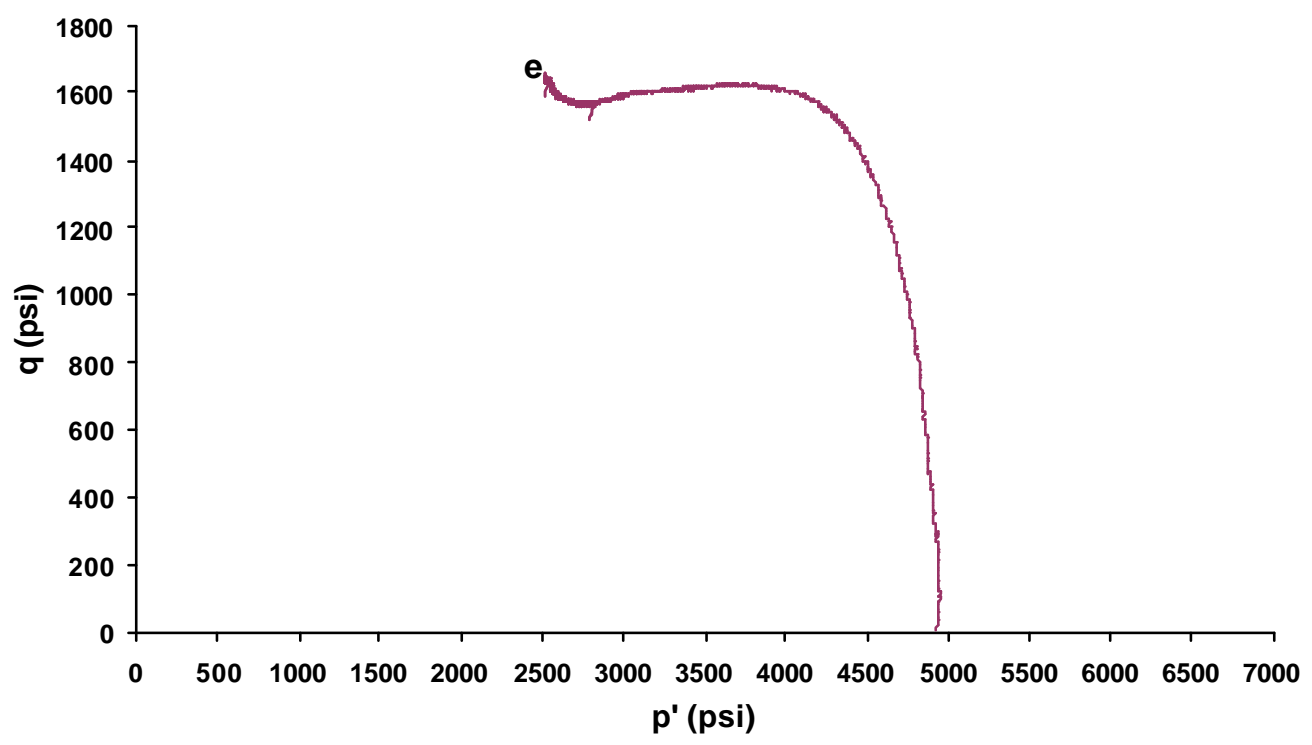

Fig. 11. The shear stress (q) versus effective mean pressure ( $\left.p^{\prime}\right)$ plot for an undrained triaxial compression experiment at 5500 psi confining pressure and 600 psi starting pore pressure. 


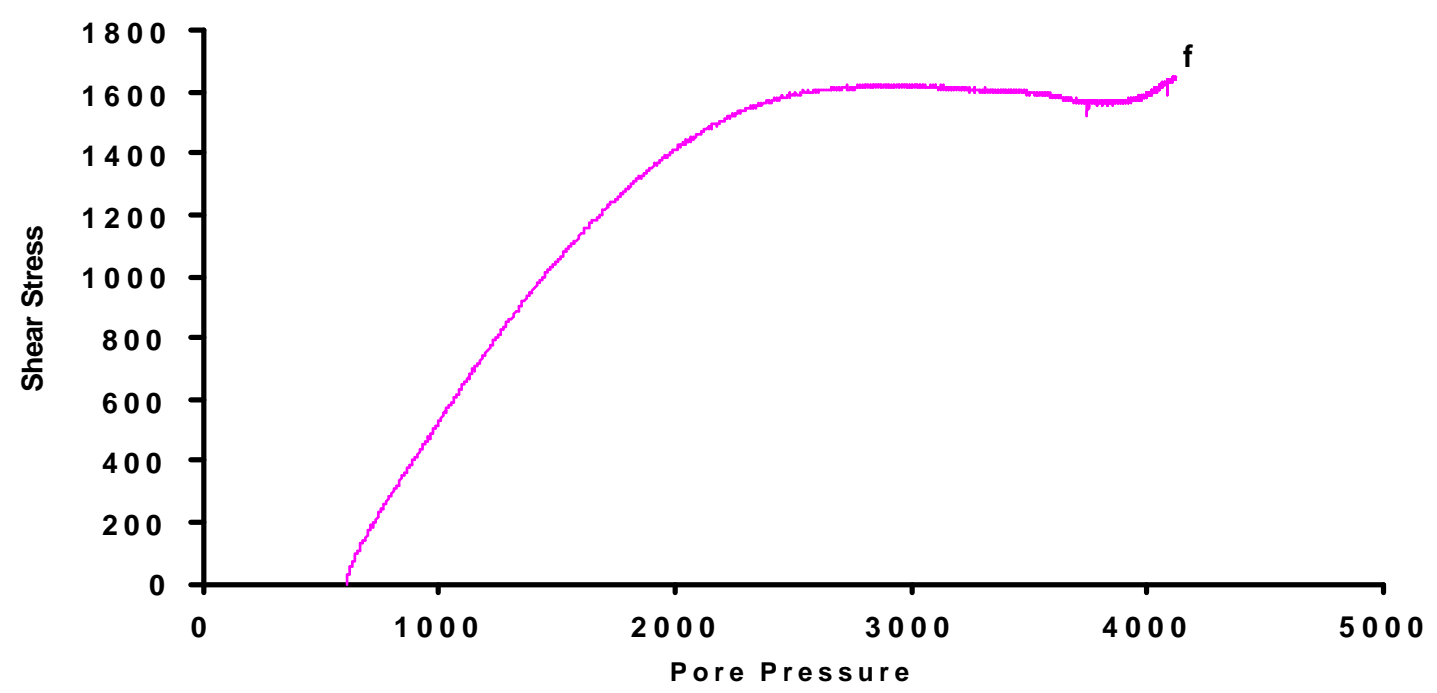

Fig. 12. The shear stress $(q)$ versus pore pressure plot for an undrained triaxial compression experiment at 5500 psi confining pressure and 600 psi starting pore pressure. 


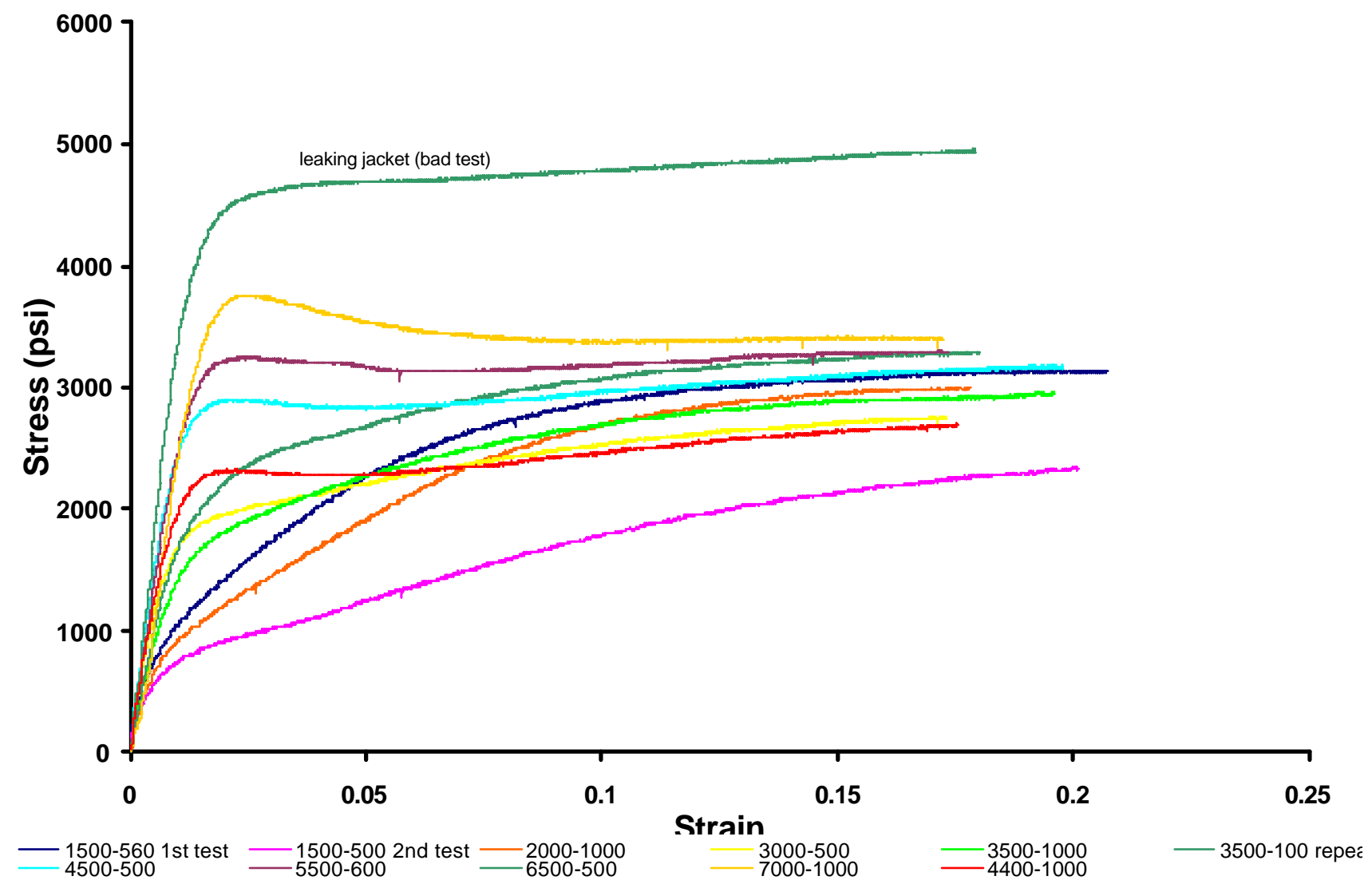

Fig. 13. Stress-strain plots on a series of undrained triaxial compression experiments on unconsolidated Oil Creek sand. The first numbers of the legend represent the confining pressure and the second number is the starting pore 


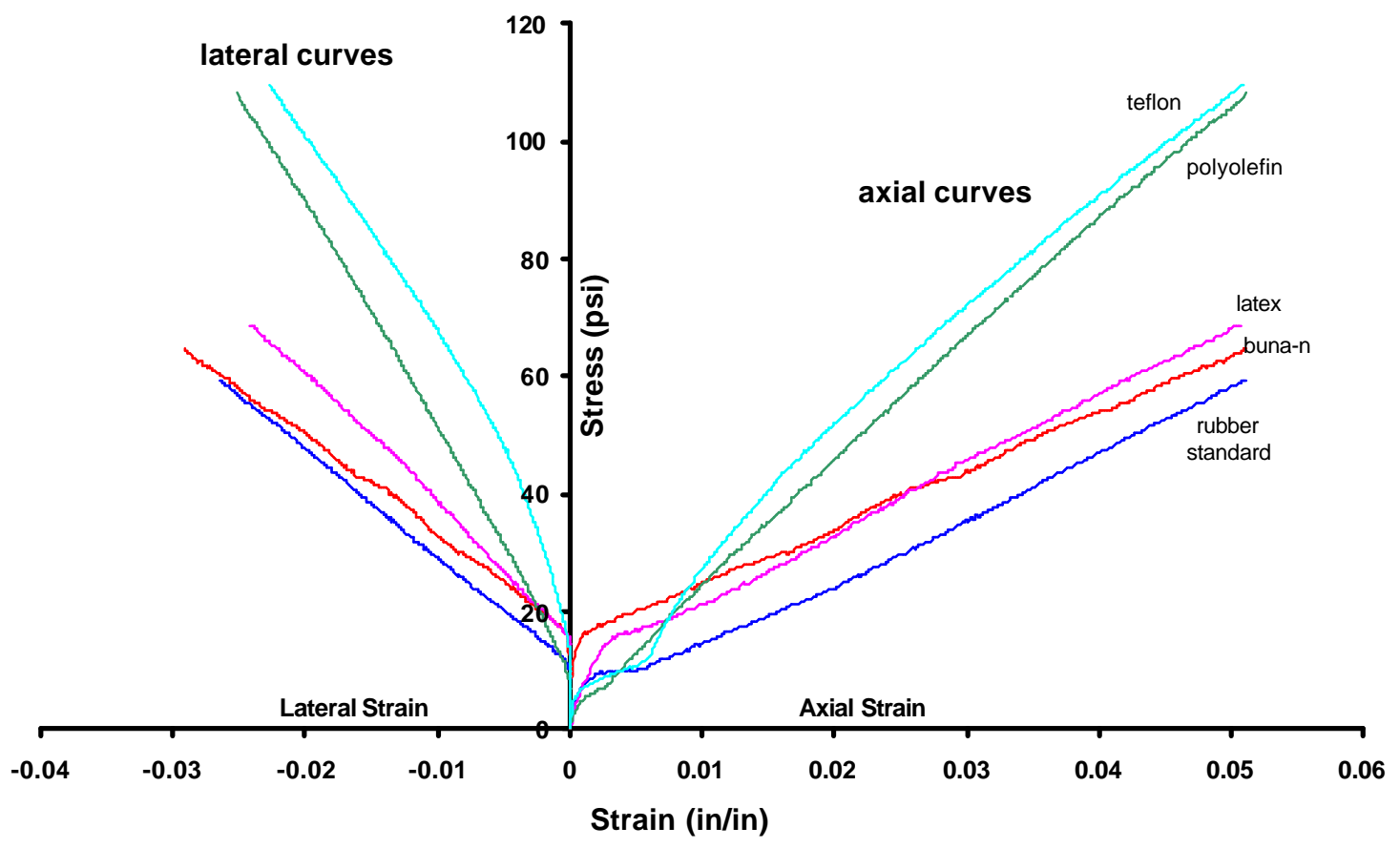

Fig. 14. A comparison of the strength effect of various types of jacket types on a rubber standard. 


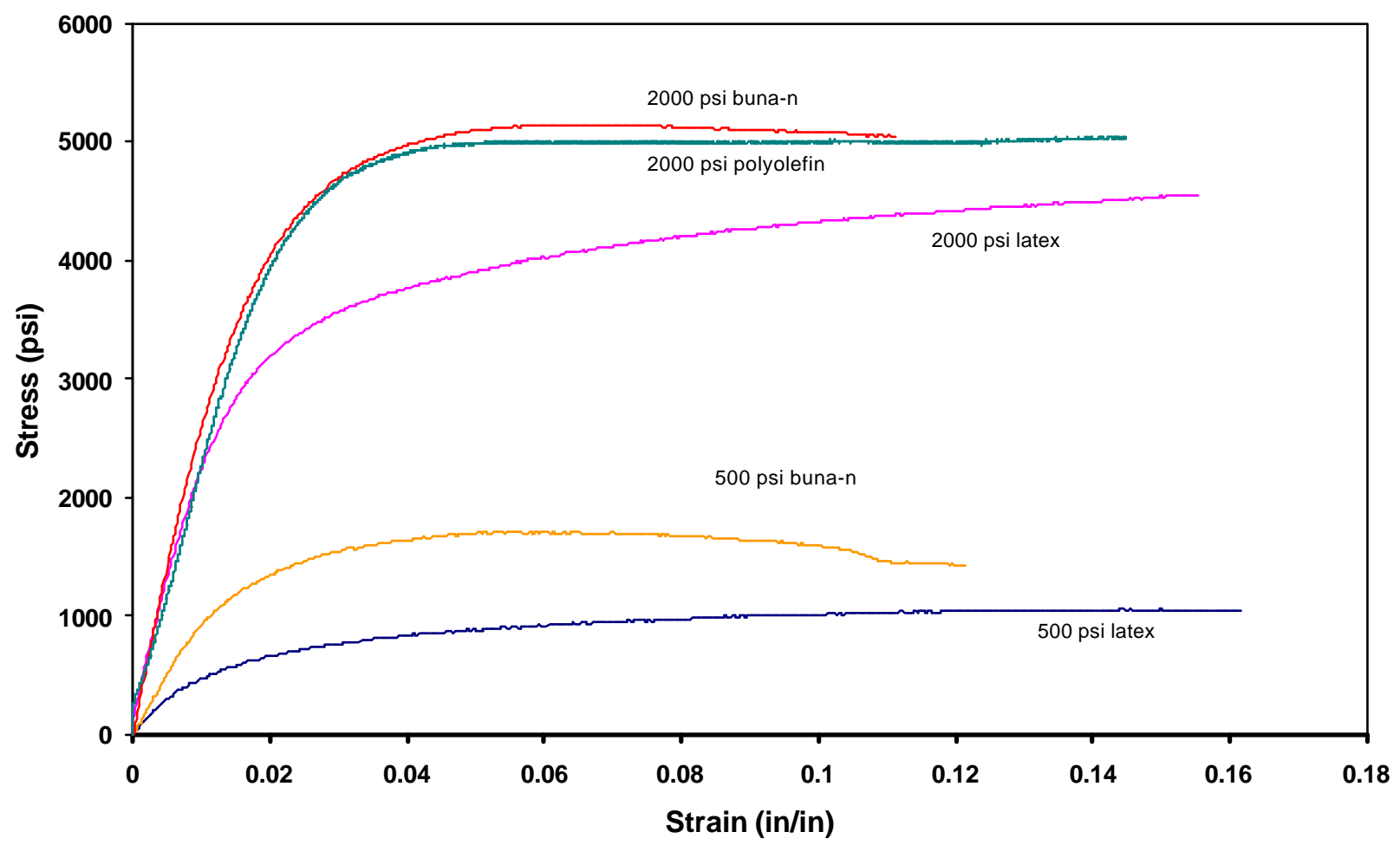

Fig. 15. A comparison of jacket strength effects on the deformation of unconsolidated sand (Oil Creek sand). 


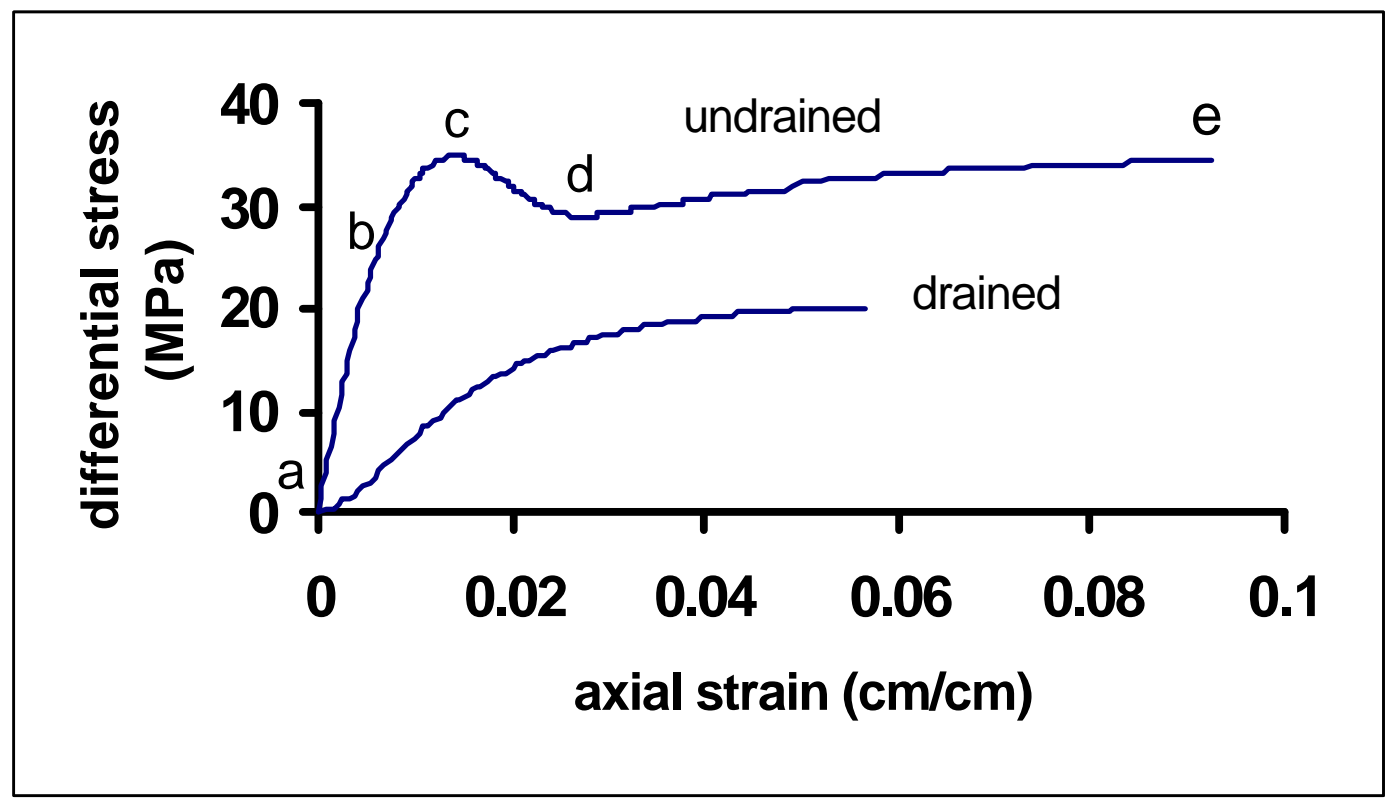

Fig. 16. The differential stress-axial strain curve for the undrained Oil Creek sand at 4500 psi confining pressure and the drain experiment at 2000 psi confining pressure. 


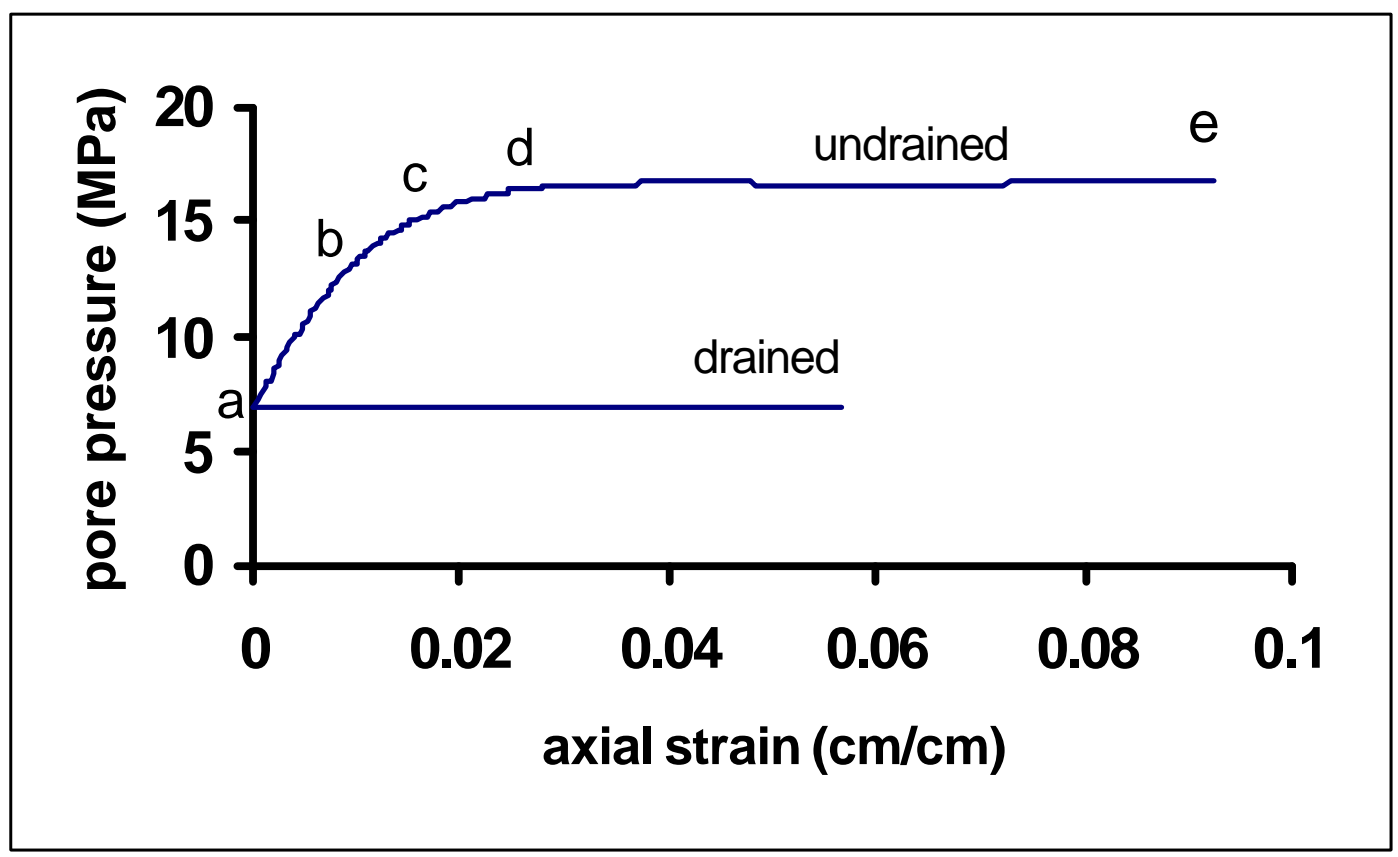

Fig. 17. The changes in pore pressure during the undrained triaxial compression experiments on Oil Creek sand. 


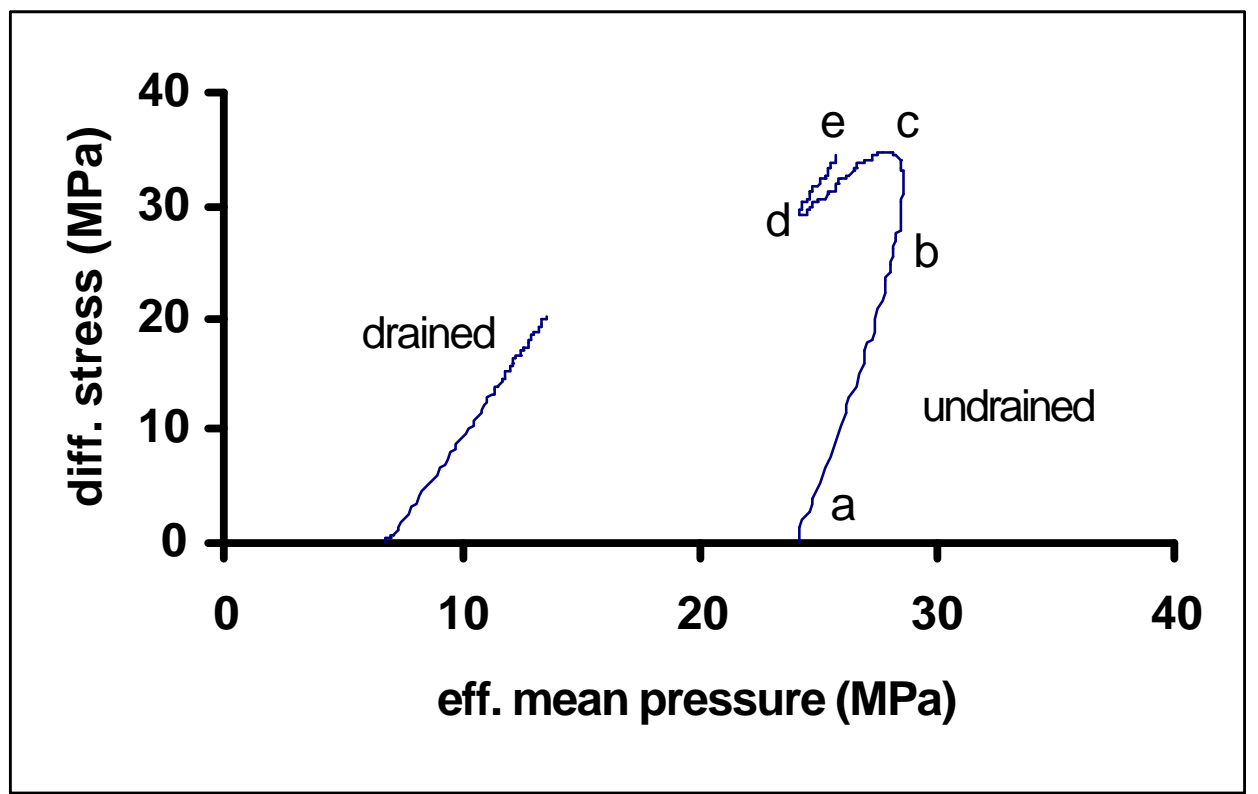

Fig. 18. The deformational stress paths of the Oil Creek sand mapped in differential stress-effective mean pressure stress space. 


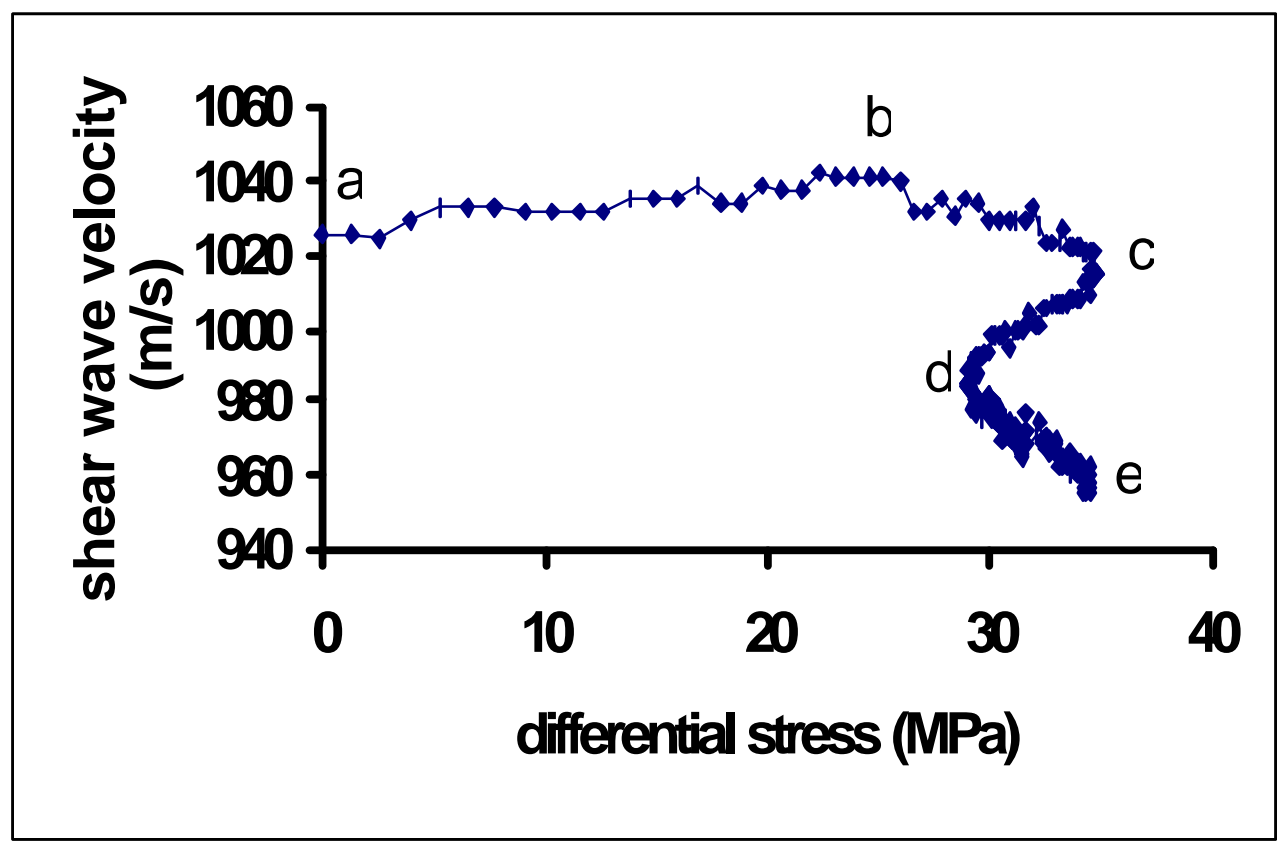

Fig. 19. Shear wave velocities of the Oil Creek sand during the undrained triaxial experiment. 


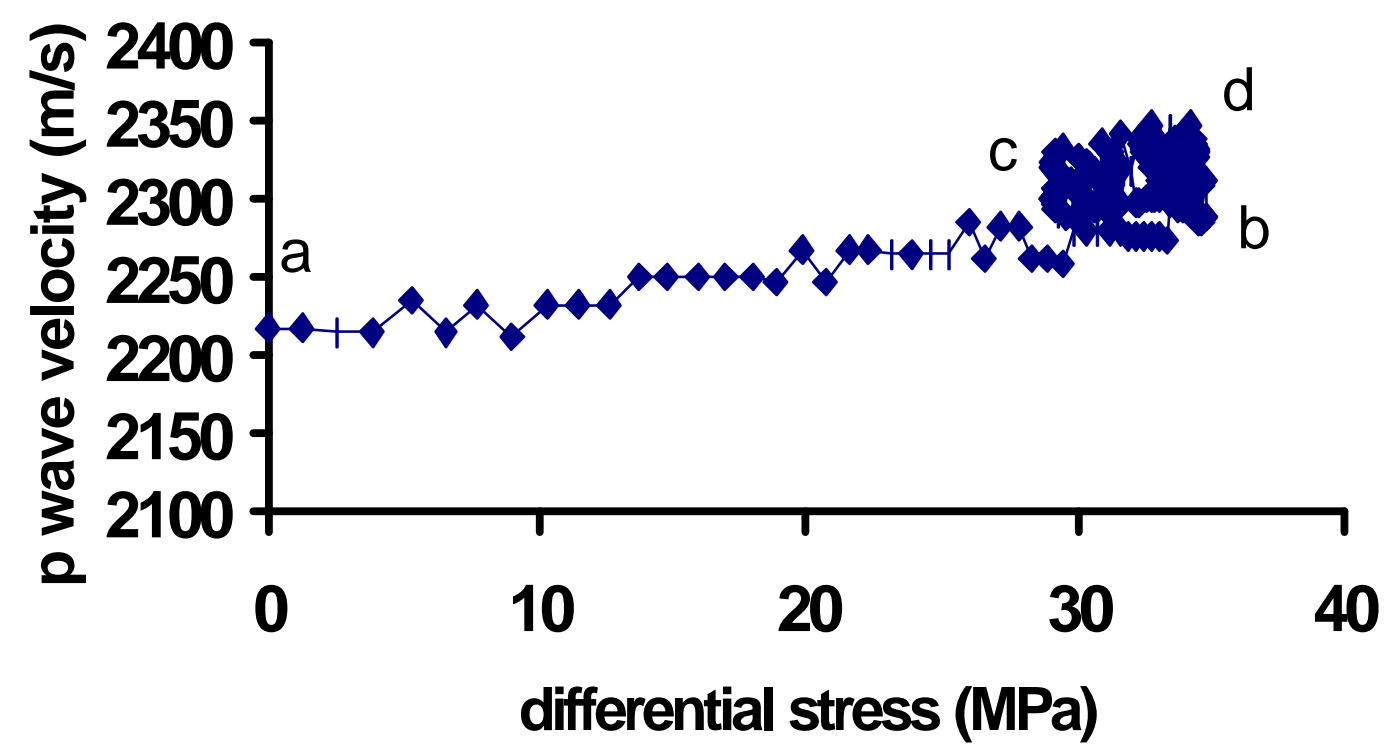

Fig. 20. The change in the compressional wave velocity (Vp) differential stress during the undrained triaxial compression experiment. 


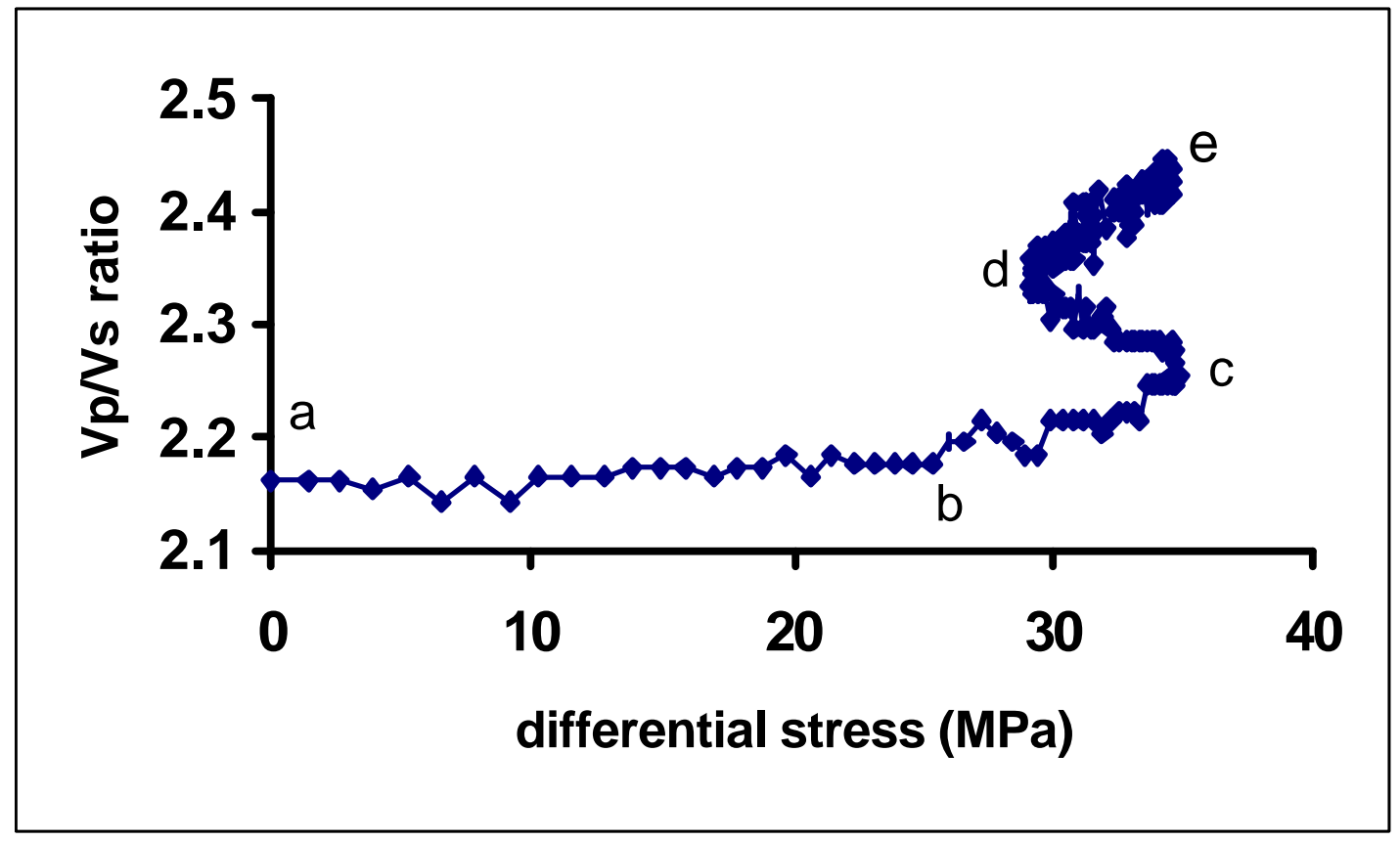

Fig. 21. The change in the $\mathrm{Vp} / \mathrm{Vs}$ ratio with differential stress during the undrained triaxial compression experiment. 


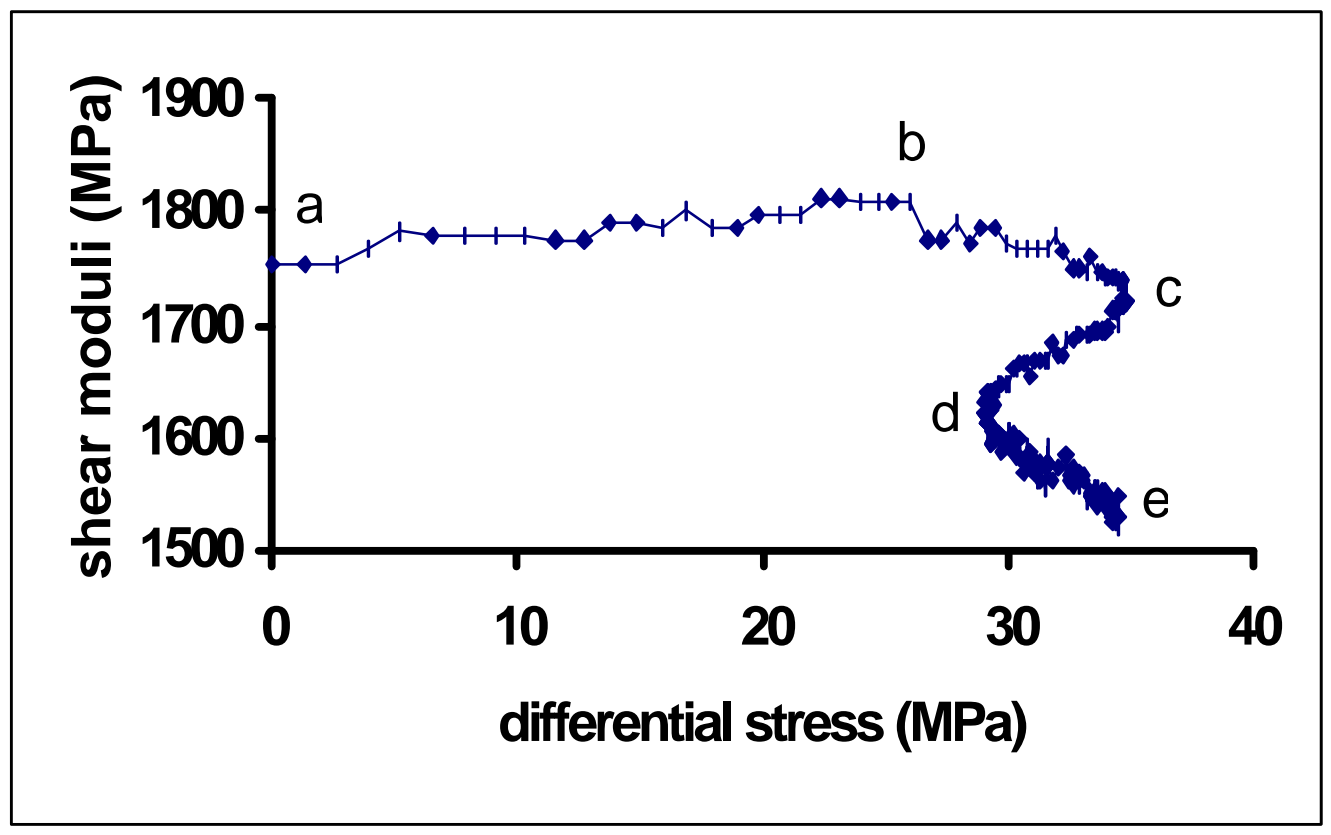

Fig. 22. The shear moduli during the undrained triaxial compression test. 


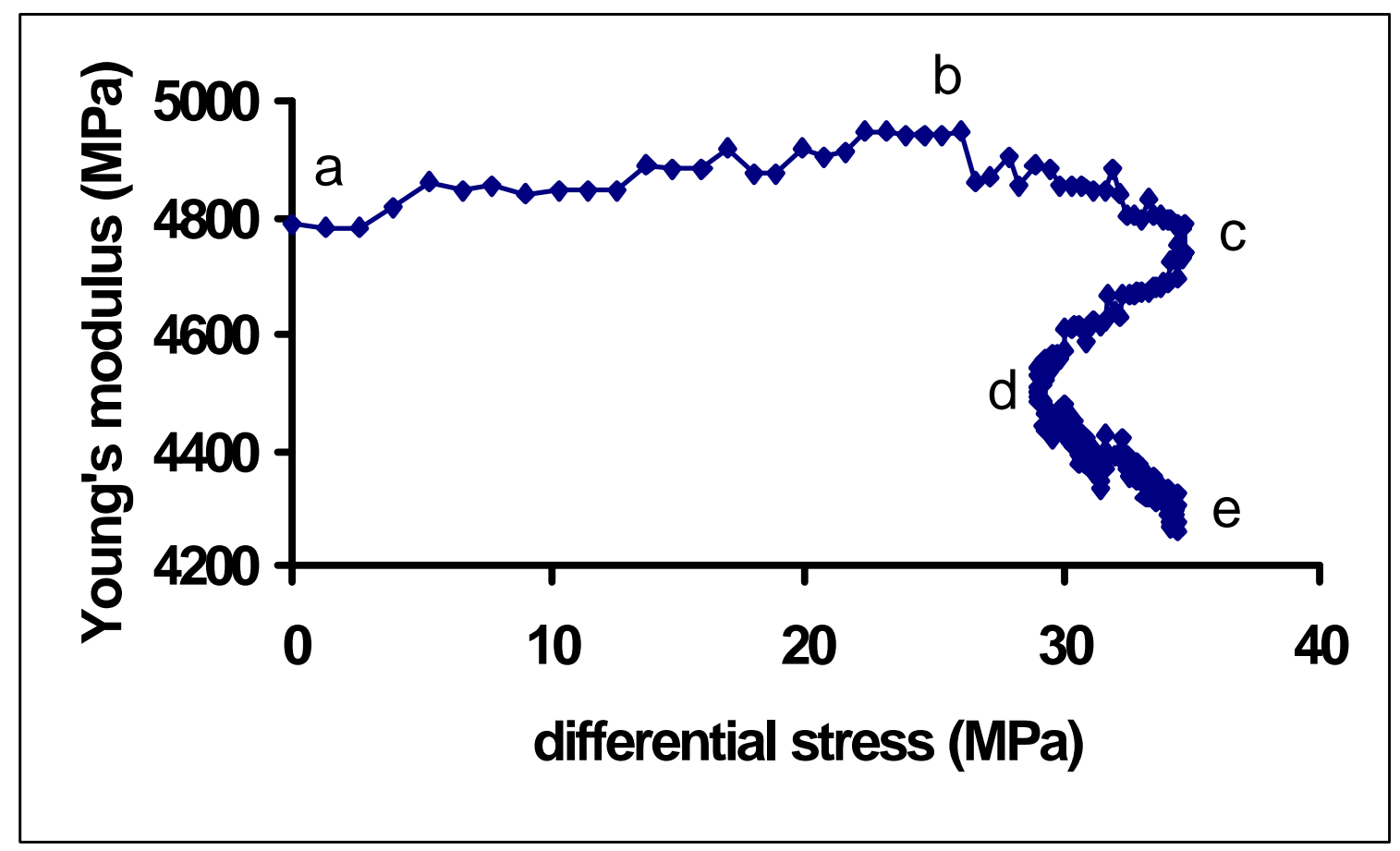

Fig. 23. The Young's modului during the undrained triaxial compression test. 


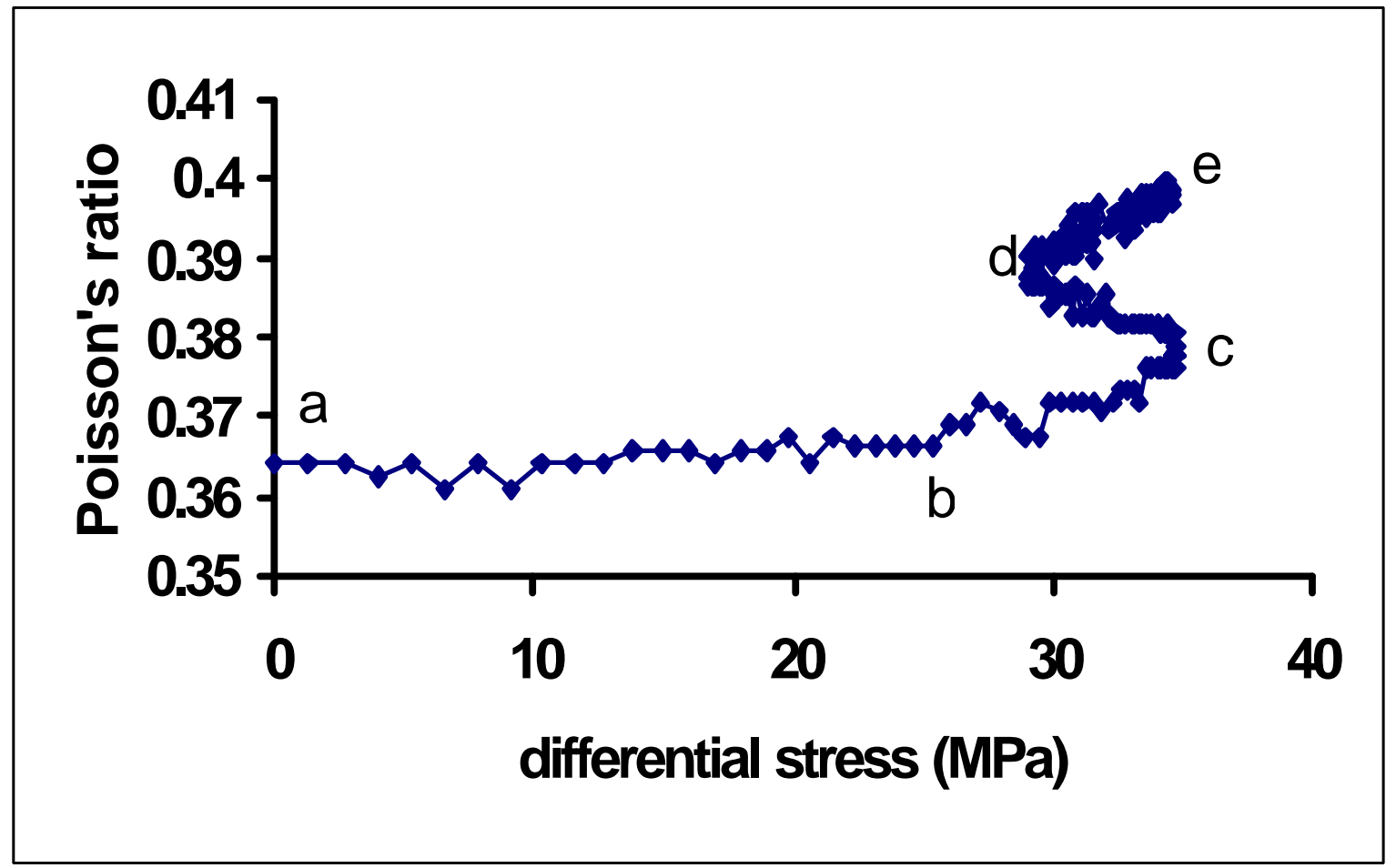

Fig. 24. The change in Poisson's ratio during the undrained triaxial compression experiment. 


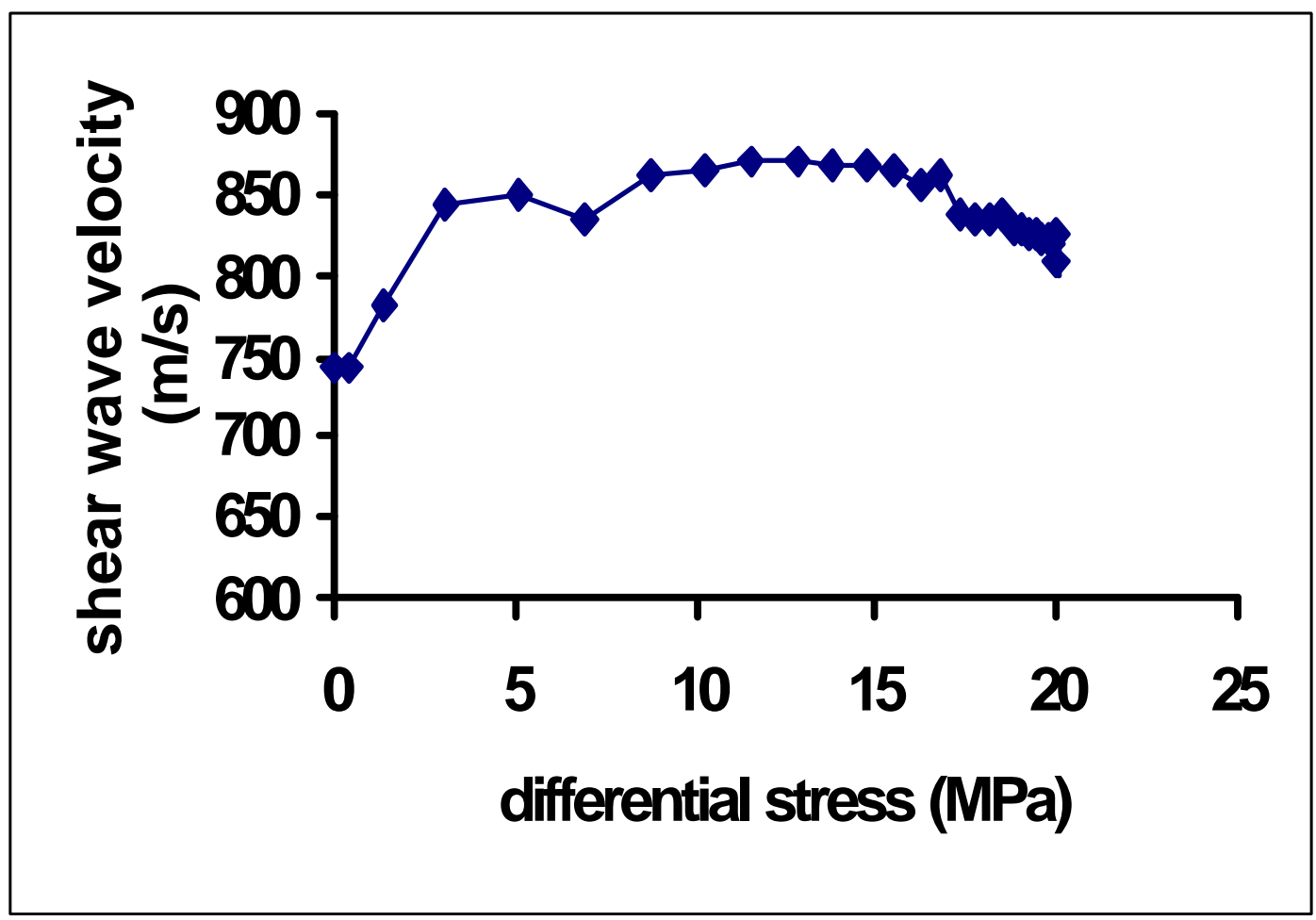

Fig. 25. The shear wave velocity during the drained triaxial compression experiment at 2000 psi confining pressure and 1000 psi pore fluid pressure 


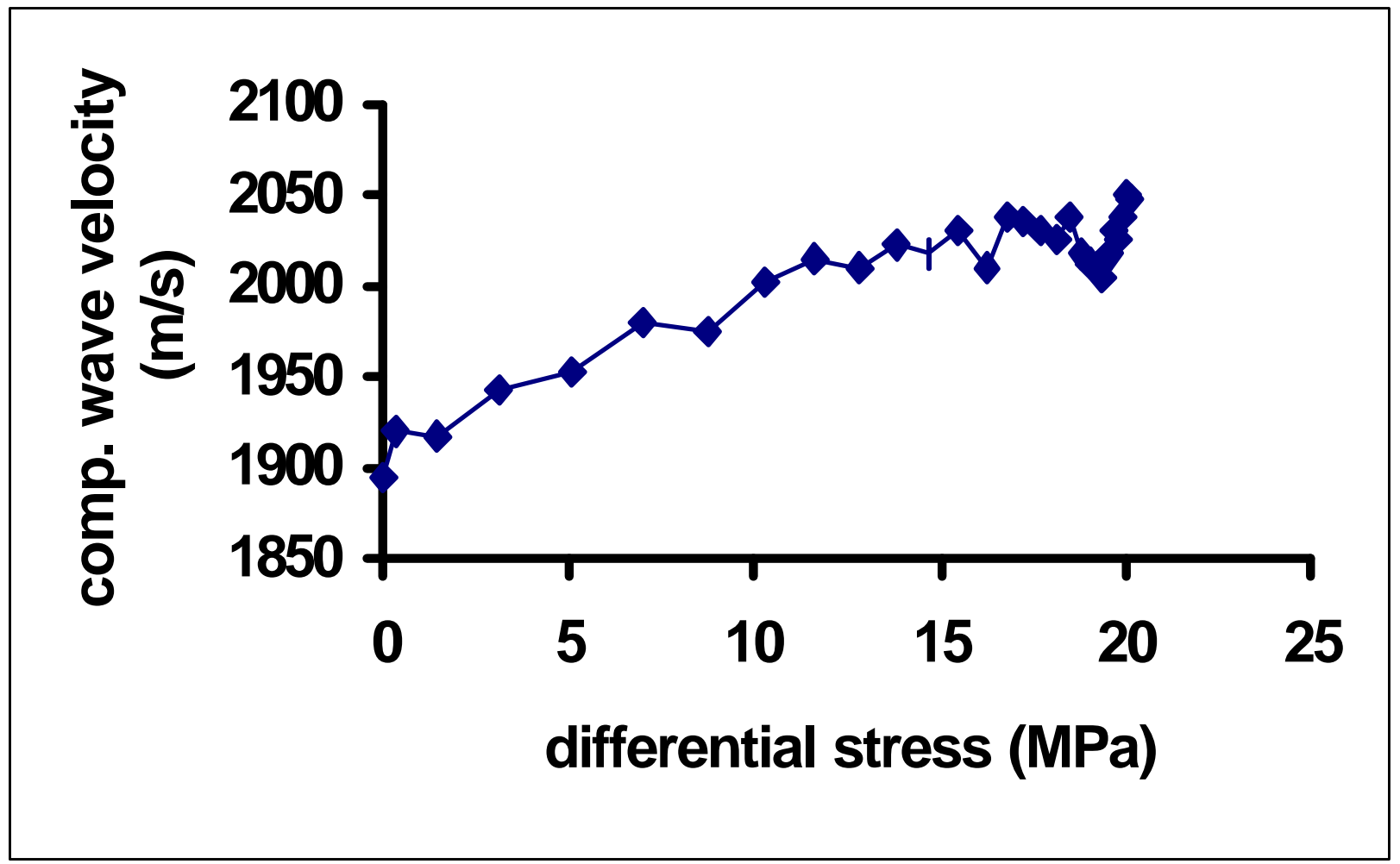

Fig. 26. The compressional wave velocity during the drained triaxial experiment. 


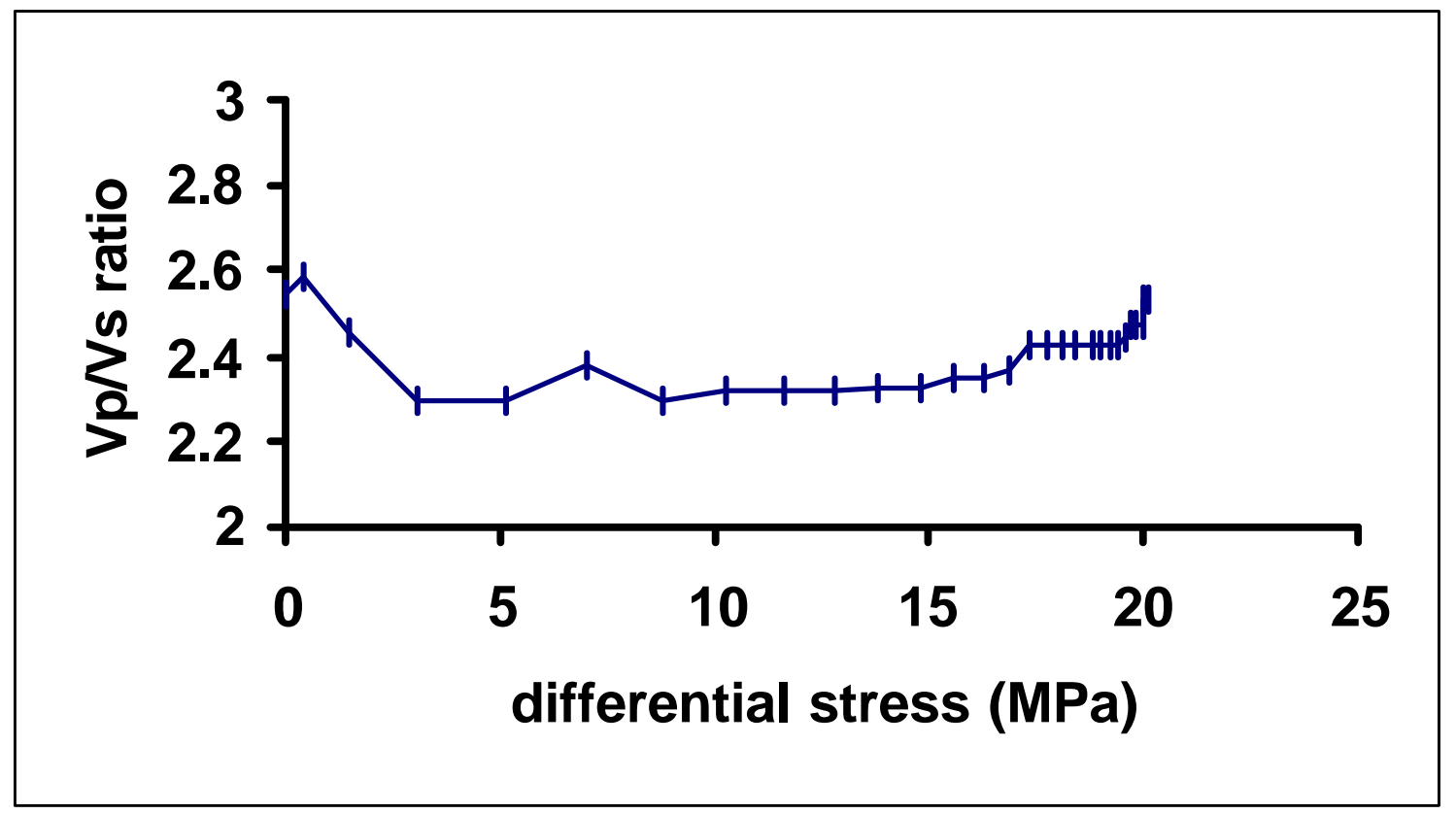

Fig. 27. The Vp/Vs ratio during the drained triaxial experiment. 


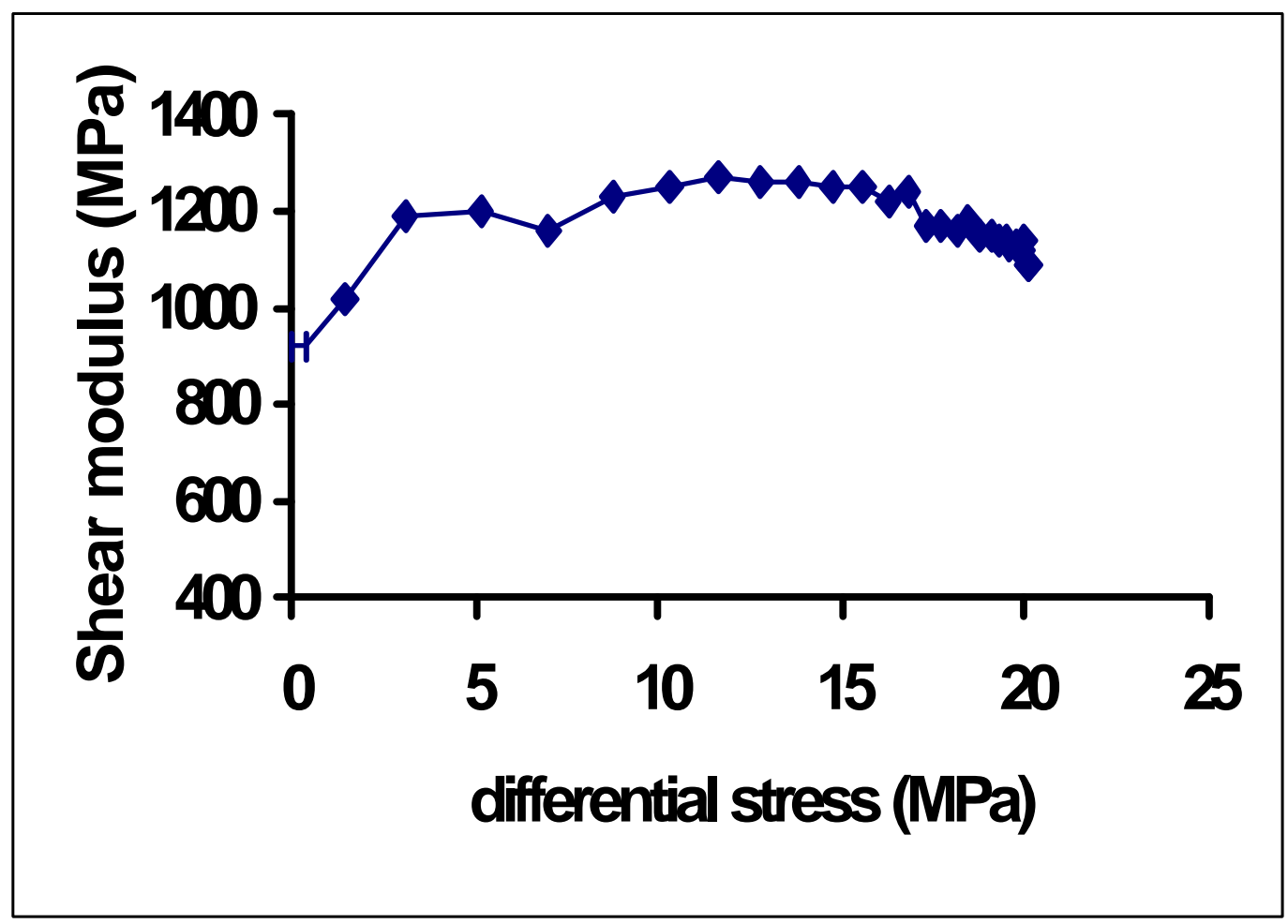

Fig. 28. The change in shear moduli during the drained triaxial experiment. 


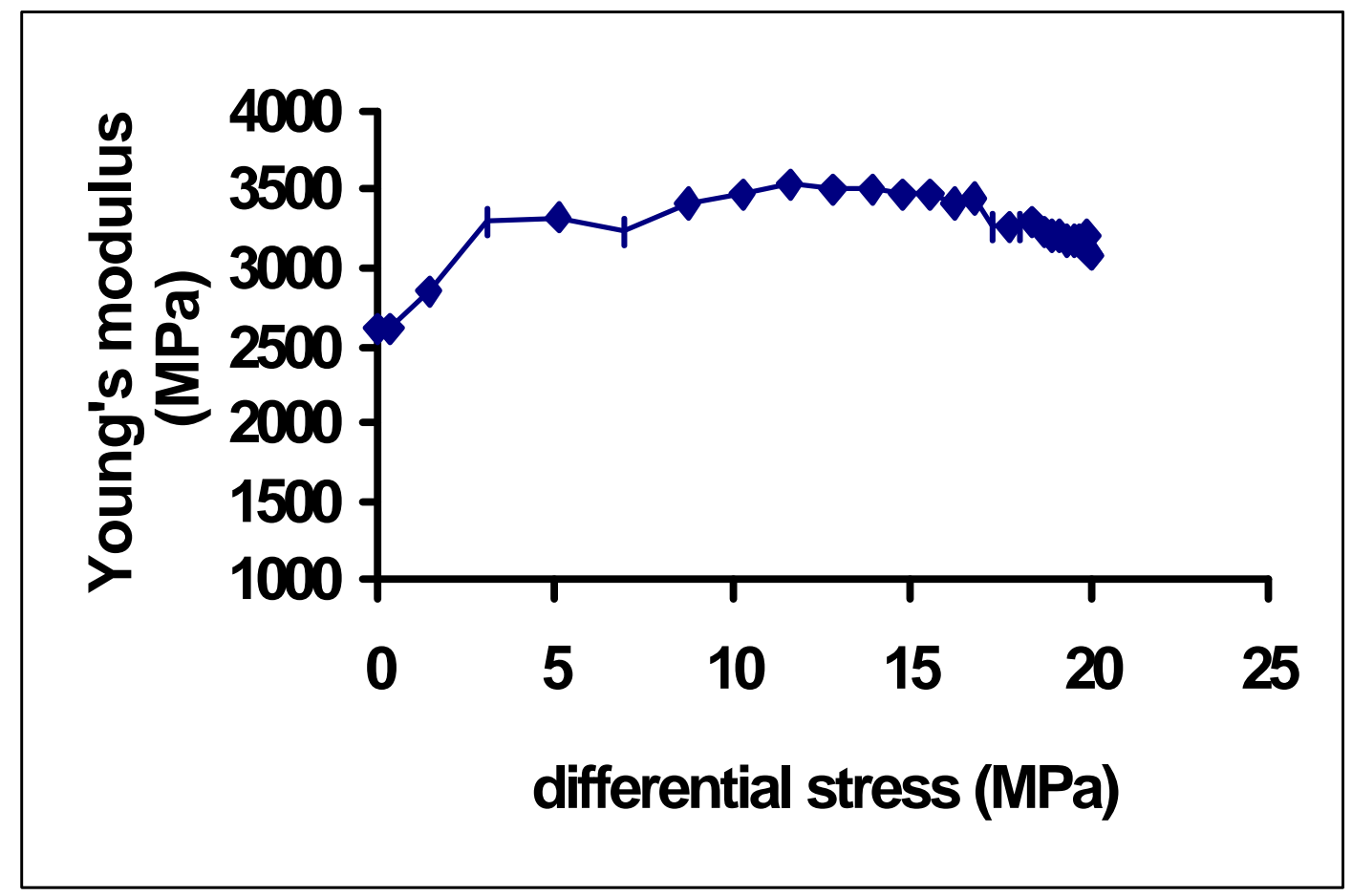

Fig. 29. The change in Young's moduli during the triaxial experiment. 


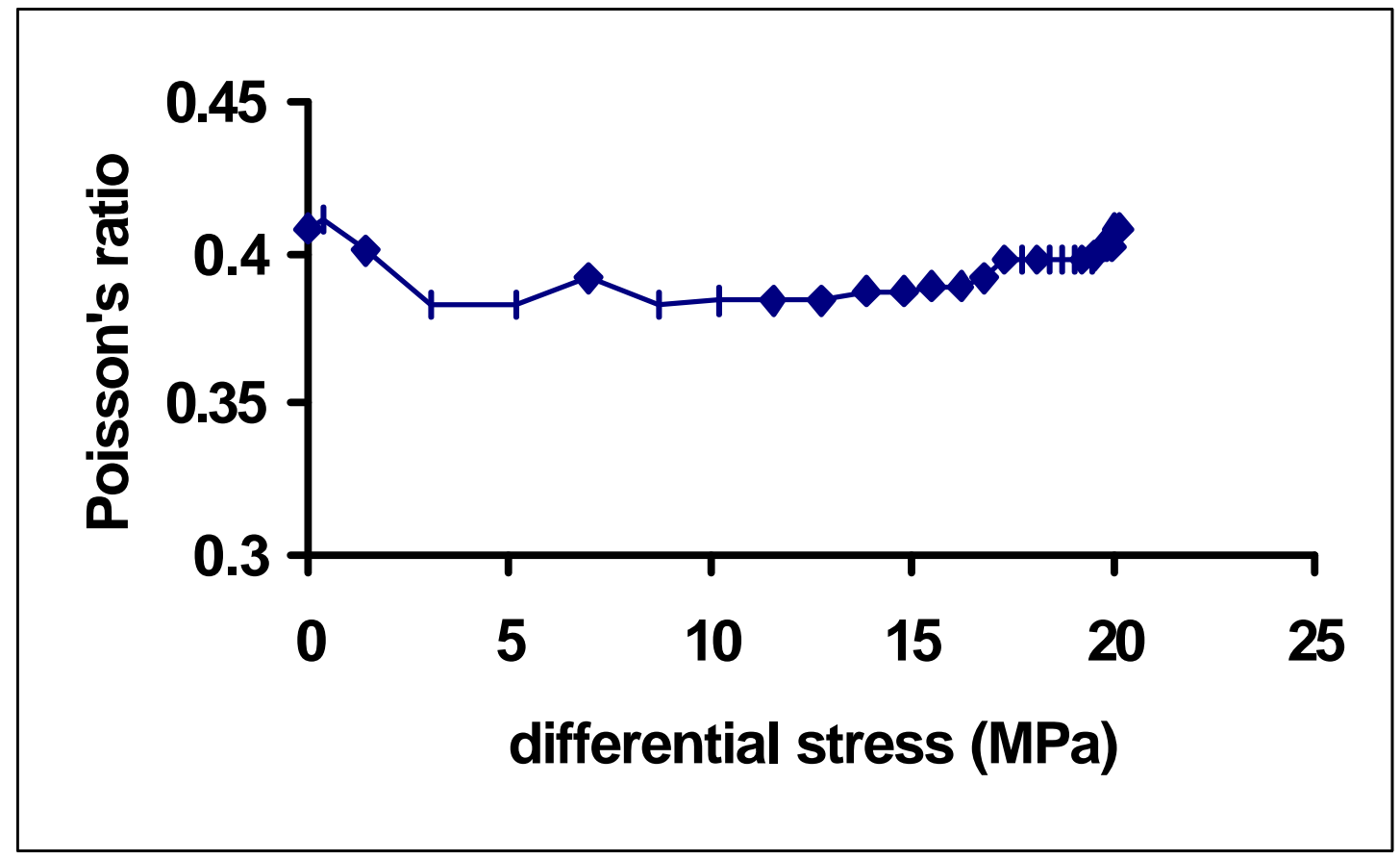

Fig. 30. The change in Poisson's ratio during the the drained triaxial experiment. 


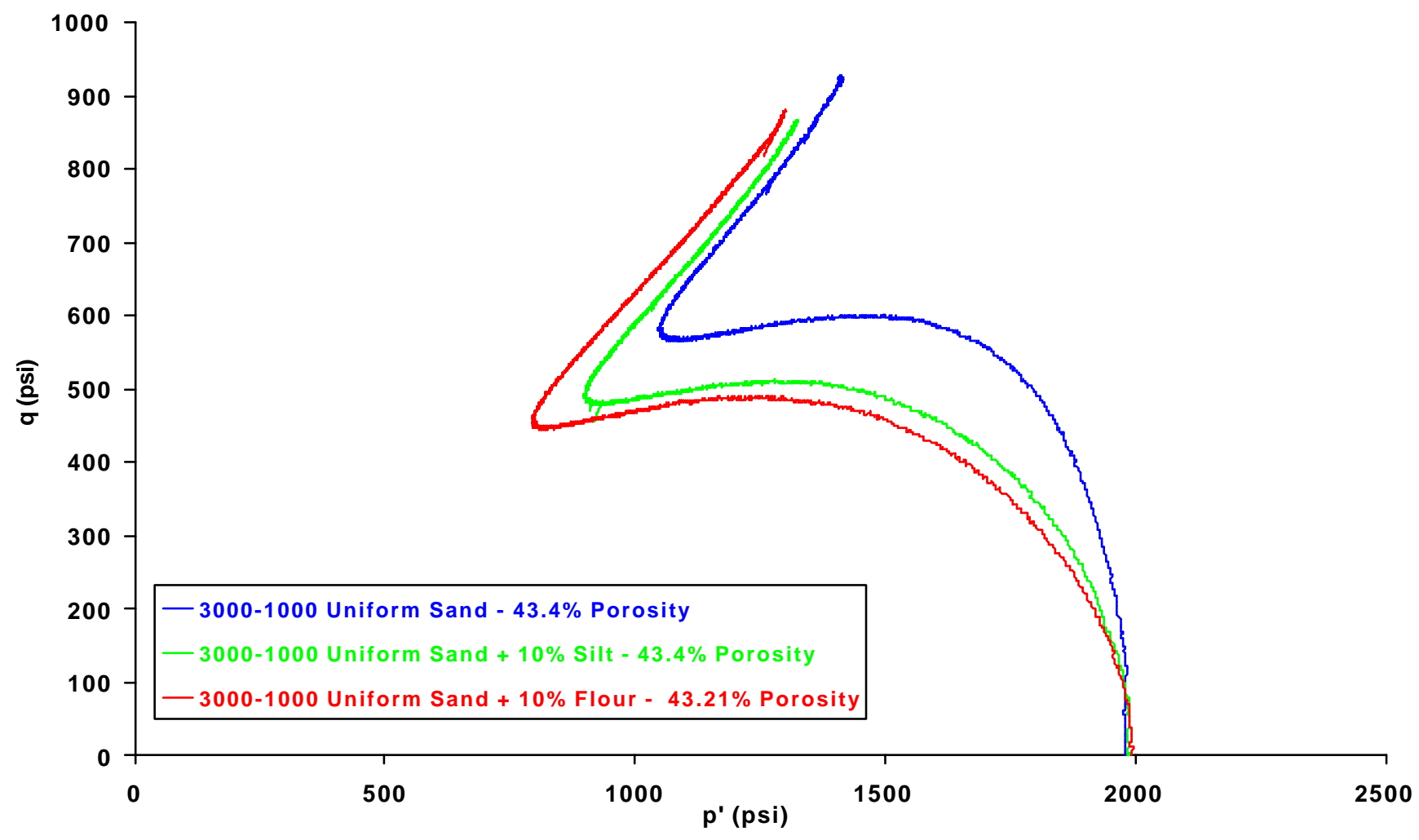

Fig. 31. Undrained triaxial pathways for three sands with different amounts of fines added. 


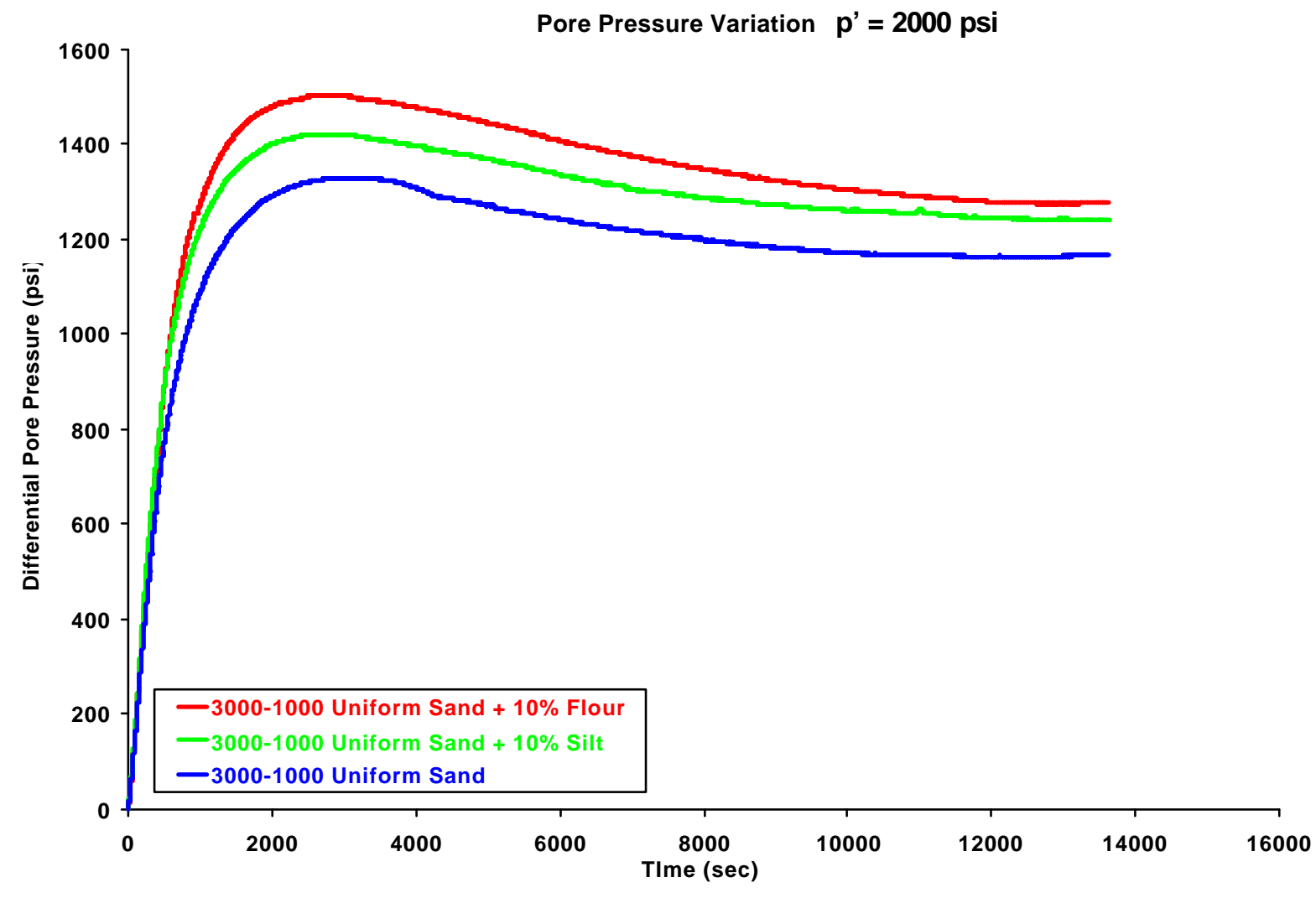

Fig. 32. Pore pressure-times curves for three different mixtures

of Oil Creek sand as finer materials are added to the sand. 


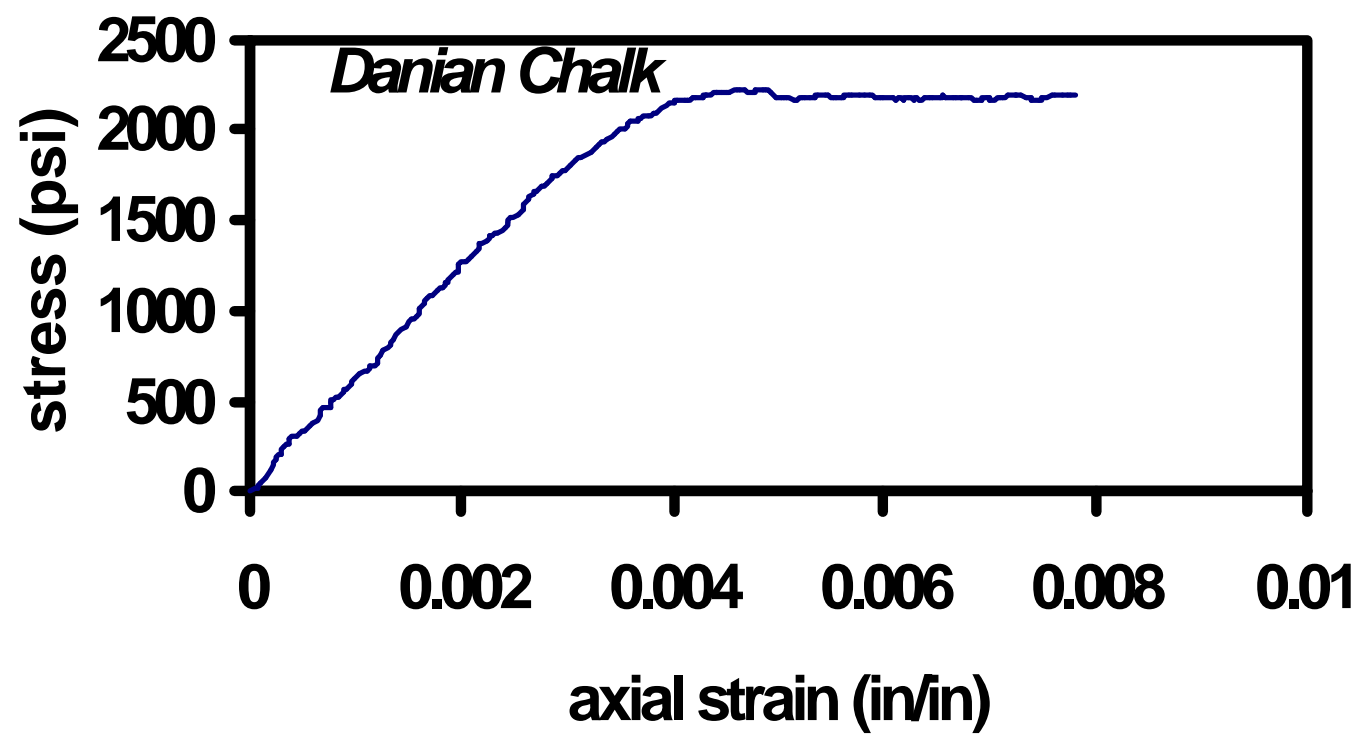

Fig. 33. Stress-strain diagram for Danian chalk. 


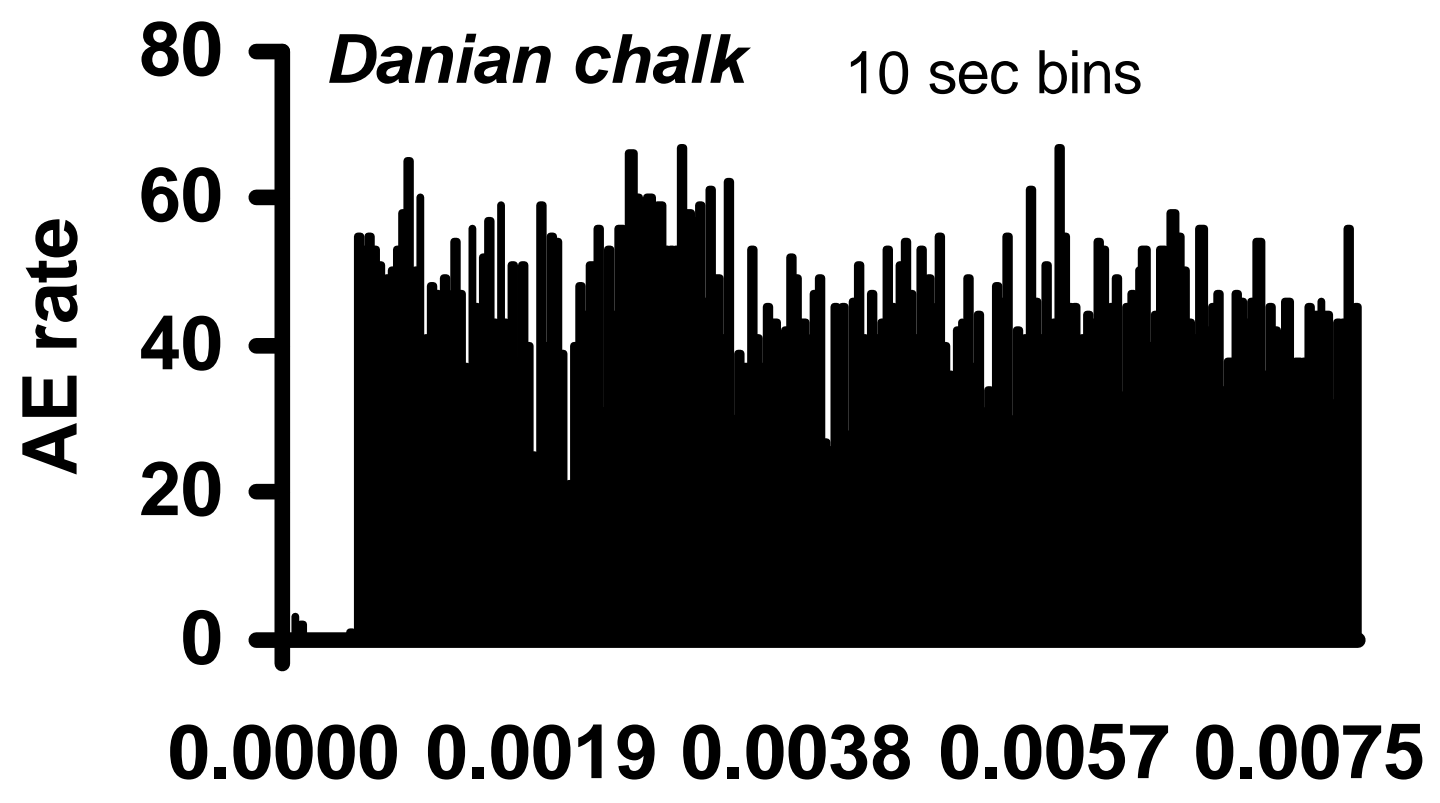

Fig. 34. AE rate diagram for Danian chalk. 


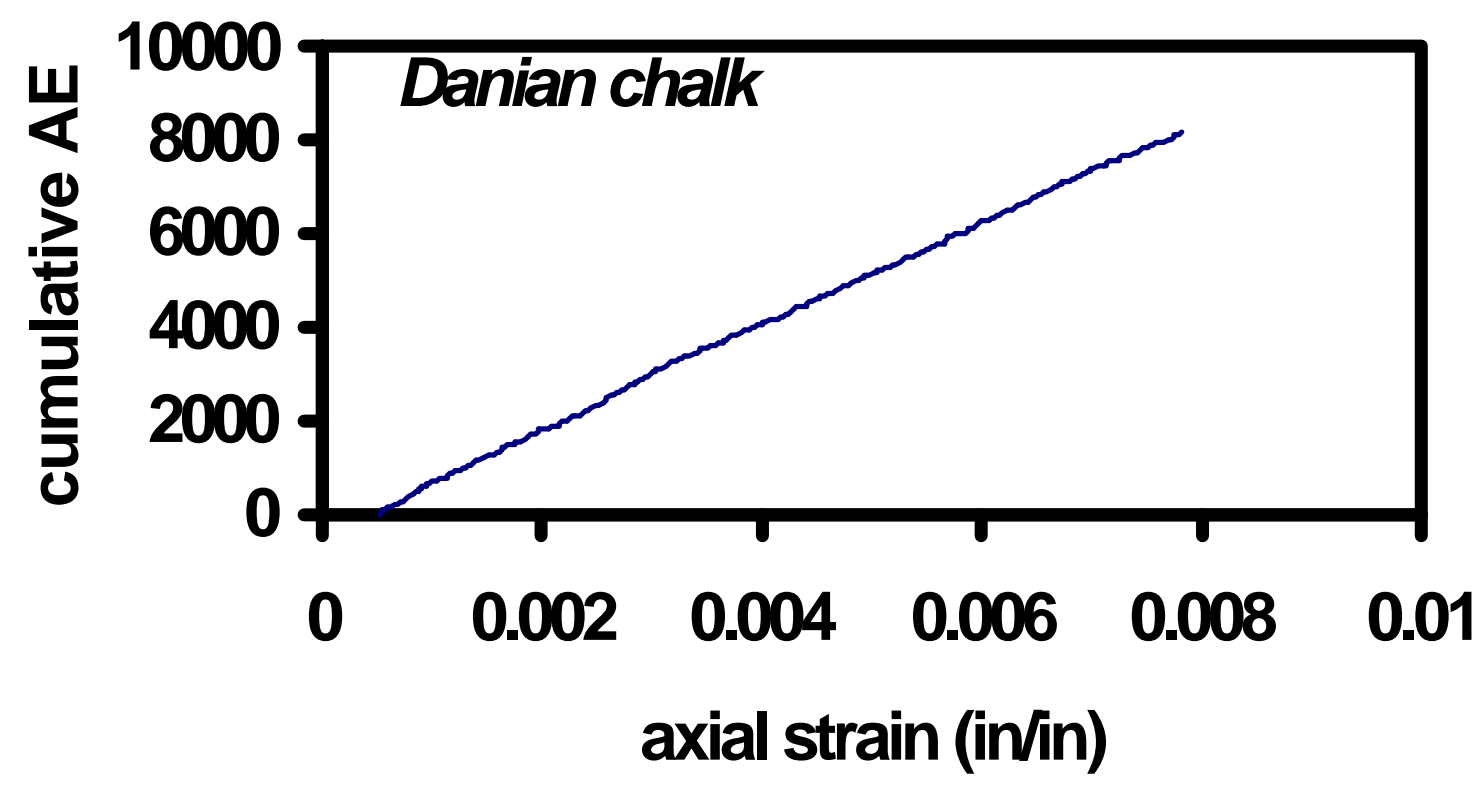

Fig. 35. Cumulative AE for Danian chalk. 


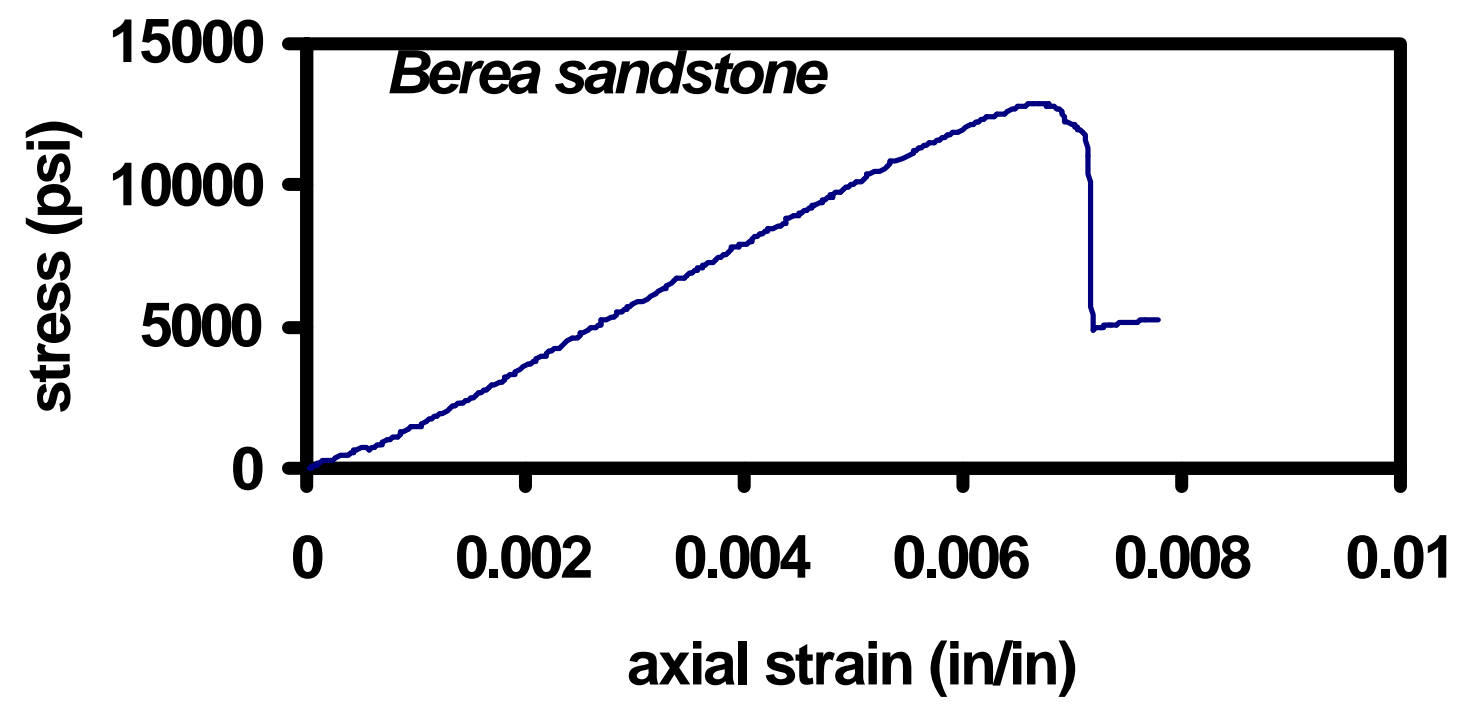

Fig. 36. Stress-strain diagram for Berea sandstone AE reference. 


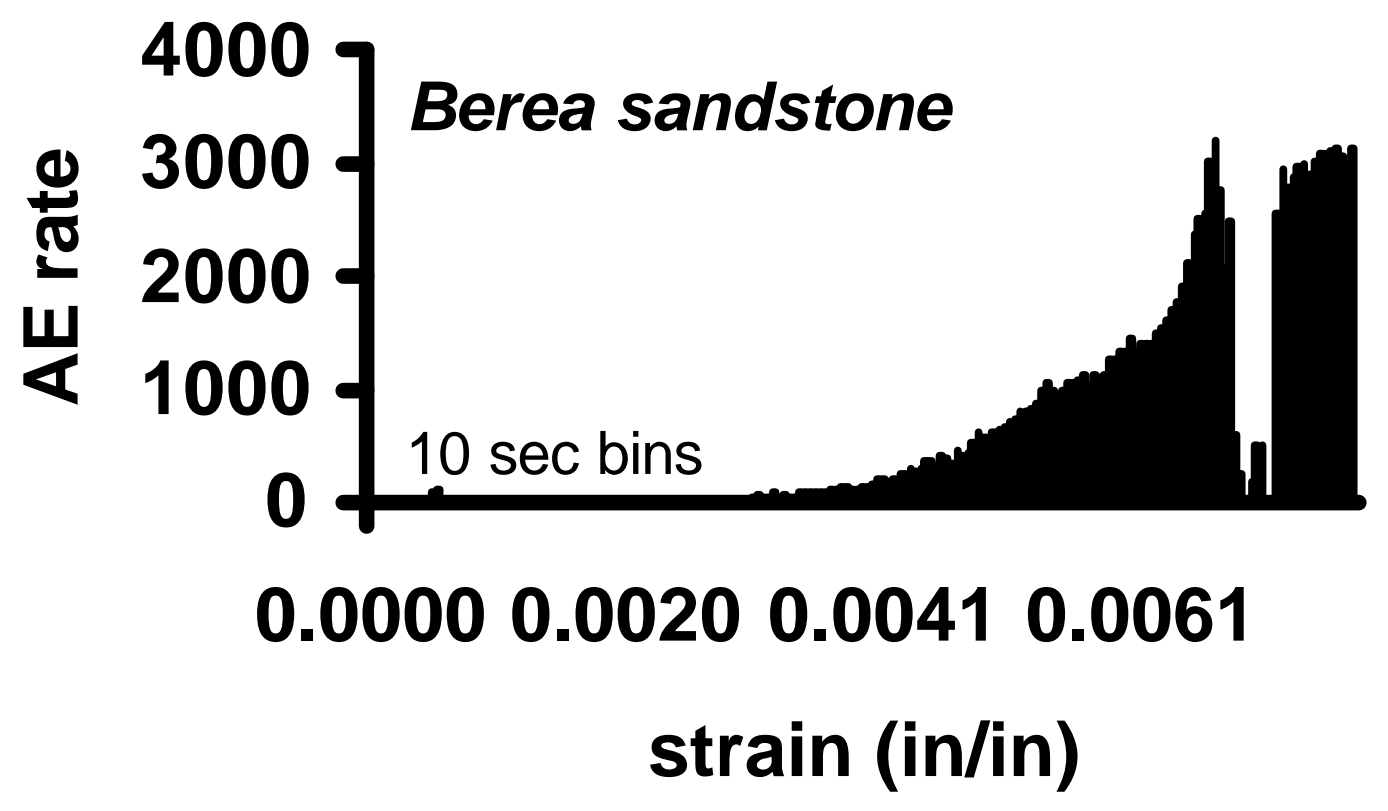

Fig. 37. AE rate diagram for Berea sandstone $A E$ reference. 


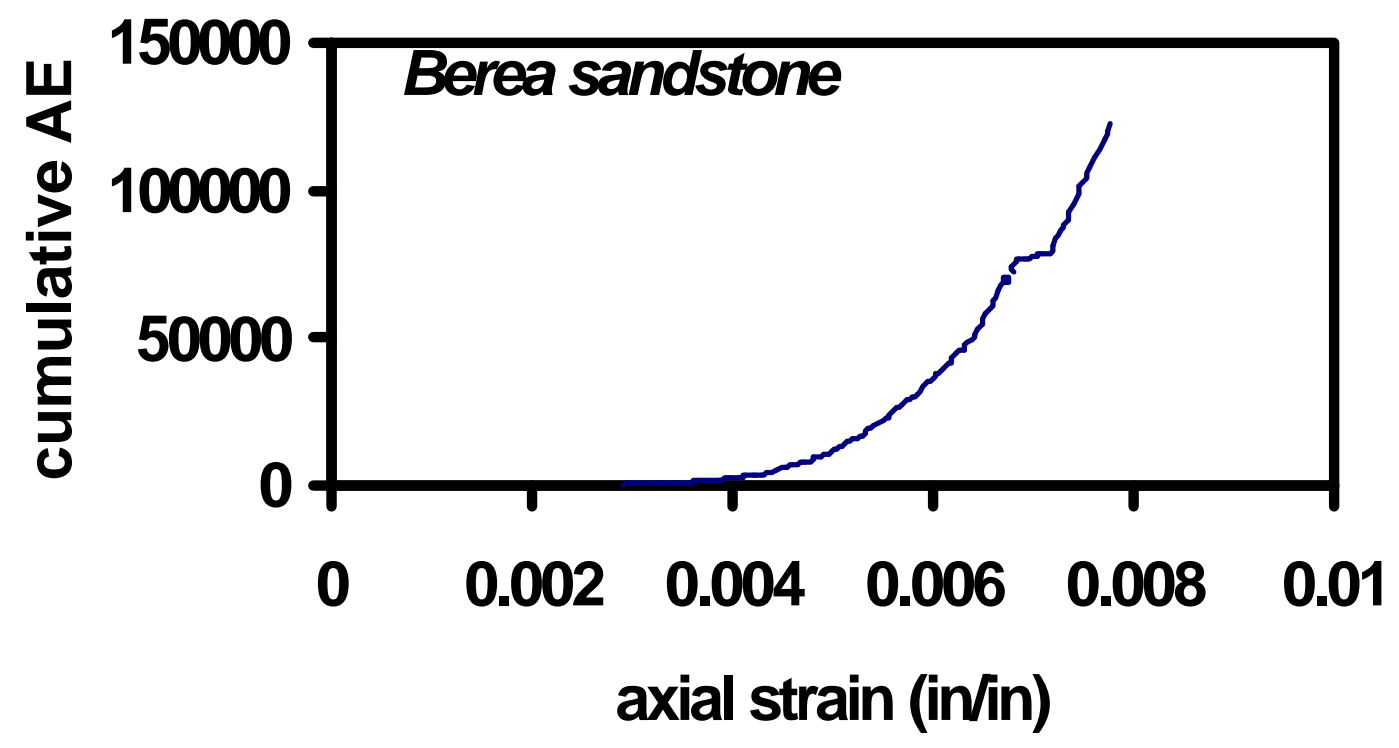

Fig. 38. Cumulative AE for Berea sandstone $A E$ reference. 


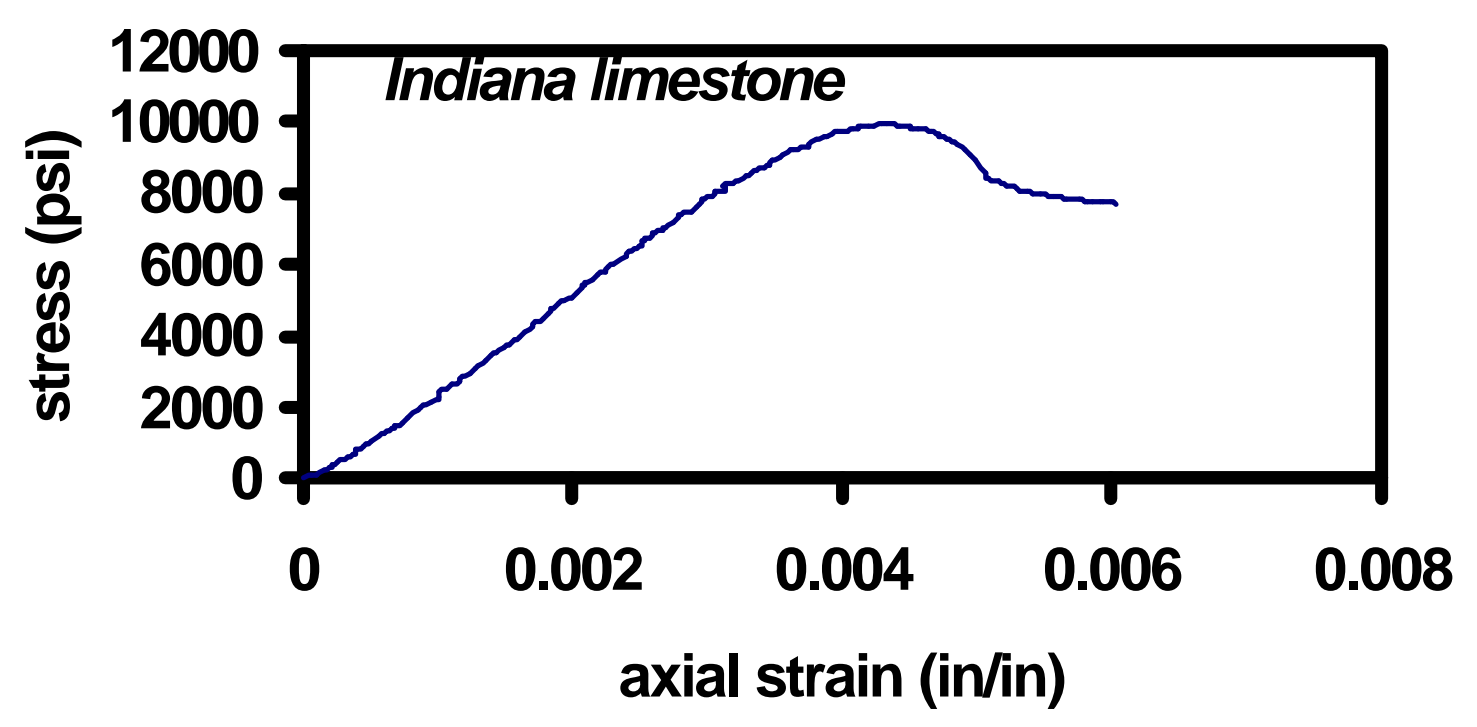

Fig. 39. Stress-strain diagram for Indiana limestone. 


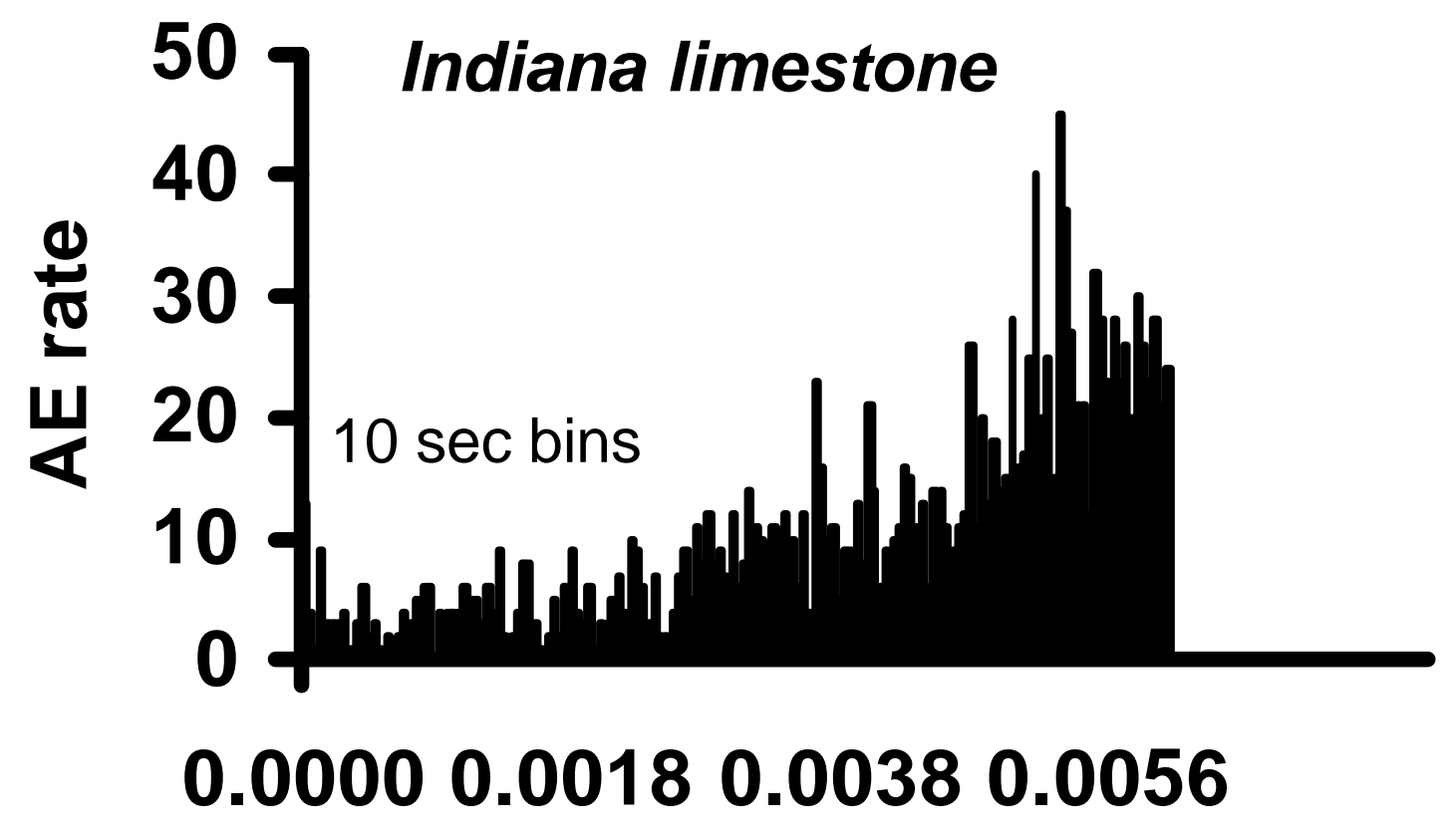

Fig. 40. AE rate diagram for Indiana limestone. 


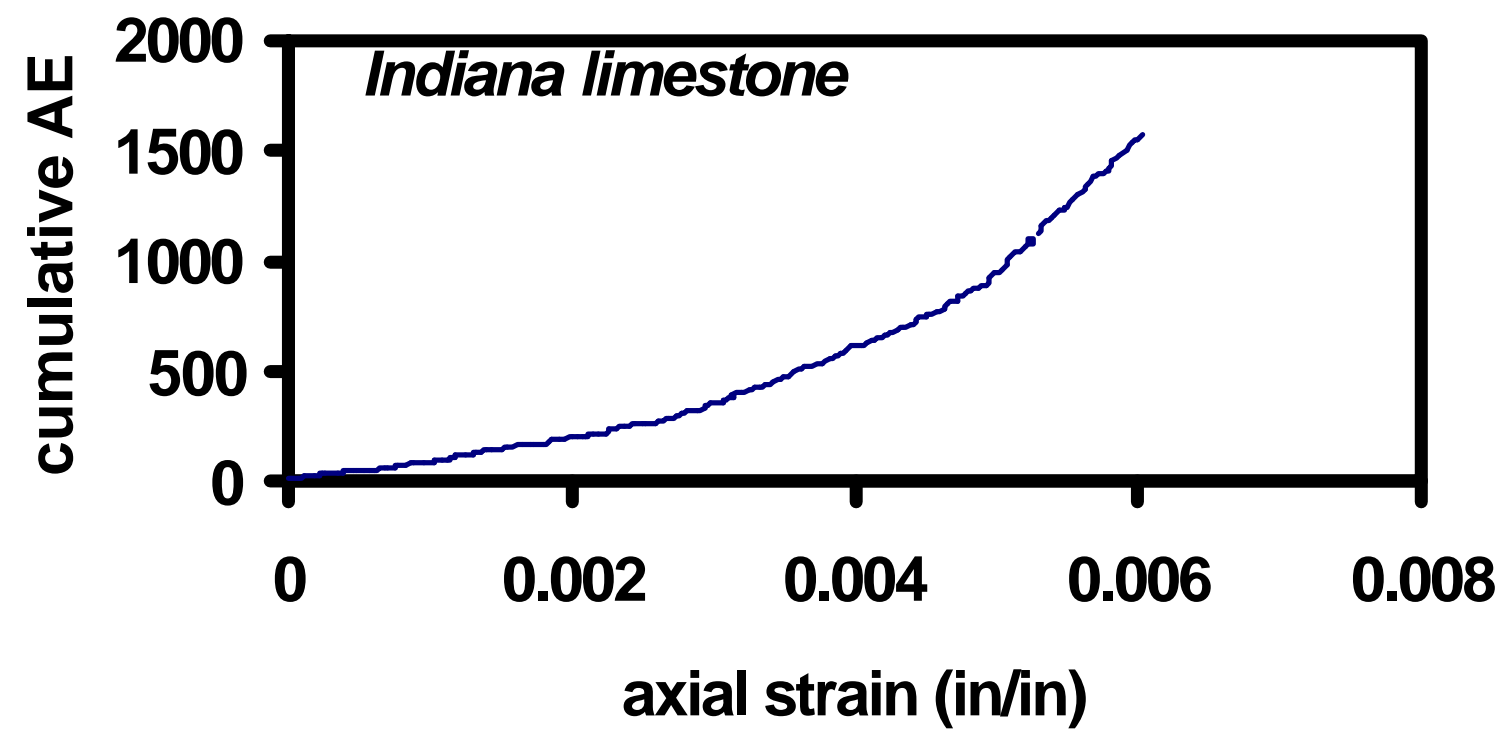

Fig. 41. Cumulative AE for Indiana limestone. 


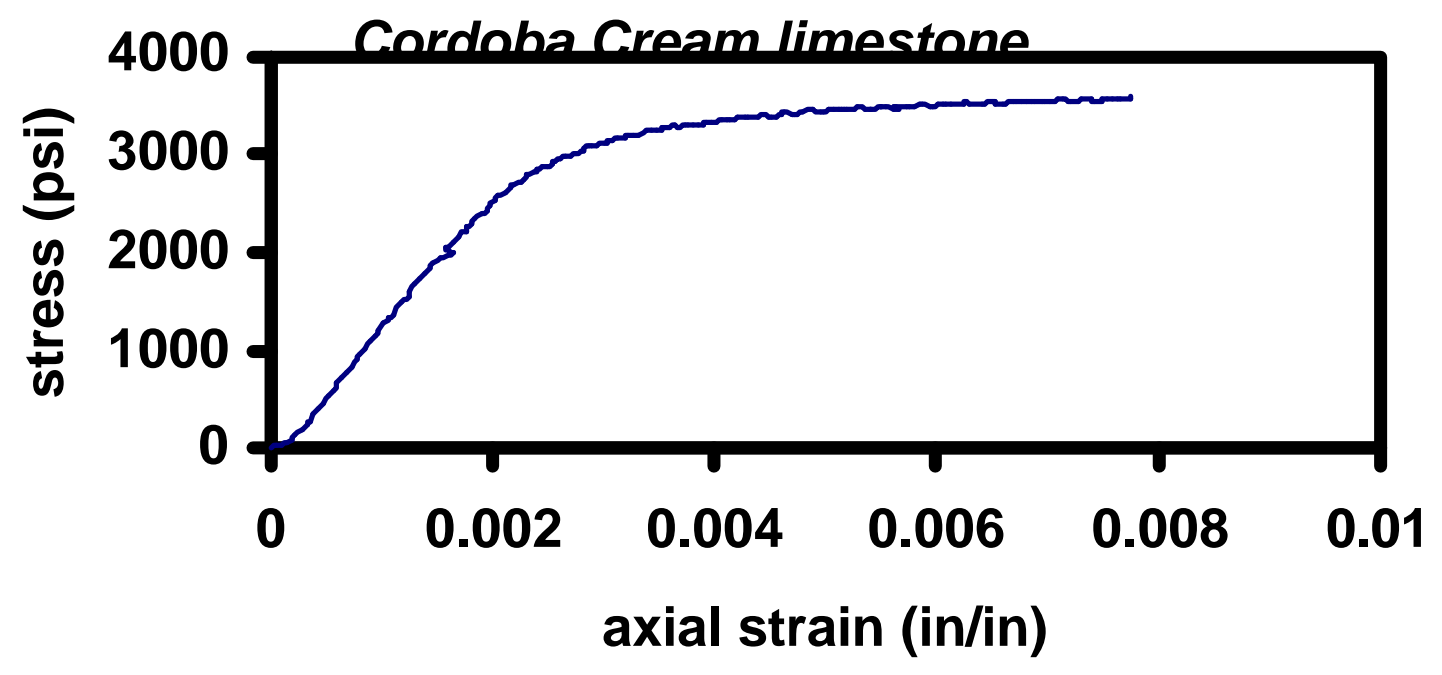

Fig. 42. Stress-strain diagram for Cordoba Cream limestone. 


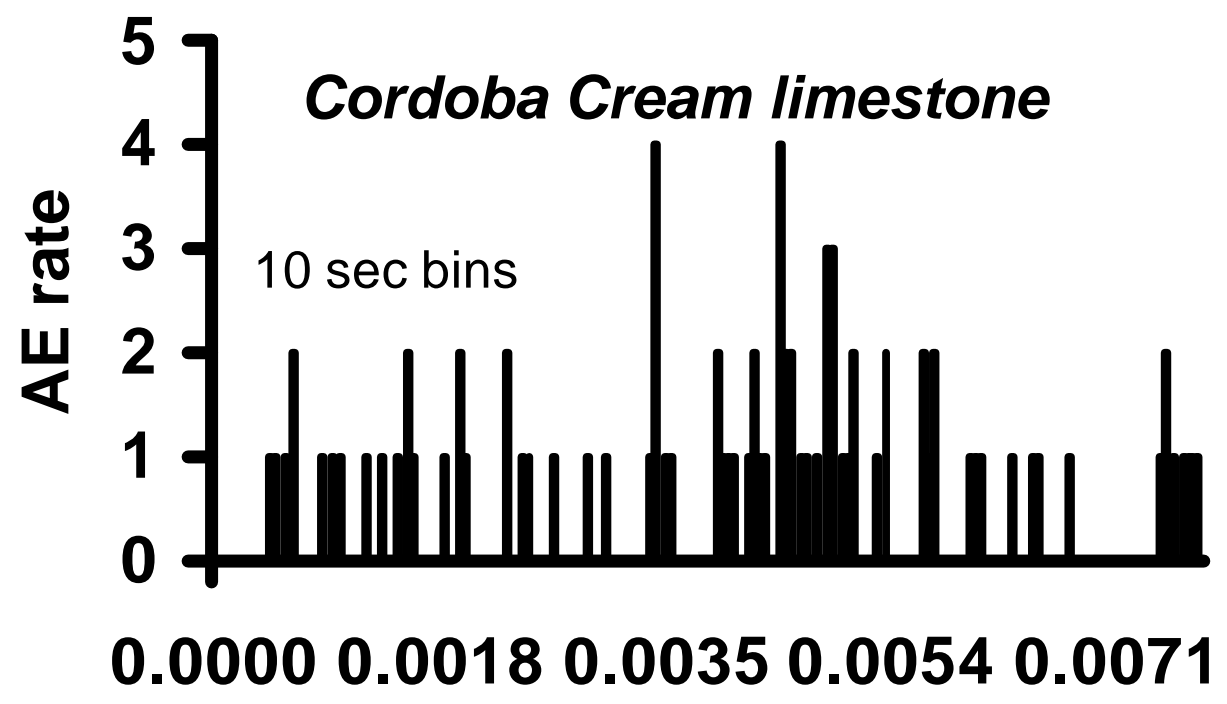

Fig. 43. AE rate diagram for Cordoba Cream limestone. 


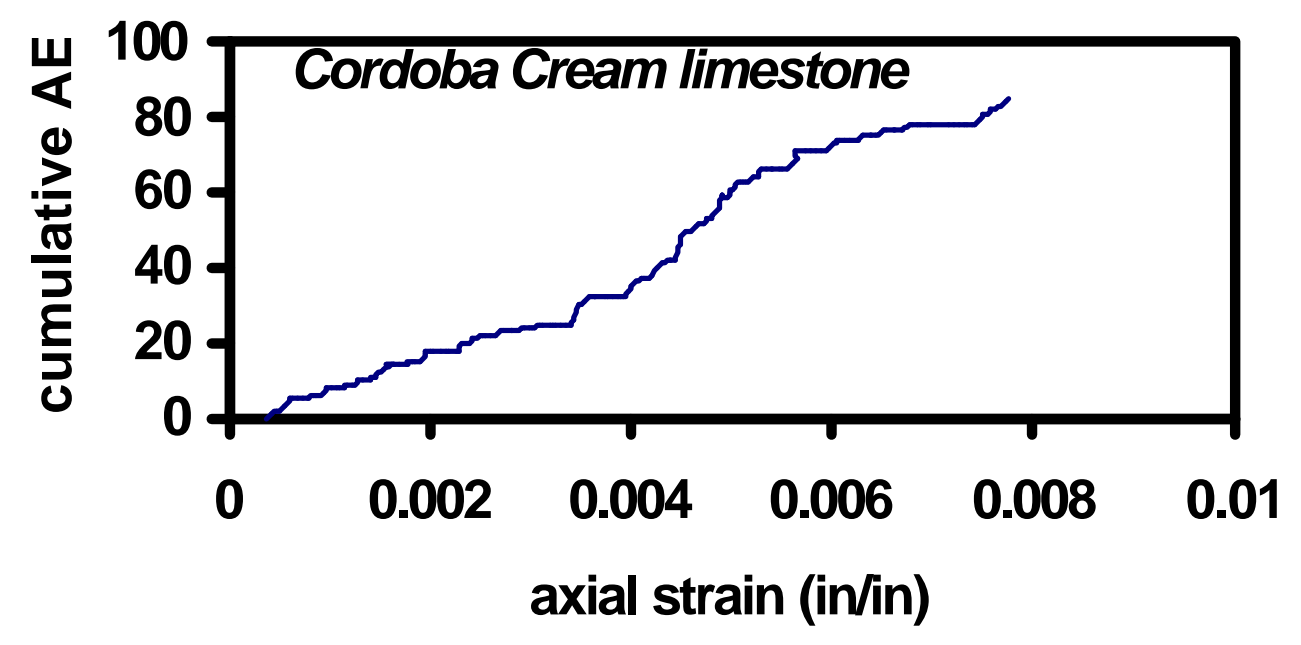

Fig. 44. Cumulative $A E$ for Cordoba Cream limestone. 


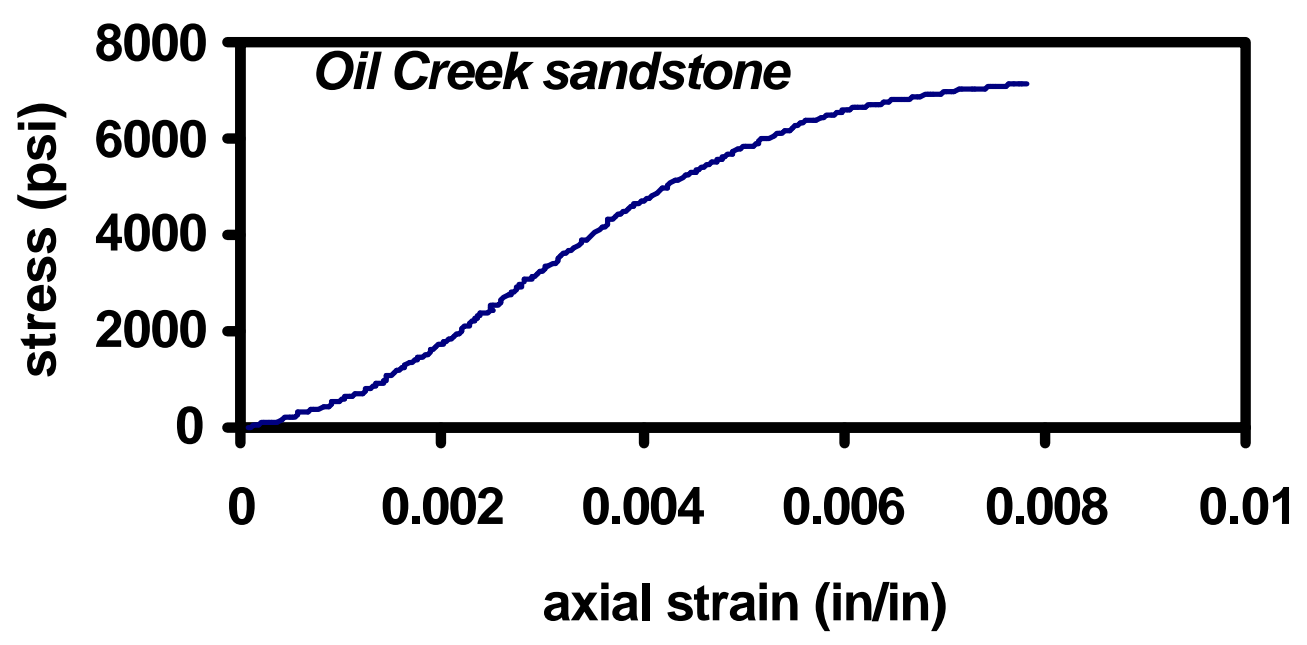

Fig. 45. Stress-strain diagram for Oil Creek sandstone. 


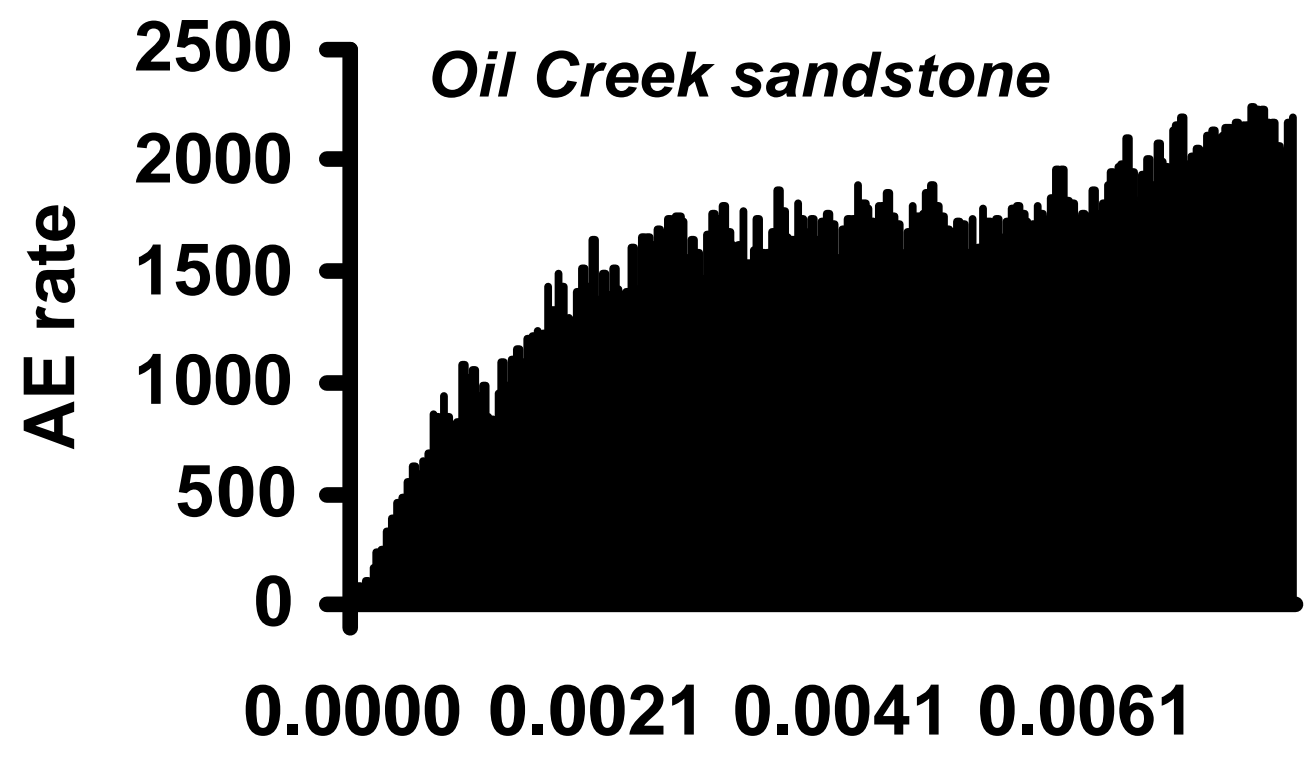

Fig. 46. AE rate diagram for Oil Creek sandstone. 


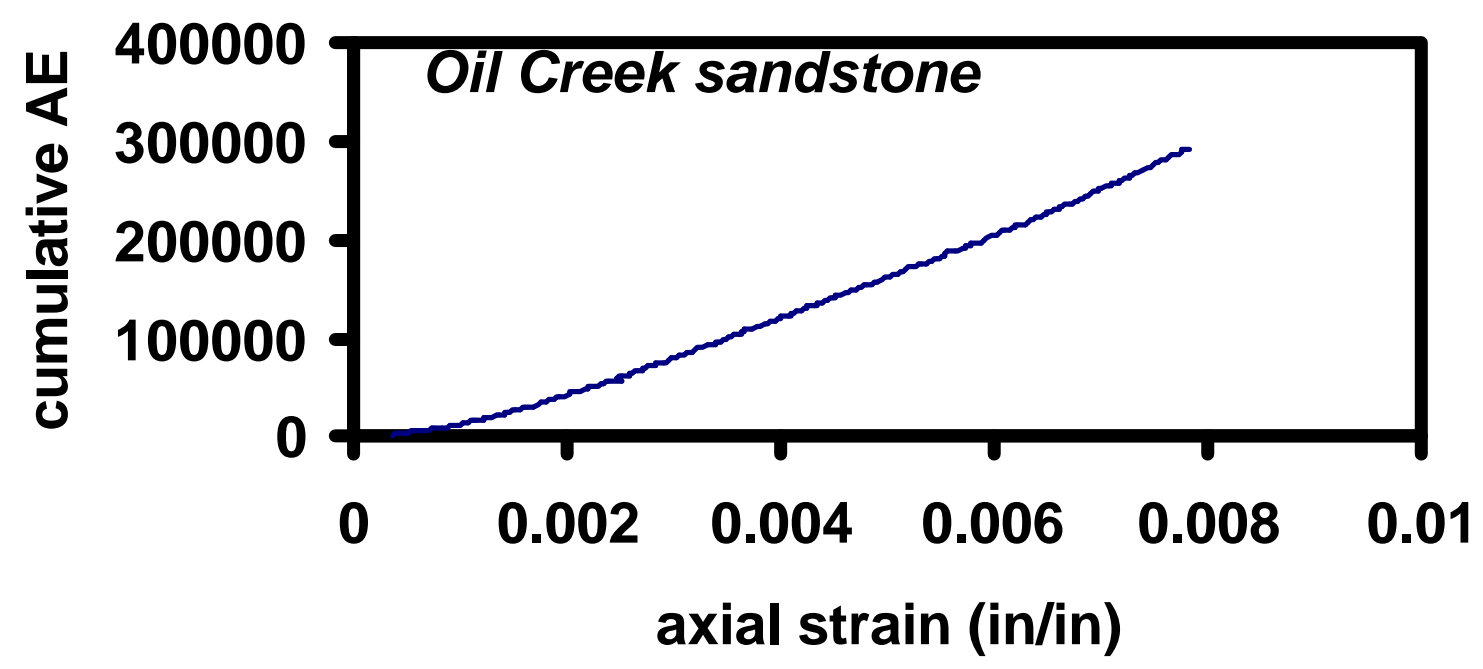

Fig. 47. Cumulative AE for Oil Creek sandstone. 


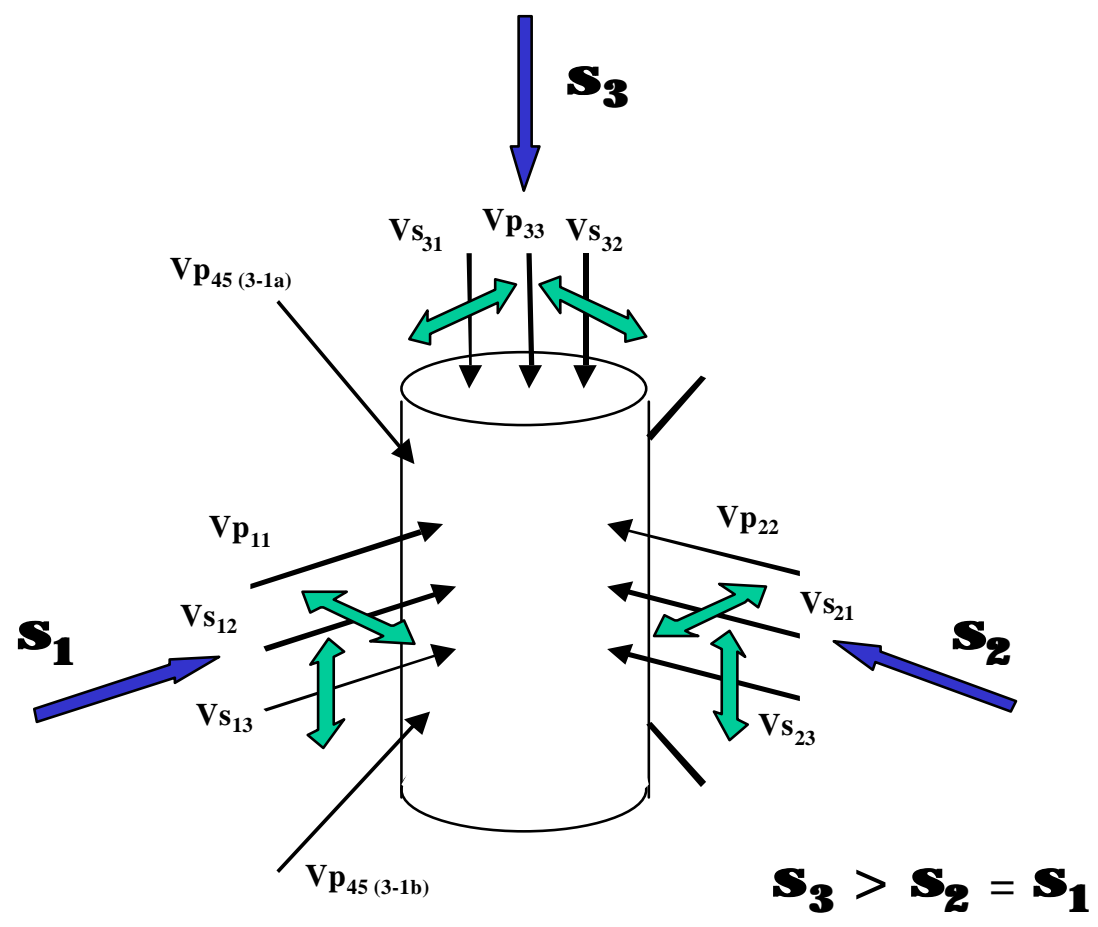

Fig. 48. The three-dimensional orientation of the acoustic raypaths on the cylindrical core samples. This is the new single core method. 


$\begin{array}{ll}1 & V p_{11} \\ 2 & V p_{22} \\ 3 & V p_{33} \\ 4 & V s_{12} \\ 5 & V s_{13} \\ 6 & V s_{21} \\ 7 & V s_{23} \\ 8 & V s_{32} \\ 9 & V s_{31} \\ 10 & V p_{45 a 1-3} \\ 11 & V p_{45 b 1-3}\end{array}$

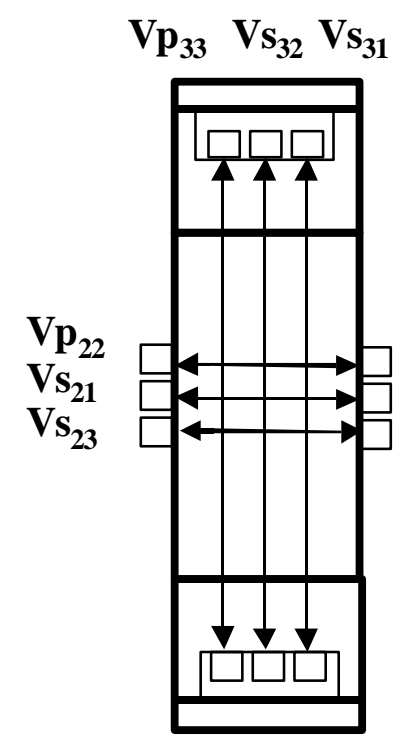

The '3-2' plane

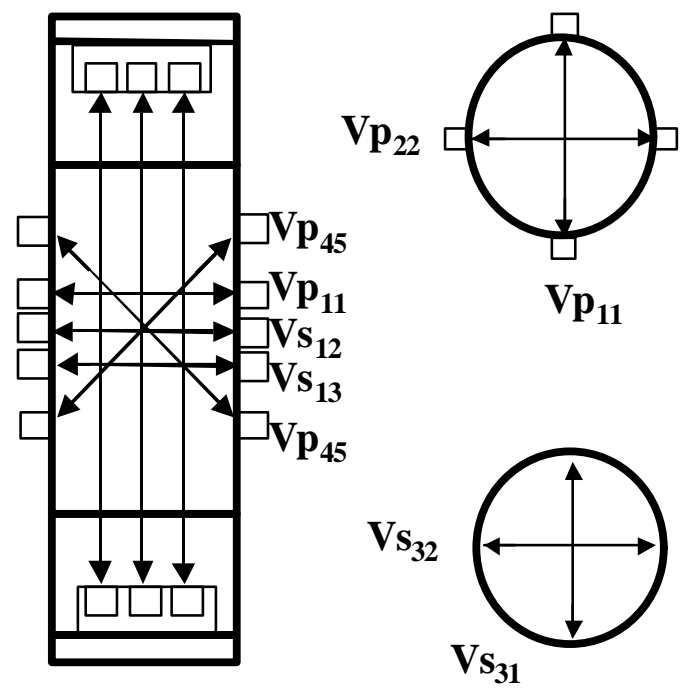

The '3-1' plane

Fig. 49. A schematic illustrating the various acoustic raypaths in the cylindrical samples. 


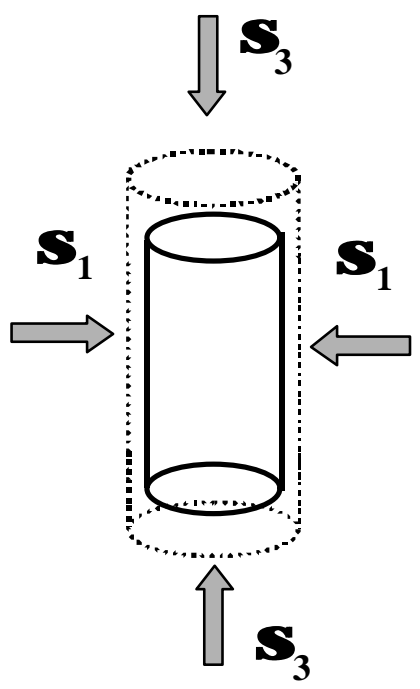

Hydrostatic compression test

$$
\sigma_{3}=\sigma_{2}=\sigma_{1} \neq 0
$$

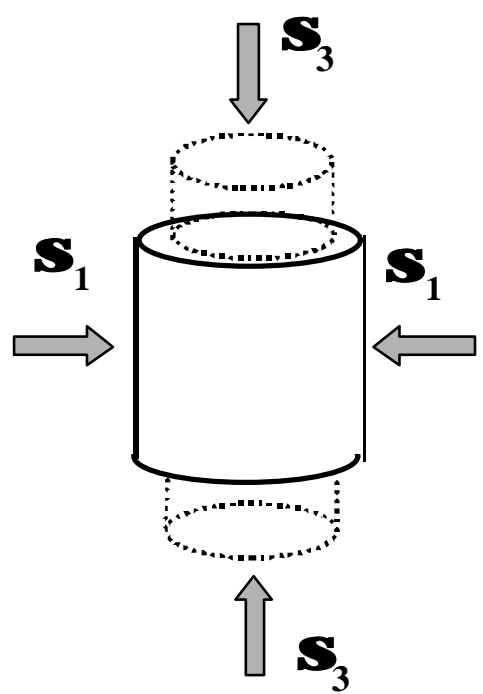

Triaxial compression test

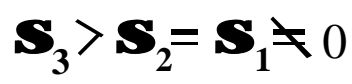

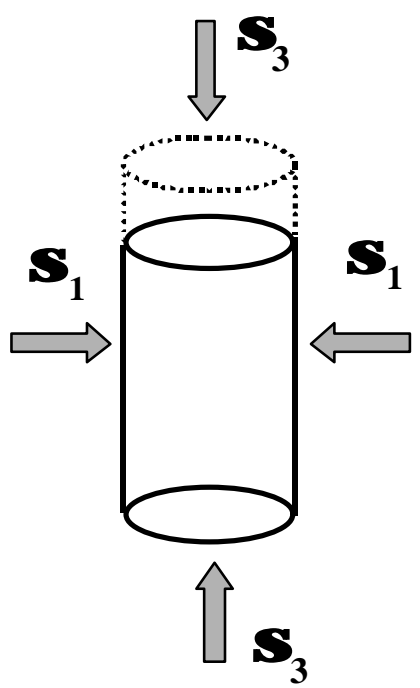

Uniaxial strain test

$\sigma_{3}>\sigma_{2}=\sigma_{1} \searrow 0$ $\varepsilon_{1}=0$

Fig. 50. A schematic illustrating the types of deformation experiments conducted in the study. 


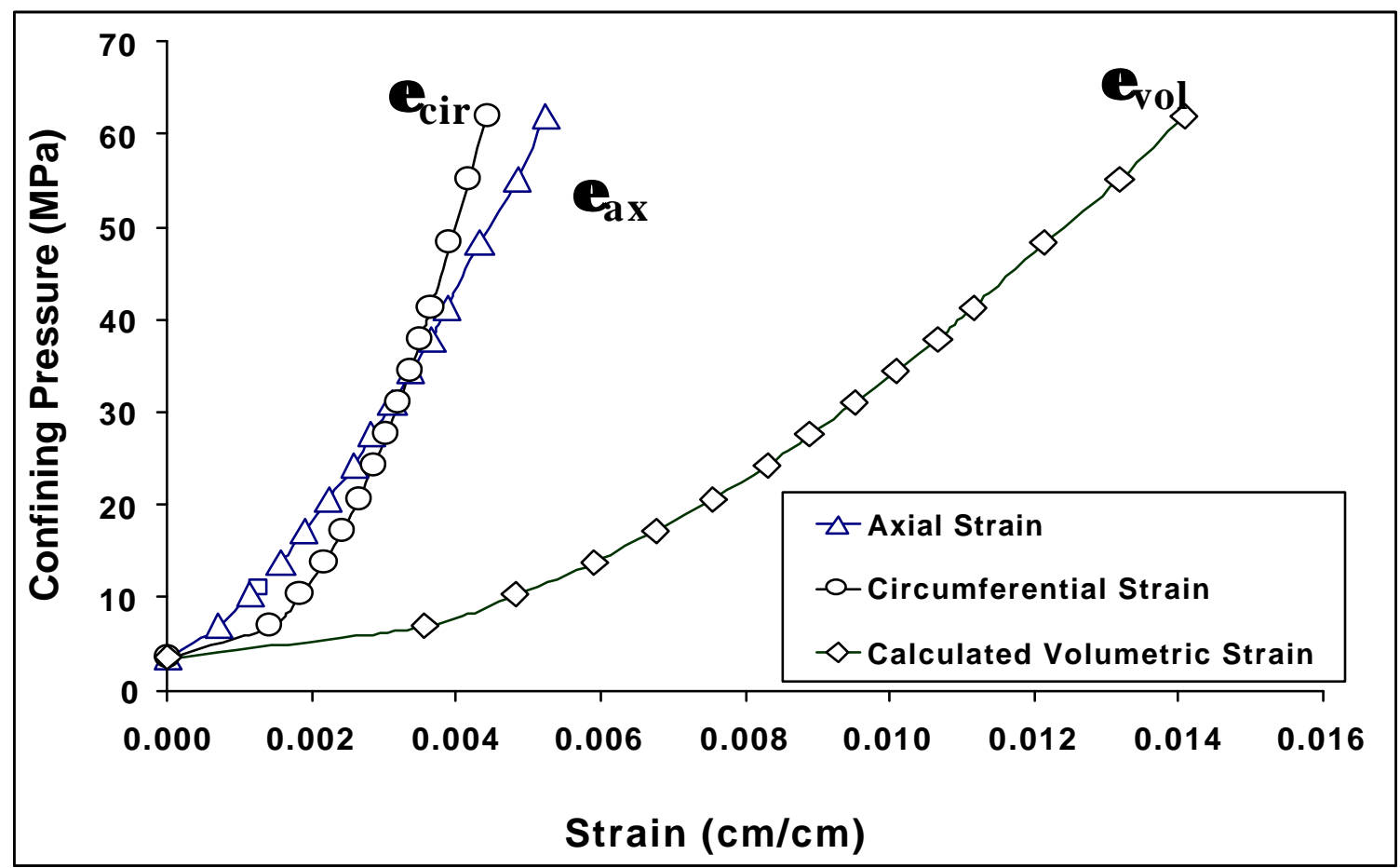

Fig. 51. A plot of the confining stress vs. axial and circumferential strains during a hydrostatic compression experiment. 


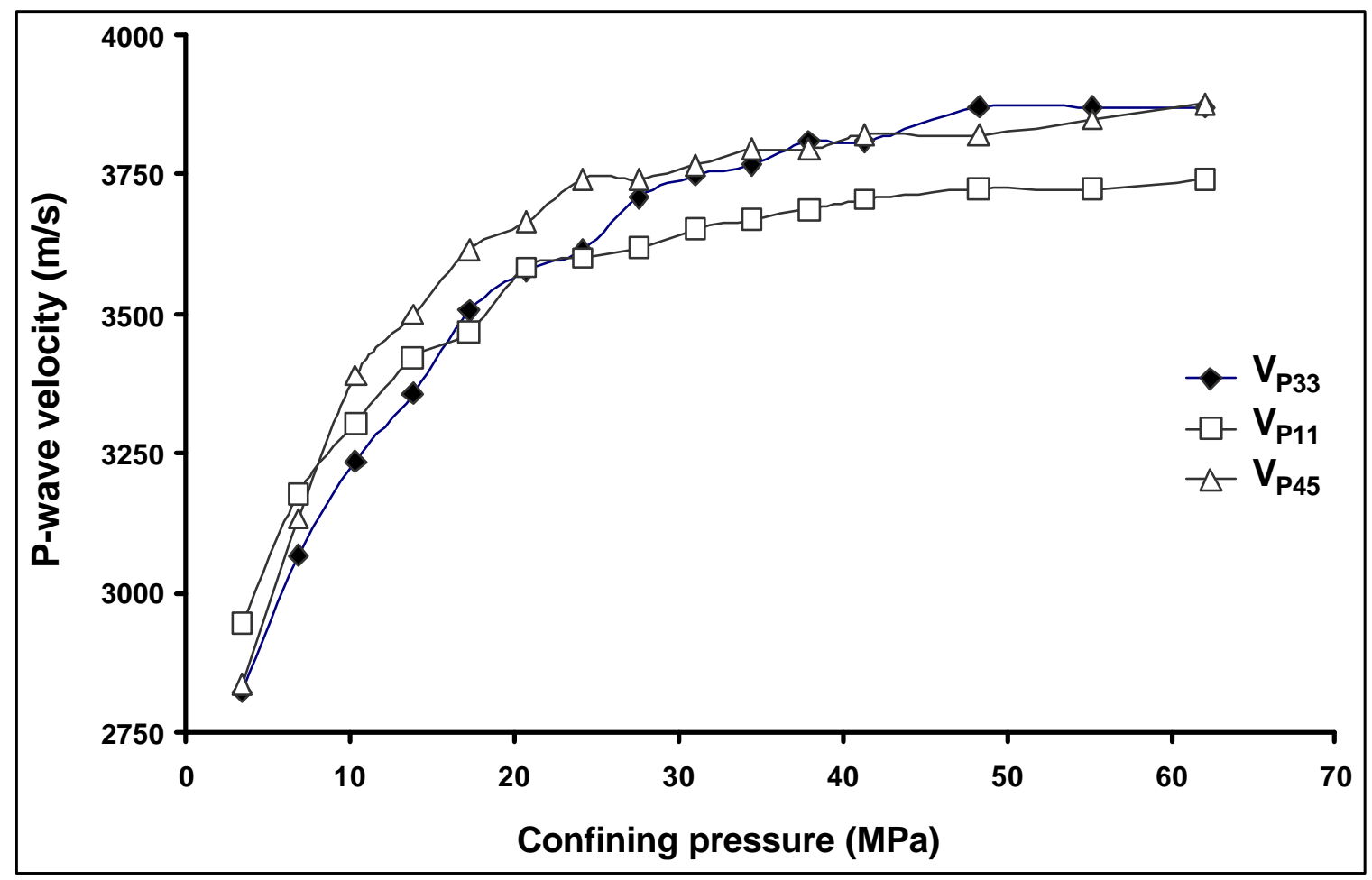

Fig. 52. A plot of the compressional wave velocities during the hydrostatic compression experiment. 


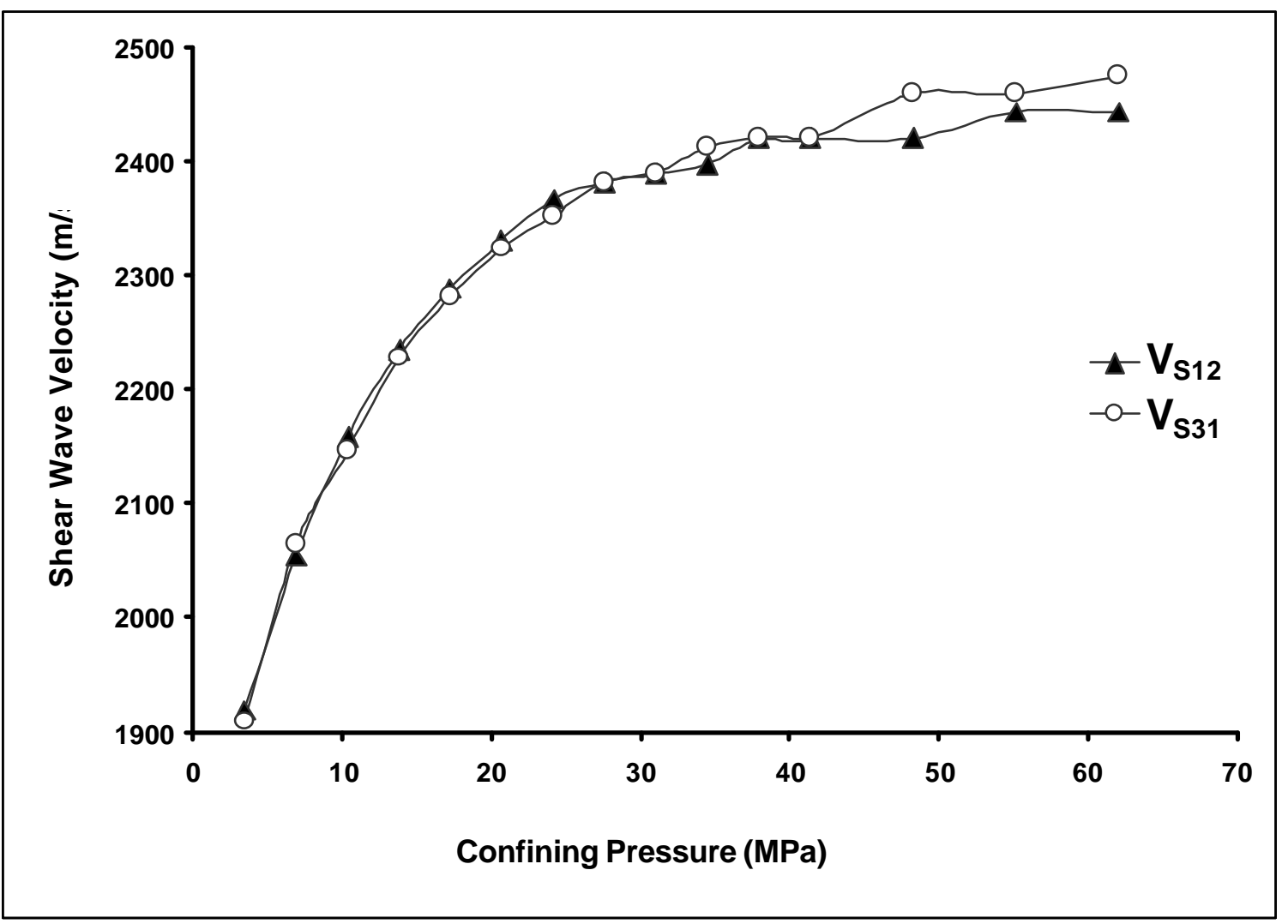

Fig. 53. A plot of the shear wave velocities obtained during the hydrostatic compression experiment. 


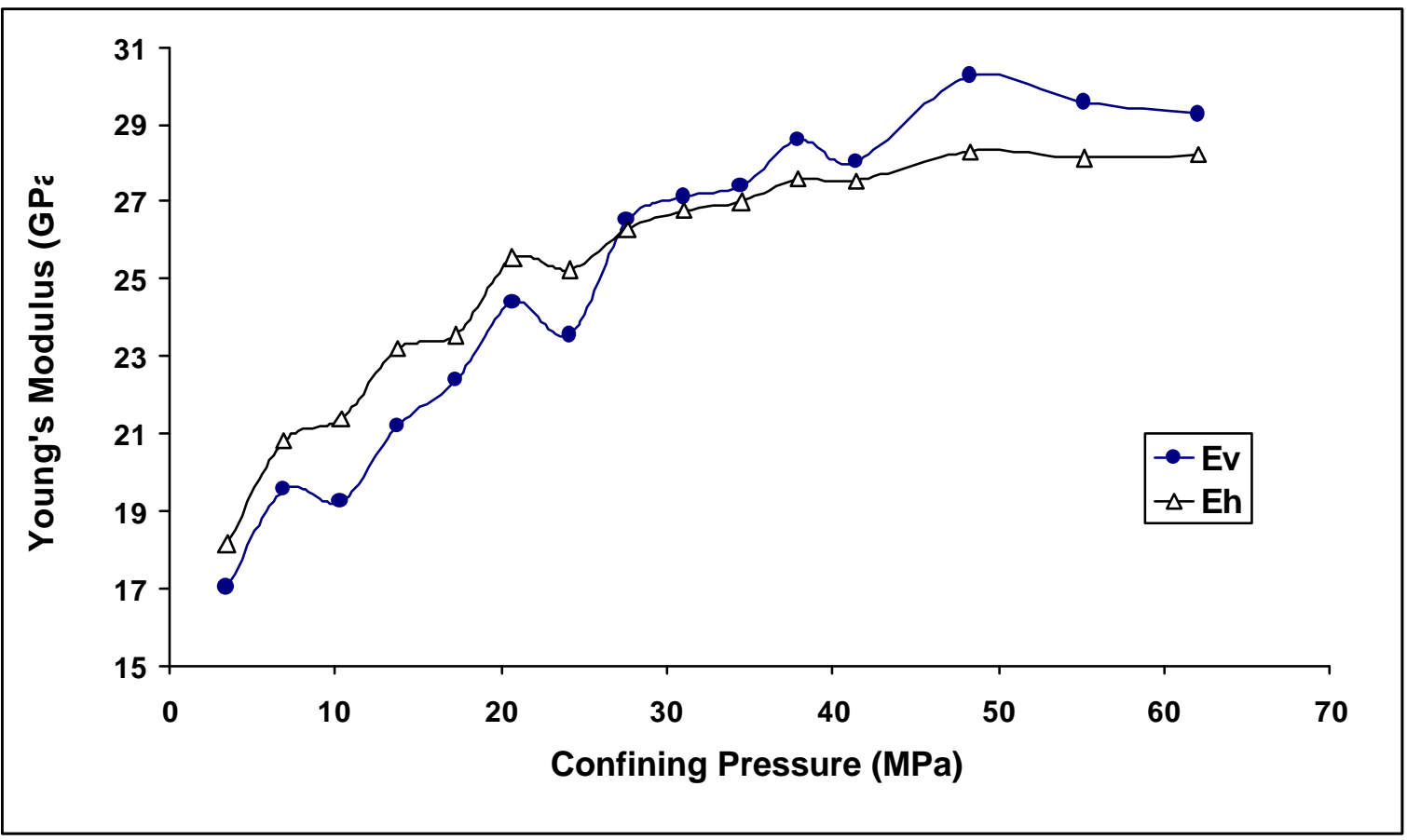

Fig. 54. A plot of the anisotropic Young's moduli obtained during the hydrostatic compression experiment. 


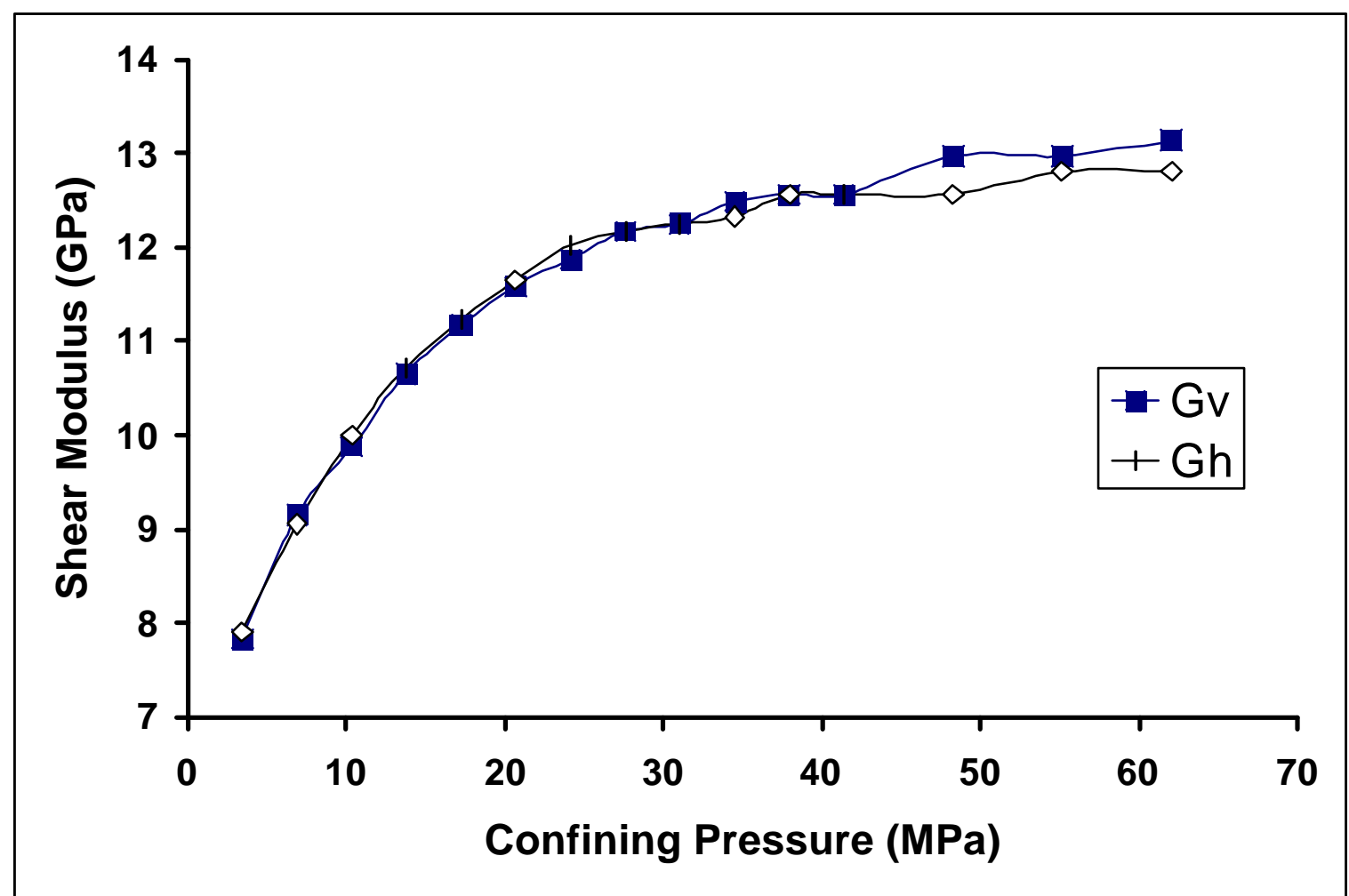

Fig. 55. A plot of the anisotropic shear moduli obtained during the hydrostatic compression experiment. 


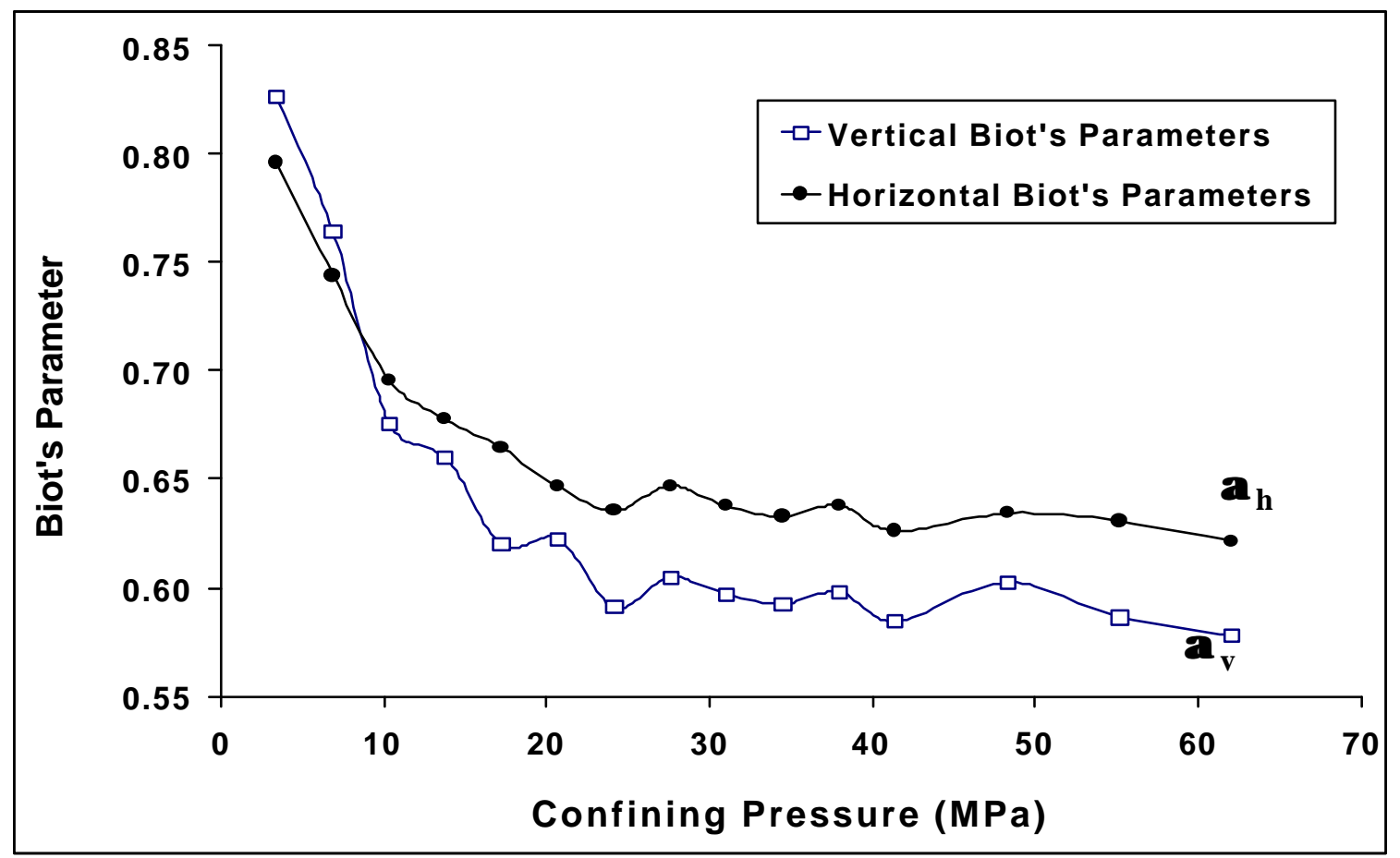

Fig. 56. A plot of the anisotropic Biot's effective stress parameters during the hydrostatic compression experiment. 


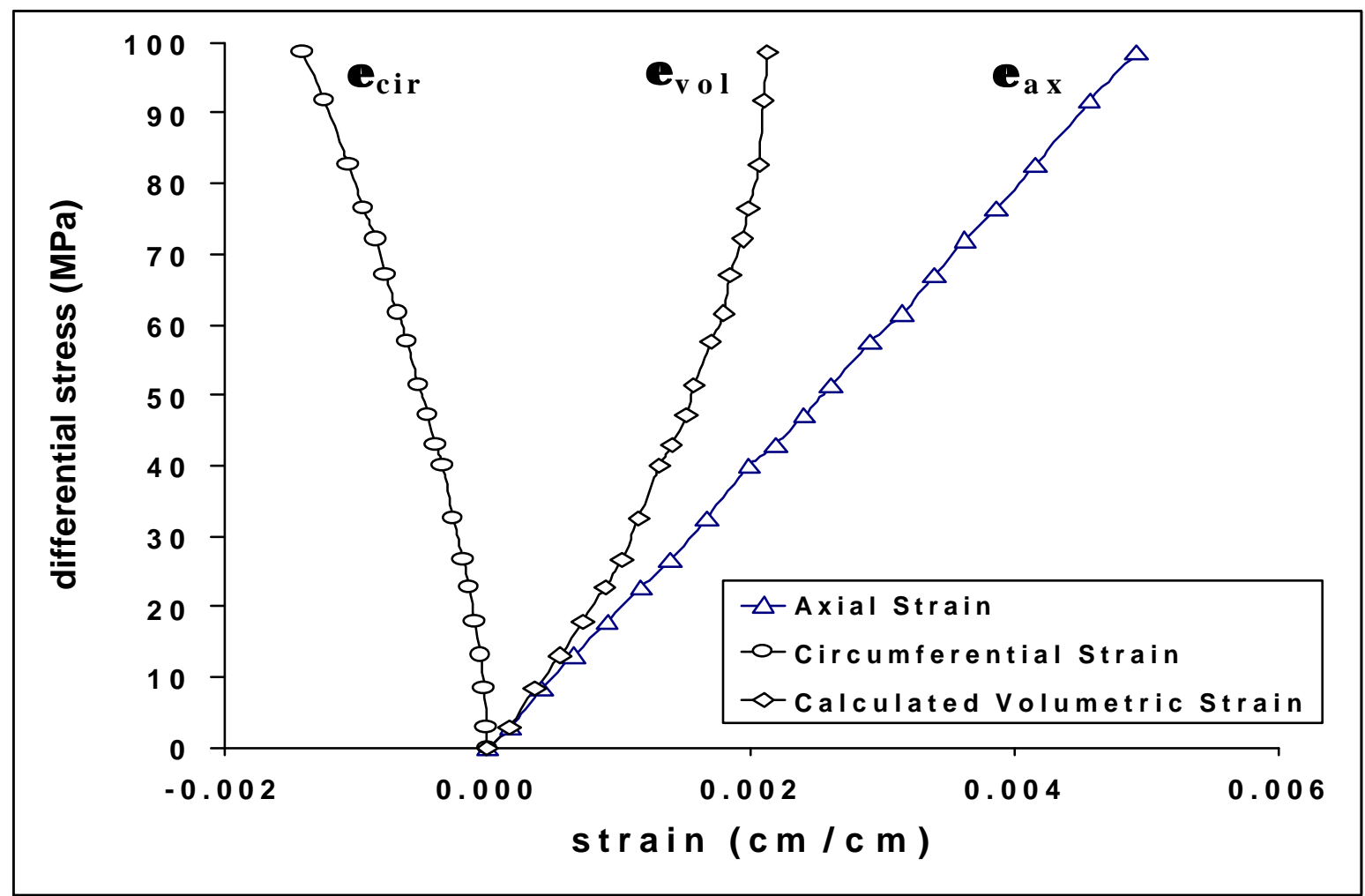

Fig. 57. A plot of differential stress vs. axial and circumferential strains during a triaxial compression experiment. 


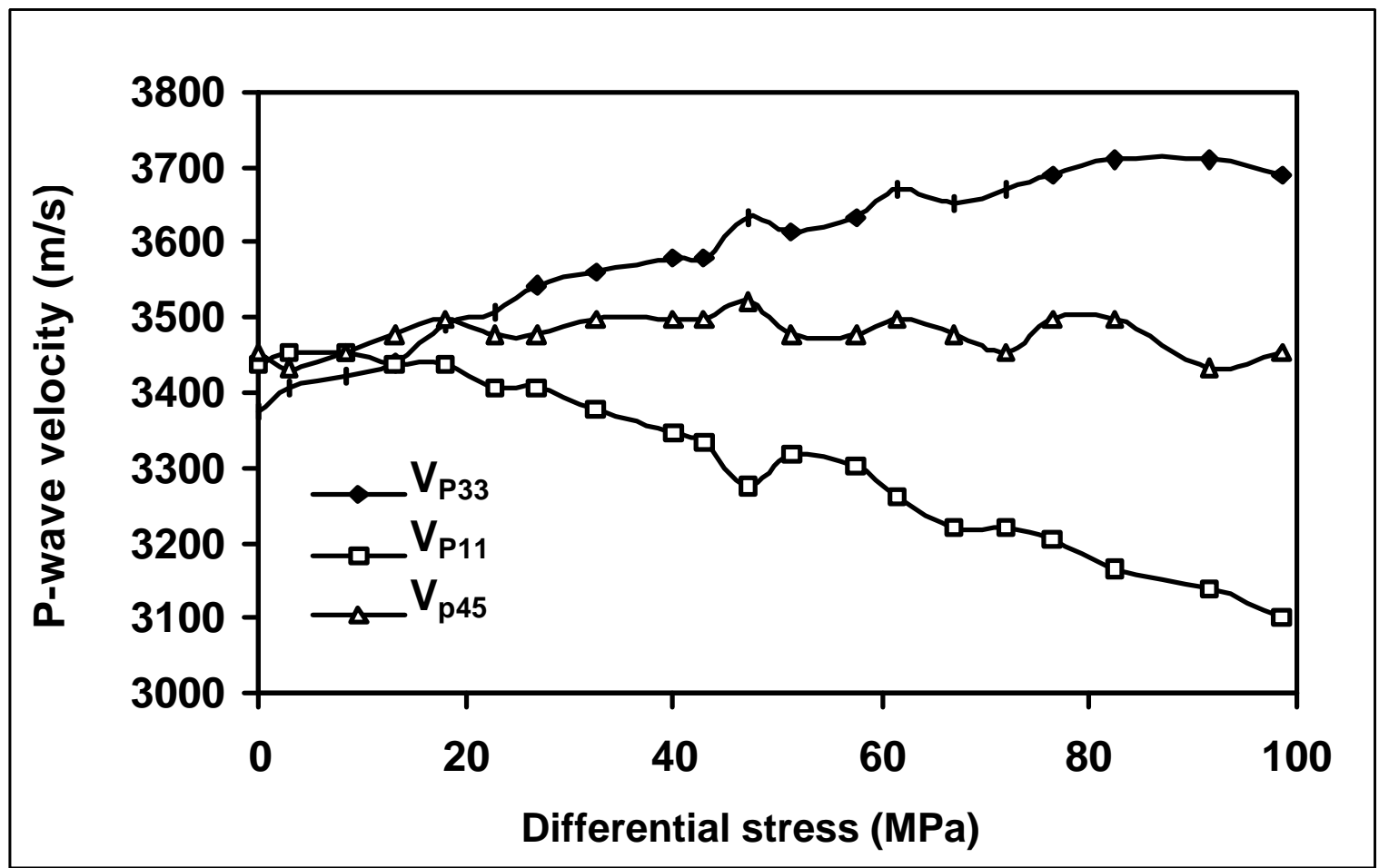

Fig. 58. A plot of the compressional wave velocities during the triaxial compression experiment. 


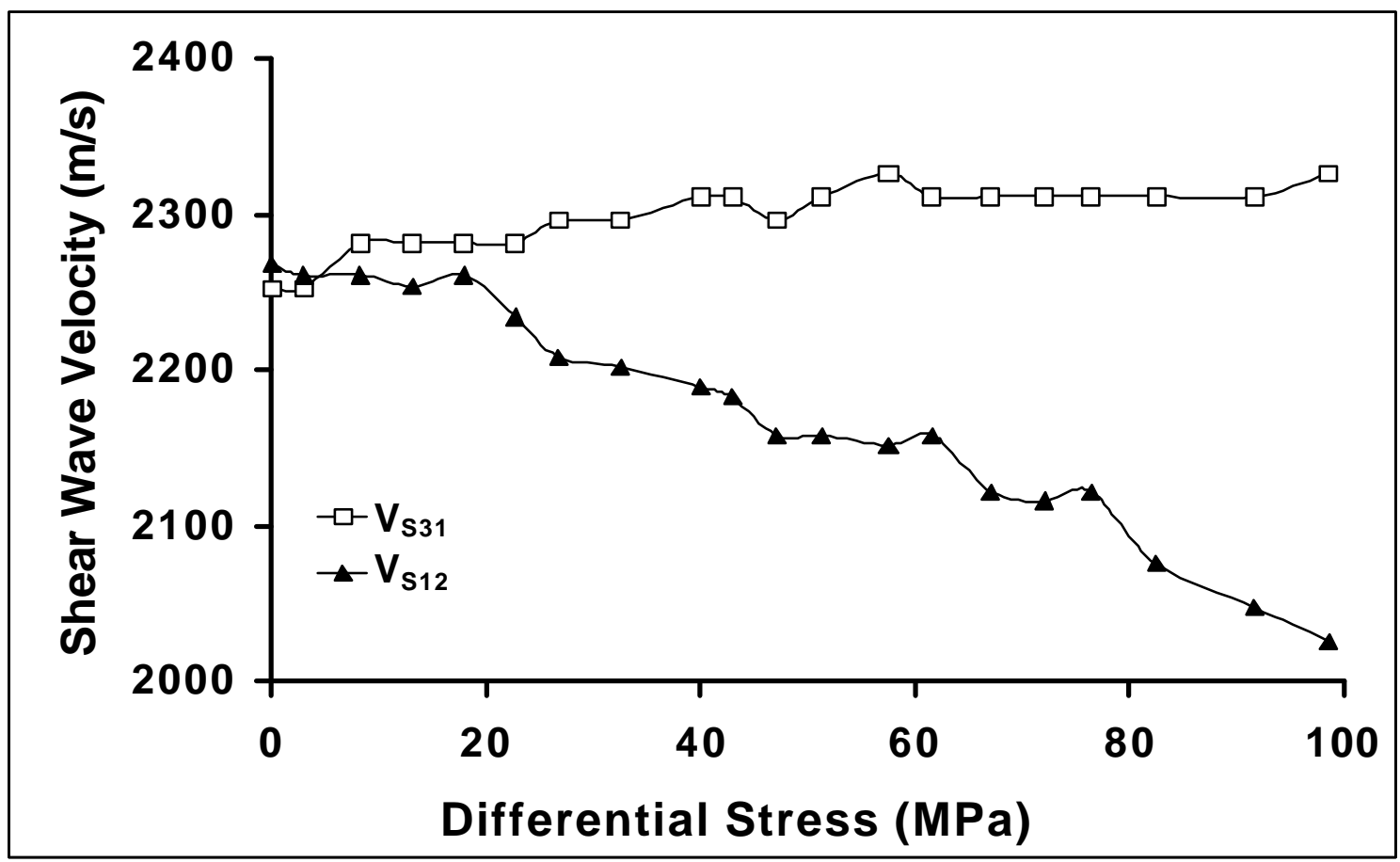

Fig. 59. A plot of the shear wave velocities obtained during the triaxial compression experiment. 


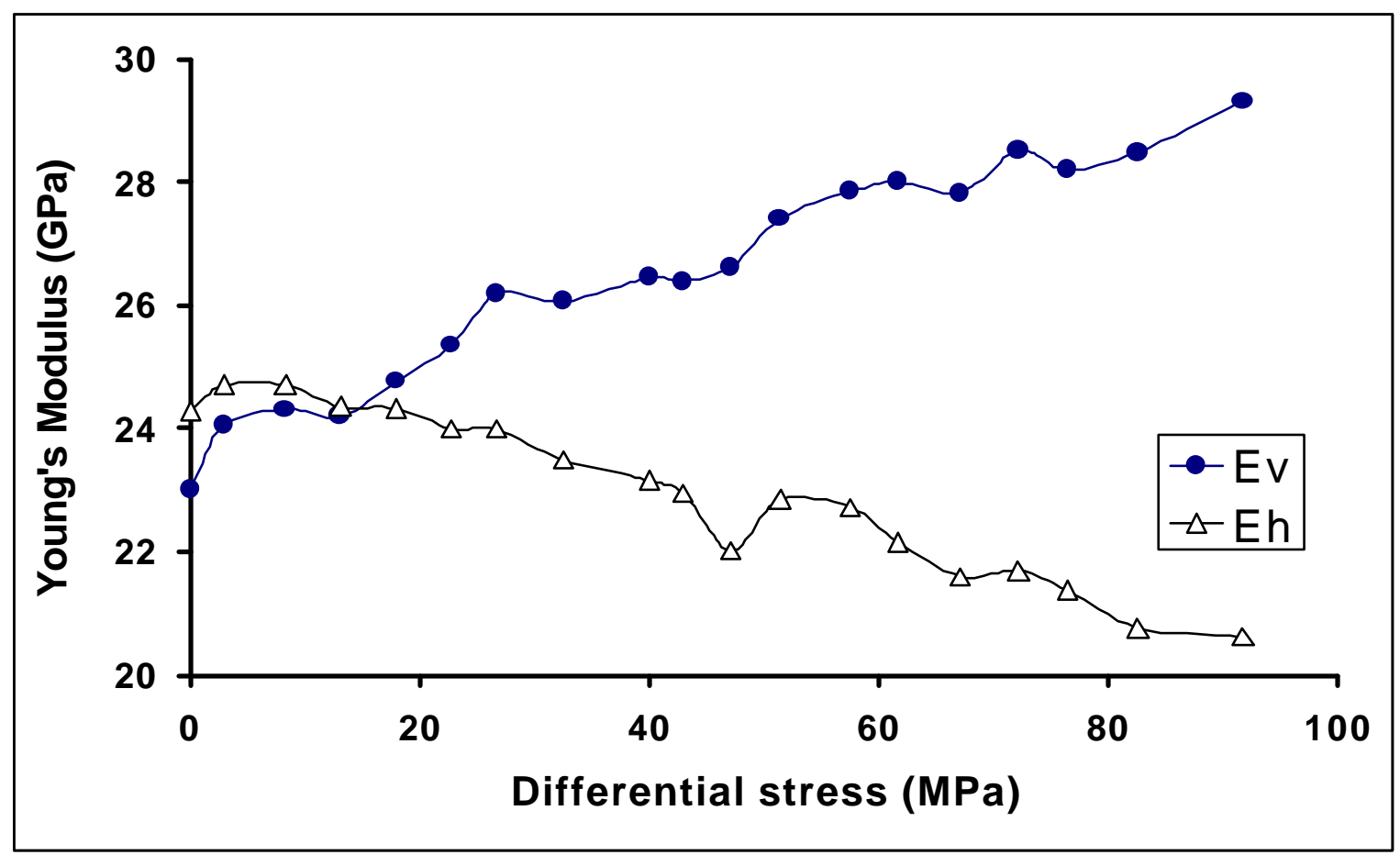

Fig. 60. A plot of the anisotropic Young's moduli obtained during the triaxial compression experiment. 


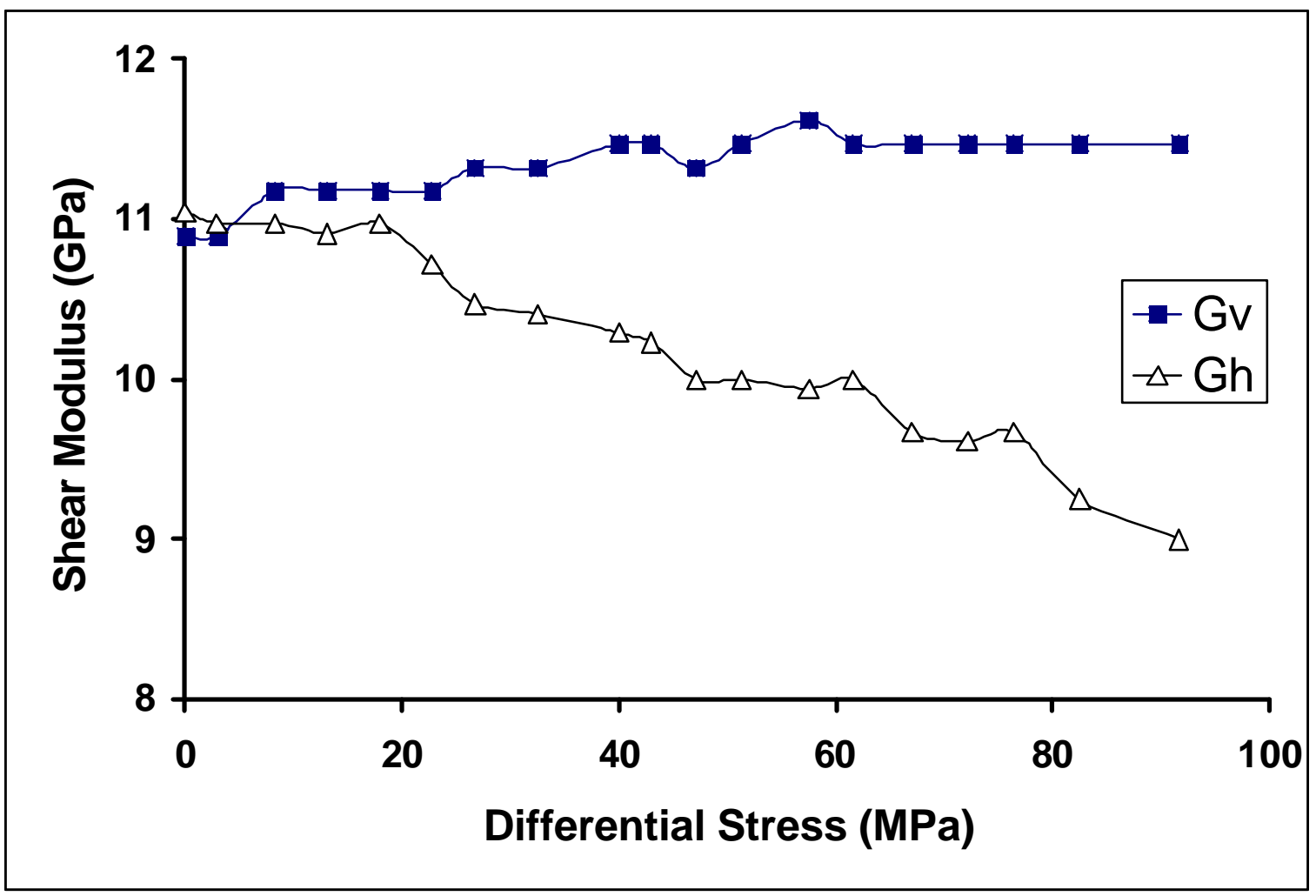

Fig. 61. A plot of the anisotropic shear moduli obtained during the triaxial compression experiment. 


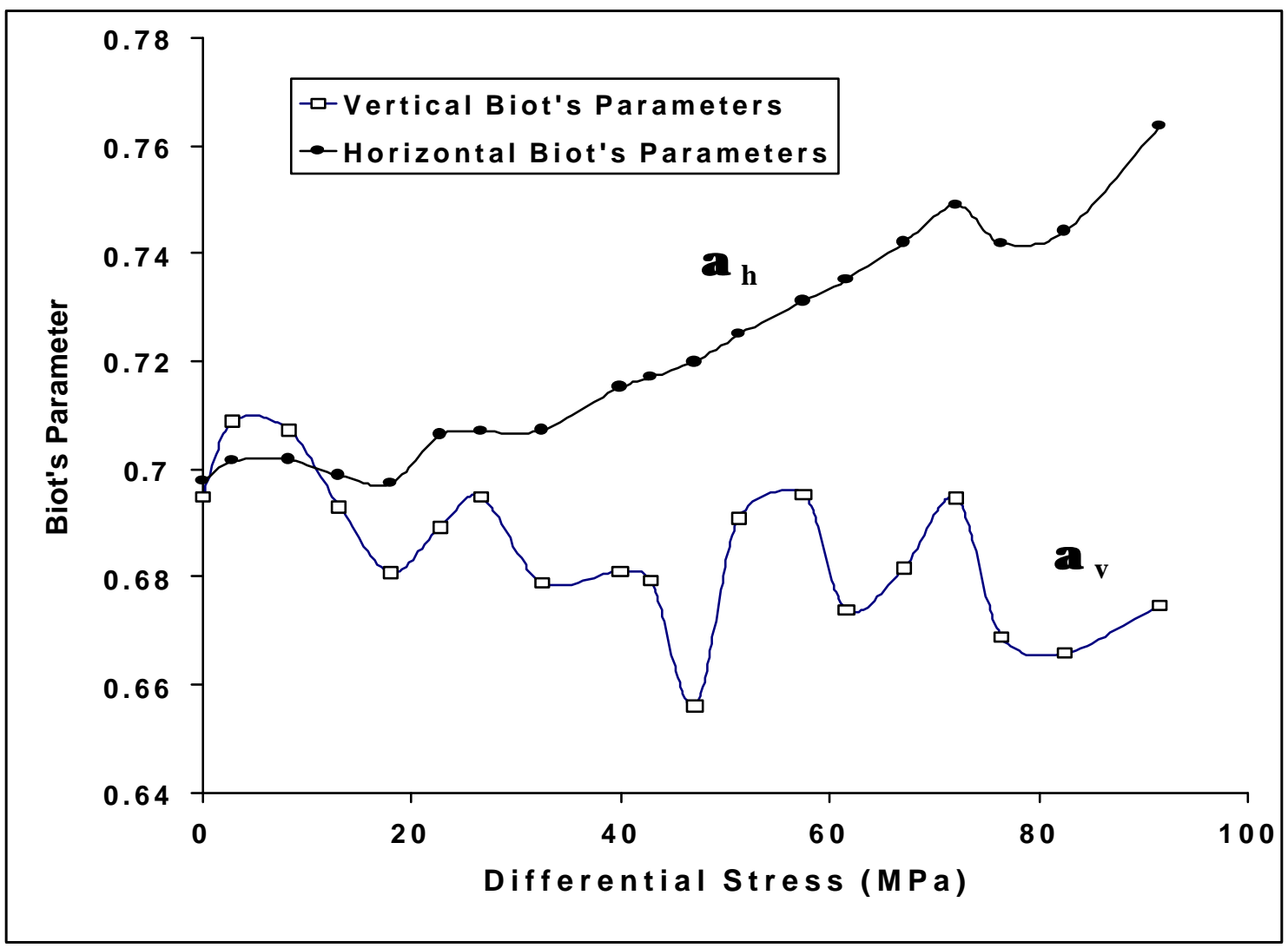

Fig. 62. A plot of the anisotropic Biot's effective stress parameters during the triaxial compression experiment. 


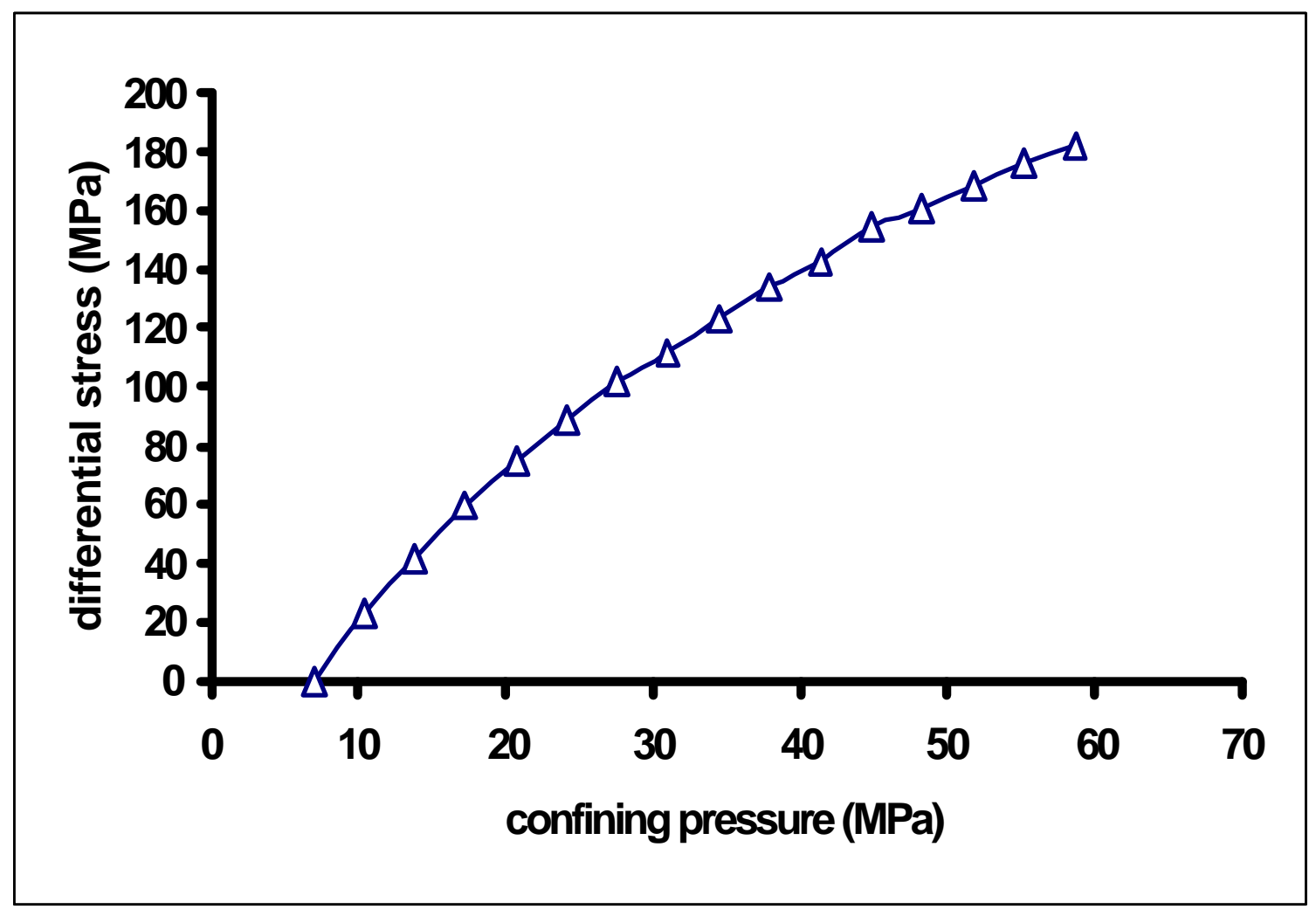

Fig. 63. A plot of the differential stress vs. confining stress during the uniaxial strain experiment. 


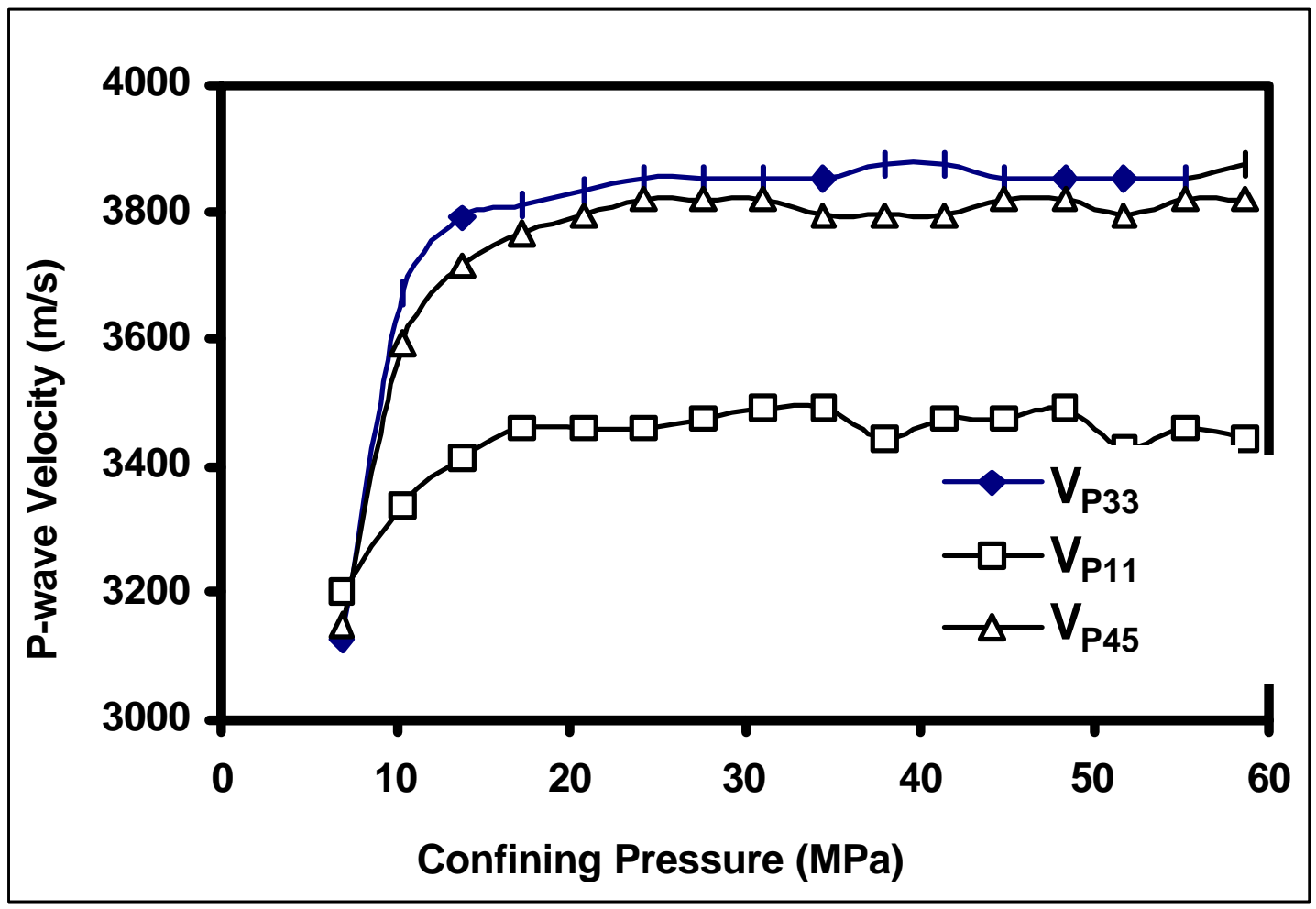

Fig. 64. A plot of the compressional wave velocities obtained during the uniaxial strain experiment. 


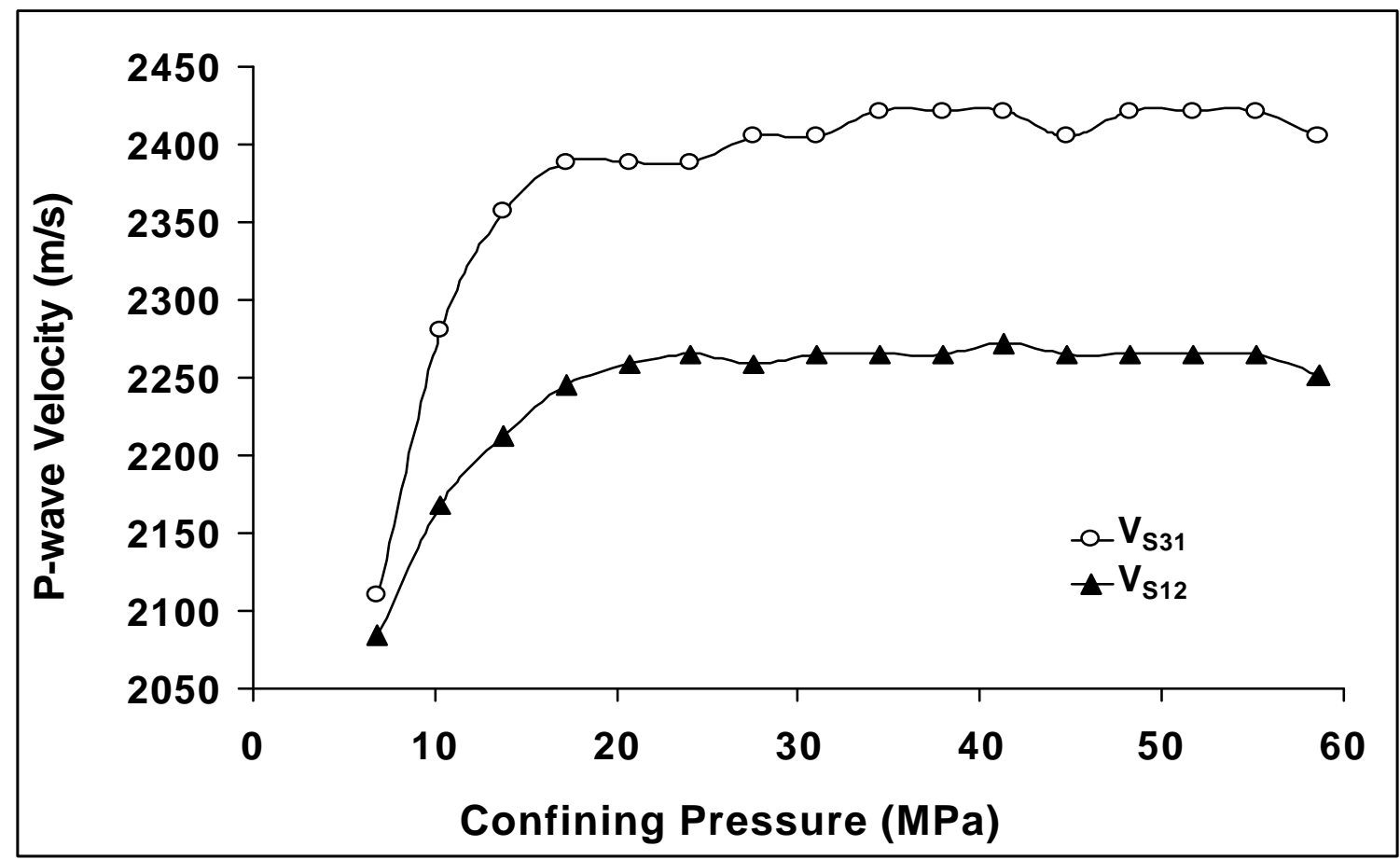

Fig. 65. A plot of the shear wave velocities obtained during the uniaxial strain experiment. 


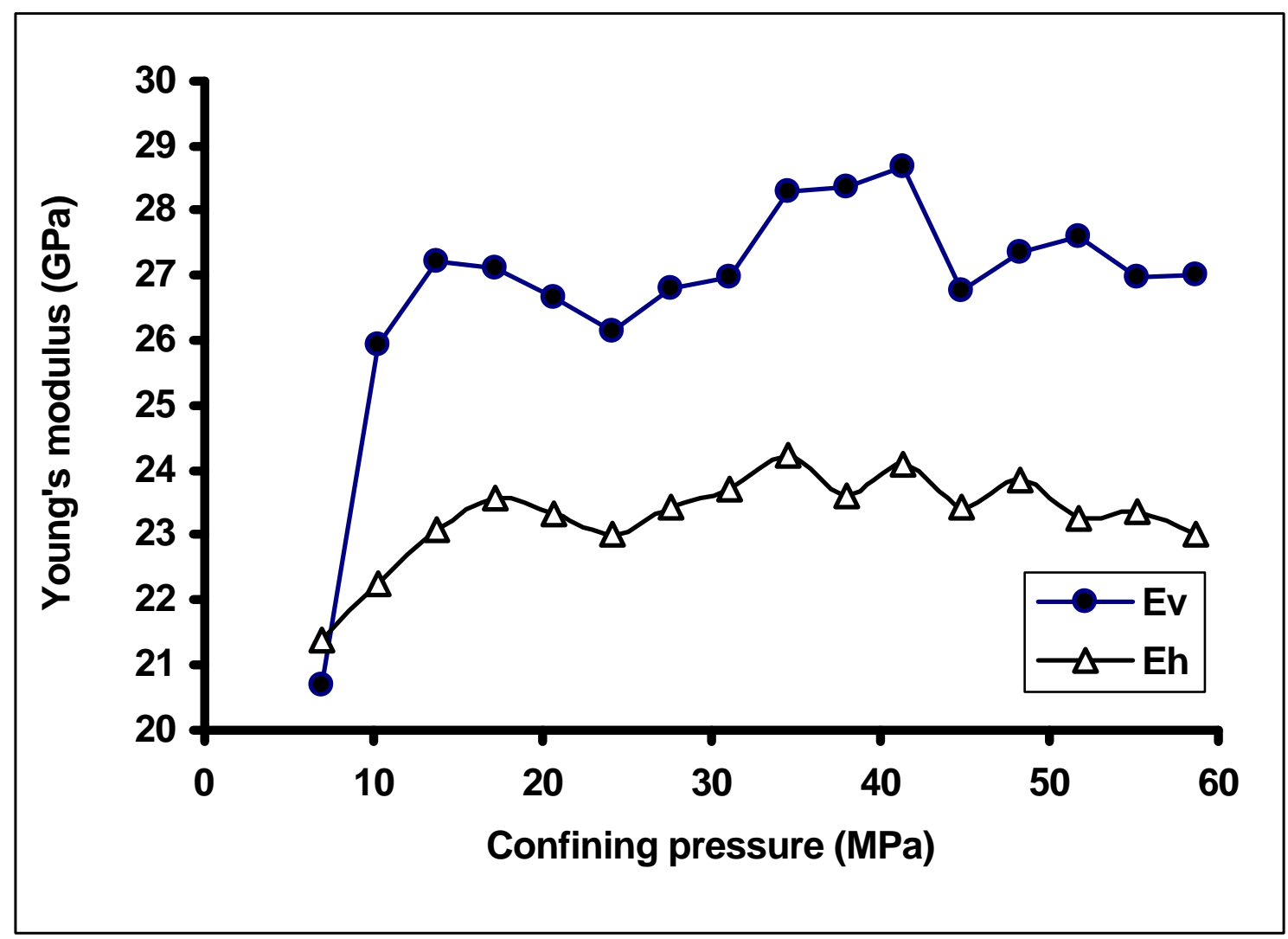

Fig. 66. A plot of the anisotropic Young's moduli obtained during the uniaxial strain experiment. 


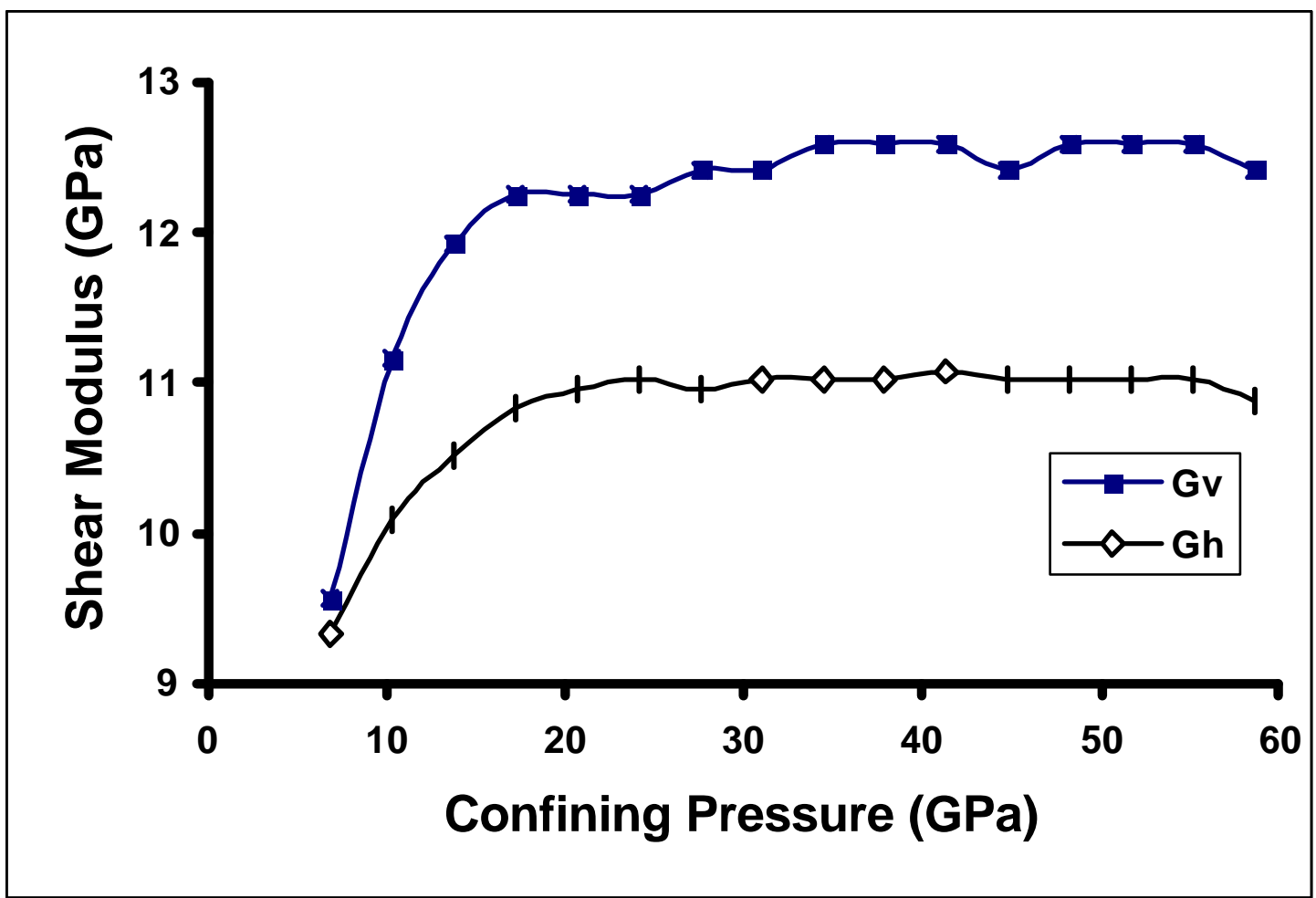

Fig. 67. A plot of the anisotropic shear moduli obtained during the uniaxial strain experiment. 


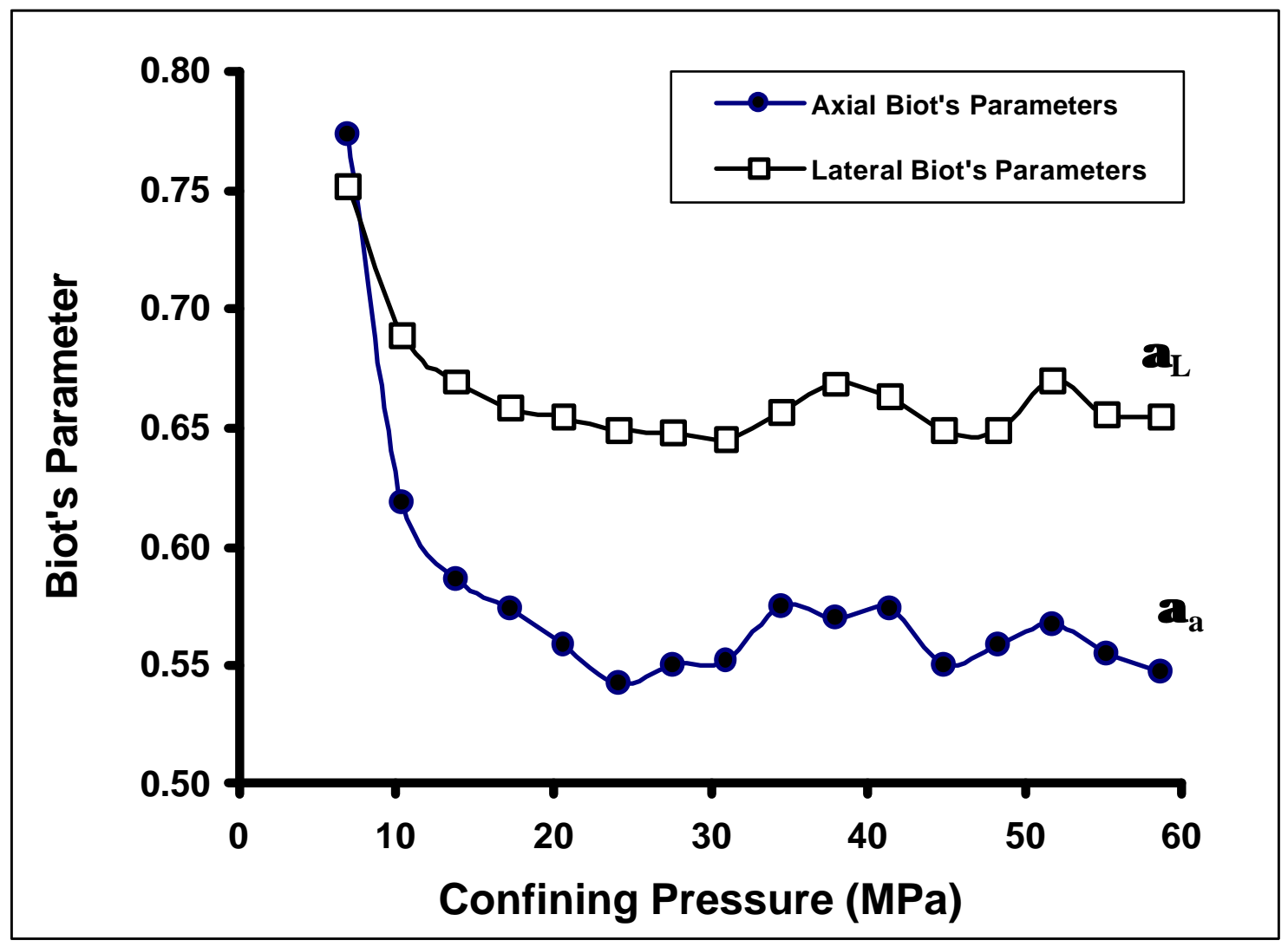

Fig. 68. A plot of the anisotropic Biot's effective stress parameters during the uniaxial strain experiment. 


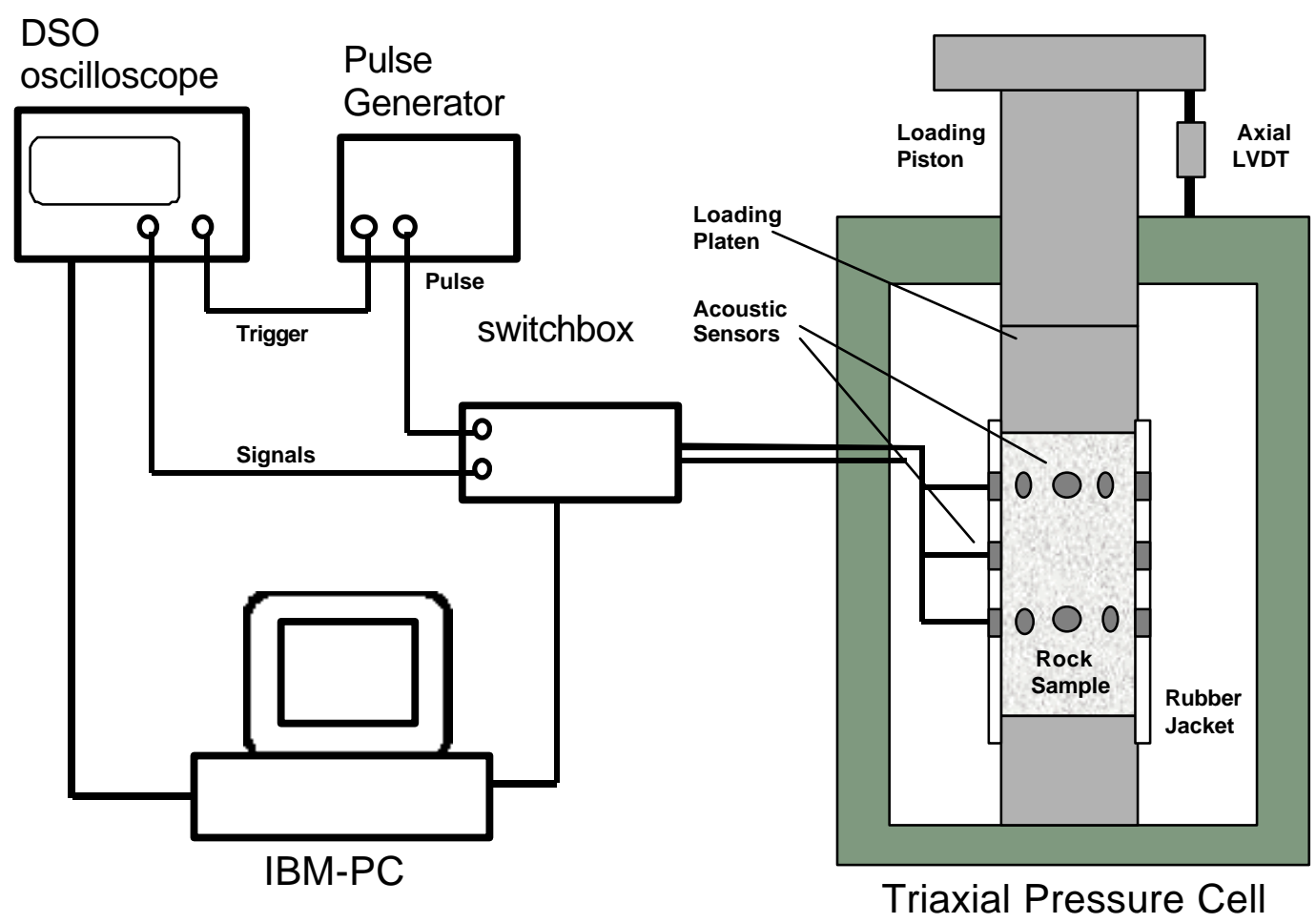

FIG. 69. A schematic of the equipment for the ultrasonic tomography experiment. 


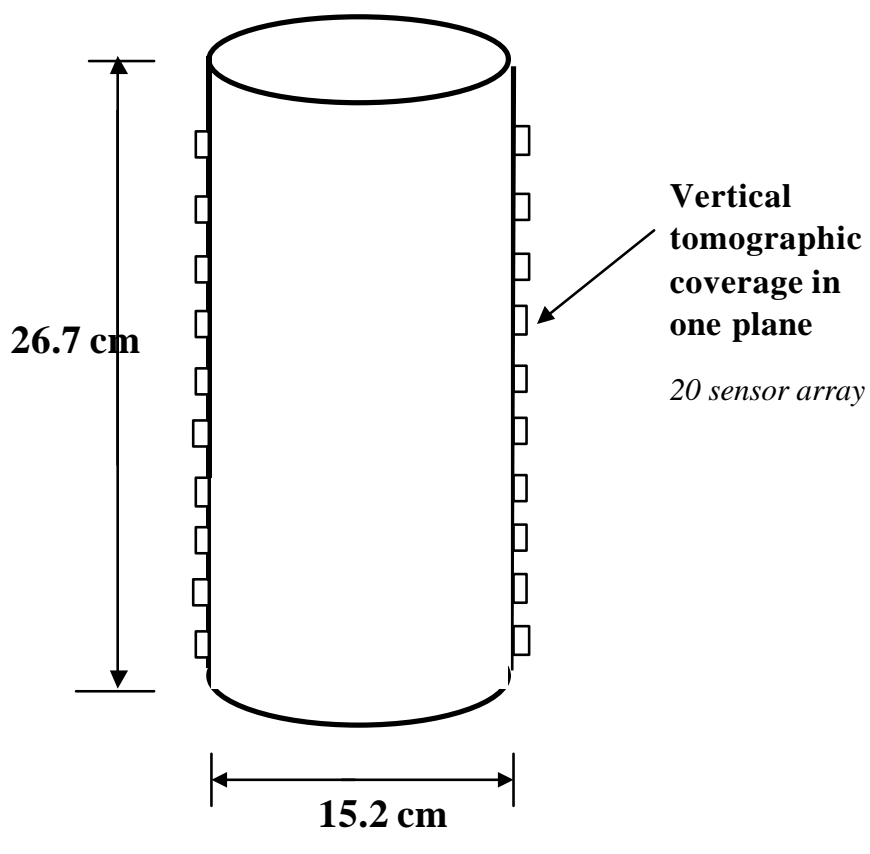

A total of 20
$600 \mathrm{KHz}$ sensors
will be mounted
on the sample.

Fig. 70. A schematic showing the dimensions of the sample and the locations of the acoustic sensors for the vertical tomography. 


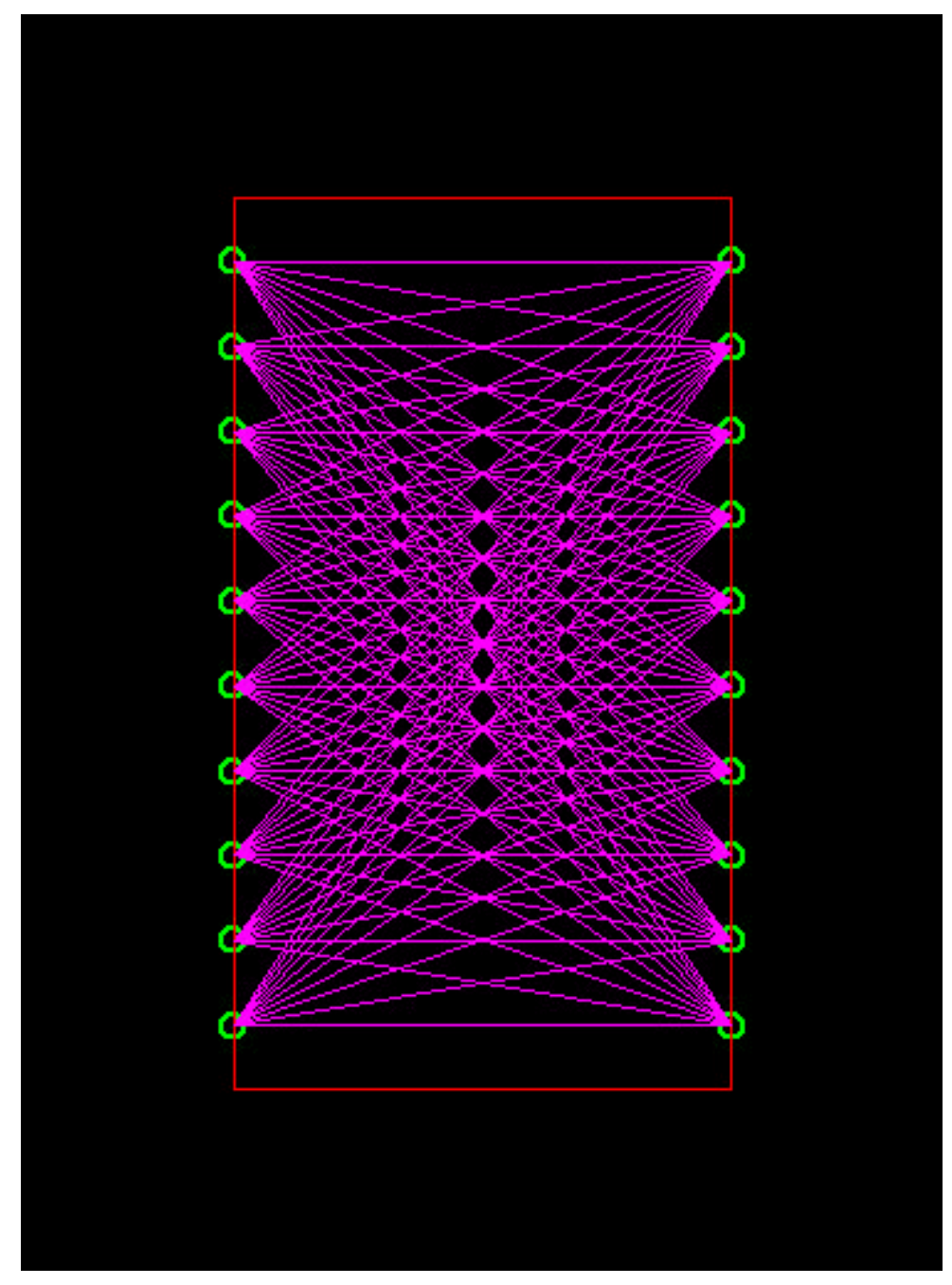

FIG. 71. A cross-sectional view of the acoustic pulse transmission sensors on the rock core sample set up for vertical tomography. 


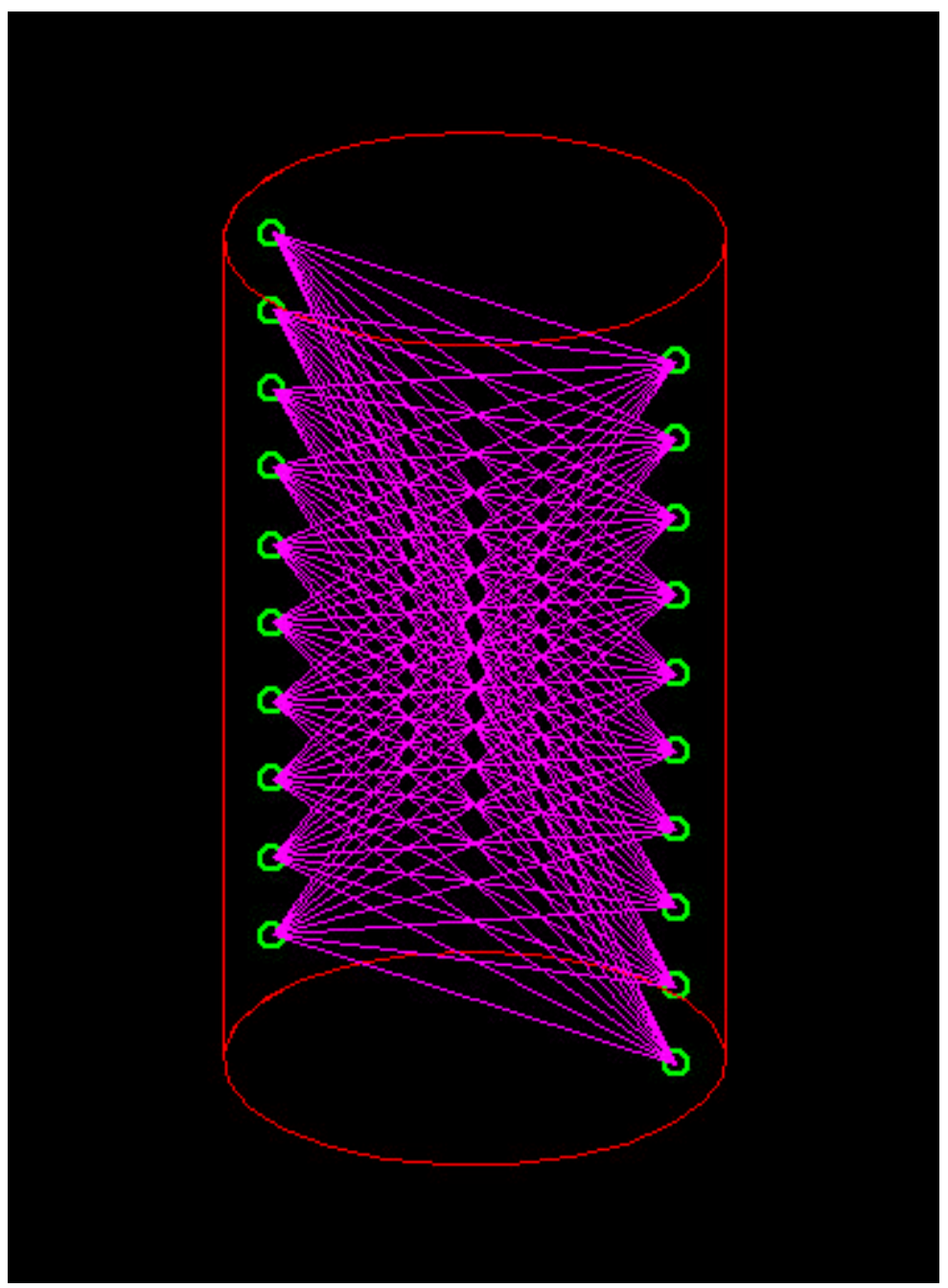

Fig. 72. A 3-dimensional view of the configuration of acoustic raypaths in a sample setup for vertical tomography 


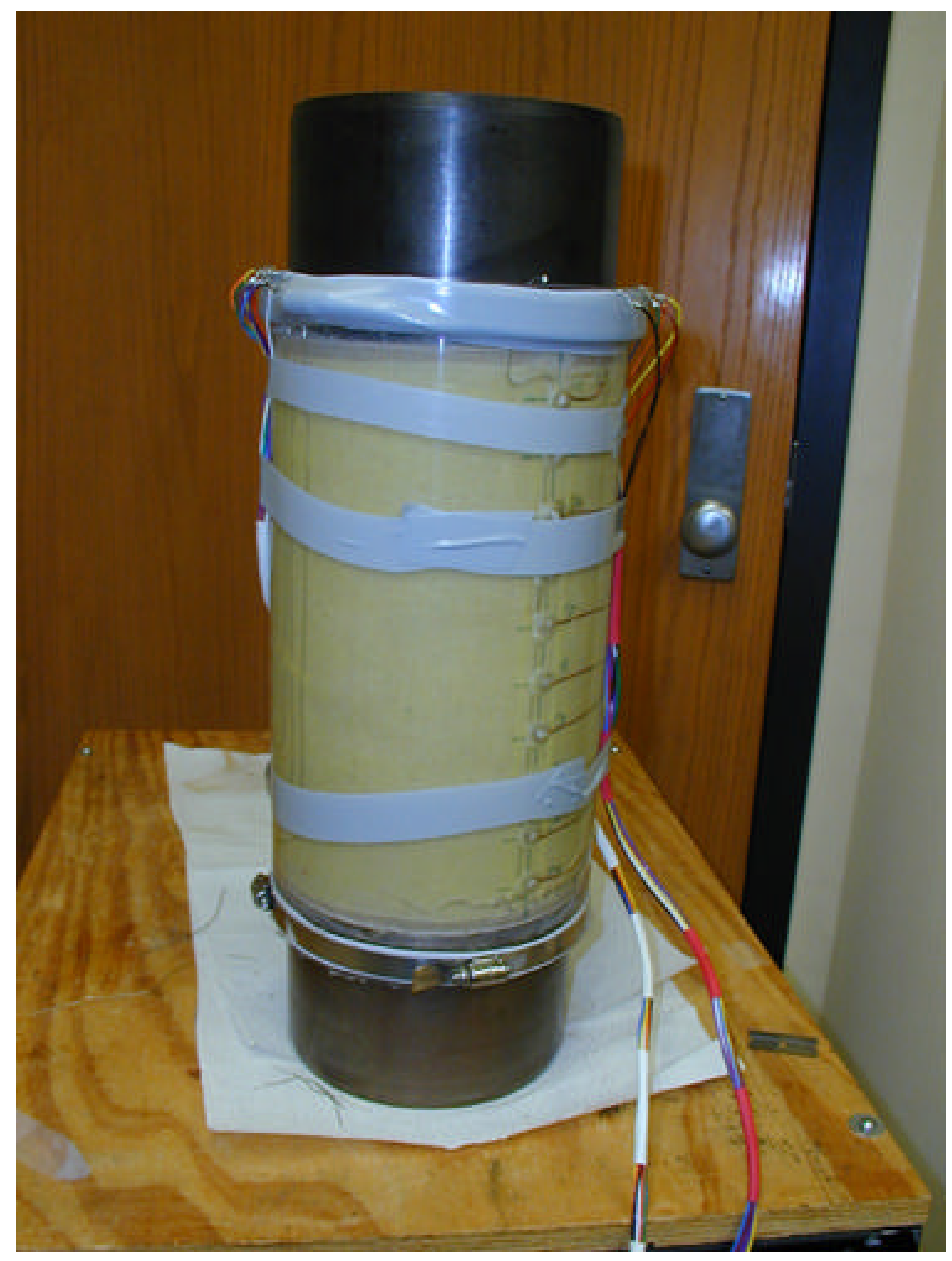

FIG. 73. A photograph of the jacket/sample assembly for vertical tomography. 


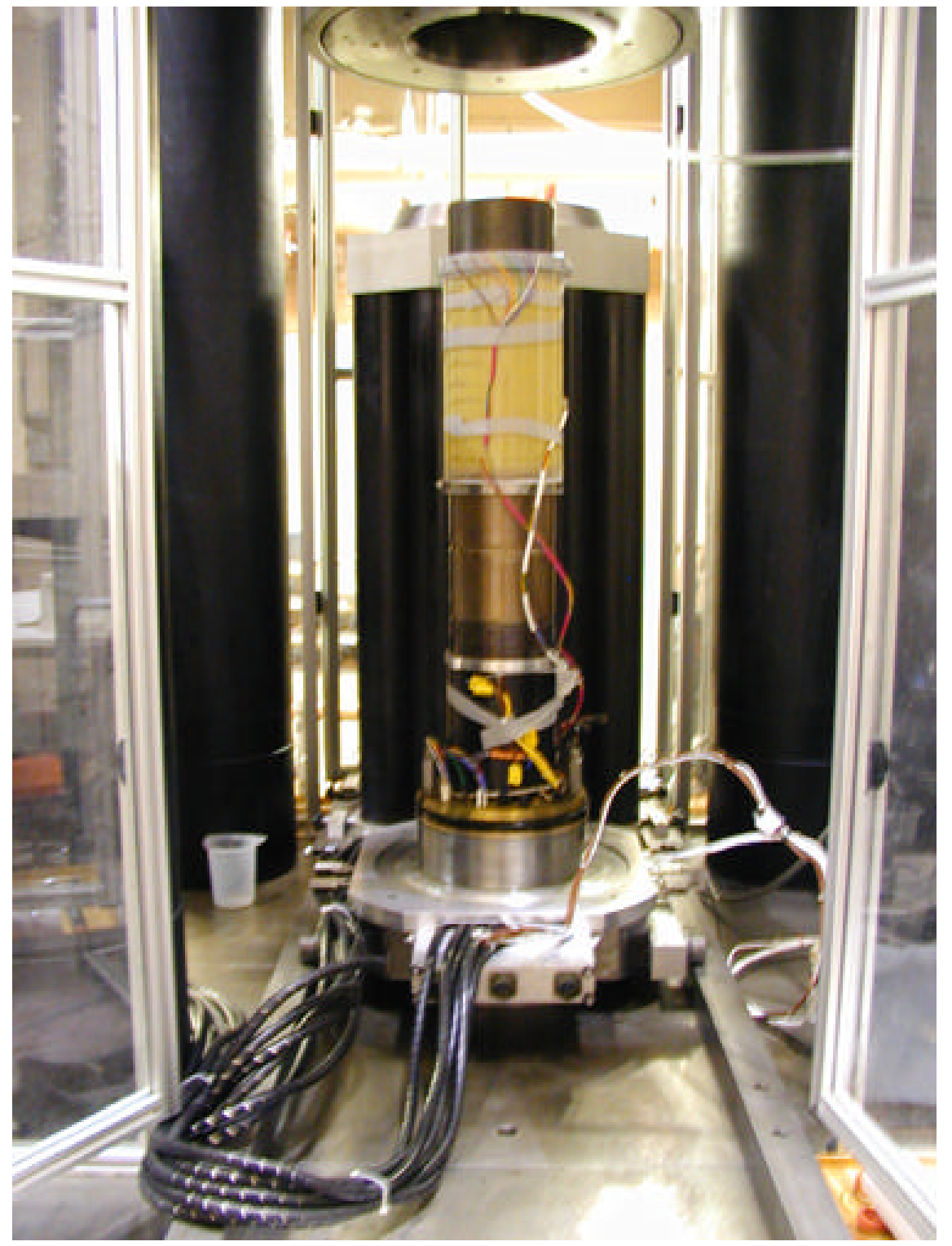

FIG. 74. A photograph of the sample in the Keck load frame before insertion into the pressure cell 


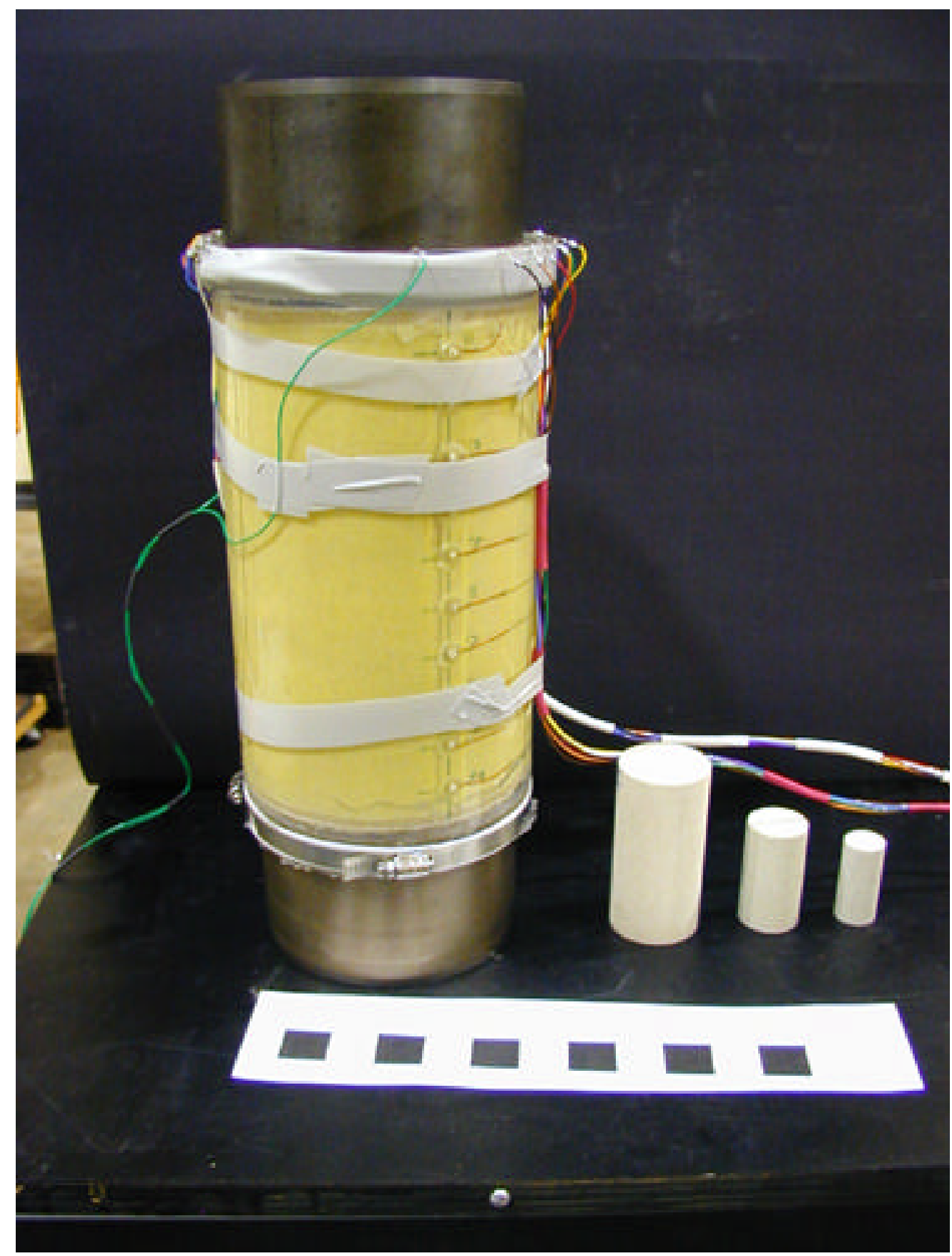

FIG. 75. A photograph illustrating the scale of the large size of the tomographic imaging samples (6 inch diameter) compared to smaller NX, 1.5 inch, and 1 inch diameter samples. 


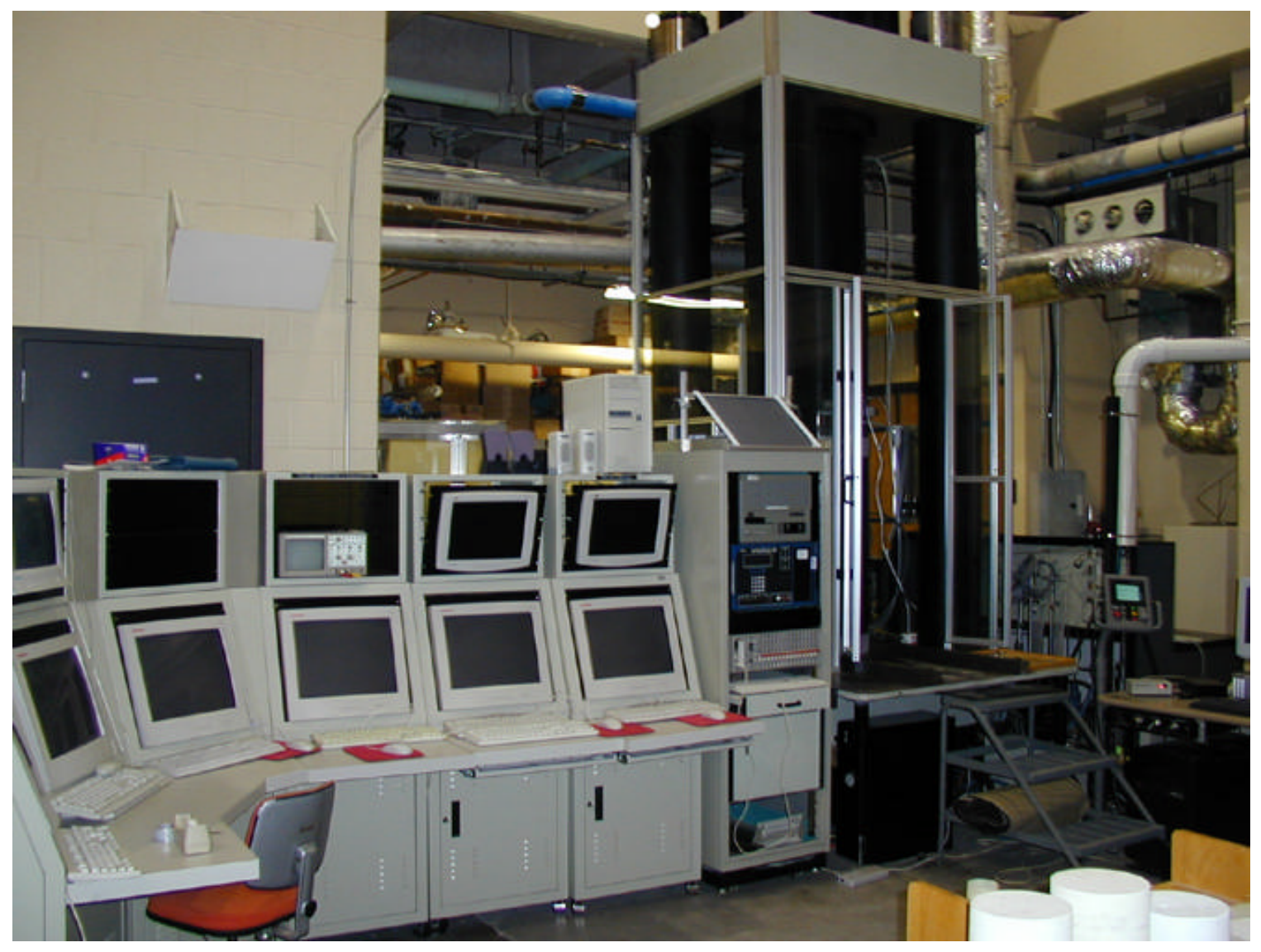

FIG. 76. A photograph of Keck Acoustic Imaging System during testing. 


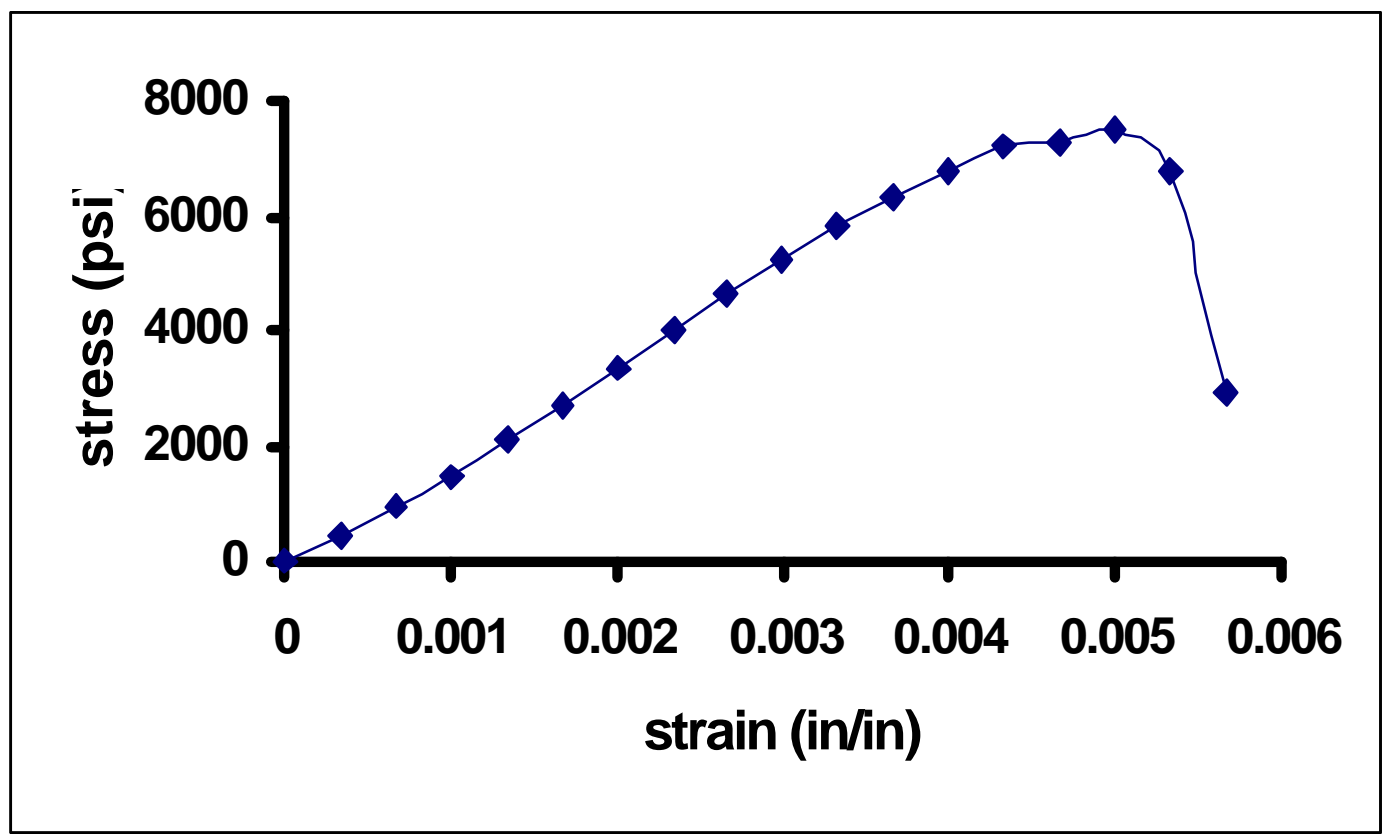

FIG. 77. The stress-strain curve for Indiana Limestone at 500 psi confining pressure. 


$3,900 \mathrm{~m} / \mathrm{s}$
3,908
3,915
3,923
3,931
3,939
3,946
3,954
3,962
3,970
3,977
3,985
3,993
4,001
4,008
4,016
4,024
4,031
4,039
4,047
4,055
4,065

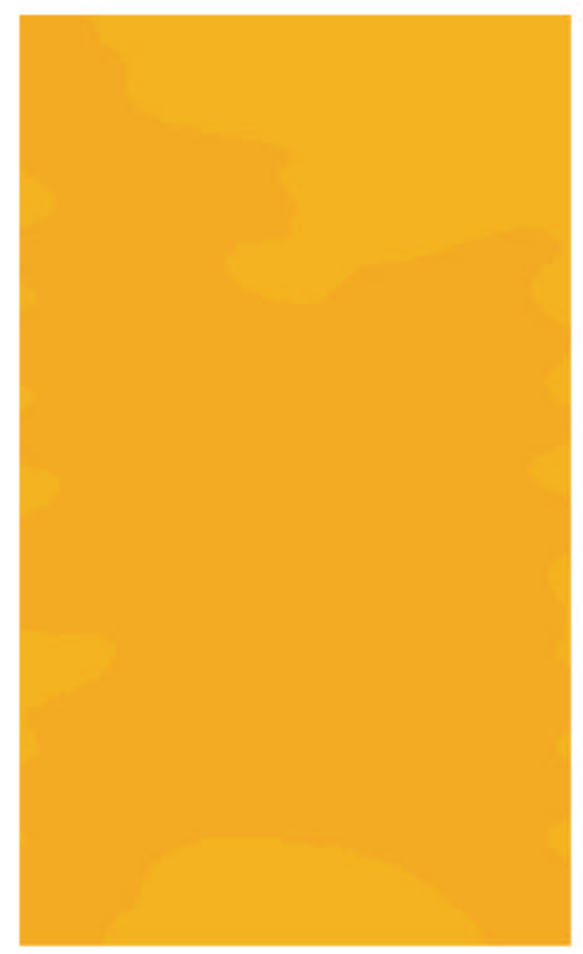

\section{Initial tomogram at $\mathbf{5 0 0} \mathbf{p s i}$ confining pressure}

FIG. 78. The tomogram for Indiana limestone at 500 psi confining pressure with no differential stress applied. 


$3,900 \mathrm{~m} / \mathrm{s}$
3,908
3,915
3,923
3,931
3,939
3,946
3,954
3,962
3,970
3,977
3,985
3,993
4,001
4,008
4,016
4,024
4,031
4,039
4,047
4,055
4,065

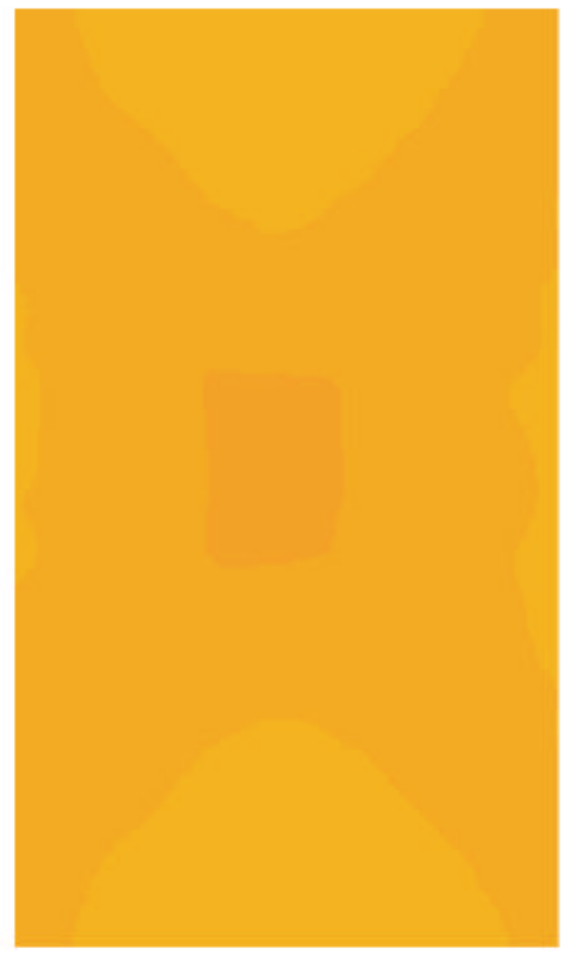

500 psi confining pressure and a differential stress of $937 \mathrm{psi}$

FIG. 79. The tomogram for Indiana limestone at $500 \mathrm{psi}$ confining pressure and a differential stress of $937 \mathrm{psi}$. 


$3,900 \mathrm{~m} / \mathrm{s}$
3,908
3,915
3,923
3,931
3,939
3,946
3,954
3,962
3,970
3,977
3,985
3,993
4,001
4,008
4,016
4,024
4,031
4,039
4,047
4,055
4,065

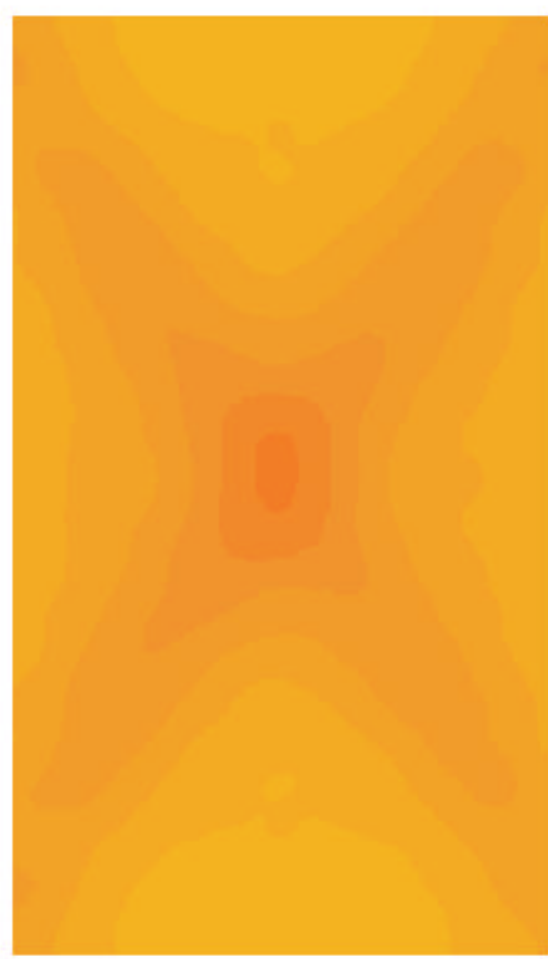

$500 \mathrm{psi}$ confining pressure and a differential stress of 2727 psi

FIG. 80. The tomogram for Indiana limestone at 500 psi confining pressure and a differential stress of 2727 psi. 


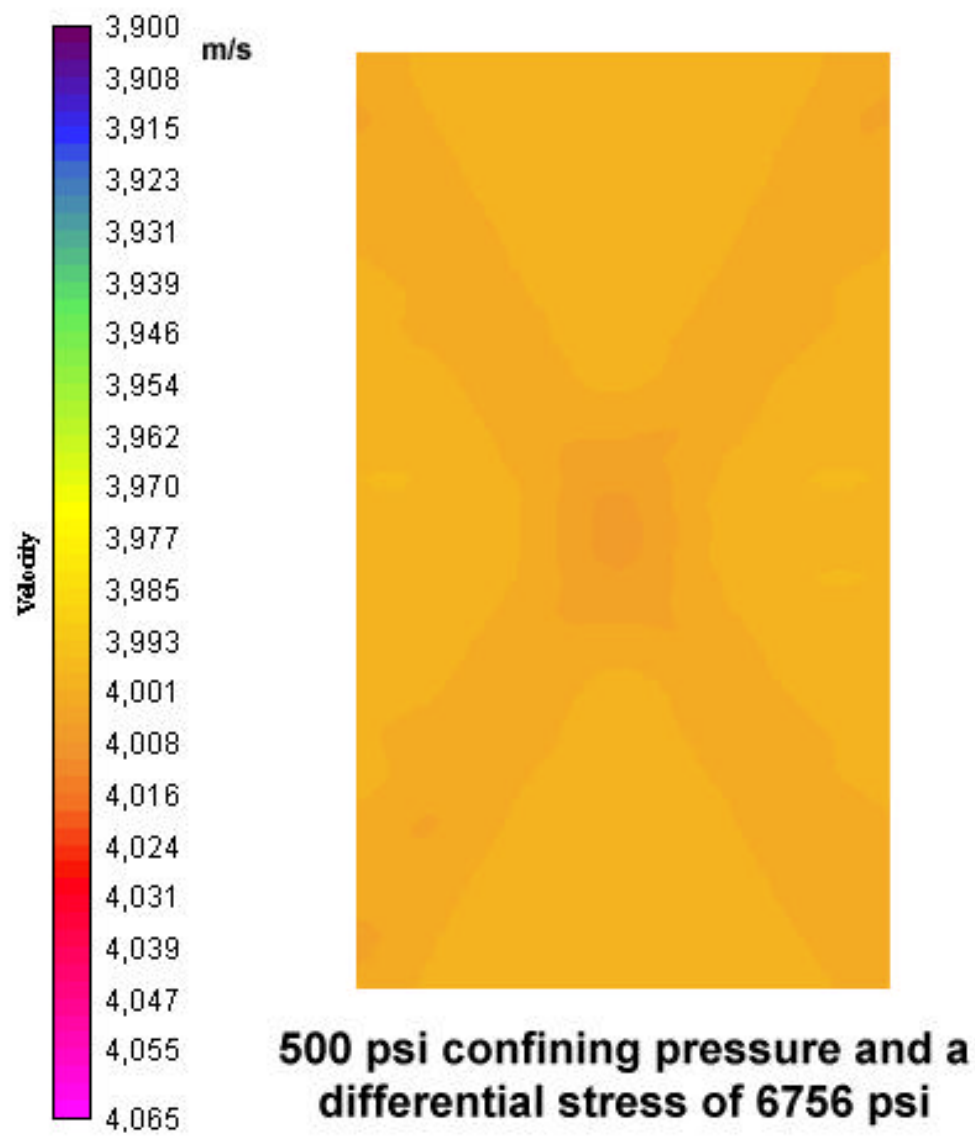

FIG. 81. The tomogram for Indiana limestone at $500 \mathrm{psi}$ confining pressure and a differential stress of 6756 psi. 


$3,900 \mathrm{~m} / \mathrm{s}$
3,908
3,915
3,923
3,931
3,939
3,946
3,954
3,962
3,970
3,977
3,985
3,993
4,001
4,008
4,016
4,024
4,031
4,039
4,047
4,055
4,065

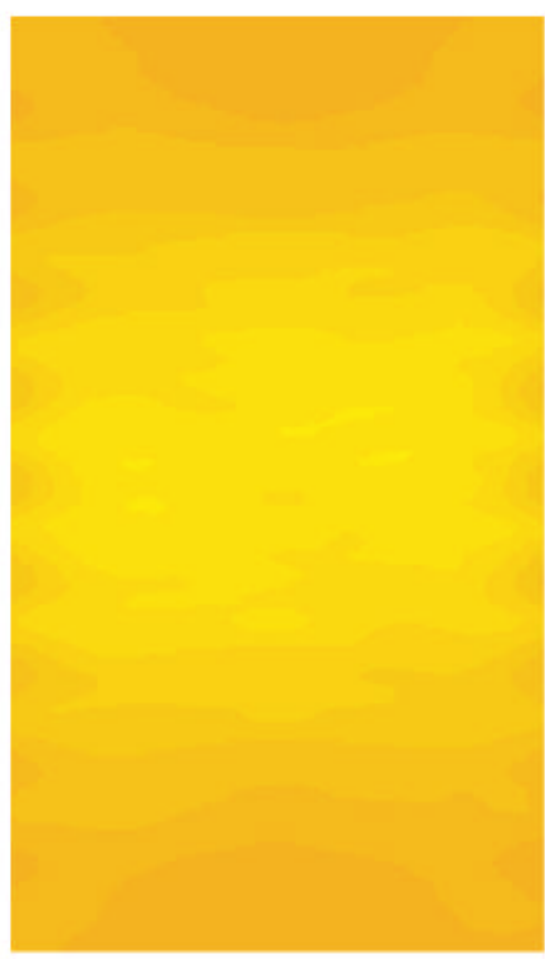

500 psi confining pressure and a differential stress of 7287 psi

FIG. 82. The tomogram for Indiana limestone at 500 psi confining pressure and a differential stress of 7287 psi. 


$\int_{3,900}^{3,900} \mathrm{~m} / \mathrm{s}$

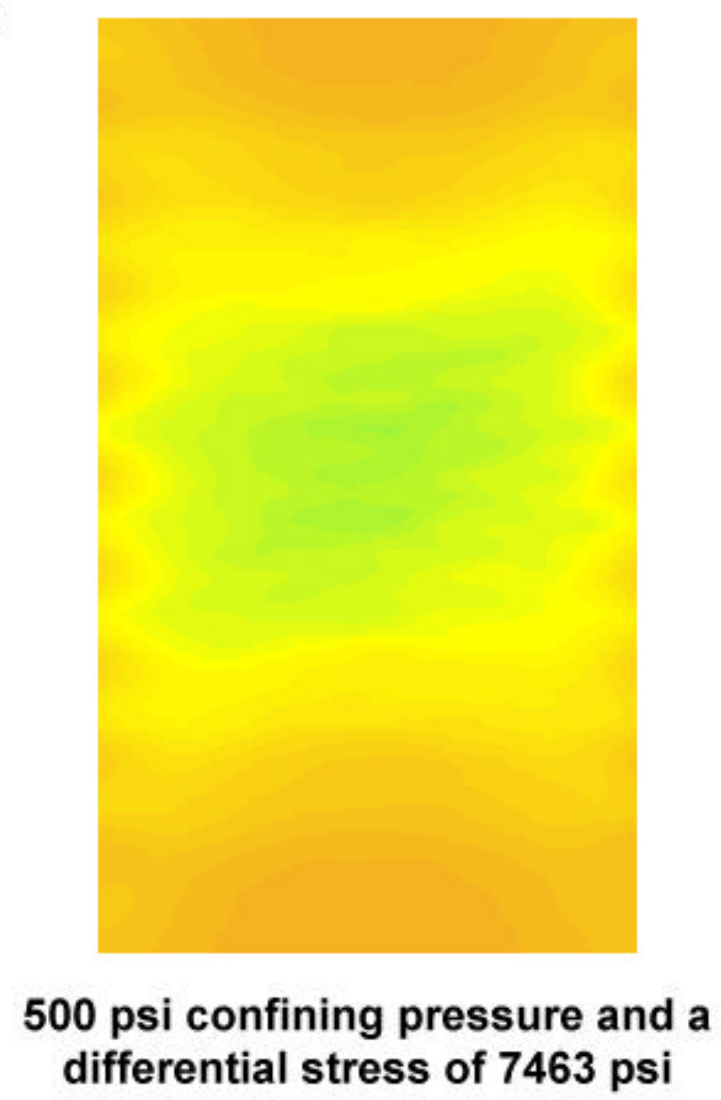

FIG.83. The tomogram for Indiana limestone at 500 psi confining pressure and a differential stress of 7463 psi. 


$3,900 \mathrm{~m} / \mathrm{s}$
3,908
3,915
3,923
3,931
3,939
3,946
3,954
3,962
3,970
3,977
3,985
3,993
4,001
4,008
4,016
4,024
4,031
4,039
4,047
4,055
4,065

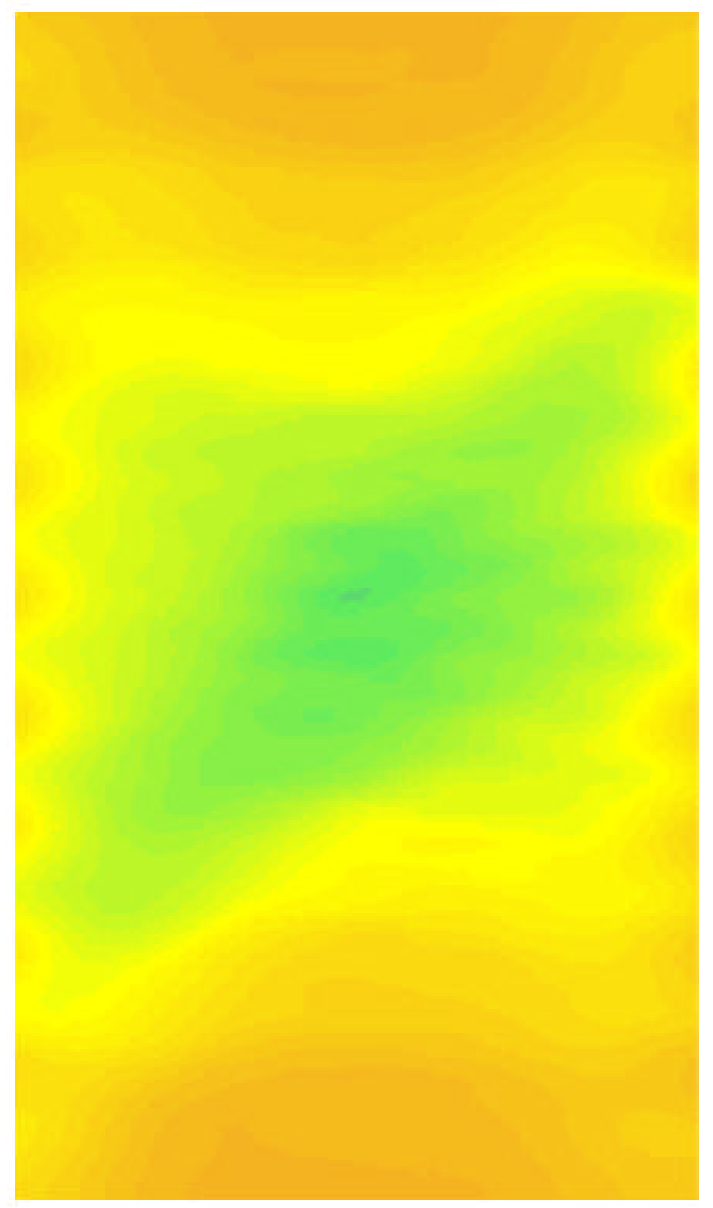

500 psi confining pressure and a differential stress of 2935 psi

FIG. 84. The tomogram for Indiana limestone at 500 psi confining pressure and differential stress.of 2935. 


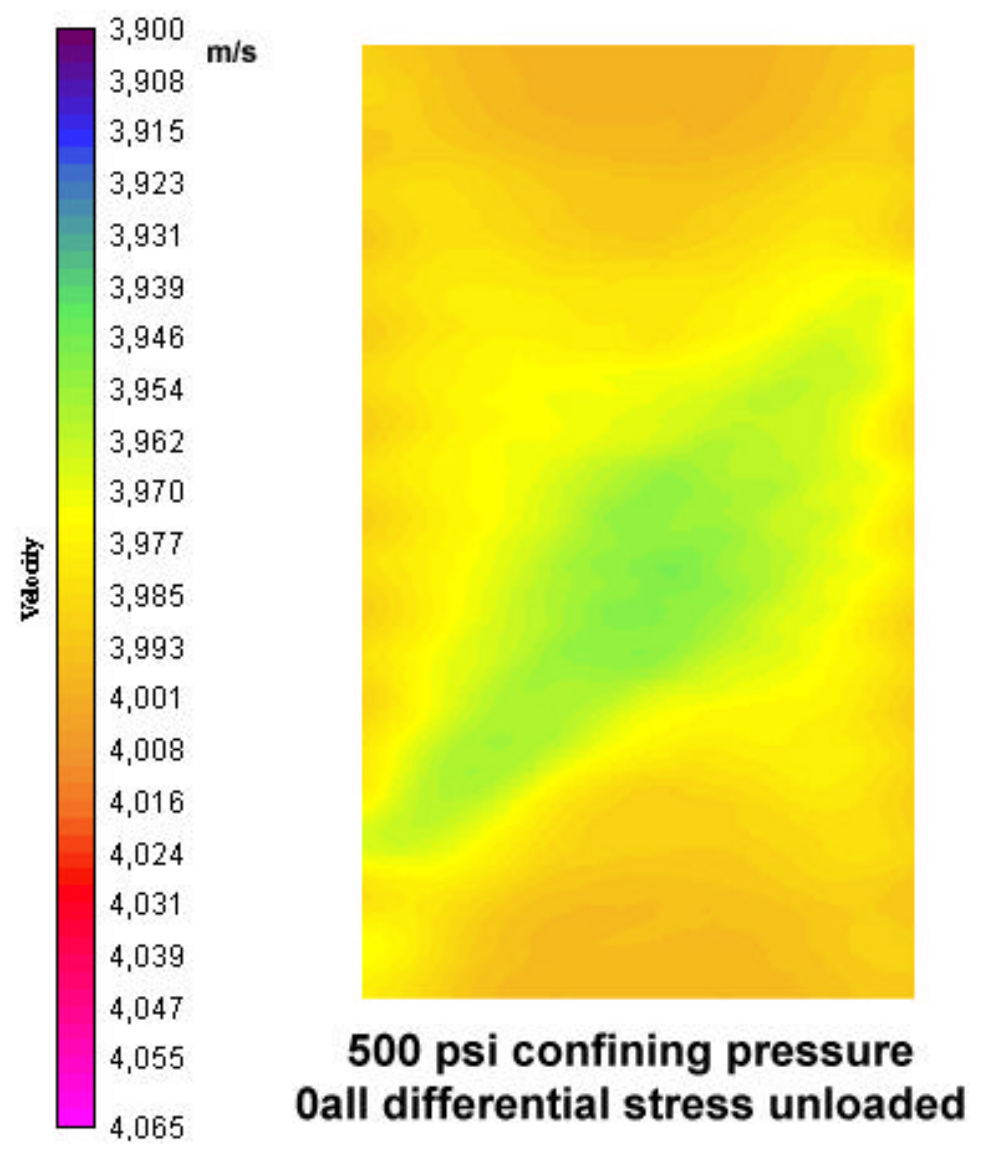

FIG. 85. The tomogram for Indiana limestone at $500 \mathrm{psi}$ confining pressure and after completely unloading the differential stress. 


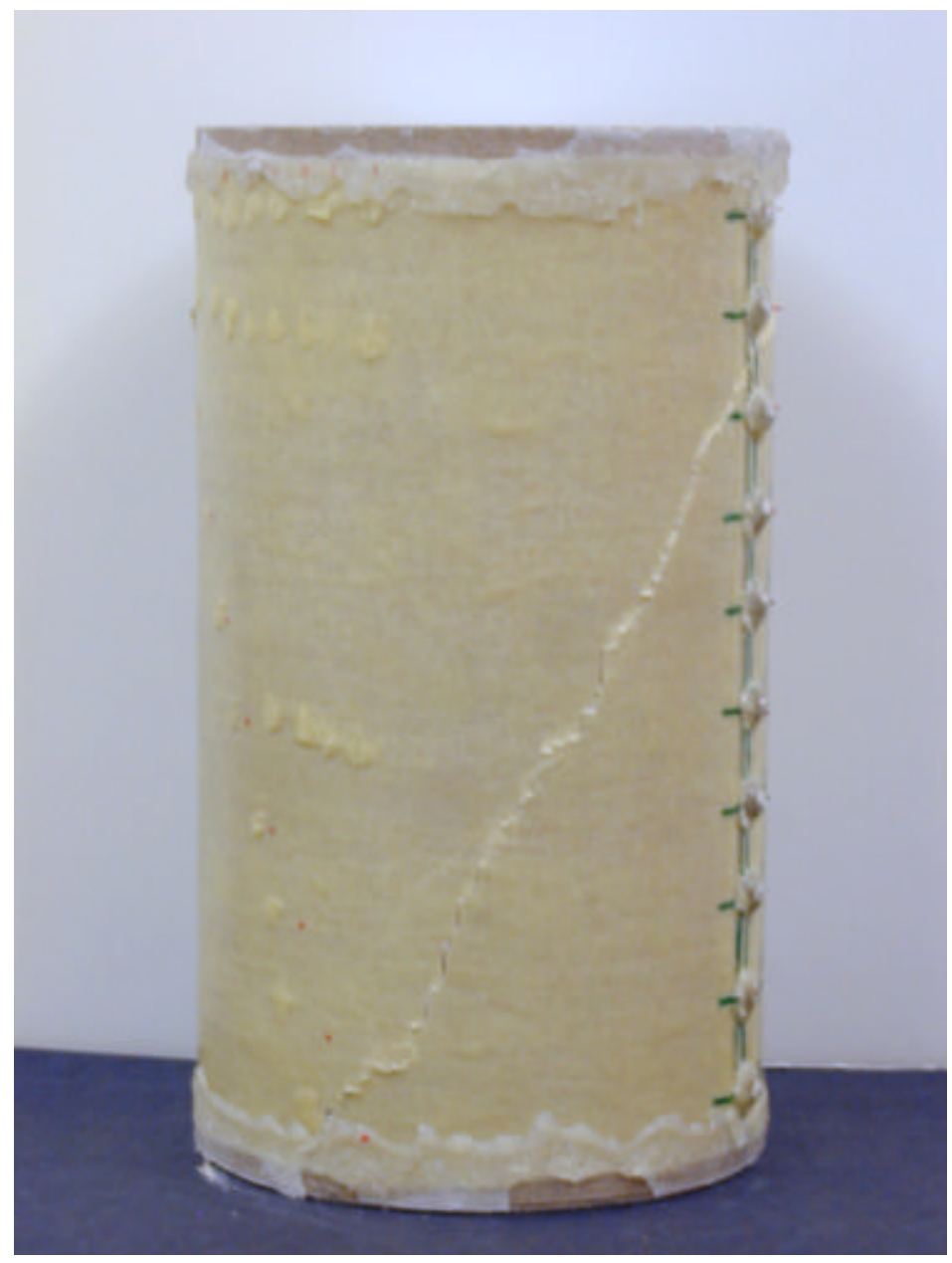

Fig. 86. A photograph of the fractured sample test at 500 psi confining pressure. 


\section{LIST OF ACRONYMS AND ABBREVIATIONS}

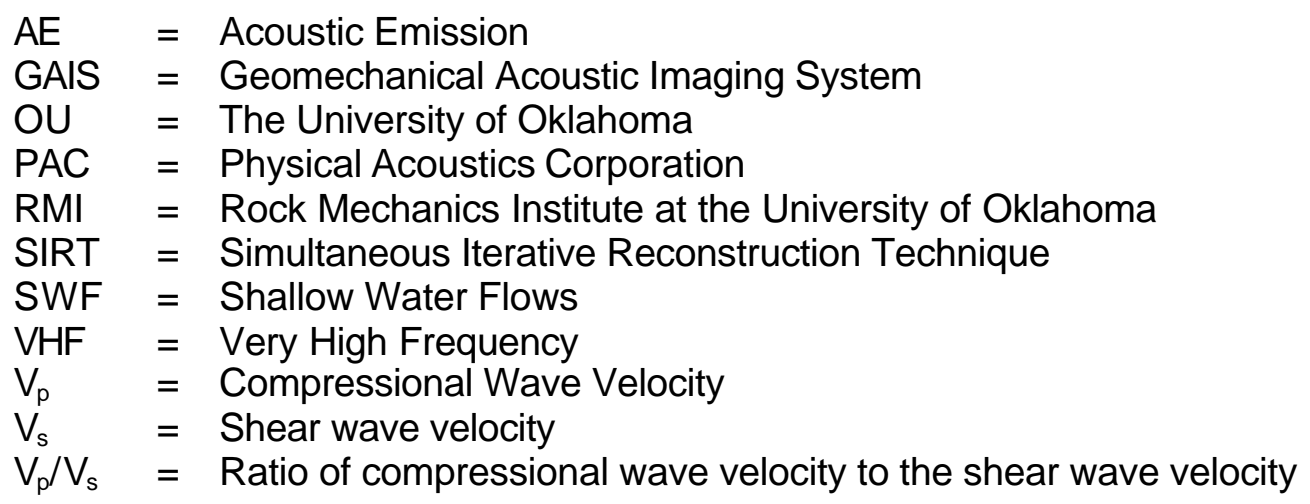

